\title{
WestVirginiaUniversity
}

THE RESEARCH REPOSITORY @ WVU

Graduate Theses, Dissertations, and Problem Reports

2011

\section{Career and Technical Education at a Crossroads: A Delphi Study}

Michael W. Cutright

West Virginia University

Follow this and additional works at: https://researchrepository.wvu.edu/etd

\section{Recommended Citation}

Cutright, Michael W., "Career and Technical Education at a Crossroads: A Delphi Study" (2011). Graduate Theses, Dissertations, and Problem Reports. 3539.

https://researchrepository.wvu.edu/etd/3539

This Dissertation is protected by copyright and/or related rights. It has been brought to you by the The Research Repository @ WVU with permission from the rights-holder(s). You are free to use this Dissertation in any way that is permitted by the copyright and related rights legislation that applies to your use. For other uses you must obtain permission from the rights-holder(s) directly, unless additional rights are indicated by a Creative Commons license in the record and/ or on the work itself. This Dissertation has been accepted for inclusion in WVU Graduate Theses, Dissertations, and Problem Reports collection by an authorized administrator of The Research Repository @ WVU.

For more information, please contact researchrepository@mail.wvu.edu. 
Career and Technical Education at a Crossroads: A Delphi Study

\author{
Michael W. Cutright
}

\author{
Dissertation submitted to the \\ College of Human Resources and Education \\ at West Virginia University \\ in partial fulfillment of the requirements \\ for the degree of
}

\author{
Doctor of Education \\ in \\ Educational Leadership Studies
}

Paul Chapman, Ph.D., Chair

Mildred Beer, Ed.D.

Helen Hazi, Ph.D.

Ted Price, Ph.D.

Neal Shambaugh, Ph.D.

Department of Educational Studies

Morgantown, West Virginia

2011

Keywords: Career and Technical Education, Delphi, $21^{\text {st }}$ Century, School Reform 


\section{ABSTRACT \\ Career and Technical Education at a Crossroads: A Delphi Study}

\section{Michael W. Cutright}

Career and technical education in the United States has reached a critical juncture. A three round Delphi method was used to determine a consensus on the future events of career and technical education to better inform educational decision makers. Forty-one individual experts in the field were invited to serve as panelists for the Delphi study and 19 agreed to participate. The first round asked the panel to respond to a general statement about their views of the future of career and technical education. In Round Two, the panel of experts provided feedback by rating each event regarding the time frame in which it will occur, the desirability should it occur and the impact if it does occur. Round Three consisted of reaching a consensus and defending minority opinions. The events for which consensus was achieved led to constructed scenarios of the future of career and technical education. Compilation of expert responses forecast several important events. Among those were the demand for CTE students to exit programs with a nationally recognized industry certification will become the norm. There will be a blending of academic and technical programs of study which will result in an increased interest in CTE. Policy and practice must begin to address the issue of allowing CTE to continue as the dumping ground for students who cannot succeed in the general education classroom. Career and technical education will be called upon to retrain America's workforce as the economy continues to change. 


\section{DEDICATION}

This work is dedicated to the memory of my grandmother, Julya B. Cutright. One of the most valuable lessons she taught me was to never give up. 


\section{ACKNOWLEDGMENTS}

This work would not have been possible without the help and support of many people. I would first like to thank my chair(s). I was fortunate to work with two outstanding men. Dr. Richard Hartnett wisely steered me through the initial process of selecting a topic and completing the prospectus. Dr. Paul Chapman, the dutiful shepherd, guided me home. I would like to thank them both for their support and guidance. I would also like to thank my other committee members Millie Beer, Ed. D., Helen Hazi, Ph. D., Neal Shambaugh, Ph. D. and Ted

Price, Ph. D. Their assistance and suggestions have proven invaluable throughout this process.

I owe a great deal of gratitude to my expert panel. The Delphi process requires knowledge, time and energy. Their tireless effort in making this research a reality is truly appreciated. Their dedication to career and technical education is amazing.

I extend a special thank you to Dr. Sara Stankus. She was with me from the beginning to the very end. She kept me focused and on task. She believed in me when I had trouble believing in myself.

The support of my colleagues in the doctoral cohort proved to be the motivation I needed in the most difficult times. The memories and friendships will remain forever.

Finally, thank you to my family and friends. I would not have been able to complete this project without support and encouragement from them. My wife, Janet, and daughters, Cara and Erin, have always been my biggest fans. 


\section{TABLE OF CONTENTS}

\section{CHAPTER 1}

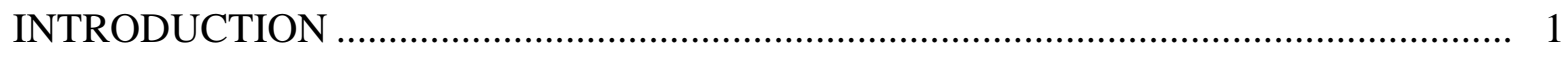

Statement of Problem............................................................................... 8

Research Questions ................................................................................... 9

Significance of the Study ……………….......................................................... 9

Limitations of the Study......................................................................................... 10

Operational Definitions....................................................................................... 10

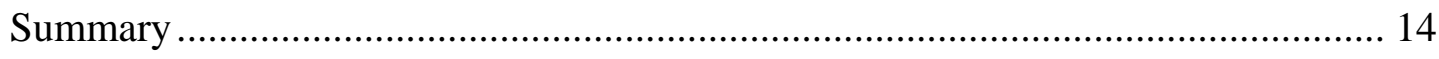

\section{CHAPTER 2}

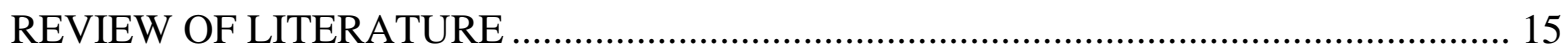

A Historical Perspective of Career Technical Education ............................................ 15

Federal Government's Role in Career Technical Education ....................................... 19

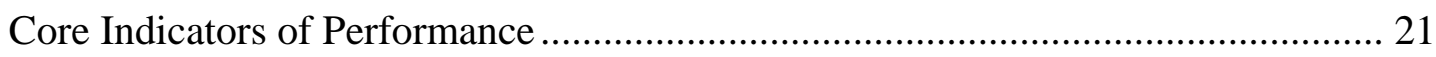

Career Technical Education's Role in School Reform .............................................. 23

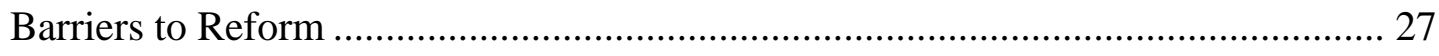

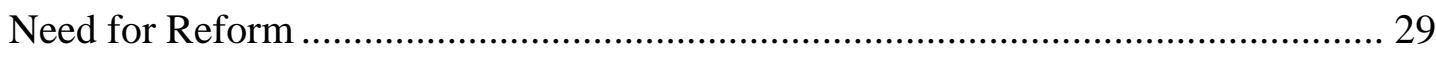

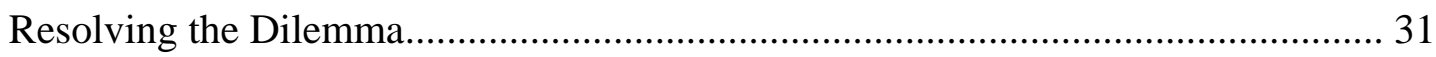

Setting the Course for the Future of Career Technical Education ............................... 32

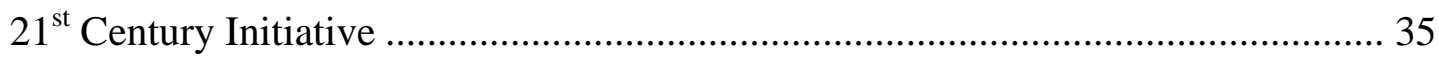

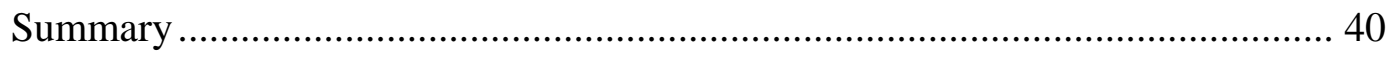

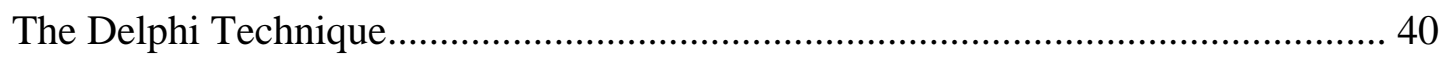

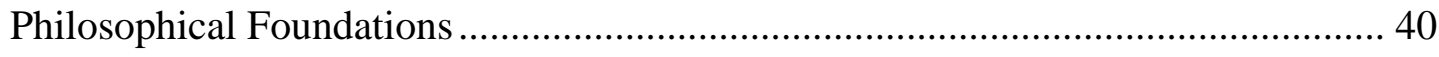




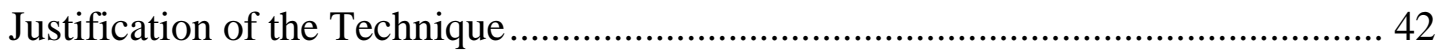

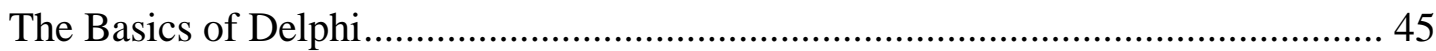

Panel Selection......................................................................................... 45

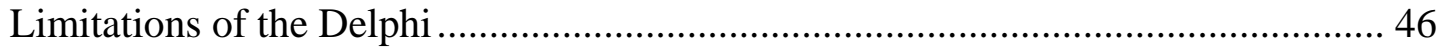

Applications of the Delphi Technique ............................................................. 49

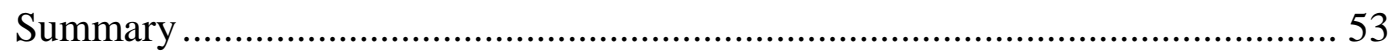

\section{CHAPTER 3}

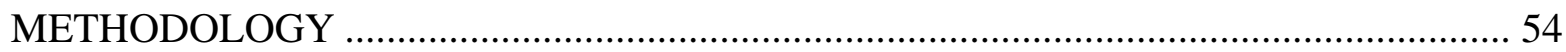

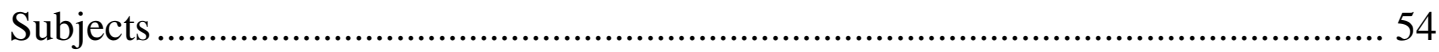

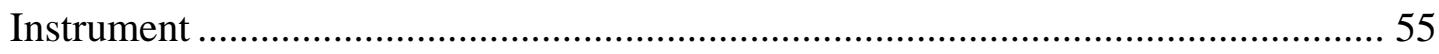

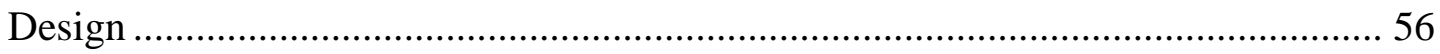

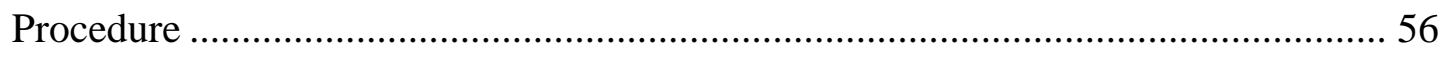

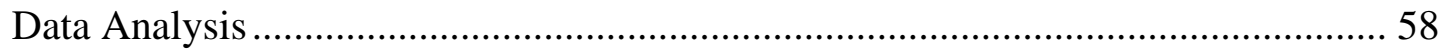

\section{CHAPTER 4}

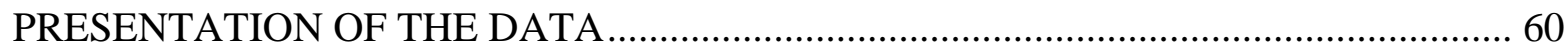

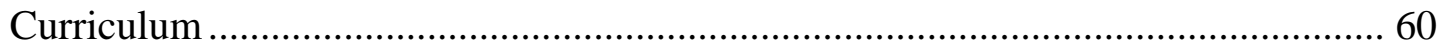

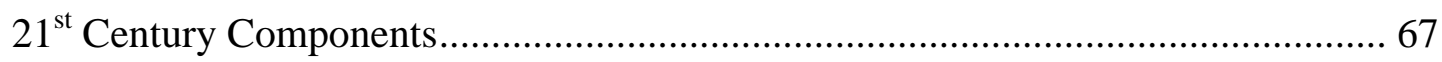

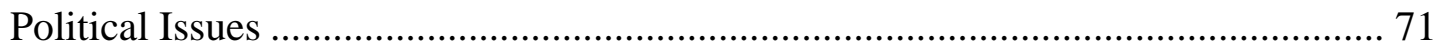

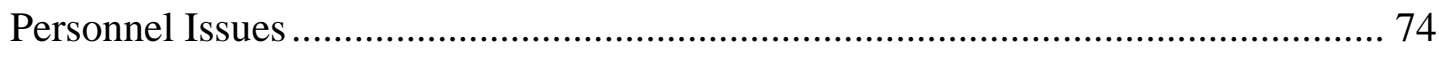

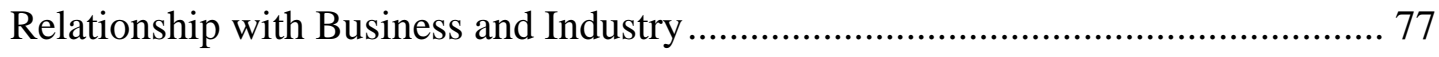

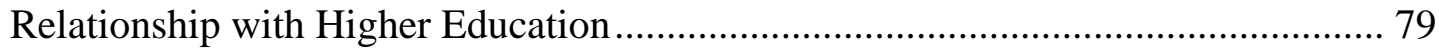

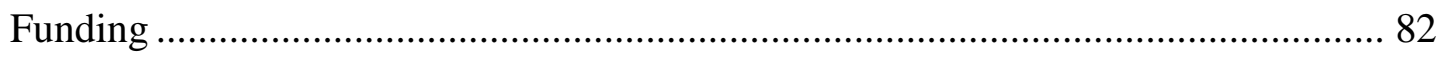

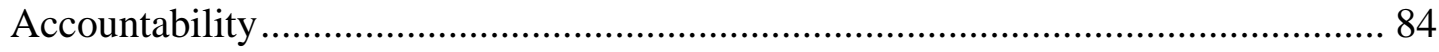




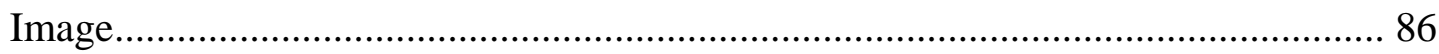

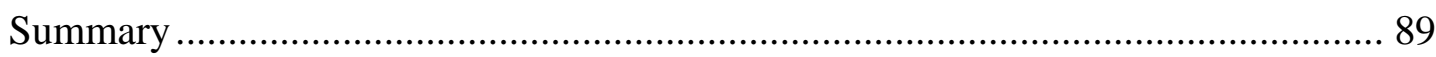

\section{CHAPTER 5}

SCENARIO, CONCLUSIONS, DISCUSSION AND RECOMMENDATIONS................ 93

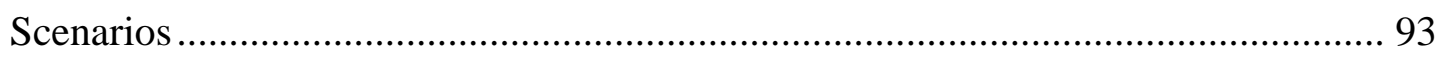

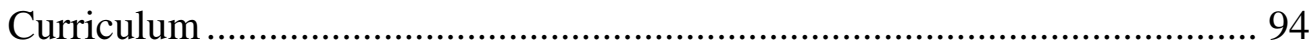

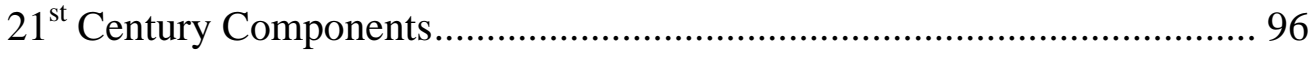

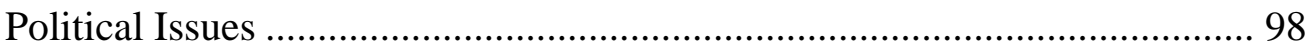

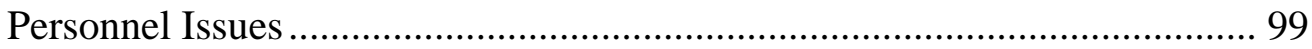

Relationship with Business and Industry ..............................................101

Relationship with Higher Education ......................................................103

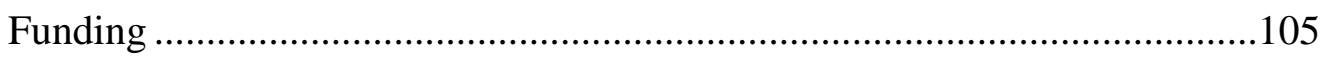

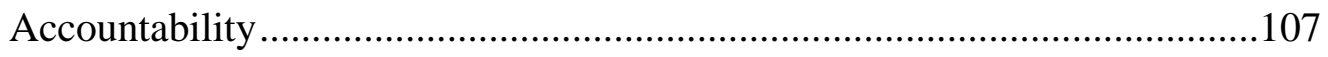

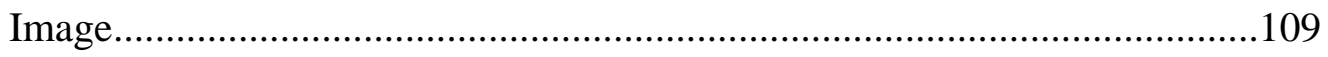

Scenario Summary ....................................................................114

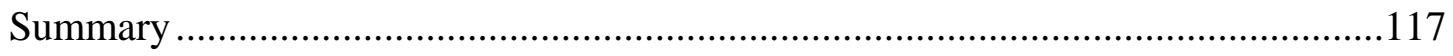

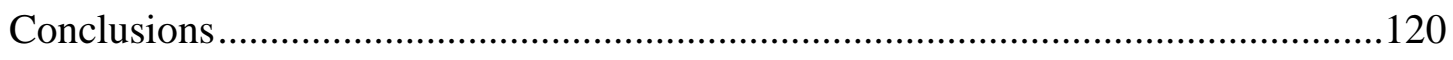

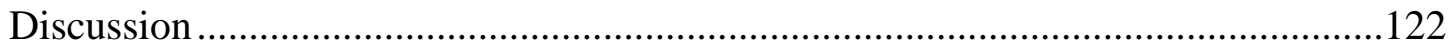

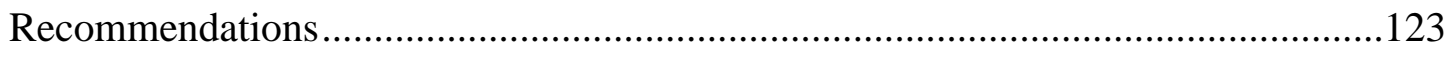

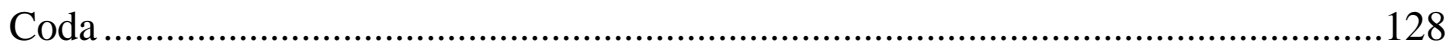

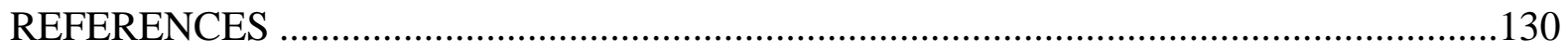

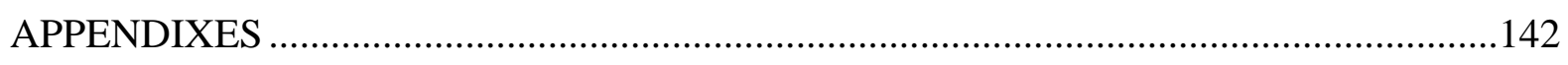

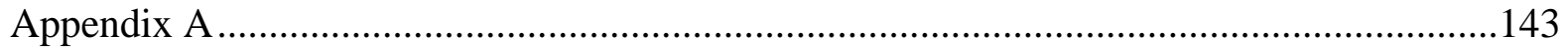




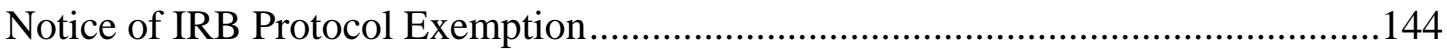

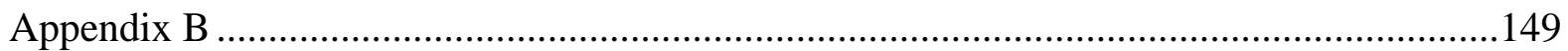

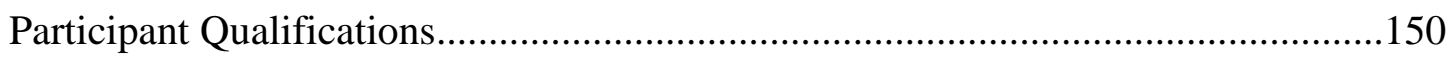

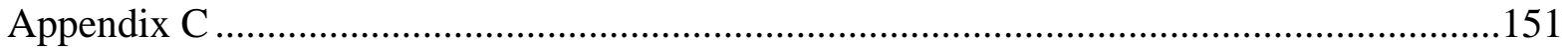

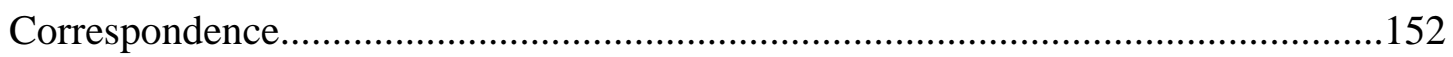

Email Message - Invitation to Participate ...............................................152

Follow-up Email - Confirmation to Participate.........................................153

Email Message Sent with Cover Letter and Professional Data Sheet ...........154

Informational Cover Letter ...................................................................155

Professional Data Sheet ..............................................................157

Email Message Prior to Round 1 ..........................................................158

Round 1Survey.......................................................................159

Email Message Prior to Round 2 ........................................................160

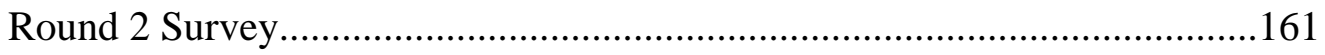

Email Message Prior to Round 3 .........................................................218

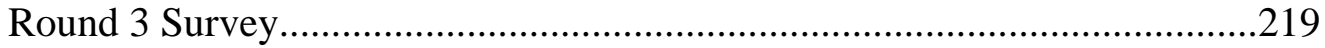

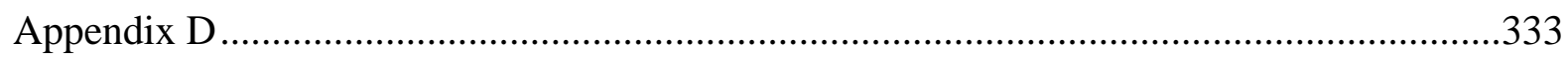

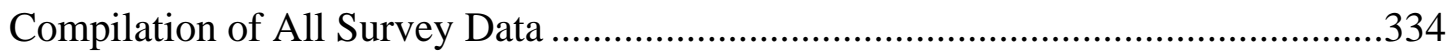

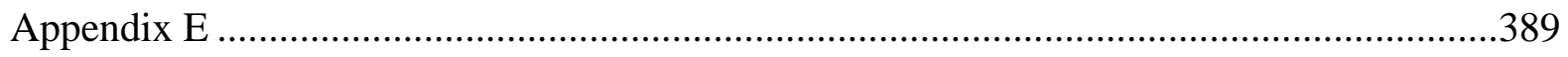

Summary of All Responses in Numerical Order .................................................390

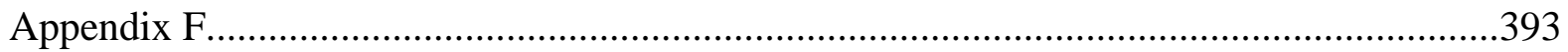

Response Frequency Distributions Round 2 ....................................................394

Response Frequency Distributions Round 3 ...................................................414 


\section{LIST OF TABLES}

TABLE 1 - West Virginia Required Levels of Performance .............................................22

TABLE 2 - Events Related to Curriculum ................................................................64

TABLE 3 - Events Related to $21^{\text {st }}$ Century Components................................................69

TABLE 4 - Events Related to Political Issues ..............................................................72

TABLE 5 - Events Related to Personnel Issues ..............................................................75

TABLE 6 - Events Related to Relationship with Business and Industry ............................78

TABLE 7 - Events Related to Relationship with Higher Education ...................................81

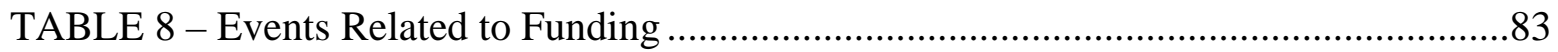

TABLE 9 - Events Related to Accountability...........................................................86

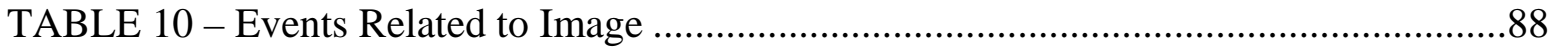

TABLE 11 - Event Summary ........................................................................92 


\section{CHAPTER 1 \\ INTRODUCTION}

Career and Technical Education (CTE) is an integral part of the educational system in the United States. According to the Carl D. Perkins Career and Technical Education Improvement Act of 2006, career and technical education is defined as:

organized educational activities that offer a sequence of courses that provides individuals with coherent and rigorous content aligned with challenging academic standards and skills needed to prepare for further education and careers in current or emerging professions (P. L. 109-270, 2006, p. 4).

In 1998 the American Vocational Association voted to change its name to the Association for Career and Technical Education and encouraged other organizations and government agencies to stop using the phrase "vocational education.” The change was intended to remove the negative image often associated with the term "vocational." The scope has now expanded to include career and technical education (Lynch, 2000b).

Career and technical education is diverse, large and complex. Ninety-three percent of the nation’s 15,200 comprehensive high schools offer one or more courses that can be identified as career technical (Lynch, 2000b). Approximately seventy-five percent of comprehensive high schools offer some type of specialized occupational program. More extensive programs are offered in approximately 1,100 area career technical centers (Lynch, 2000a). Programs of this type include but are not limited to the medical field such as practical nursing and dental assisting programs. Students attend these centers for a portion of the day and take academic or general courses at their home high schools. There are about 50 career technical high schools in the 
United States that focus on preparing students for work in a particular career but also offer academic courses as well (Lynch, 2000b).

Career and technical education has an important role in preparing both youth and adults for a wide range of careers. According to the U.S. Department of Education's Office of Vocational and Adult Education (OVAE), ninety-seven percent of all high school students take at least one CTE course, and one in four students take three or more courses in a single program area. One-third of college students are involved in CTE, and as many as 40 million adults engage in short-term postsecondary occupational training (ACTE, 2006).

The mission of the West Virginia CTE is to better prepare students for the world of work and higher education through programs and training offered at the CTE sites throughout the state. CTE programs are available to students in every county in the state. West Virginia CTE facilities include 34 high schools with five or more occupational areas; 24 county centers with five or more occupational areas; 7 multi-county centers; 16 colleges and universities that offer CTE courses; and 3 specialized facilities (West Virginia Department of Education, 2009a).

Statistics provided by the National Association of State Directors of Career Technical Education Consortium show that in 2008 there were 83,900 secondary students enrolled in a CTE course in West Virginia. The report also shows that there were 21,871 postsecondary students involved in some type of CTE training in the state (National Association of State Directors of Career Technical Education Consortium, 2009). Students at the secondary, postsecondary, and adult levels have easy accessibility to training.

Vocational education is certainly nothing new in either West Virginia or the rest of the country. Indeed, the first formalized vocational education system in America can be traced back to the apprenticeship agreements common during the colonial period. The practice of 
indenturing orphans, economically disadvantaged children and delinquents to serve as apprentices was a type of care giving. This practice led to institutional programs for these youths where the curriculum was job training (Lynch, 2000b).

The history of vocational education in the United States is incomplete without considering the role of the federal government in shaping and funding it. The Smith-Hughes Act of 1917 supported a separate vocational education system. The legislation called for specific training centered on entry-level skills in order to supply a workforce for jobs created by the industrial revolution. The purpose of the act was to provide an alternative to the general curriculum which was "too exclusively literary in spirit, scope, and methods" (Swanson, 1951, p. 16). As a result, Smith-Hughes established vocational education with a separate board, students, curriculum, teacher preparation and certification (Lynch, 2000b). This act identified a new era for students who were attending high school, by placing emphasis on separating from the traditional curriculum and calling for a new one that would better meet the needs of the children of the working class (Gray, 1991).

Before 1900, vocational programs were focused on the need to prepare more immigrants and blue-collar-type workers with practical skills for the nation's farms, factories, and homes. As the needs of the nation shifted, so did the federal legislation dealing with vocational education. States were encouraged to offer programs and training to support national defense efforts (1920s), reduce unemployment problems (1930s), assist the war effort (1940s), incorporate programming within junior colleges in the 1950s, and shift industries to peacetime economic development in the 1950s and 1960s. The main goal of federal policy and funding was to train young men and women for jobs in the economy (Lynch, 2000b). 
The Vocational Education Act of 1963 was the beginning of a major shift in federal policy. For the first time, vocational education was mandated to meet the needs of individual students, not just the workforce needs of industry (Gordon, 2008). The act provided funding for construction of area vocational schools and broadened the definition of vocational education to include the occupational programs offered in comprehensive high schools. In addition, a provision encouraging states to offer programs and services for disadvantaged and disabled students was included.

In 1984, the emphasis of federal funding in vocational education changed from program expansion to program improvement with a focus on at-risk populations. With the renaming of the Vocational Education Act to the Carl D. Perkins Vocational Education Act (Perkins I, P.L. 98-524), federal monies established programs emphasizing the acquisition of job skills.

In September 1990, President George H. W. Bush signed into law the Vocational and Applied Technology Act (Perkins II, P.L. 101-392), which made several revisions to the 1984 Act. This act signaled congressional interest in preparing students for the $21^{\text {st }}$ Century workforce. Among the changes, it created the tech-prep program which is a planned sequence of study in a technical field beginning as early as the freshman year of high school. The sequence extends through two years of postsecondary occupational education following secondary instruction, and culminates in an associate degree or certificate. The law also mandated states to create and implement performance standards and measures to assess achievement in academic and skill acquisition.

Congress reauthorized the Perkins Vocational and Technical Education Act (P.L. 105332) in 1998. The law required that a core set of performance indictors be adopted by the states. In order to maintain funding, states were required at minimum to include the following 
measures: student attainment of challenging skill proficiencies, student attainment of a secondary school diploma or its equivalent and credential attainment, placement and retention in employment or postsecondary education, and participation in and completion of non-traditional programs (Gordon, 2008).

President George W. Bush signed the Carl D. Perkins Career and Technical Education Improvement Act on August 12, 2006. There were four prevailing themes under the new legislation: accountability and program improvement, secondary and postsecondary connections, links to rigorous academics and finally, a greater focus on business and industry (Gordon, 2008).

The 2006 revision increased accountability by incorporating a system to coincide with the No Child Left Behind standards mandated for public education in the United States. Under this system of accountability, academic attainment and graduation rates of students enrolled in CTE at the secondary level must be measured annually. Subsequent sanctions are included in the event states fail to meet predefined indicators.

Federal support for CTE continues to be a significant element in meeting the needs of students and employers. Funds have been provided throughout the years to the states to assist with the improvement and expansion of occupationally oriented education. In order to secure America's place in the global economy, federal investment in CTE must continue to support the improvement of academic and occupational skills and the expansion of access for all students in these programs (Gordon, 2008).

Elliott Medrich, Director of External Affairs and Development for MPR Associates, Inc., (2005) believes that CTE at the secondary level has reached the point that it must "change or die." (p. 24) Enrollment in CTE programs experienced a sharp decline in the twelve-year span 
from 1982-1994 (Lynch, 2000a). Research revealed multiple reasons for this decline, and factors such as poor image and dissatisfaction among relevant stakeholders heightened official realization that CTE needs to seek a new direction for the $21^{\text {st }}$ Century. Traditionally, educators have viewed high school career-focused education as an option for those who do not intend to pursue post-secondary education. At its inception, the goal of vocational education was to prepare students for entry-level jobs in fields that did not require advanced training. Changing times have made that mandate obsolete. Students today face a vastly different world and will compete in a global economy with citizens from all nations.

Career and technical education must find ways to plan for the future and adapt programming to embrace the $21^{\text {st }}$ Century. Anticipating future needs will assure viability and enhance curriculum design for generations to come. In order to promote reform, research can assist in anticipating events that could significantly impact CTE in the $21^{\text {st }}$ Century. The Delphi Method is the forecasting tool that was utilized in this research study. Named after the Greek oracle at Delphi to whom the Greeks went for predictions about their future, the Delphi Method focuses on predicting the future by allowing experts to deal systematically with a complex problem (Adler \& Ziglio, 1996). Developed in the beginning of the Cold War to assist in forecasting the impact of technology on warfare, Delphi helped overcome problems associated with traditional methods. It is well matched as a means and method for consensus-building by using a series of questionnaires to collect data from a panel of selected subjects (Dalkey, 1969; Dalkey \& Helmer, 1963; Lindeman, 1981; Linstone \& Turoff, 1975; Martino, 1983; Young \& Jamieson, 2001).

The Delphi Method uses a sequence of surveys and opinion feedback. It is based on a structured process for collecting and refining knowledge and drawing consensus from a group of 
experts. This method is used for "systematic solicitation and collation of judgments on a particular topic through a set of carefully designed sequential questionnaires interspersed with summarized information and feedback of opinions derived from earlier responses" (Delbecq, Van de Ven, \& Gustafson, 1975, p. 10). This technique does not require participants to meet face-to-face, thereby making it useful to conduct surveys with qualified people over a wide geographic area.

Originating in the 1950's, the Delphi concept is a by-product of an Air Force defense research project. The Rand Corporation began a research study analyzing expert points of view regarding optimal U. S. industrial target systems and the number of A-bombs required to reduce munitions output (Linstone \& Turoff, 1975).

In a 1964 report by T. J. Gordon and Olaf Helmer, Report on a Long-Range Forecasting Study, the Delphi methodology was recognized outside of the defense community. Assessing long-range trends and their effects on society, this study reviewed multiple topics: scientific breakthroughs, population control, automation, space progress, war prevention, and weapons systems (Adler \& Ziglio, 1996, Linstone \& Turoff, 1975).

In Round One, a panel of experts is asked to predict future events impacting the profession. In this research study each panel member is asked to respond to an open-ended statement regarding the future of CTE. The statement is designed to elicit general statements of opinion from the panel members.

In Round Two, the panel of experts provides feedback by rating each event regarding the time frame in which it will occur, the desirability should it occur and the impact if it does occur. In this round, panel members are asked to provide comments on ratings they feel require 
justification. Written comments by expert panel members play an important role in the process reaching convergence of group opinions while seeking consensus (Na, 2006).

Round Three consists of reaching a consensus and defending minority opinions. The purpose of this round is to determine if there is a consensus. Responses from Round Two are analyzed by determining the median for each response. Participants are asked to review their response and the median response, respond again using the same rating scale, and add any justification or comments regarding the responses. In the final analysis of data, responses from Round Three are then analyzed to determine if there is a consensus by looking at the responses and their medians.

The proposed study of the future of CTE does not lend itself to precise quantification. Utilizing a three-round Delphi panel of nationally recognized experts allows examination of both historical and current issues facing CTE. This technique employs anonymity, controlled feedback, and statistical response resulting in exploration of ideas to serve as a change agent for policy and practice. By creating a possible scenario of the future of the profession, the Delphi study will serve as a valuable tool for $21^{\text {st }}$-century planning.

\section{Statement of the Problem}

This study drew on the views of a panel of experts in the field of career and technical education to identify the events that will occur in career and technical education in the next twenty years. The Delphi method was used to determine a consensus on the future events of career and technical education to better inform educational decision makers. 


\section{Research Questions}

1. What events are likely to occur in career and technical education in the future?

2. What is the time line for these events?

3. What will the impact of these events be for career and technical education?

4. What scenario describes the probable future of career and technical education?

\section{Significance of the Study}

Career and technical education is at a crossroads. Survival depends on making changes to meet the demands of a new economy, addressing the increased expectations of stakeholders, and defining the role of CTE in overall school reform. There has been agreement that change is needed, but how, and in what direction, has not been well established. Decisions regarding curriculum, facilities, financing, and personnel must be addressed. Future planning is an important responsibility for educators and has been made more difficult in these changing times. A consensus of a group of experts regarding the future of career and technical education should provide a tool in this planning process.

The consensus of opinion of experts should be of interest to both local and state CTE administrators who must plan and set policy for the operation of CTE programming. Visionary leadership will ensure continued progress in the profession. The results of this study will help school officials ensure that program graduates will attain the skills needed to enter the workforce or a postsecondary institution. 


\section{Limitations of the Study}

The study has limitations that are common to the Delphi method. These include the following:

- The study lends itself to certain biases by the process used to select participants, design questionnaires, and process the results (Lang, 1998).

- The results of the study concerning the future is fundamentally linked to panel members' personal values, concepts, ideas, experience and quality of opinions (Woudenberg, 1991, Johnson \& Christensen, 2000).

- The study is limited to the responses of a small number of participants. Approximately 40 individuals are expected to participate.

- Data collection will be limited to approximately a three-month period.

- In an effort to establish consensus, Delphi studies tend to limit extreme ideas which might prove to be accurate in the end.

- The study is limited by the validity and reliability of the instrument (Johnson \& Christensen, 2000).

- Forecasting the future is not an exact science, and unforeseen variables may impact outcomes.

\section{Operational Definitions}

Career Technical Education - Career and technical education is organized educational activities that offer a sequence of courses that provides individuals with coherent and rigorous content aligned with challenging academic standards and skills needed to prepare for further education and careers in current or emerging professions (P.L. 109-270, 2006, p. 4). 
Carl D. Perkins Career and Technical Education Improvement Act of 2006 - The purpose of this Act is to develop more fully the academic and career and technical skills of secondary education students and postsecondary education students who elect to enroll in career and technical education programs (P.L 109-270, 2006, p. 2).

Core Indicators of Performance - Core indicators of performance are the accountability measures set forth in the Perkins Act to optimize the return of investment of federal funds in career and technical education activities. They include academic attainment in reading and language arts, mathematics, technical skill attainment, secondary school completion, student graduation rates, secondary placement, nontraditional participation, and nontraditional completion.

CTE Concentrator - A concentrator is a student who enrolls in three or more courses in a single occupational program area (Lynch, 2000b).

$21^{\text {st }}$ Century Learning Initiative - The framework for learning in the $21^{\text {st }}$ Century based on the essential skills children need to succeed as citizens and workers in the $21^{\text {st }}$ Century. The framework includes six key elements of a $21^{\text {st }}$ Century education: core subjects, $21^{\text {st }}$ Century tools, $21^{\text {st }}$ Century context, $21^{\text {st }}$ Century content and $21^{\text {st }}$ Century assessments.

The Delphi Method - The Delphi method is a method for consensus-building by using a series of questionnaires delivered using multiple iterations to collect data from a panel of selected subjects (Hsu \& Sanford, 2007). 
Delphi Round One - Round One is the first survey of the Delphi study consisting of an openended question designed in such a way as to generate and identify events which the panel of experts believe will occur.

Delphi Round Two - Round Two uses a questionnaire developed from responses to Round One. The panel of experts provides feedback by rating each event regarding the time frame in which it will occur, the desirability should it occur, and the impact if it occurs.

Delphi Round Three - Round three of the Delphi method is designed to refine, through group consensus, the time frame of each generated event and to provide the opportunity for each panel member to explain any difference of opinion.

Desirability - Desirability is described as something beneficial or something that someone is enthusiastic to accomplish. High desirability is defined as a mean desirability rating which equals or exceeds 3.0 on a five-point Likert scale.

Event - An outcome which has a high probability of occurring.

Expert - An expert for this Delphi study is a person with extensive knowledge of career and technical education. These include state department of education officials charged with policy development and implementation; local CTE administrators with experience and training in delivering curriculum and programming; and educators known nationally either through scholarly publications or membership in professional organizations. 
Forecast - A forecast is an opinion or estimate about a future happening or condition (Stead, 1975).

Impact - Impact is defined as the measure to which an event will have a significant effect on Career and Technical Education. High impact will be represented by a median rating above 3.0 on a five-point Likert scale.

Likert scale - A Likert scale is defined as an ordinal measurement which assigns points to five or more categories measuring responses in a questionnaire (Stead, 1975).

Median Consensus Range - The median consensus range specified in this study is defined as immediate (one - two years), mid-range (three - ten years), long-range (eleven - twenty years), beyond twenty years, or never.

Scenario- The scenario is a narrative forecast that describes a potential course of events (Walonick, 1995). This is a systematic, analytical discussion of selected occurrences (events) by designated time frames representing short-range, intermediate-range, and long-range forecasts in conjunction with an impact/desirability rating (Stead, 1975).

Time Frame - Time frames used in this study will be immediate (one - two years), mid-range (three - ten years), long-range (eleven - twenty years), beyond twenty years, and never. 


\section{Summary}

Chapter one introduces the reader to career and technical education and its future challenges. The Delphi technique, which is a flexible forecasting tool that can be effectively utilized to study these issues, is also introduced. The expert panel selection and time frame was carefully considered prior to initiating this study. Although there are limitations and precautions concerning low response rates, unintentionally guiding feedback, and surveying panelists, these considerations were built into the design and implementation of the study. The Delphi technique has been and will continue to be an important data collection methodology that will provide important information from experts who are immersed and imbedded in CTE and whose advice regarding the best avenue for future policies and practices is invaluable.

Chapter 2 includes a review of the literature regarding the future and history of CTE, the role of federal government, CTE's contribution to school reform, including $21^{\text {st }}$-century initiatives, the need for change and the Delphi method of forecasting. Chapter 3 explains the methodology used in this study. Chapter 4 presents the data collected from the three rounds of the Delphi study. Finally, Chapter 5 provides a summary of the study, a scenario for the future of CTE based on the results, conclusions, and recommendations for CTE educators. 


\section{CHAPTER 2}

\section{REVIEW OF LITERATURE}

This chapter includes a review of the literature regarding the history of Career and Technical Education (CTE), the role of federal government, CTE's contribution to school reform, a need for change, $21^{\text {st }}$ Century initiatives, setting the course for the future of CTE and the Delphi method of forecasting. The writings presented in this chapter represent a portion of the literature related to the research problem of this study. This chapter does not provide an allinclusive summary of the literature on these topics, but is intended to present the key concepts related to the study of the future of CTE.

\section{A Historical Perspective of Career and Technical Education}

To comprehend the current and future issues of CTE, it is necessary to explore the origins of the field. Education for and about work began at the very beginning of time with the development of civilization. Prehistoric artifacts demonstrate men working with tools more than 50,000 years ago and passing their knowledge to "students." Even the highest acclaimed professions of today—astronaut, physician, philosopher, clergy—are about work and all call for a concrete education in addition to job abilities to prepare them well for the tasks, duties, and responsibilities of the trade. So, indeed, vocational education (or career and technical education) is ever-present (Lynch, 2000b).

Major contributions can be attributed to Booker T. Washington, educator and leader; David Snedden, an educational administrator; Charles Prosser, a lawyer; and John Dewey, a philosopher. Washington contributed to the theory and practice of education, founding Tuskegee Institute which offered training in a number of trade and industrial programs. Washington defined an educated person as one who possesses problem-solving skills, self-discipline, high 
moral standards and a sense of service to others (Gordon, 2008). Washington held that the route to success for the majority of the population was through the acquisition of vocational skills. These principles articulated over a century ago still have validity for CTE today.

David Snedden and Charles Prosser from Columbia University served as powerful advocates for vocational education and believed that schools should prepare individuals for their destined occupations (Camp \& Hillison, 1984). Prosser believed that in vocational education practice and theory must go hand in hand. The more closely they are related, the more likely the learner would be successful in society. Ultimately the work of Prosser led to the first major legislation dealing with vocational education. Processer's vision of vocational education included a duel system with two clearly divided paths, one clearly academic and the other vocational.

Snedden further defined the criteria for teachers in the vocational setting, contending that vocational teachers should be selected from the related industry or trade and not from regular education (Barlow, 1967). In 1910 Snedden was appointed commissioner of education for Massachusetts. Through this role, he was empowered to influence and promote industrial education in the image of his mentor, Charles Prosser (Dutton \& Snedden, 1916).

In vast contrast to the views held by Snedden and Prosser, John Dewey was a major critic of the duel school system. His contention was that this type of system would segregate children of well-to-do families from those who would have to work for a living in manual or commercial employment. Dewey believed that the separation of trade education and general education would result in a less effective and significant educational experience for all students (Dewey, 1915). 
Beginning in 1862 and again in 1890, Congress passed the Morrill Acts providing aid to higher education for land-grant colleges. The focal point of vocational education in the United States has developed in response to federal legislation. The Hatch Act of 1887 and the Adams Act of 1906 allocated aid to agricultural experiment stations, and the Smith-Lever Act of 1914 provided support for agricultural and home economics extension programs (Roberts, 1957). These acts helped to create land-grant colleges and began the practice of federal subsidies to education (Roberts, 1957; Swanson, 1951).

Major federal influences in secondary and postsecondary vocational education began with the Smith-Hughes Act of 1917, devising a response to a complex set of social, economic, and political forces. This legislation was enacted to prepare youth for jobs created as a result of the industrial revolution and to provide them with an alternative to the general curriculum of schools. Smith-Hughes provided for a continuing appropriation for vocational education in agriculture, trades and industry, and home economic and teacher preparation. Upon documentation of success, funds were appropriated for the national administration. Ultimately, Smith-Hughes provided an alternative high school education experience from that typically provided at the time for middle and wealthy classes of students. The Smith-Hughes Act emphasized independence from the traditional curriculum and called for a new curriculum that would better meet the needs of the working class (Gray, 1991).

Congress passed the Carl D. Perkins Vocational Education Act (Perkins I) in 1984, a precursor to today's federal legislation, with two main goals, economic and social. Economically, the hope was to improve the skills of the labor force and prepare students for job opportunities. Socially, the goal was to provide equal opportunities for students with special 
needs. Perkins I shifted the emphasis from expansion to program improvement and providing service to at-risk populations (Gordon, 2008).

The Carl D. Perkins Vocational and Applied Technology Education Act of 1990 (Perkins II) amended and extended Perkins I. The passage of this act signaled the beginning of congressional interest in stressing the application of academic and vocational skills necessary to compete in a technologically advanced global society (Gordon, 2008). Perkins II proposed a three-way approach to improve training the workforce: integration of academic and vocational education, articulation between segments of education involved in workforce preparation, and finally, closer linkages between school and work. Representing a major shift in how vocational education had historically been provided in the United States, Perkins II increased accountability while integrating school and community. The act required each state to develop a system of performance measures and standards for career and technical education at both the secondary and postsecondary levels.

Vocational education was emerging in size and quality of programs, driven by the fundamental objective to improve training for the American work force. The Carl D. Perkins Vocational and Technical Education Act of 1998 (Perkins III) replaced Perkins II, authorizing vocational education for five years. Perkins III challenged career and technical instructors to educate students with the skills needed in order to work successfully in a technologically sophisticated and internationally competitive workplace.

The Carl D. Perkins Career and Technical Education Improvement Act of 2006 (Perkins IV) reauthorized Perkins III. Focused on academic achievement of CTE students, this act strengthened the connections between secondary and postsecondary education, improving state and local accountability (P.L. 109-206, 2006). Congress also added a new purpose to the act: 
"Providing individuals with opportunities throughout their lifetimes to develop, in conjunction with other education and training programs, the knowledge and skills needed to keep the United States competitive" (P.L. 109-206, 2006, p. 2-3).

\section{Federal Government's Role in CTE}

The prominent 1983 report on American education, A Nation at Risk, from the National Commission of Excellence in Education contributed to the ever-growing sense that American schools are failing miserably, and it touched off a wave of local, state, and federal reform efforts. Attention was drawn to curricular offerings with particular emphasis on core academic subjects. States responded to the report by increasing the academic courses required for high school graduation. Colleges and universities followed suit by increasing admission requirements. As a result, enrollment in elective CTE courses decreased. The decrease was related directly to rigid curricular requirements rather than program quality (Herr, 2002).

Federal and state mandates have transformed the requirements and expectations of CTE. Under the George W. Bush administration, high school reform was positioned at the forefront of the educational agenda. Previously in 1965, Congress had passed the Elementary and Secondary Education Act (ESEA) which remained in effect until 2003. Over a span of thirty-eight years, the federal government exhausted more than $\$ 242$ billion on education (U.S. Department of Education, 2003). Although government funding for education consistently increased, an achievement gap continued to exist between the rich and poor, and white and minority students. In 2000, the National Assessment of Educational Progress (NAEP) on reading confirmed that 32 percent of fourth-graders could read at a proficient level. The 2001 NAEP revealed that the test scores of high-performing students have increased over time, while scores of low-performing students have decreased (U.S. Department of Education, 2003). These disturbing statistics were 
instrumental in the creation and passage of the No Child Left Behind Act (NCLB) of 2001. This Act is a reauthorization of the ESEA and it is designed to hold schools accountable for students' academic performances. Accountability is measured through high-stakes testing administered to students in grades 3 through 11 . Schools are also expected to make Adequate Yearly Progress (AYP) by showing that a higher percentage of the district's student population is at or above achievement levels in math, reading and writing each year. By the year 2014, NCLB calls for one hundred percent of a school district's student population to achieve in these academic areas. Schools that accept federal funding are expected to work toward this goal. In short, the goals of NCLB are to advance achievement for all students, augment educational equity, and ensure that there are more qualified teachers in the education system (Darling-Hammond, 2004).

No Child Left Behind and standards-driven reform have raised academic achievement to a position that allows little room for some of the priorities that drove school-to-work advocates (Kazis, 2005). However, under new federal mandates, a coherent blend of both rigorous academic skills and career and technical studies is a major component of a well-rounded high school program. Acquisition of academic and technical knowledge increases the likelihood of career success. Based on the belief that most students can master complex academic and technical concepts if schools create an encouraging environment, Gene Bottoms (2005), Senior Vice President of The Southern Regional Education Board, asserts that high-quality career and technical programs leading to high-end careers may be the only way to encourage some students to see the importance of education.

In order to add resources to a new high school reform initiative, President George W. Bush's 2006 budget proposal removed all dedicated funding for CTE. This plan was rejected by Congress, as a result of a strong lobbying effort by proponents of CTE. Federal and state 
legislative initiatives affect enrollment as funding resources directly impact expansion or reduction of CTE programming. Equally important is the message that is sent to the public about the legitimacy of CTE when legislators actively support or fail to support CTE's position in the delivery of education. Historically, public perception toward CTE has significant impact on enrollment trends (Gaunt, 2005).

\section{Core Indicators of Performance}

Perkins III required each state to provide data on four core indicators of performance: attainment of academic and vocational/technical proficiencies; attainment of a secondary degree or General Educational Development (GED) certificate, proficiency credential in conjunction with a secondary diploma, and a postsecondary degree or credential; placement in, retention in, and completion of postsecondary education or advanced training, placement in military service, or placement or retention in employment; and participation in and completion of programs that lead to nontraditional training and employment (Lynch, 2000b, p. 10). The United States Department of Education requires states to submit their proposed student definitions and measurement approaches for the core indicators of performance in their five-year state plan submission.

West Virginia, along with all other states, is required to submit this information when they submit their full five-year plan. Each state must also provide an annual update to the plan. Secondary career and technical education participants in West Virginia schools are defined as those students who take at least one credit course in a career and technical education program area. Concentrators or completers are students who successfully complete the four required courses in an occupational career and technical education concentration as approved by the Division of Technical and Adult Education (West Virginia Department of Education, 2009b). 
To measure academic proficiency, completers take ACT WorkKeys assessments in Reading for Information, Applied Mathematics and Locating Information. Nationally, West Virginia is at the forefront, measuring technical skills through Global 21 Performance Assessments. In addition, completers are also tracked in order to obtain information regarding job placement, retention rates and non-traditional participation. Table 1 reflects West Virginia’s 2009-2010 required levels of performance as negotiated with the United States Department of Education. For example, 80.66 percent of CTE completers will be required to meet reading standards in the 2009-2010 school year (West Virginia Department of Education, 2009b).

Table 1

West Virginia Required Levels of Performance

\begin{tabular}{llll}
\hline Core Indicator of Performance & $\mathbf{2 0 0 7 - 2 0 0 8}$ & $\mathbf{2 0 0 8 - 2 0 0 9}$ & $\mathbf{2 0 0 9 - 2 0 1 0}$ \\
\hline Academic Attainment-Reading & 75.83 & 75.93 & 80.66 \\
Academic Attainment-Mathematics & 65.83 & 65.83 & 72.67 \\
Technical Skill Attainment & & 66.00 \\
Secondary School Completion & & & 95.00 \\
Graduation Rates & 80.00 & 80.00 & 80.20 \\
Placement & & & 91.56 \\
Nontraditional Participation & & 38.58 \\
Nontraditional Completion & & & 14.45
\end{tabular}

Note. Levels indicate percentage of completers meeting standards as established by West Virginia State Department of Education, Division of Technical and Adult Education.

The United States Department of Education continues to negotiate levels and hold states accountable for the core indicators of performance. If states fail to meet performance levels for 
the core indicators of performance, Perkins III mandates accountability through sanctions. Consequences range from required program improvement plans, to, at the extreme, withholding vital federal funds. However, at all levels, career and technical programs are required to monitor academic attainment of all students.

\section{Career and Technical Education's Role in School Reform}

School reform has been a constant throughout the history of education in the United States (Tyack, 1974). Educational change encompasses a change in practice at any level within an organization (Fullan, 2001). According to Fullan's research, there are three dimensions associated with educational change and the implementation of new ideas, policies, or practices: (a) the possible use of new materials (technologies), (b) the possible use of new teaching approaches (strategies or activities), and (c) the possible alterations of beliefs (pedagogical assumptions and underlying theories). A strong understanding of these dimensions is the foundation for those charged with leading school reform efforts.

John Dewey $(1900,1916)$ expressed reasons to be concerned with educational improvement, two of which stand out in the $21^{\text {st }}$ Century: furthering democratic ideals through a broadly educated citizenry, and obtaining a viable economic future for all of our citizens. According to Dewey, education is society's most promising hope of enabling productive citizens. Research indicates that the relationship between education and income has never been stronger.

During the 1980s, educational reform began to focus on academic skills and increasingly recognized the importance of vocational preparation. Vocational education began to prove to be an essential component in the United States' endeavor to be competitive in the ever-increasing technologically advanced workplace. CTE emerged during the 1990 s with a myriad of educational reform initiatives. Prominent themes included the integration of academics and 
vocational education, emphasis on developing transferable work skills, articulation between secondary and post-secondary programs, program realignment with changing workforce demographics, and increasing use of high-level technology and interpersonal skills (Rojewski, 2002).

According to the United States Department of Labor, education is critical in order to obtain a high-paying job (2009). Murnane and Levy (1996) support this premise and identify nine "new basic skills" required for success in the $21^{\text {st }}$ Century: reliability, positive attitude, ninth-grade-or-higher mathematics and reading abilities, problem solving skills, the ability to work in groups, communication skills, and technology skills. The academic community has largely ignored vocational education's role in school reform until recent research. Therefore, it is critical for CTE to demonstrate contributions, not only to applied workplace competencies, but also to the academic proficiencies of students on state-mandated assessments (Daggett, 2005).

Career and technical education has grown to include a wide range of participants, activities and purposes. A recent study shows that nearly half of all secondary students and about one-third of college students are involved in some type of vocational training as a major part of their studies. The study also reports that as many as 40 million adults, or one in four, enroll in short-term, postsecondary occupational training (Silverberg et al., 2004). Students elect to participate in vocational education for various reasons, choosing different venues and career applications. Today, strong skills and lifelong learning are desired commodities. The nature of student experiences in vocational education holds potential implications for the workforce and our nation's place in the global economy.

Bishop and Mane (2004) found a statistically significant and strong positive correlation: an increase in the number of secondary students enrolled in career technical programs is related 
to an increase in high school graduation rates. Plank (2001) also found evidence and concluded that the risk of dropping out was four times higher when students took no CTE courses than when students completed three Carnegie units of CTE courses for every four units in academic subjects. National and local professionals in CTE have discussed how CTE can help educators and policymakers decrease the number of students who leave high school before earning diplomas or who graduate without the skills, knowledge, habits and attitudes needed to prosper as postsecondary students, as workers and as citizens. Finding ways to counter those trends is expected to be a central concern of policy makers.

Hans Meeder (2006), Executive Vice President of Visions Unlimited, Inc. and former Deputy Assistant Secretary at the U.S. Department of Education, in a position paper issued in January 2006 by ACTE, says CTE in high school (1) supports students in the acquisition of rigorous core knowledge, skills, habits, and attitudes needed in postsecondary education and high-skilled workplaces; (2) engages students in specific career-related learning experiences that equip them to make well-informed decisions about further education, training and employment opportunities, and (3) prepares students who may choose to enter the workforce directly after high school with levels of skill and knowledge in a particular career area that will be valued in the workplace.

The consensus of the research reflects that CTE is no longer an alternative for students not wishing to attend college, but rather the foundation and the instructional basis for the development of academic skills (Castellano et al., 2003, Daggett, 2005). Career and technical education at the high school level cannot be reformed independently of other major educational reform. There must be a very symbiotic relationship between CTE and academics. It is 
impossible for CTE programs to operate as a separate organizational structure in program, curriculum or instructional delivery as it relates to student achievement.

Contemporary programs must be organized around the education and training needs of business and industry. Successful reform must include more rigorous and challenging assignments, project-based learning, increased integration of academics, advanced technology, work-based learning, and added collaboration with business, industry and postsecondary institutions. A final consensual theme in $21^{\text {st }}$ Century reform includes improved measures to assure accountability (Lynch, 2000b).

The research clearly indicates that career exposure itself, absent a quality core academic curriculum, will not raise academic performance. Rather, evidence from recent years supports upgrading the academic content and rigor of CTE programs without sacrificing the technical and occupation-related component of the curriculum (Kazis, 2005). Research literature on schoolbased career exploration found evidence of student benefits from a variety of programs: comprehensive guidance programs, career courses in high school, and computer-based guidance systems (Hughes \& Karp, 2004).

The National Assessment of Vocational Education (NAVE) evaluated the status of vocational education and the impact of Perkins III. The three year study found:

- Vocational education has important short- and medium-run earning benefits for most students at both the secondary and postsecondary levels, and these benefits extend to those who are economically disadvantaged;

- Over the last decade of academic reforms, secondary students who participate in vocational programs have increased their academic course enrollment and achievement, making them better prepared for both college and careers than were their peers in the 
past. In fact, for those students who take both a strong academic curriculum and a vocational program of study may have better outcomes than those who pursue one or the other;

- Although positive change is certainly happening at the high school level, secondary vocational education itself is not likely to be a widely effective strategy for improving academic achievement or college attendance without substantial modifications to policy, curriculum, and teacher training. The current legislative approach of encouraging “integration" as a way to move secondary vocational education toward supporting academics has been slow to produce significant reforms (Silverberg, et al., 2004, p 1.)

\section{Barriers to Reform}

Career and technical education in the $21^{\text {st }}$ Century is more challenging with a greater focus on academics; however, many negative perceptions still exist. Hull (2003) stated that while some CTE programs are preparing students for the future, many are viewed as a "dumping ground" for the students who are struggling academically. Lewis (2001) in his study, Major Needs of Career and Technical Education in the Year 2000: Views from the Field, established a case for the need to improve the image of CTE. In this study, those surveyed report beliefs that CTE offered inferior curriculum, appropriate only for students who were unable to meet the demands of a college preparatory program.

Research suggests a ten-percent decline between the years of 1991 and 2001 in the number of post-secondary schools offering CTE teacher training programs (Bruening, et al., 2001). However, there is an increase in the number of teachers entering the profession through alternative certification programs. A number of states blame the lack of CTE teacher training programs for the shortage of CTE teachers (Stasz \& Bodilly, 2004). Gray and Daugherty (2004) 
advocate other issues such as increased primary and secondary student enrollment, expansion of CTE programs, and teacher attrition rates have lead to a national CTE teacher shortage. In addition, an aging workforce has increased the number of retirees. In 1990, Dugger found over fifty percent of all technology teachers were over the age of 50 (Gray \& Daugherty, 2004). One out of fifteen schools was unable to fill its CTE teacher vacancies in 2000 (Levesque, 2004).

In order to improve CTE on a national level, we must first account for the knowledge base of vocational teachers. In 2000, almost nine percent of vocational high school teachers did not hold a baccalaureate degree. More striking is that prospective vocational teachers have lower scores in reading and writing on basic skills assessments than those planning to teach at the elementary level (Silverberg, et al., 2004). Integrating academics into federally supported vocational programs requires a significant investment in professional development. In addition, states must set standards for acceptable levels of knowledge for CTE teachers. This may require development of a national policy regarding standards for CTE teacher preparation programs.

According to a research summary by the Aspen Institute, in the past decade the overall rigor of vocational education has improved; however, much improvement is needed to overcome many obstacles and adequately improve the academic experience for CTE students.

Career and technical education is at a critical juncture in terms of reform. In some locations, at one end of the spectrum, we find up-to-date, innovative and successful programs that offer rigorous academics with knowledge and skills necessary for career preparation. While in other areas there exist schools and programs that fail to update and depend on disadvantaged populations for large percentages of their enrollment. A number of high school vocational programs may be isolated from the needs of the workforce. In addition local school boards, administrators, and counselors may hold the antiquated belief that CTE is an alternative for 
students who are less academically inclined. The NAVE in 1994 documented a number of cases where vocational schools were focused on teaching entry level job skills to students who are educationally disadvantaged. Reform in such a system will require a paradigm shift, educational advocacy for CTE programs, and policy realignment to assure advancement of student career and academic achievement (Lynch, 2000b).

\section{Need for Reform}

Student enrollment remains a primary concern for CTE programs across the nation. Courses are considered electives within the high school curriculum. Declining enrollment may possibly result in the discontinuation of programs. A clear understanding of historical enrollment trends will increase understanding of CTE educators regarding the interest and needs of future student populations. Enrollment in high school CTE courses decreased from nearly 34 percent of the 1982 graduates to 25.5 percent in 1994 (Lynch, 2000a). More alarming to CTE educators was the percentage of graduates disproportionately represented by special population students (Boesel et al., 1994; Levesque et al., 2000).

There are many reasons for the steep decline in CTE program participation. Programs were perceived as not meeting the needs of students and employers. Competition for a shrinking student population with traditional curriculum programs also had an effect. Vocational education has battled an image problem of a "dumbed-down" curriculum for years. Many parents and academic educators have the elitist view that CTE courses are not appropriate for students wanting to attend a four-year college (Lynch, 2000b).

Student attitude and perceptions about CTE are influenced by a number of factors which may include parental views, peer approval, and scheduling challenges. Contributing factors to enrollment decline may include student attitudes, perceptions, and career maturity (Lam, 1982). 
Career maturity can be described as the repertoire of behaviors that assist students in identifying, choosing, planning and executing career goals (Rossetti, 1991). The challenge in career maturity arises when students are asked to make a career choice too early, prior to developing sound decision-making skills. Herr (2002) considers the senior year as the pinnacle of the career decision-making process for the high school student. According to this research, it is too early for the typical tenth grader to make such vital career choices.

According to Cohen and Besharov (2002), an increasing number of college graduates are enrolling in associate degree or certificate programs in technical fields at community colleges with the expectation of finding improved employment. The research also indicates that the image of CTE is dependent upon exposing the myth that all students attend college. Studies indicate the majority of jobs do not require a college degree. The Bureau of Labor Statistics project that of the total job openings between 2000 and 2010, seventy percent will require no postsecondary training, Within the remaining thirty percent, nine percent will require an associate's degree or postsecondary vocational certificate, and only twenty-one percent will require a bachelor's degree or higher.

With statistics indicating that a great number of students desire to pursue a college education, CTE is working diligently to be included in that equation. Consequently, a shift in philosophy to incorporate an increased focus on academic skills and preparation for postsecondary education is taking place (Cohen \& Besharov, 2002).

The Perkins Act represents the largest federal investment in high school education in the history of the United States. Progress has been made, but the challenges of modernizing a career technical education system are indisputable. For CTE, the challenge is how to maintain program integrity and improve learning in a society that encourages preparation for both career and future 
education. The global economy demands academic progress as the bottom line, and suggests further post secondary learning as essential for all graduates.

According to much research, change is not a singular event, rather a process that takes place over time (Hall, et.al., 1975, Kleiner \& Clorrigan, 1989). Fullan and Miles (1992) agree that change should be considered a journey, not a blueprint. In order to change a system, CTE must consider the needs of the $21^{\text {st }}$ Century student. O'Neil (1995) confirmed that schools must make fundamental changes to the institution.

\section{Resolving the Dilemma}

In order to improve the image of CTE, students must be convinced that CTE offers a wide range of career opportunities. Gordon (2008) cites five possible strategies:

- Infuse career and technical education into the curriculum of public schools

- Highlight the marketability of career and technical education program completers

- Collaborate with business and industry to ensure a highly trained workforce

- Establish constant communication with parents

- Re-educate guidance counselors. (p. 308)

Improving the image of CTE requires an intensive effort of all stakeholders to assure CTE's viability in the $21^{\text {st }}$ Century. This may involve examination of the social, economic, historical and philosophical foundations of CTE.

States are beginning to establish criterions regarding the format components for a $21^{\text {st }}$ century version of career-focused education. Most agree that more academic rigor is an essential condition to CTE's survival in the $21^{\text {st }}$ Century (Medrich, 2005). New York State has made CTE reform a priority and instituted a program re-approval process to drive improvement and change (Kazis, 2005). In New York State, as Katherine Hughes of the Institute for Education and the 
Economy at Teachers College reports, all new CTE programs must have a postsecondary partner and a clear articulation agreement that encourages continuation of technical studies after high school. In Maryland, a statewide reassessment of secondary CTE programs has led to the identification of a specific number of career pathways that the state will promote. As Katharine Oliver of the Maryland Department of Education notes, the state uses its funding to create incentives for pathway programs to partner with industry associations or particular firms for their valuable resources, labor market reality testing, and job networks.

According to the goals of NCLB, schools need to build career-focused curricula that motivate students to stay in school and encourage them to continue on to higher education. Ultimately, when CTE programs align with the needs of business and industry, these relationships will provide for economic success and quality of instruction that build skills and make course work relevant. This requires schools to analyze changes in the labor markets and redefine career-focused education in response to emerging economic trends. Fields such as information technology, communications and marketing require different preparation than traditional trade and industry CTE programs (National Center for Educational Statistics, 2000).

\section{Setting the Course for the Future of CTE}

Richard Lynch, a professor of occupational studies at the University of Georgia, completed a yearlong research study for the United States Department of Education, Office of Vocational and Adult Education. The purpose of the project was to identify and describe new directions for CTE in the first decade of the $21^{\text {st }}$ Century. Four distinct themes emerged from this study:

Career Planning. There is a need to introduce career planning throughout the entire curriculum, from pre-K through lifelong learning. Career awareness should begin early in a 
child's life and continue through age 11. Career introduction and interaction with adults are suggested opportunities for this stage. Middle school career exploration should be field based and action oriented. The focus should be on relationships between careers and personal goals. High school career exploration involves more focused preparation for workplaces and college majors.

High School Reform. Lynch found that the challenge to improve high school career tech is directly linked to improving high schools themselves. Suggestions for high school improvement included making schools smaller, more focused, more challenging, more interesting, and more friendly and fair to all students and parents. Other reform measures mentioned were added real-world connections, more resources, more technology and betterprepared teachers.

Upgrade to a New Career and Technical Education. Most prestigious colleges and universities admission requirements do not favor high school career tech courses. The study also revealed that many employers did not feel that high school career tech graduates were adequately prepared for entry level employment positions in their firms. Along with an improved image, high school career technical education should be more rigorous and challenging. The curriculum should include more reading, more integration of academics, more preparation in technology, and more work-based learning. Reform should also include more collaboration with business, industry and postsecondary institutions, and more accountability.

The K-14 Model. The final theme to emerge from Lynch's research was consideration for some type of postsecondary education for all high school students, including those enrolled in CTE programs. The two main proposals for reforming CTE, put forward by school and business 
leaders, were tech prep and articulation between secondary and postsecondary institutions (Lynch 2000a, 2000b).

Based on these four themes, Lynch identified six components that state and local leaders should consider when charting the direction of high school CTE in the future. These include:

Majors. Organizing high school programs, curriculum and instruction around major fields of study, similar to majors in colleges and universities.

Contextual Teaching and Learning. The high school curriculum should include more contextual teaching and learning.

Work-Based Learning. More substantive work-based learning will result in activities that are more grounded in the curriculum and will contribute to mastery of standards.

Authentic Assessment. Authentic evaluation of student progress is needed to meet educational standards.

Career Academies. Career academies have grown nationwide and show promise for high school students and teachers. They are consistent with the ideals of school improvement and reform.

Tech Prep. Business and education leaders have lauded the concept and design of tech prep. There was general agreement on philosophy, intent and responsiveness to the objectives of education and business and industry (Lynch, 2000a, 2000b).

These components will play important roles in the future of high school CTE. An academically rigorous and relevant CTE is integral to the reform of American high schools. High school CTE has an important role to play in the future of our country. It is the responsibility of educational leaders to see that CTE fulfills the role of providing a $21^{\text {st }}$-century education for the next generation of high school students. 
According to Daggett (2002) CTE has "weathered many storms" in the past and will face significant new challenges as a result of NCLB. The requirement that all students achieve proficiency in academic classes will put CTE programs at risk. CTE programs will see a decline in enrollment unless CTE leaders can show that their programs are contributing to the academic success of students, and that the courses are serving as a motivation for students to stay in school, helping them perform better in academic courses.

The demand for schools to raise academic standards came mostly from the business community. The increasingly global and competitively intense workplace requires more advanced and different academic skills than those required for entry into a four-year institution (Daggett, 2002). This presents a challenge because it requires a cultural shift from the belief that many Americans hold that the highest academic standards students will need are those required for higher education.

America has changed. The workplace now demands strong academic skills and the ability to apply those skills to solve real-world problems. CTE must move from the long held perception that it is a good program "for somebody else's child" to one of providing a viable option for a meaningful education for all students. In order for CTE programs to thrive in this new age of educational accountability, Career and technical education leaders must continue to find ways to equip students with the competencies that employment requires, and develop and reinforce the academic standards that are being assessed by embedding and reinforcing these skills in CTE courses (Daggett, 2002).

\section{$21^{\text {st }}$ Century Initiative}

In a report for the Partnership for $21^{\text {st }}$ Century Skills, the board promotes a national dialog regarding CTE and $21^{\text {st }}$-century learning skills, recognizing that both are essential and, 
when done in tandem, each reinforces the other. The report suggests six elements schools can incorporate for an effective $21^{\text {st }}$-century education: emphasize core subjects, emphasize learning skills, use $21^{\text {st }}$-century tools to develop learning skills, teach and learn in a $21^{\text {st }}$-century context, teach and learn $21^{\text {st }}$-century content, and use $21^{\text {st }}$-century assessments that measure $21^{\text {st }}$-century skills (Partnership for $21^{\text {st }}$ Century Skills, 2009).

A solid foundation in core academic subjects is the foundation on which to build $21^{\text {st }}$ century learning. In its 1983 report, A Nation at Risk, the National Commission on Excellence in Education recommended that high school students take four years of English, three years of mathematics, three years of science, and three years of social studies. College-bound students were encouraged to add two years of a foreign language. In 1982 less than fourteen percent of graduates took this sequence of courses, compared to fifty-six percent in 1998 (Olson, 2003). The National Center for Education Statistics considers emphasis on core subjects at early ages critical to future academic success. The more content students are taught early on, the more they learn, and the better students perform on later achievement tests (National Center for Educational Statistics, 1997).

A Nation at Risk called for students to be technologically literate by the end of the eighth grade (Gould, 2002). There is a growing sense of urgency for states to adopt standards that incorporate $21^{\text {st }}$-century tools and learning skills as part of the NCLB eighth-grade literacy requirement. In addition to technology literacy, states would benefit from embedded information and communication technology (ICT) into core educational standards. ICT is basically all technical means for processing and communicating information. State policy makers have an obligation to move forward to evaluate existing standards, curricula, assessments, and redefine them to meet the new demands of the $21^{\text {st }}$ Century. 
Learning skills are cognitive skills that enable the student to acquire new knowledge, connect new information to existing knowledge, and work well with others. Students who are versed in these skills are better prepared for the business world. A key competency that employers across the nation demand is the ability to think critically, the ability to apply knowledge to new situations, the ability to analyze information, the skill to communicate effectively, the skill to collaborate with others, the skill to solve problems and the ability to make decisions. Higher level thinking skills are increasing in importance in today's workplace. In its publication Why Business Cares about Education, the Business Coalition for Education Reform (2001) noted that today's global economy is immensely different from fifty years ago, fueled now by brains rather than brawn. In order to survive, businesses need individuals who possess a wide range of high-level skills and abilities. In a digital world, knowledge regarding $21^{\text {st }}$-century tools is critical. The need for technologically literate citizens and workers increases each year. Technology will continue to be the driving force of the workplace, community, and personal lives in this decade. However, today's technology may be obsolete tomorrow; consequently, students must learn to acquire the skills that will enable them to learn the next generation of technology (Cradler, 1994).

Educators can create a balanced curriculum that reflects both national concerns and local needs by teaching in a $21^{\text {st }}$-century context. Students today are confronted with vast amounts of trivial and profound information. Teachers can help students make meaningful connections between skill and content by making the content relevant to the students' lives. The classroom can be expanded by bringing in outside experts from the community. Technology allows the world to be brought into the classroom and enables students to take charge of their own learning. Research shows that contextual learning in rigorous school-to-career programs in the northeast 
leads to positive results for students including higher academic achievement, lower dropout rates, better attendance, and better college preparation (National Employer Leadership Council, 1999).

As early as 1789, Benjamin Rush, who signed the Declaration of Independence, believed that future citizens of the new republic should learn foreign languages, arts, sciences, history, government and logic. He believed that education should reflect global influences on the republic. Today's generation of Americans also believe that schools should prepare students for the world. The new content crucial for the $21^{\text {st }}$-century schools includes global awareness, as well as financial and economic concerns, and business and civic literacy.

Friedman (2005), in his book It's a Flat World After All, brought to the forefront the concept of globalization. People began to realize that high school and college students today will be competing for jobs against the best students from a much wider range of countries than any previous generation. They will need a deeper understanding of the thinking, motivations and actions of different cultures and countries. Global awareness encourages understanding, tolerance and acceptance of the vast differences represented in communities throughout the world.

People are responsible for making complicated economic and business choices that will affect their futures profoundly in both their personal and professional lives. Little or no education has been provided on these topics. The result, according to the National Endowment for Financial Education (2002), is that millions of financially illiterate Americans, unable to meet financial goals for themselves and their families, will have large-scale implications for the nation. Providing financial, economic and business literacy instruction will help people improve personal financial management and become more productive in workplaces (Partnership for $21^{\text {st }}$ Century Learning, 2009). 
Civic literacy helps students understand and participate in government locally and globally. It is important to have informed, responsible citizens involved in the political process in order for the system to work effectively. Schools can help by integrating this content into core subjects or by using it in contextual learning experiences. Political awareness helps citizens to make better-informed decisions.

No Child Left Behind has put increased pressure on states to improve student achievement and thus there remains a national focus on assessment. The Partnership for $21^{\text {st }}$ Century Learning (2009) has observed the following about assessments: standardized tests must measure $21^{\text {st }}$-century skills along with core subjects; standardized tests must be used in conjunction with classroom assessments in order to measure the full range of students' skills; and classroom assessments must be improved and integrated with the instruction to reinforce learning. Technology may improve methods of assessing acquisition of skills. Students, who are asked to provide written responses and normally use computers to record data, may perform poorly on standardized tests (Russell, Goldberg, \& O’Connor, 2003). Technology-driven assessments may give schools the ability to provide more accurate, timely measurements of students' proficiency.

Career and technical education must embrace this road to $21^{\text {st }}$-century learning in order to survive. States vary in their approach to implementing these skills into the curriculum. Dr. Steven L. Paine, West Virginia State Superintendent of Schools, believes that $21^{\text {st }}$-century learning is a necessity for students who must compete in a global economy (Nagel, 2009). The content standards for each course, including CTE courses, in the state have been rewritten to include $21^{\text {st }}$-century skills. 


\section{Summary}

Career and technical education has had a long and storied history as indicated through the review of the literature. In its conception, CTE served the nation by providing a well-trained workforce. Federal support for CTE has been a vital component in meeting the needs of both students and industry. Federal legislation has served as the major force of unification for CTE in America. Globalization and a changing economy necessitate reform throughout the educational system. Career and technical education has an important role to play in this reform effort. Examination of CTE program coherence will assist in analyzing enrollment trends, program viability and assess the need for transformation into the next era. Understanding the current dynamics related to these issues will assist CTE leaders in developing strategies to capitalize on $21^{\text {st }}$-century reform efforts.

\section{The Delphi Technique}

According to Dr. Norman C. Dalkey (1969), a co-inventor of the technique, Delphi is a method of obtaining and refining group judgments. In practice, it involves interaction between the researcher and a group of individuals identified as experts on a specific topic, usually through a series of questionnaires (Yousuf, 2007). It is useful where the opinions of experts and practitioners are desired concerning future trends and projections on the subject.

\section{Philosophical Foundations}

Inquiring systems based on Lockean reasoning are experimental and consensual. Empirical information, gathered from outside observations, is used inductively to build a representation of the world (Courtney, Croadsell \& Paradice, 1998). Mitroff and Turoff (1975, p. 21) believe that the Lockean basis of Delphi still remains the prime philosophical basis of the technique. They point to the fact that the raw data inputs represent the opinions of the experts 
while the validity of the resulting group judgment is measured in terms of degree of consensus among the experts.

A pure Lockean inquiring system works best on logical, structured problems for which a strong consensus on the nature of the problem exists (Mitroff \& Turoff, 1975). Interpreting the Delphi with Lockean philosophy is an appropriate means for technological or scientific forecasting.

The Kantian inquiring system contains both theoretical and empirical components. The empirical component is capable of receiving inputs, so it generates hypotheses on the basis of inputs received. A major view of the Kantian systems is that truth is synthetic and that data and theory are equally important. As a result, Mitroff and Turoff assert that in applications of Delphi as a tool for planning, Kantian inquiry has become the medium. A unique feature of Kantian systems is that the theoretical component allows an input to be subjected to different interpretations. This allows for many perspectives for problems that do not have a clear consensus. Mitroff and Turoff believe that leaders are better served when presented with alternative models of problems.

In addition to knowing the philosophical foundation of the Delphi method, the practical, value of the Delphi method depends on how well we can justify perceived knowledge regarding an issue. The Delphi method is a means for experts to deal methodically with complex problems (Adler \& Turoff, 1996). 


\section{Justification of the Technique}

Pill (as cited in Adler \& Ziglio, 1996) believes that there are two alternatives when dealing with problems that address complex issues which cannot be easily described in a concise, complete manner. The first is to wait until there is enough sufficiently tested scientific knowledge to address the problem. This option is not feasible when problems need immediate attention. The second alternative is what the Delphi method is based on: gather relevant information from experts and use their judgments as methodically as possible (p. 4). It is this perspective that suggests that the Delphi method can be used in the fields of social policy and public health with the goal of generating new insight to help in knowledgeable decision making.

According to Dalkey (1969) there are three types of information used in decision making. The first is knowledge, which he describes as assertions that are supported by a good deal of evidence backing them up. On the other end of the spectrum is speculation, which has little or no evidential backing. Somewhere in the middle is material for which there is some basis for belief, but not necessarily enough to be called knowledge. Dalkey refers to this middle ground as opinion (p. 2). He admits that while the dividing line among the three is "fuzzy," there are advantages to considering the information instead of the common tendency to dismiss what is not knowledge.

The Delphi method attempts to analyze the information for which there is some evidence, but no actual knowledge, and help improve the decision-making process (Kirby, 2007). When the problem goes beyond the intellectual capabilities of one individual, the Delphi Method has been successfully utilized to decrease the complexity or ambiguity associated with a particular problem (Sandrey \& Bulger, 2008). This method is based on the assumption that the educated, collective judgment of a group of experts is more accurate and reliable than individual judgment 
within situations where effective decision-making is dependent on the knowledge, resourcefulness, expertise and creativity of different types of people (Sahakian, 1997).

Research by psychologists has shown that the traditional way of gathering group information through face-to-face meetings poses serious concerns (Dalkey, 1969). Group opinion is often influenced by dominant individuals within the group. Noise is the second concern of Dalkey. Communication within the group often has to do with individual and group interests instead of problem solving. Finally, group pressure for conformity can distort individual judgment. Group response is more often less accurate after face-to-face discussion (p. 14).

Dalkey believes that the Delphi technique has three distinct features that lead to greater acceptance of group consensus than those arrived at by more direct group interaction:

- Anonymity, achieved through the use of questionnaires, reduces the effect of dominant individuals

- Controlled feedback, consisting of a series of rounds between which a summary of the results of the previous round are relayed to the participants, reduces noise

- Statistical group response helps reduce group pressure for conformity. The group opinion is defined as a statistical average of the final opinions of individual members, hence assuring that the opinion of every member is reflected in the final response (p. 16) Linestone and Turoff (1975) argue that the nature of the Delphi makes its application appropriate only in certain circumstances. They believe that one or more of the following properties must exist before employing Delphi:

- The problem does not lend itself to precise analytical techniques, but can instead benefit from subjective judgments on a collective basis 
- The individuals needed to contribute to the examination of a broad or complex problem, have no history of adequate communication amongst themselves, and may represent diverse backgrounds with respect to experience or expertise

- More individuals are needed than can effectively interact in a face-to-face exchange

- Time and cost make frequent group meetings infeasible

- The efficiency of face-to-face meetings can be increased by a supplemental group communication process

- Disagreements among individuals are so severe or politically unpalatable that the communication process must be refereed and/or anonymity assured

- The heterogeneity of the participants must be preserved to assure validity of the results, i.e., avoidance of domination by quantity or by strength of personality ("bandwagon effect") (p. 4)

The Delphi technique has been used to research fields such as public administration, economics, business, resource and environmental management, education, health care, energy policy, and urban and regional analysis because of its many advantages (Miller, 1993). It is a cost-effective methodology that involves experts without bringing them together in one place (Masser \& Foley, 1987). Delphi studies have proven valid and reliable because expert judgments are combined (Bardecki, 1984; Parente, Anderson, Myers, \& O’Brin, 1984). The anonymity of a Delphi panel allows them to interact, rethink, and compare their thoughts in a “non-threatening forum" without being influenced by the opinions of others (Miller 1993, p. 198). The accuracy of the group judgment may be reduced because of the anonymity and lack of group interactions (Woudenberg, 1991). 


\section{The Basics of Delphi}

The Delphi method is an exercise in group communication among a panel of geographically dispersed experts (Adler \& Ziglio, 1996). The experts are chosen and invited to participate in the study. Round One consists of the initial questionnaire that poses the problem in broad, general terms and encourages responses to an open ended question. Responses to Round One are summarized by the researcher and used to construct a second questionnaire for Round Two. The Round Two survey represents a synthesis of the responses from Round One and asks the panel to rate each item by some criterion of importance. Round Three includes the results of the first two rounds and gives the experts the opportunity to revise previous responses in an attempt to gain consensus (Pfeiffer, 1968). This method involves repeated surveying of the same respondents on the same issue or problem in anticipation of achieving consensus.

Linestone and Turoff (1975) describe four distinct phases that a Delphi study experiences. The first phase is characterized by exploration of the topic being discussed. Individual panel members contribute additional information they feel is pertinent to the issue. Phase two involves the process of understanding how the group views the issue. Phase three explores reasons for significant disagreement. The last phase consists of a final evaluation after all previously gathered information has been analyzed and sent back to the panel for consideration.

\section{Panel Selection}

Selection of the panel is perhaps the most critical point in using the Delphi Method (Lang, 1998). Effective selection of the panel increases the likelihood of quality responses, and adds creditability with a wider audience (Bjil, 1992). Scheele (1975) suggests that three different groups should be included in the selection of the panel. First, there should be stakeholders who 
are or will be directly affected by the issue being studied. Second, those with expert knowledge should be selected. Third, there should be those who will act as facilitators and have the skills to stimulate those with differing views. Adler and Ziglio (1996) suggest the expertise of the panel ensures that responses will be more meaningful than if random participants are selected. Delphi participants should be highly trained and competent within the area of knowledge related to the issue at hand. Researchers need to closely examine and seriously consider the qualifications of potential subjects (Hsu \& Sanford, 2007).

Research varies on the appropriate number of experts to include on the panel. Witkin and Altschuld (1995) noted that the estimated size of a Delphi panel is normally under 50. Ludwig (1997) suggests that in most Delphi studies, group size has been between 15 and 20. This would indicate that the number of Delphi subjects is variable (Delbecq, Van de Ven, \& Gustafson, 1975). If the sample size of a Delphi study is too small, the panel may be viewed as not representing the pool of judgments regarding the issue. On the other hand, if the sample size is too large, the drawbacks could include potentially low response rates and the obligation of large blocks of time by the respondents (Hsu \& Sanford, 2007).

\section{Limitations of the Delphi}

The Delphi method is not without critics. In 1974, Sackman attacked the technique as being unscientific (Lang, 1998). He went on to say that it lacked the rigor to be taken seriously and that its application was highly questionable. Linestone (1975) defended the method by suggesting that in the right circumstances it was an effective research tool. He echoed Coate's view that the Delphi method only be considered as a last resort, dealing with complex problems for which no other model worked. 
Some researchers believe that Delphi is a simple technique that can easily be done.

Experts caution that one must consider the problems associated with Delphi before starting a study (Yoursuf, 2007). Linestone and Turoff (1975) believe that there are five common reasons that Delphi studies fail:

- Imposing monitor views and preconceptions of a problem upon the respondent group by over specifying the structure of the Delphi and not allowing for contribution of other perspectives related to the problem

- Assuming that Delphi can be a surrogate for all other human communications in a given situation

- Poor techniques of summarization, presenting the group response, and ensuring common interpretations of the evaluation scales utilized in the exercise

- Ignoring and not exploring disagreement so that discouraged dissenters drop out, generating an artificial consensus

- Understanding the demanding nature of a Delphi, and the fact that the respondents should be recognized as consultants and be properly compensated for their time if the Delphi is not an integral part of their job function. (p. 6)

Delkey (1972) cautioned against using the Delphi method as the defining factor in answering uncertain questions because an individual panel member's cultural bias can lead to similar answers for some questions; or there could be an instance where the experts legitimately do not know the answer.

J. L. Barnes (1987) has listed additional disadvantages of the technique:

- Judgments are those of a select group of people and may not be representative

- Tendency to eliminate extreme positions and force a middle-of-the-road consensus 
- More time-consuming than the nominal group process

- Should not be viewed as a total solution

- Requires skill in written communication

- Requires adequate time and participant commitment (about 30 to 45 days to complete the entire process.) (p.63)

Fortune (as cited in Yousuf, 2007) believes that panel members can become so close to a problem that they may not be able to see the future. They may not be able to see the vision or the "big picture" of the project in which they are involved. This can also lead to the failure of a Delphi study.

Limitations can be overcome and successful Delphi studies achieved if thorough consideration is given to the context within which the method is applied (Delbecq et al., 1975). Adler and Ziglio (1996) suggest that certain questions should be asked before deciding on the Delphi technique:

- What kind of group communication is wanted to investigate the issue at hand?

- Who are the individuals with the expertise on the issue and where are they located?

- What other techniques are available and what results can reasonably be expected from their application?

One can decide if the Delphi method is appropriate to the context of the problem only after these questions are answered. Failure to adequately address these questions can lead to inappropriate applications of Delphi and discredit the entire creative effort (Adler \& Ziglio, 1996).

According to Goldschmidt (1975), there have been many Delphi studies that have been conducted inadequately. He warns that it is fundamentally wrong to equate applications of the 
Delphi method with the Delphi method itself. There is an important conceptual difference between evaluating a procedure and evaluating an application of a procedure.

\section{Applications of the Delphi Technique}

Dr. Floyd Stead (1975) wrote in his doctoral dissertation:

One of the most recent forecasting tools in educational planning and decisionmaking is the Delphi technique. The Delphi technique was originally developed by the RAND Corporation for obtaining greater consensus among experts about urgent defense problems without face-to-face discussion. The RAND Corporation has performed a number of studies employing the Delphi technique. One example was its use in conducting an extensive survey in forecasting long-range developments, some as far as fifty years into the future, in such areas as scientific breakthroughs, population growth, automation, space progress, probability, and prevention of war and future weapons systems. (p. 15)

The Delphi technique has been utilized in various facets of education for many years. According to Judd (1972) the earliest educational studies looked at goal and objective setting, curriculum and campus planning, and development of evaluation criteria. Judd concludes that education can benefit from using the Delphi method for planning. Given the concern for seeking consensus and predicting the future, Delphi is "a healthy development that bodes well for higher education and for problem-solving in general." (p. 22)

Dr. W. T. Weaver (1971) felt that Delphi had application for education in the following areas: a method for studying the process of thinking about the future; a pedagogical tool or teaching tool which forces people to think about the future in a more complex way than they 
ordinarily would; a planning tool which may aid in ascertaining priorities held by members and constituencies of an organization. (p. 271)

Judd and Weaver's early assessments of the Delphi technique's utility for education have proven accurate. Based on the extensive literature, this investigator will present relative examples of education studies utilizing this research method.

Stead (1975) used the Delphi method to study the future of nursing education in West Virginia. A panel of the administrative heads of all nursing education programs in the state provided insight for the project. As a result of the events provided, he was able to develop a time, impact, and desirability scenario. Stead was able to conclude that within a period of five to fifteen years, three common concerns would affect nursing. These include increased collaboration by central decision-makers in the profession, demands for intense prerequisite requirements, and increased attention to professional identity and role.

Friebel (1999) investigated events that will affect the future of public education in West Virginia. He used a three-round modified Delphi to identify events, estimate when each might occur, and determine their level of impact and desirability. Seven long-term trends were identified which should be of significant importance to educators: (1) accountability and expectations for student achievement and behavior will increase (2) schools will play an increasing role in the resolution of the problems of society (3) a projected teacher shortage will affect changes in funding and staffing patterns (4) public education will experience increasing competition from the private sector (5) technology will play an increasing role in the education process (6) new systems of financing public education will be developed, and (7) there will be continued emphasis on improving and replacing school facilities throughout West Virginia. 
Carman (1999) used a three-round modified Delphi technique to determine the life expectancy and affordability of West Virginia school systems that desired to upgrade or construct new technology infrastructures of their schools. He found that the technology infrastructure that was most affordable and had the longest life expectancy was staff development. Business and education panelists concurred with this conclusion. He was able to further conclude that the technology implemented into programs depended upon the training of staff. The support category, including Staff Development, Help Desks, and Maintenance Contracts, was considered the most important. Secondary conclusions were that technology infrastructures would not change in the immediate future and were considered to be affordable.

Another modified Delphi study was conducted to create a task list for the clinical experience program in the agricultural teacher education programs in North Carolina, South Carolina, and Virginia (Dobbins, 1999). The objectives of the study were to compile a list of clinical experiences, both early field and student teaching, that are currently provided in the clinical experiences for students of agricultural education in three selected teacher education programs. The expert panel was also used to determine what should be included in early field experiences and student teaching experiences for students enrolled in the agricultural teacher education program. The findings resulted in the development of a task list for early field experiences and student teaching experiences to be considered for use by the agricultural education programs in the three participating states. The comprehensive list relates to all aspects of the clinical experience.

Mirra (2004) conducted a study to define the role of the school superintendent as an effective technology leader in terms of knowledge, performances, and dispositions. The study was conducted using a three-round Delphi with an expert panel made up of stakeholders with 
various perspectives in the area of school technology leadership. Mirra concluded that for a superintendent to be considered an effective technology leader, he or she should possess the necessary technology knowledge, perform actions that are beneficial to school community growth and development through the use of technology, and demonstrate those dispositions that are indicative of a positive and growth-oriented posture toward technology within an organization.

Broyles (2004) used a seventeen-member expert panel to help determine the essential agri-science laboratory and classroom components needed to implement a biological applications course in agriculture for Virginia secondary schools. He concluded that: (a) there was not a current comprehensive list of equipment necessary to implement the agri-science course, (b) an essential equipment and component list should be generated for the course, and (c) that there is a need for a list of equipment and components for the course that should include items for both the agricultural education classroom and laboratory.

$\mathrm{Na}$ (2006) utilized a three-round, online modified Delphi study to reach consensus on future course delivery modes and recommended teaching competencies that would be required for teacher education faculty in 2015. The panel reached consensus on 77 general teaching competencies needed by higher education faculty in the coming years. These competencies were grouped into five categories: planning and designing learning environment, teaching and learning, technology, assessment and evaluation, and cultural and ethical issues.

Kirby (2007) used a nationally known panel of experts to explore the future of the clinical laboratory science profession. The panel predicted several noteworthy events would occur in the field. Reimbursement for services will decrease until the government is forced to examine the current reimbursement system. Laboratories should experience an increase in 
testing due to the aging of the population. The shortage of "laboratorians" will reach a critical point. Certifying agencies will need to merge, and professional organizations will be forced to collaborate. Increased advances in technology will require an expanded knowledge base for laboratorians. Management skills and increased sophisticated technical performance will be added to the scope of practice. Clinical laboratory programs will require outside funding to remain viable.

\section{Summary}

The Delphi process has been utilized in numerous research studies as a means of predicting trends and investigating related issues. This technique gained popularity as a research tool based on cost and time efficiency. Delphi applications are used as a means of reliable and creative examination of ideas in order to make informed decisions. Based on a structured process, the Delphi Method collects and refines knowledge from a group of experts by means of a series of questionnaires combined with controlled opinion response. The Delphi uses a threeround process to collect information that is not easily quantifiable by other research methodology and seeks to draw consensus from a panel of experts. The literature review indicates that the Delphi method has been utilized in many educational research studies in order to determine objectives, evaluate possible outcomes, and plan for future curricular programming. 


\section{CHAPTER 3}

\section{METHODOLOGY}

\section{Subjects}

Forty-one individuals were invited to serve as expert panelists for the Delphi study. Invited participants were selected based on their positions and experience within the field of career and technical education. The list included national, state and local representation; United States Department of Education officials, state directors and assistant directors of CTE, state level CTE program directors, national and state professional organization officers, and local CTE administrators. Officials from both the National Research Center for Career and Technical Education and the Southern Regional Education Board were included. All participants have extensive knowledge of career and technical education. The panel of experts is representative of practitioners, researchers, policy makers and leaders in the field. See Appendix B for a list of participant qualifications.

The panel members were selected via email communication. The two main advantages to selecting panel members by email are time and cost (Andrews \& Allen, 2002). Email messages can be sent simultaneously to all potential panelists as opposed to traditional mailings to individuals. The response time to email inquiries is quicker than mailed solicitations (Na, 2006). Cost savings is a major advantage since the cost of postage is eliminated.

Nineteen of the invited experts agreed to serve on the expert panel. Each of the panelists completed all three rounds of the study. The identity of panel members was kept confidential throughout the course of the Delphi study. Each panel member was assigned a unique code that made it possible to keep their identity anonymous to the other panel members. 


\section{Instrument}

Three separate instruments were developed to gather information in three rounds of the Delphi study. All data was collected via email and the World Wide Web utilizing the Zoomerang online survey software tool.

\section{Round One}

The survey instrument for Round One consisted of an open-ended statement: As I consider the next 20 years of career and technical education, I believe the following events might occur. This survey generated a wide-ranging list of possible events which the investigator synthesized into a list of 114 events for use in the second round.

\section{Round Two}

The second survey instrument listed the 114 events synthesized from Round One. The panel was asked to indicate the time period in which each event would likely occur. The time frames from which they chose were: Immediate (1 to 3 years), Mid-range (4 to 10 years), Longrange (11-20 years), Beyond 20 years, and Never. The survey used a five-point Likert scale for rating the impact and the desirability of each event.

\section{Round Three}

The third round consisted of a separate survey for each participant. In an attempt to achieve consensus, panelists were presented with the events that differed from the median. This included the expert responses for time frame, impact and desirability. Their individual responses were listed along with the median group responses. They were asked to change their responses to the median or defend their opinions by stating the reasons for their views. 


\section{Design}

This research study utilized the Delphi technique. The investigator employed a threeround Delphi model in an attempt to bring the panel of experts to consensus regarding future events that will impact career and technical education. Theoretically, the Delphi process can be continued until consensus is determined to have been achieved. In most cases, researchers have found that three rounds are sufficient to collect the needed information and to reach consensus (Custer, Scarcella, \& Stewart, 1999; Hsu \& Sanford, 2007). The information collected through the surveys was used to construct a scenario for potential use by career and technical educators in future planning. This study is similar to the study completed by Beverly Kirby (2007) applying the Delphi Technique to the future of clinical laboratory science.

\section{Procedure}

The investigator contacted each potential panel member via email. The initial email message briefly explained the project and invited participation. A follow-up email message was sent one week later inquiring about receipt of the first message and seeking confirmation of participation. Each individual who agreed to participate in the project was sent an email with the following attachments: letter thanking them for their participation, an informational cover letter, and a personal data sheet outlining qualifications. Panelists were asked to confirm they had read and agreed to the information contained on the informational cover letter. They were instructed to return via email attachment the personal data sheet. See Appendix $C$ for a copy of all correspondence with panelists.

One week prior to sending the first round survey, the investigator emailed each panel member alerting them to its arrival. The message also reminded panel members of the importance of prompt replies. 


\section{Round One}

In Round One of the Delphi study, panel members were emailed a letter and a survey which asked one question: "As I view the future of career and technical education in the next 20 years, the following events might occur." Participants were asked to complete the survey and return it via email within three weeks. Responses from the first round resulted in 252 possible events.

Each event was listed on index cards and organized into topic clusters. Duplicate events were combined, and similar responses were merged to produce a final list of 114 possible events.

\section{Round Two}

The final list of possible events compiled from the first round was incorporated into an online survey instrument and the link to the survey was emailed to the panel members in Round Two. Panel members were asked to indicate the approximate time period in which each event may occur. The possible time frames were: Immediate (1 to 3 years), Mid-range (4 to 10 years), Long-range (11 to 20 years), Beyond 20 years, and Never.

Participants were also asked to use a 5-point Likert scale to indicate the potential impact each of these events will have on career and technical education with 1 representing very low impact and 5 signifying very high impact. Panel members were also instructed to rate the desirability of each event using a similar scale with 1 indicating very undesirable and 5 very desirable. Events that were rated "Never" were not required a response for impact. It is logical that if an event will not happen, it will have no significant impact.

The investigator used responses from the second-round survey to calculate the median time frame response and the median impact and desirability rating for each item. The median was chosen as the preferred measure of centrality for time frame because each category 
represents a distinct time period, and it was not reasonable to average categories of this type. An impact rating of 1 was assigned for events rated as Never for time frame, assuming an event that would never occur would not have impact. The median was used as the measure of centrality for impact because the automatic responses of 1 to the Never time frame would significantly skew a mean.

\section{Round Three}

Each panel member received a separate survey in the third round of the Delphi. The survey consisted of items for which that individual differed from the median response. Because there were 114 events and each event had a median for time frame, impact and desirability, the third round survey had a possible 342 items. The number of items per individual survey ranged from 133 to 288 items with a mean of 194 items per panelist. Each individual's survey had his or her responses displayed beside the median group responses. They were then asked to change their responses to the median, or to defend each conflicting response by giving a reason for the difference of opinion. The differing responses and defenses are listed as minority opinions in Appendix D.

\section{Data Analysis}

The investigator compiled responses from the third round and determined a new median for each item based on the research questions; what events are likely to occur in career and technical education in the future, what is the time line for these events, what will the impact of these events be for career and technical education and what scenario describes the probable future of career and technical education. The events that achieved 60 percent or greater agreement with the median for the projected time frame was interpreted as having achieved consensus. The Round Three responses for impact were also compiled to determine new 
medians. Events for which 60 percent or more of the respondents are in line with the median were measured as achieving consensus. The events were ranked according to projected time frame and degree of impact. For example, Kirby (2007) found an event that may impact the clinical laboratory science profession "educational programs will continue to be challenged to attract high caliber students as we compete against a myriad of other high tech opportunities that are attractive to them, many of which pay better (p. 250).”

Scenarios were constructed for each time frame. Recommendations for planning for the future of career and technical education were made and directed to CTE administrators. Kirby (2007) was able to develop a scenario based on the above event. Panelists agreed that within the immediate time frame (one to three years) clinical laboratory science educational programs will find it difficult to attract high quality students due to competition from superior salaries and career opportunities. The panel also agreed that this would have a very high impact on the profession and that this was very undesirable. Among the recommendations, Kirby suggested optional recruitment begins as early as elementary school for students. 


\section{CHAPTER 4}

\section{PRESENTATION OF DATA}

The data obtained from the three-round modified Delphi study of the future of career and technical education is presented in Chapter 4. The 114 events identified by the panel fell generally into nine broad topic areas: curriculum, $21^{\text {st }}$-century components, political issues, personnel issues, relationship with business and industry, relationship with higher education, funding, accountability, and image. The data is presented in tables corresponding to these issue clusters. The event number, event, median time frame (T), median impact (I), and median desirability (D) for the third round are listed on each table. Consensus, defined as 60 percent of respondents on the median for time frame, impact and desirability, is indicated for each item.

Additional data for each item can be found in Appendix D. This appendix presents all results in order that the events were listed on the survey. Median time lines, impact and desirability are listed for both Round Two and Round Three. Minority opinions for each event are also listed.

Appendix E shows a table of each response in order and Appendix F presents the frequency distribution for all data.

\section{Curriculum}

Twenty-eight events were listed under the general classification of curriculum (Table 2). Consensus was achieved for all 28 events for time line and impact. Events under this topic are listed in order of significance, with the most immediate items described first. The items within each time frame are described in order of impact beginning with the highest impact. 


\section{Immediate Time Frame}

Panel members concurred that 12 events in this category will occur in the one to threeyear time period. They agreed that three of these will be very high impact (5) events. Event 5 involving student internships, job shadowing, or work experience in a technical area before graduation was deemed desirable (4). Event 6 regarding the increased use of industryrecognized standards to validate career-ready status of graduates was viewed as very desirable (5). Finally, it was agreed that increased interest in CTE career areas (Event 14) is also very desirable (5).

Six immediate time frame events achieved consensus as high impact events (4). Respondents agreed that national security concerns will continue to grow along with programs in Criminal Justice and Bio-Security (Event 3) and viewed this as desirable (4). Software and machine management will become the new basics of education in CTE while standardized tests and other forms of testing will disappear (Event 8). This was viewed as moderately desirable (3). The emerging economic development industry clusters will align with current CTE clusters (Event 10). This was viewed as very desirable (5). Panelists believed that CTE is the catalyst that will enable all high school students to make wise academic and career choices and achieve their goals for the future (Event 13). This event was deemed very desirable (5). In addition, secondary CTE programs will offer two tracts, one for highly capable and one for less achieving or challenged students (Event 15). Panelists considered this to be moderately desirable (3). The final high impact event under the immediate time frame consensus was that rigor and relevance of content and delivery will be significantly increased in CTE curriculum and instruction (Event 16). Consensus was not achieved regarding desirability for this item. This was the single item in which consensus was not achieved throughout the study. 
Respondents agreed that three events will have moderate impact on CTE curriculum. Making entrepreneurship a part of all CTE programs (Event 1) was considered desirable (4). Event 2 dealing with the relationship between Health Occupation CTE programs and health care providers and/or facilities reached consensus as desirable (4). The final moderate impact event, which involved decreasing support of "practical” programs such as technology education until they no longer existed, was viewed as undesirable (2).

\section{Mid-Range Time Frame}

Consensus was reached for all three variables for the 16 events panelists predicted to occur in the four to ten-year time frame. Two events were considered to be very high impact (5) issues. The blending of career and technical education with academic education to the point that it would no longer be an either/or situation (Event 17) was considered to be very desirable (5). The panel also deemed that it would be very desirable (5) if career and technical education concentrations (Event 25) were a part of graduation requirements for all students.

Respondents perceived ten mid-range events as having high impact (4) on career and technical education. Event 9 stating that CTE will be driven by a common national vision, mission, and set of core values was seen as desirable (4). Event 11 which said that curriculum standards will undergo a major overhaul as research shows the futility of trying to make a onesize-fits-all list of criteria for completion was viewed as somewhat desirable (3) by the panel. Replacing grade-level tracking with content learning, where students can build on their knowledge and abilities, and leave grade classification behind (Event 12), is considered a profitable change (4). Replacing comprehensive high schools with career academies and small learning communities (Event 18) was also seen as desirable (4). Replacing the Carnegie unit with something not based on seat time (Event 20), and requiring students to participate in career 
and technical student organizations (Event 22), were both regarded as desirable (4) events. The panel concurred that Event 23, which states that career and technical education will be renamed technical skills achievement, was an undesirable (2) event. Stand-alone, academy, and area CTE centers will have counselors, core-subject teachers and student health centers on campus (Event 24). This was held to be a very desirable (5) issue. Panelists consider global standardization of education accreditation (Event 26) as somewhat desirable (3). Finally, Event 28 stating that traditional lines of schools, districts, and institutions will blur was considered desirable (4).

Four mid-range events were judged as having moderate impact (3) on the future of career and technical education. The panel considers it desirable that language instruction become part of a complete and effective CTE program (Event 4). Panelists agreed that Event 7, dealing with CTE meeting the needs of hard-to-reach students as a rebirth of interest in local occupations that provide a good living, was desirable (4). Offering career and technical education in elementary schools (Event 19) was viewed as desirable (4) by panel members. Finally, the experts concurred that changing the school calendar drastically (Event 21) was a desirable (4) event.

Results for all events classified as career and technical education curriculum issues are summarized in Table 2. 
Table 2

Events Related to Curriculum

\begin{tabular}{|c|c|c|c|c|c|c|c|}
\hline $\mathrm{E} \#$ & Question & $\mathrm{T}$ & & $\mathrm{I}$ & & $\mathrm{D}$ & \\
\hline 1 & $\begin{array}{l}\text { Entrepreneurship will become a part of all career and } \\
\text { technical education programs. }\end{array}$ & $\mathrm{Im}$ & + & 3 & + & 4 & + \\
\hline 2 & $\begin{array}{l}\text { Health Occupations CTE programs will be more closely } \\
\text { connected with identified health care providers and/or } \\
\text { facilities: there will be a more pronounced OJT/co-op } \\
\text { component required for CTE program completion. }\end{array}$ & $\mathrm{Im}$ & + & 3 & + & 4 & + \\
\hline
\end{tabular}

3 National Security concerns will continue and career preparation programs in Criminal Justice, Bio-Security will continue to grow.

4 The teaching of languages will become part of a complete and effective CTE program.

5 Students must do an internship, shadow, or work in the technical area before they graduate high school.

6 CTE leads the validation of career-ready status of every high school graduate by increasing the use of instruments that measure skills employers' value (industry recognized certifications).

7 Simultaneously, as career and technical education tries to address the needs of the hard-to-reach student, there will be a rebirth of interest in occupations that will stay local and provide a good living.

8 Software and machine management will become new basics of education in CTE while standardized tests and other forms of testing will disappear.

9 Career and technical education will be driven by a common national vision, mission, and set of core values.

$\mathrm{Im}+4+4+$ $\mathrm{M}+3+2+$ $\operatorname{Im}+5+4+$ $\mathrm{Im}+5+5+$ $\mathrm{M}+4+4+$ $\operatorname{Im}+4+3+$ $\mathrm{M}+4+4+$

10 CTE leads the Career Clusters initiative by emerging and aligning with economic development industry sectors/clusters. 
\begin{tabular}{llll}
\hline E \# & Question & T & I \\
\hline 11 & Content standard objectives (CSOs) and similar standards & $\mathrm{M}+4+3+$
\end{tabular} in other states will undergo a major overhaul, as research shows the futility of trying to make a one-size-fits-all list of criteria for completion. Programs of the same name, in different places, under different industry/business needs, will look different.

12 Grade-level tracking will be replaced with content learning, where students can build on their knowledge and abilities, and leave the grade classification behind, allowing more time for the CTE effort.

13 CTE is the catalyst that expands the assistance available to $\operatorname{Im}+4+5+$ all high school students to enable them to make both wise academic and career choices, and achieve their goals for the future.

14 There will be an increase in the interest of CTE career areas.

15 Secondary CTE programs will all offer a minimum of two tracts, one for highly capable and a different level for those students recognized as less achieving or challenged.

16 Rigor and relevance of content and delivery will be increased significantly in CTE curriculum and instruction.

17 The blending of career and technical education and academic education will overlap considerably - it will no longer be an either/or situation.

18 Career academies and small learning communities will replace the comprehensive high school setting.

19 CTE will be offered in elementary schools.

20 The Carnegie unit will be replaced with something new which is not seat-time based.

21 The school calendar will change drastically, perhaps even becoming individualized depending on geographic area of the state(s). 


\begin{tabular}{lllll}
\hline E \# & Question & T & I & D \\
\hline 22 & Active participation in Career and Technical Student & $\mathrm{M}+4+4+$
\end{tabular}

Organizations (CTSO'S) will be a requirement to complete the CTE course with students routinely attending leadership and competitive events.

23 Career and Technical Education will be renamed to Technical Skills Achievement (TSA), meaning there is more of the industry certification focus than what we have now.

24 All stand-alone, academy, and area CTE centers will have counselors, core-subject teachers, and a student health center on campus.

25 CTE concentrations will be part of graduation requirements for all students.

$\mathrm{M}+4+2+$

26 Global standardization of education, accreditation will occur.

27 Those secondary programs that were called "practical," $\quad \operatorname{Im}+3+2+$ e.g., technology education, will receive decreasing support until they no longer exist.

28 Traditional lines of schools, districts and institutions will $\mathrm{M}+4+4+$ blur.

Note. $\mathrm{T}=$ Time Frame; $\mathrm{I}=$ Impact; $\mathrm{D}=$ Desirability

Im $=$ Immediate (1-3 years); $\mathrm{M}=$ Mid-range ( $4-10$ years)

$\mathrm{E \#}=$ Event Number; + = Consensus; - = No Consensus 


\section{$21^{\text {st }}$ Century Components}

Eighteen events are listed in this topic cluster (Table 3). Consensus was reached for each of the three variables: time frame, impact, and desirability. Events are presented in order of significance with the most immediate items described first. The items within each time frame are described in order of impact beginning with the highest impact.

\section{Immediate Time Frame}

The expert panel agreed that nine events would occur within the one to three-year time frame. Members believed that CTE will play a major role in STEM (Science, Technology, Engineering and Mathematics) education (Event 38). This was considered a very high impact (5) and very desirable (5) event.

Eight of the items in this time frame were rated as high impact (4) events. The development of the right side of the brain, fostered by activities that require synthesis and holistic thinking (Event 30), was deemed desirable (4). Panelists believed that green initiatives will emerge as new CTE programs (Event 36), and agree that this is very desirable (5). An additional event considered to be very desirable was teaching soft skills such as working as team members in CTE programs (Event 39). The need for cultural tolerance brought about by societal changes (Event 41) was considered to be desirable (4). Increased use of instructional technology as a course delivery component (Event 42) and advances in technology to increase learning outside of the brick walls (Event 43) were believed to be desirable (4) events. Project-based and work-based learning will become more common (Event 45). This was judged to be very desirable (5). The use of technology to drive the teaching and learning process (Event 46) was rated as a very desirable (5) event. 


\section{Mid-Range Time Frame}

The experts were in agreement that eight events would occur in the four to ten-year time frame. One event was determined to be a very high impact (5) issue. Modernizing CTE centers will be vital in maintaining an edge in the labor market (Event 37). This was thought to be a very desirable (5) event.

Six of the events were deemed high impact (4) topics by the panel. Event 29, which stated that the United States and other advanced societies will move toward continuous innovation to meet job market demand founded by information technology, was believed to be a desirable (4) event. Panelists predicted that globalization resulting in multi-national education programs (Event 31) was somewhat desirable (3). There was consensus that learning in career and technical education will be performance and innovation based (Event 33). This was a very desirable (5) event. Adding international business to CTE programming (Event 35) was considered a desirable (4) event. In addition, career development of life-long learners at all levels will become very important as we move from the manufacturing model to individualization (Event 40). This was viewed as desirable. Finally, change in public education will be strongly influenced by outside innovators (Event 44). This was rated as somewhat desirable (3).

The panel agreed that one event would have moderate impact on career and technical education. Rural America obtaining high speed internet access (Event 34) was regarded as a highly desirable (5) event. 


\section{Long-Range Time Frame}

Panel members concurred that one event would take place in the 11 to 20 -year time frame. The goal of career technical education systems in 20 years will be to produce flexible, resilient, software-supported students, workers, and citizens who can successfully compete, thrive, and live with dignity in a technology-driven continuous innovation society capable of embracing constantly changing goods and services of consumer needs (Event 32). They also concurred that this event was a high impact (4) and desirable (4) event.

Results for all events classified as career and technical education $21^{\text {st }}$-century components are summarized in Table 3.

Table 3

Events Related to $21^{\text {st }}$ Century Components

\begin{tabular}{|c|c|c|c|c|c|c|c|}
\hline E \# & Question & $\mathrm{T}$ & & $\mathrm{I}$ & & $\mathrm{D}$ & \\
\hline 29 & $\begin{array}{l}\text { The United States and other advanced societies will move } \\
\text { toward continuous innovation to meet job market demand, } \\
\text { which is founded by information technology. }\end{array}$ & $\mathrm{M}$ & + & 4 & + & 4 & + \\
\hline 30 & $\begin{array}{l}\text { The development of the right side of the brain will be } \\
\text { fostered by activities that require synthesis and holistic } \\
\text { thinking. }\end{array}$ & $\mathrm{Im}$ & + & 4 & + & 4 & + \\
\hline 31 & $\begin{array}{l}\text { Continued globalization will result in multi-national } \\
\text { education programs. }\end{array}$ & M & + & 4 & + & 3 & + \\
\hline 32 & $\begin{array}{l}\text { The goal of career technical education systems in } 20 \text { years } \\
\text { will be to produce flexible, resilient, software-supported } \\
\text { students, workers, and citizens who can successfully } \\
\text { compete, thrive, and live with dignity in a technology- } \\
\text { driven Continuous Innovation Society capable of } \\
\text { embracing constantly changing goods and services of } \\
\text { consumer needs. }\end{array}$ & $\mathrm{L}$ & + & 4 & + & 4 & + \\
\hline 33 & $\begin{array}{l}\text { Learning in career and technical education will be } \\
\text { performance and innovation based. }\end{array}$ & M & + & 4 & + & 5 & + \\
\hline
\end{tabular}


\begin{tabular}{llll}
\hline E \# & Question & T & I \\
\hline 34 & Rural America with no access to high-speed internet will & $\mathrm{M}+3+5+$
\end{tabular} get access.

35 International Business will be added to programming in $\mathrm{M}+4+4+$ CTE.

36 Green technology initiatives emerge as new CTE programs.

37 Modernizing CTE centers will be vital in maintaining an edge in the labor market.

38 Career and technical education will play a major role in $\operatorname{Im}+5+5+$ STEM (Science, Technology, Engineering and Mathematics) education.

39 Career and technical education will include the teaching of soft skills, such as the ability to work well together, in its programming.

40 Career development of life-long learners at ALL levels will become very important as we move from the manufacturing model to individualization.

41 Societal changes and more ethnic diversity will occur at a $\operatorname{Im}+4+4+$ faster rate, thus increasing the need to understand and tolerate the cultural needs and function of others amongst us.

42 Instructional technology (ex. virtual learning) will increase its presence as a course delivery component.

43 Technology advances will continue to drive curriculum and program changes, increasing learning outside of the brick walls at all levels.

44 Change in public education will be strongly influenced by $\mathrm{M}+4+3+$ outside innovators.

45 Project-based and work-based learning will become more $\operatorname{Im}+4+5+$ common. 


\begin{tabular}{lllll}
\hline E \# & Question & $\mathrm{T}$ & $\mathrm{I}$ \\
\hline 46 & $\begin{array}{l}\text { The use of technology to drive the teaching and learning } \\
\text { process will become commonplace. }\end{array}$ & $\mathrm{Im}+4+5+$ \\
\hline
\end{tabular}

Note. $\mathrm{T}=$ Time Frame; $\mathrm{I}=$ Impact; $\mathrm{D}=$ Desirability

Im = Immediate (1-3 years); M = Mid-range (4-10 years); $\mathrm{L}=$ Long-range (11-20 years)

E\# = Event Number + + = Consensus; - = No Consensus

\section{Political Issues}

Ten events were classified as political issues for career and technical education (Table 4).

Consensus was reached for time frame, impact, and desirability for each of these events. The most immediate events are presented first.

\section{Immediate Time Frame}

Three events were expected to occur in the one to three-year time frame. Two of these were considered to be very high impact (5) events. Panel members found Event 50 to be very desirable (5). It is their expectation that decision and policy makers will realize the gravity of allowing CTE to continue as the dumping ground for students who cannot succeed in the general education classroom. China and India will control the world economically, pushing the United States to get very serious about creating, implementing, and marketing innovation (Event 55). The United States losing its place as the world economic leader was deemed undesirable (2) by the panel.

Event 52, judged a high impact (4) event, was also rated undesirable. Panelists believed that high school dropout rates will continue to climb due to a disengaged student population from middle school upward.

\section{Mid-Range Time Frame}

The panel concurred that seven events would take place in the four to ten-year time frame. One of those events was considered a very high impact (5) and very desirable (5) event. 
It was their expectation that career and technical education facilities and programs will have a strong, vocal, and informed voice on Capitol Hill (Event 53).

Five events in the mid-range time frame were classified as high impact (4). Students leaving low performing public schools for other viable options (Event 47) was considered a somewhat desirable (3) event by panel members. More stringent qualifications for school board membership (Event 48) were deemed desirable (4) by the panel. Public education will remain, but there will be expansion of private sector education and new hybrids of public-private sector partnerships (Event 51). This was considered somewhat desirable (3). Global, national, state, regional, and local economic changes will cause greater shifts in the wealth of populations (Event 54). Panel members found this to be somewhat desirable (3). Finally, it was agreed that social changes will move from the old manufacturing models of education, work, and life, to one where individuals decide what path they want to follow to fit in the global scheme (Event 56). This was considered somewhat desirable (4).

One event was deemed to have moderate impact (3) on career and technical education. Current education hierarchies will be challenged. Chief among those will be the school board authority, which will be eliminated as an archaic way of running a school system (Event 48). The panel deems this somewhat desirable (3).

All events thought to be political issues impacting career and technical education are summarized in Table 4.

Table 4

Events Related to Political Issues

\begin{tabular}{lllll}
\hline E \# & Question & T & I & D \\
\hline 47 & $\begin{array}{l}\text { Student flight from low-performance public schools to } \\
\text { other viable options will occur. }\end{array}$ & $\mathrm{Im}+4$ & +
\end{tabular}




\begin{tabular}{lllll}
\hline E\# & Question & T & I & D \\
\hline 48 & $\begin{array}{l}\text { Current education hierarchies will be challenged, } \\
\text { especially the school board authority, which will be } \\
\text { eliminated as an archaic way of running a school system. }\end{array}$ & $\mathrm{M}+3+3+$ \\
& & &
\end{tabular}

49 There will be a concentrated evaluation of the qualifications for County (or Regional) Board of

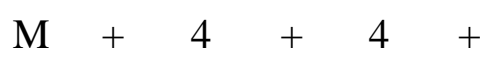

Education membership. There will be a requirement that individuals have some interest in or value for education and the public schools, and, perhaps even some education themselves, which will take the credibility and influence of board members up several notches.

50 Decision and policy makers will realize the gravity of allowing CTE to continue as the dumping ground for students who cannot succeed in the general education classroom.

51 Public education will remain, but there will be expansion of private sector education and new hybrids of publicprivate sector partnerships.

52 High school dropout rates will continue to climb due to disengaged student population from middle school upward.

53 Career and technical education facilities and programs will have a strong, vocal, and informed voice on Capitol Hill.

54 Global, national, state, regional, and local economic changes will cause greater shifts in the wealth of populations.

55 China and India will control the world economically, pushing the United States to get very serious about creating, implementing, and marketing innovation.

56 Social systems move from the old manufacturing models of education, work, and life to one where individuals decide what path they want to follow to fit in the global scheme.

\footnotetext{
Note. $\mathrm{T}=$ Time Frame; I = Impact; $\mathrm{D}=$ Desirability

Im $=$ Immediate ( $1-3$ years); $M=$ Mid-range ( $4-10$ years)

E\# = Event Number + + = Consensus; - = No Consensus
} 


\section{Personnel Issues}

Fourteen events were identified as personnel issues facing career and technical education (Table 5). Consensus was reached for each of the three variables: time frame, impact, and desirability. Events under this topic are listed in order of significance with the most immediate items described first. The items within each time frame are described in order of impact beginning with the highest impact.

\section{Immediate Time Frame}

Panelists agreed that two events would occur in the one to three-year time frame. Considered to be a very high impact (5) and very desirable (5) issue, Event 65 stated that career and technical education programs will have great teachers who foster passion and curiosity. The panel credits Event 64 as high impact (4) and very desirable (5). According to this event, CTE instructors must understand and participate in professional development activities to prepare them for the subjects being taught, and utilize a variety of strategies.

\section{Mid-Range Time Frame}

Panel members concurred that 12 events would take place in the four to ten-year time frame. Three of these events were considered to be very high impact (5). It was agreed that the demand for CTE teachers will increase (Event 59). This was very desirable (5). The blending of technical and academic delivery (Event 60) was considered very desirable, significantly changing education programs for CTE teachers. The final very high impact, very desirable event involves secondary school counselors' increase of information, and cognizance of the opportunities awaiting students in CTE programming (Event 66).

Nine mid-range events were deemed to be high impact (4). Requiring CTE educators to hold postsecondary degrees (Event 57) was desirable (4). The panel deemed it very desirable (5) 
that CTE teachers be required to hold industry certification (Event 68). It was also desirable that there be a career and technical education tract in higher education similar to those required for regular education fields (Event 61). CTE teachers employed part-time as opposed to full-time (Event 62), was deemed somewhat desirable (3). Performance-based pay for CTE educators (Event 63) was also considered somewhat desirable by panel members. Event 67 considers the evolution of stakeholder roles in various realms of education and was deemed very desirable (5). Stakeholders will emerge steadily as important informants and collaborators in not only evaluating, but also planning and executing instructional programs. Additionally, career and technical education administrator preparation programs will be designed to better equip principals in the CTE realm (Event 68). The panel determined this event as very desirable (5). Finally, the panel agreed that two events were desirable (4). Event 69 considers the shift in CTE governance resulting in an increase in contact between educators and state/regional leaders. Moreover, faculty will become consultants to students who will become innovators and entrepreneurs (Event 70).

All events classified as personnel issues facing career and technical education are summarized in Table 5.

Table 5

Events Related to Personnel Issues

\begin{tabular}{lllll}
\hline E \# & Question & $\mathrm{T}+\mathrm{I}$ & $\mathrm{D}$ \\
\hline 57 & $\begin{array}{l}\text { Educators in career and technical education fields will be } \\
\text { required to hold postsecondary degrees (associate, } \\
\text { bachelor or master). }\end{array}$ & $\mathrm{M}+4+4+$ \\
58 & $\begin{array}{l}\text { Career and technical education teachers will be required } \\
\text { to hold industry certification. }\end{array}$ & $\mathrm{M}+4+5+$ \\
59 & $\begin{array}{l}\text { The demand for CTE teachers will increase. } \\
\mathrm{M}+5+5+\end{array}$
\end{tabular}




\begin{tabular}{lllll}
\hline E \# & Question & T & I & D \\
\hline 60 & Teacher education programs for CTE teachers will change & $\mathrm{M}+5+5+$
\end{tabular}
significantly as a result of the blending of technical and academic delivery.

61 There will be a teacher education tract in higher education $\mathrm{M}+4+4+$ for those wishing to pursue a career in industrial, technical or health occupations education much like regular education fields.

62 Many teachers will be part-time as opposed to full-time. $\mathrm{M}+4+3+$

63 CTE performance-based educator pay will come to the $\mathrm{M}+4+3+$ forefront.

64 CTE instructors must understand and participate in professional development activities to prepare them for the subjects being taught and with a variety of strategies.

65 CTE programs will have great teachers who foster passion $\operatorname{Im}+5+5+$ and curiosity.

66 Secondary school counselors will be informed and cognizant of the opportunities awaiting students in CTE programming.

67 Stakeholders in various realms of education (CTE, secondary, post-secondary, general secondary, higher ed) will emerge steadily as important informants and collaborators in not only evaluating, but also planning and executing instructional programs.

68 CTE Administrator preparation programs will be designed to better equip principals in CTE realm.

69 There will be a shift in CTE governance resulting in an increase in contact between local educators and state/regional leaders.

70 Faculty will become consultants to students, who will become clients, while the students will become innovators and entrepreneurs.

Note. $\mathrm{T}=$ Time Frame; I = Impact; $\mathrm{D}=$ Desirability

Im $=$ Immediate (1-3 years); $\mathrm{M}=$ Mid-range ( $4-10$ years)

E\# = Event Number; + = Consensus; - = No Consensus 


\section{Relationship with Business and Industry}

Consensus was reached on ten events classified as issues dealing with the relationship between business and industry and CTE (Table 6). Consensus was reached for each of the three variables, namely time frame, impact, and desirability. Items are presented in order of significance with the most immediate listed first.

\section{Immediate Time Frame}

Respondents agreed that five events would occur in the one to three-year time frame. Two of those were determined to be very high impact (5) events. Experts agreed upon the increasing demand for skilled workers (Event 72). This was deemed very desirable (5). Three immediate time frame events were thought to have high impact (4) and be very desirable (5) for career and technical education. Panel members were of the same opinion regarding the increasing collaboration between stakeholders and CTE (Event 73) and the demand for workers with postsecondary education (Event 74). Finally, panelists concurred that CTE is the critical link that connects business leaders with educators in a unified effort to help all students understand the relevance of their education. Collaboration between CTE and business will assist students in setting future goals and prepare them with the knowledge, talent and skills valued and needed in today's workplace (Event 77).

\section{Mid-Range Time Frame}

Five events were determined to occur in the four to ten-year time frame. Three events were thought to be very high impact (5). Panel members concurred that career and technical education will be called upon to retrain America's workforce and that this was a very desirable (5) event. The panel agreed that in order to be more competitive in the workplace, students will seek more specific technical skills training (Event 79). In addition, career and technical 
education will serve as the change agent in building existing governance structures to bring state, regional, and local leaders in education, workforce, and economic development together to support and grow each state's economy (Event 80). Each of the two events (79 and 80) was considered very desirable (5).

The expert panel agreed that two events would have a high impact (4) on career and technical education. Local industry advisory councils will play a bigger role in ensuring lab tools and equipment are updated to meet and/or exceed the requirements of the workplace (Event 71). This was considered to be a desirable (4) event. Another desirable, high impact event includes focus on workforce development, which will require the alignment of education, work, and data in order to develop programs (Event 76). In addition, it was agreed that CTE will be called upon to retrain America's workforce (Event 75). This was also considered a very desirable event.

The events determined to be issues related to the relationship between CTE and business and industry are summarized in Table 6.

Table 6

Events Related to the Relationship with Business and Industry

\begin{tabular}{|c|c|c|c|c|c|c|c|}
\hline E\# & Question & $\mathrm{T}$ & & $\mathrm{I}$ & & $\mathrm{D}$ & \\
\hline 71 & $\begin{array}{l}\text { The local industry advisory council will play a bigger role } \\
\text { in ensuring that the lab tools and equipment are updated to } \\
\text { meet and/or exceed the requirements of the workplace. }\end{array}$ & $\mathrm{M}$ & + & 4 & + & 4 & + \\
\hline 72 & The demand for skilled workers will increase. & $\operatorname{Im}$ & + & 5 & + & 5 & + \\
\hline 73 & $\begin{array}{l}\text { Collaboration between stakeholders and CTE will } \\
\text { increase. }\end{array}$ & $\operatorname{Im}$ & + & 4 & + & 5 & + \\
\hline 74 & $\begin{array}{l}\text { The demand for workers with postsecondary education } \\
\text { will increase. }\end{array}$ & $\mathrm{Im}$ & + & 4 & + & 5 & + \\
\hline
\end{tabular}




\begin{tabular}{llll}
\hline E\# & Question & T & I \\
\hline 75 & Career and technical education will be called upon to & $\mathrm{M}+5+5+$
\end{tabular}
retrain America's workforce.

76 The focus of education will be on workforce development, $\mathrm{M}+4+4+$ which will mean the alignment of education and work, and the use of data to develop what programs are offered.

77 CTE is the link that connects business leaders with educators in a unified effort to help all students understand the relevance of their education to their future goals, and prepare them with the knowledge, talent and skills valued and needed in today's workplace.

78 Jobs will constantly evolve to meet workforce demand, forcing constant updating for career technical education in America, and formulating an Innovation Society driven by continuously enhanced human capital.

79 All students will seek more specific technical skills training in order to be more competitive in the workplace.

80 CTE will serve as the change agent in building existing governance structures to bring state, regional, and local leaders in education, workforce, and economic development together to support and grow each state's economy.

Note. $\mathrm{T}=$ Time Frame; $\mathrm{I}=$ Impact $\mathrm{D}=$ Desirability

Im $=$ Immediate (1-3 years); $\mathrm{M}=$ Mid-range ( $4-10$ years)

E\# = Event Number; + = Consensus; - = No Consensus

\section{Relationship with Higher Education}

Ten events were classified as issues associated with the relationship between career and technical education and higher education (Table 7). Consensus was reached on time frame, impact, and desirability for each event under this issue cluster.

\section{Mid-Range Time Frame}

Panel members established nine events would occur in the four to ten-year time frame. Four events were determined to be very high impact (5) and very desirable (5). Respondents 
recognized the importance of CTE as a credible choice for college-bound students rather than a last resort for marginalized students (Event 82). In order to assure smoother transition from high school to college and from college to college, Event 85 considers implementation of worldwide articulation agreements. Career and technical education will be a valuable part of all students' overall high school experience, and will be used to help prepare them for postsecondary education and/or career success (Event 89). Event 90 held that CTE will drive innovation and creativity by transforming the culture of education, producing academically-skilled and careerready lifelong learners. The single undesirable (2), very high impact (5) event determined by the panel members involves the absorption of post-secondary CTE programs by the community college system (Event 81).

It was agreed that four mid-range events will have a high impact (4) on career and technical education. Increasing seamless transition to post-secondary education through better alignment with community colleges (Event 83) was deemed desirable (4). The panelists concurred that higher education will offer multiple tracks for advancement through the degree process for students entering from CTE with certifications in similar career fields (Event 84). This was thought to be very desirable (5). Members of the panel were in agreement that the chasm between secondary and post-secondary CTE will either get smaller or be eliminated with the implementation of programs of study (Event 87). This was judged to be desirable (4). According to the survey results, secondary CTE will become more agile and focused on supporting transitions to higher education that support the local, regional, state, national, and global workforce and economic needs (Event 88). This too was considered desirable. 


\section{Long-Range Time Frame}

The panel determined that one event would occur in the 11 to 20 -year time frame. Event 86, which states that learning centers will exist and traditional schools will be obsolete, was considered very high impact (5) and somewhat desirable (3).

All events thought to be issues related to the relationship between career and technical education and higher education are summarized in Table 7.

Table 7

Events Related to the Relationship with Higher Education

\begin{tabular}{|c|c|c|c|c|c|c|c|}
\hline E \# & Question & $\mathrm{T}$ & & I & & $\mathrm{D}$ & \\
\hline 81 & $\begin{array}{l}\text { Post secondary CTE programs will be absorbed in the } \\
\text { community college system. }\end{array}$ & $\mathrm{M}$ & + & 5 & + & 2 & + \\
\hline 82 & $\begin{array}{l}\text { Career and Technical Education will be recognized as a } \\
\text { credible choice for college-bound high school students, } \\
\text { rather than as a last resort for marginalized students. }\end{array}$ & M & + & 5 & + & 5 & + \\
\hline
\end{tabular}

83 There will be better program alignment with community $\mathrm{M}+4+4+$ colleges, enabling a much more seamless transition to post secondary education.

84 Higher education will offer multiple tracks for advancement through the degree process for students entering from Career and Technical Education with certifications/completions in similar career fields.

85 Worldwide articulation agreements will be implemented $\mathrm{M}+5+5+$ to assure smooth transition of students from high school to college and from college to college.

86 Learning centers will exist and traditional schools will be obsolete.

87 The chasm between secondary and postsecondary career and technical education will either get smaller or be eliminated with the implementation of programs of study. 


\begin{tabular}{|c|c|c|c|c|c|c|c|}
\hline E \# & Question & $\mathrm{T}$ & & $\mathrm{I}$ & & $\mathrm{D}$ & \\
\hline 88 & $\begin{array}{l}\text { High school CTE will become more agile and focused on } \\
\text { supporting transitions to higher education that support the } \\
\text { local, regional, state, national, and global workforce and } \\
\text { economic needs. }\end{array}$ & $\mathrm{M}$ & + & 4 & + & 4 & + \\
\hline 89 & $\begin{array}{l}\text { CTE will be a valuable part of all students' overall high } \\
\text { school experience and is used to help them prepare for } \\
\text { postsecondary education and/or training and career } \\
\text { success. }\end{array}$ & M & + & 5 & + & 5 & + \\
\hline 90 & $\begin{array}{l}\text { CTE drives innovation and creativity in the state's high } \\
\text { schools by transforming the culture of education so every } \\
\text { school produces lifelong learners who are both } \\
\text { academically-skilled and career-ready. }\end{array}$ & M & + & 5 & + & 5 & + \\
\hline
\end{tabular}

Note. $\mathrm{T}=$ Time Frame; I = Impact; D = Desirability

$\mathrm{M}=$ Mid-range (4-10 years); $\mathrm{L}=$ Long-range (11-20 years)

$\mathrm{E \#} \mathrm{=} \mathrm{Event} \mathrm{Number;} \mathrm{+} \mathrm{=} \mathrm{Consensus;} \mathrm{-} \mathrm{=} \mathrm{No} \mathrm{Consensus}$

\section{Funding}

The expert panel identified six events associated with the future funding of career and technical education (Table 8). Consensus was reached on three variables for each event: time frame, impact, and desirability.

\section{Immediate Time Frame}

Panel members concurred that a single event would take place in the one to three-year time frame; federal funding will be the key to the survival or demise of career and technical education (Event 92). This was considered to have a very high impact (5) on CTE and believed somewhat desirable (3).

\section{Mid-Range Time Frame}

Five events were thought to occur in the four to ten-year time frame. One event was regarded as a very high impact (5); the failure of the re-authorization of the Carl D. Perkins 
Career and Technical Education Act of 2006 beyond 2018 (Event 96) was deemed somewhat desirable (3).

Four events were identified as high impact (4). Career and technical education funding will become dependent on competitive grants which would require additional proof that programs are valid (Event 91). This was deemed somewhat desirable (3). Panelists agreed that the CTE research database will grow significantly, providing a valid and substantial foundation for increasing and stabilizing funding for higher quality CTE teachers and higher quality CTE programming (Event 93). This was viewed as very desirable (5). It was agreed that Event 94 was desirable, which stated that CTE programs will be certified or recognized by industry, professional, trade associations, or state licensing agencies, and that this will lead to performance-based program support dollars (4). The final funding issue to reach consensus involved replacement or modification of Perkins funding as CTE merges with general education, higher education, and community colleges (Event 95). This was viewed as somewhat desirable (3).

All events categorized as issues concerning the future of funding for career and technical education are summarized in Table 8 .

Table 8

Events Related to Funding

\begin{tabular}{lllll}
\hline E \# & Question & T & I & D \\
\hline 91 & $\begin{array}{l}\text { CTE funding will become more dependent on } \\
\text { "competitive grants," which would require additional } \\
\text { "proof" that programs are valid. }\end{array}$ & M & & \\
92 & $\begin{array}{l}\text { Federal funding will be the key to the survival or demise } \\
\text { of career and technical education. }\end{array}$ & Im
\end{tabular}




\begin{tabular}{|c|c|c|c|c|c|c|c|}
\hline E\# & Question & $\mathrm{T}$ & & $\mathrm{I}$ & & D & \\
\hline 93 & $\begin{array}{l}\text { Career and technical education research database will } \\
\text { grow significantly, providing a valid and substantial } \\
\text { foundation for increasing and stabilizing funding for } \\
\text { higher quality CTE teachers and higher quality CTE } \\
\text { programming. }\end{array}$ & $\mathrm{M}$ & + & 4 & + & 5 & + \\
\hline 94 & $\begin{array}{l}\text { CTE programs will be certified or recognized by industry, } \\
\text { professional, trade associations, or state licensing agencies } \\
\text { and that will lead to performance-based program support } \\
\text { dollars. }\end{array}$ & M & + & 4 & + & 4 & + \\
\hline 95 & $\begin{array}{l}\text { Perkins funding may be replaced or greatly modified as } \\
\text { CTE merges with general education, higher education, } \\
\text { and community colleges. }\end{array}$ & M & + & 4 & + & 3 & + \\
\hline 96 & $\begin{array}{l}\text { There will not be a re-authorization of the Carl D. Perkins } \\
\text { Career and Technical Education Act of } 2006 \text { beyond } 2018 \text {. }\end{array}$ & M & + & 5 & + & 3 & + \\
\hline
\end{tabular}

Note. $\mathrm{T}=$ Time Frame; I = Impact; $\mathrm{D}=$ Desirability

I = Immediate (1-3 years); $\mathrm{M}=$ Mid-range (4-10 years);

E\# = Event Number; + = Consensus; - = No Consensus

\section{Accountability}

Eight events were identified as topics relating to career and technical education accountability concerns (Table 9). Consensus was reached for time frame, impact, and desirability for each item. Events are listed in order of significance with the most immediate items first.

\section{Immediate Time Frame}

Panel members agreed that one item would occur in the one to three-year time frame. Increased focus on research-based and test-driven education (Event 97) was viewed as a high impact (4) and somewhat desirable (3) event. 


\section{Mid-Range Time Frame}

Seven items were thought to occur in the four to ten-year time frame. Four were considered very high impact (5) events. The panel believed that portfolio-type assessments will replace high-stakes testing (Event 99). This was deemed desirable (4). Panelists predicted the implementation of national CTE assessments (Event 101) and viewed this as somewhat desirable (3). The panel considered it both high impact (4) and desirable (4) that a longitudinal data system designed to improve collection and data integrity would enhance accountability and aid in data-driven decision making (Event 102). Finally, panel members concurred that the emphasis on accountability in all secondary education programs will continue with CTE at great risk to prove that their contribution is worth the expense (Event 104). This was viewed as somewhat desirable (3).

Respondents agreed that three events were high impact (4) issues related to accountability and CTE. First, the likelihood that performance-based assessment would replace degrees and diplomas, and that student competencies would be observable and documented on a certificate of achievement (Event 98), was considered very desirable (5). Event 100 considered increased educational assessments, which measure ability to access knowledge rather than retain it. This was viewed as desirable (4). Finally, the panel believed increased longevity (living longer) and working longer will result in lifelong learning and the need for more frequent training (Event 103). This was considered desirable (4).

The events categorized as accountability issues for career and technical education are summarized in Table 9. 
Table 9

Events Related to Accountability

\begin{tabular}{lllll}
\hline E\# & Question & T & I & D \\
\hline 97 & The focus on research-based and test-driven education & $\mathrm{Im}+4$ & +
\end{tabular}
will increase.

98 Performance-based assessment will replace degrees and $\mathrm{M}+4+5+$ diplomas. Student competencies will be observable and documented on a certificate of achievement.

99 High-stakes testing will be replaced by portfolio-type $\mathrm{M}+5+4+$ assessments that will include firsthand works, tests, and experiences.

100 More educational assessments will be measured through the ability to access knowledge and not retain knowledge.

101 There will be national CTE assessments.

$$
\begin{aligned}
& \mathrm{M}+5+3+ \\
& \mathrm{M}+5+4+
\end{aligned}
$$

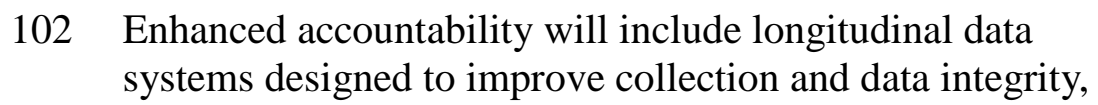
which will aid in data-driven decision making.

103 Lifelong learning will become more important because people will live longer, work longer, and need more frequent training.

104 The emphasis on accountability in all secondary education $\mathrm{M}+5+3+$ programs will continue with CTE at great risk to prove that their contribution is worth the expense.

Note. $\mathrm{T}=$ Time Frame; $\mathrm{I}=$ Impact; $\mathrm{D}=$ Desirability

I = Immediate (1-3 years); $\mathrm{M}=$ Mid-range (4-10 years);

E\# = Event Number; + = Consensus; - = No Consensus

\section{Image}

Ten events were listed under the final issue cluster which dealt with concerns related to the image of career and technical education (Table 10). Consensus was reached for all three 
variables for each event. The events are presented in order of significance, with the most immediate listed first.

\section{Immediate Time Frame}

The expert panel agreed that three events would occur in the one to three-year time frame. Two of these were considered very high impact (5) events. Career and technical education's contribution to economic development must be recognized, or CTE will continue to be marginalized (Event 105). This was rated as very desirable (5). The panel viewed it undesirable (2) that due to a lack of understanding for the need to be educated and prepared to compete in a world-wide economy, education funding will plateau or decline (Event 114).

One immediate time frame event was considered to have a high impact (4) on career and technical education. It was agreed that CTE will be expected to address the needs of the lowest quartile and the difficult-to-educate children (Event 107). This was thought to be somewhat desirable (3).

\section{Mid-Range Time Frame}

Respondents decided that seven events would occur in the four to ten-year time frame. All seven were thought to be very high impact (5) events for the future of career and technical education. Six of those events were considered to be very desirable (5). The panel concurred that the high school dropout rates will decrease as enrollment in CTE classes increases as a result of students seeing relevancy in their learning environment (Event 106). The panel believed that the "trades" will once again be positions of respect, and education will be tied to economic development (Event 108). Career and technical education will move from the elective side of the high school graduation requirements to the required core side of high school graduation according to Event 109. Panel members agreed that parents will recognize that CTE is 
paramount to achieving education and career goals (Event 111). The location of CTE will move from behind the scenes of the school to a front showcase and become the hub in which all high school knowledge revolves (Event 112). Finally, the panel predicted that students who complete a secondary program and enter the workforce as a highly skilled CTE graduate, will be valued as much as a person who has a degree (Event 113). One mid-range event was deemed desirable (4) by the experts who agreed that students will need to apply to be accepted to career and technical education programs (Event 110).

All events categorized as issues that relate to the image of career and technical education are summarized in Table 10.

Table 10

Events Related to Image

\begin{tabular}{lllll}
\hline E \# & Question & T & I & D \\
\hline 105 & $\begin{array}{l}\text { The contribution to economic development must be } \\
\text { recognized, or career and technical education will } \\
\text { continue to be marginalized. }\end{array}$ & Im & +5 & + \\
106 & $\begin{array}{l}\text { The high school dropout rates will decrease as enrollment } \\
\text { in CTE classes increases, because students will see } \\
\text { relevancy in their learning environments. }\end{array}$ & M & & \\
&
\end{tabular}

107 Career and technical education will be expected to address $\operatorname{Im}+4+3+$ the needs of the lowest quartile and the difficult-toeducate children.

108 The "trades" will once again be positions of respect, and $\mathrm{M}+5+5+$ education will be tied to economic development.

109 CTE will move from the elective side of the high school graduation requirements to the required core side of high school graduation.

110 Students will need to apply to be accepted into CTE programs.

$\mathrm{M}+5+4+$ 


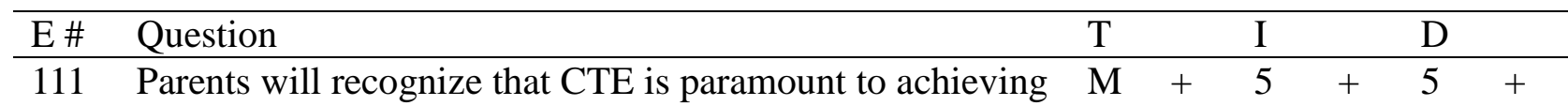
education and career goals.

112 The location of CTE will move from behind the scenes of $\mathrm{M}+5+5+$ the school to a front showcase and become the hub in which all high school knowledge revolves.

113 Students who complete a secondary program, go to work, $\mathrm{M}+5+5+$ and continue to learn either on the job and/or receive training provided by the employer, will be valued as much as a person who has a degree.

114 Education funding will plateau in the states or decline due $\operatorname{Im}+5+2+$ to a lack of understanding of the need to be educated and employed to compete in a world-wide economy.

Note. $\mathrm{T}=$ Time Frame; I = Impact; $\mathrm{D}=$ Desirability $\mathrm{I}=$ Immediate (1-3 years); $\mathrm{M}=$ Mid-range (4-10 years);

E\# = Event Number; + = Consensus; - = No Consensus

\section{Summary}

Chapter 4 presented data from the three-round modified Delphi study of the future of career and technical education. The study identified 114 events which were organized into nine general topic areas. The events were presented under each topic area according to immediacy, impact and desirability.

Twenty-eight events were categorized as issues related to career and technical education curriculum. It was agreed that 12 events would occur in the immediate time frame (one to three years). Three of these were rated as very high impact events and two were considered very desirable. Sixteen events reached consensus as mid range events (three to ten years). Two were thought to be very high impact and very desirable. One mid-range, high-impact event did not reach consensus for desirability.

The second general category was $21^{\text {st }}$-century components in career and technical education. Consensus was reached for all three variables for the eighteen events included in this 
topic area. Nine events were believed to occur in the immediate time frame. One event was considered to be a very high impact event and very desirable. It was agreed that eight events would occur in the mid-range time frame. One event was thought to have very high impact and considered very desirable for CTE. It was agreed that one event would occur in the long-range time frame (11 to 20 years). It was deemed to be a high impact and desirable event.

Political issues comprised the third broad category. Ten events were identified in this group, with three being expected to occur in the immediate time frame. Two of these events were considered very high impact. Consensus was reached on a single event as very desirable and one event to be undesirable. Seven events were thought to occur in the mid-range time frame. One of those events was identified as very high impact and very desirable.

The fourth category considers issues related to career and technical education personnel. Consensus was reached for all three variables for the 14 events in this category. It was agreed that two events would occur in the immediate time frame, one of which was considered very high impact and very desirable. The 12 mid-range events include three very high impact and very desirable events.

Ten events comprised the category associated to the relationship between business and industry and CTE. Five were rated immediate time frame events with two being very high impact and very desirable. Five events were believed to be mid-range events, three of which were rated very high impact and very desirable.

Events dealing with the relationship between CTE and higher education create the sixth category. Consensus was reached on time frame, impact, and desirability for each of the ten events in this category. The mid-range time frame includes nine events, of which five were considered very high impact. Four of the events were considered very desirable and one 
undesirable. It was determined that one event would occur in the long-range time frame. That event was considered very high impact and somewhat desirable.

The seventh category considered funding and consisted of six events. Consensus was reached that one event would occur in the immediate time frame. This event was thought to be very high impact and somewhat desirable. Five events were believed to occur in the mid-range time frame. One was determined to be very high impact and somewhat desirable.

Career and technical education accountability issues comprised the eighth general category. Consensus was reached for each of the three variables for the eight events in this category. One item was predicted to occur in the immediate time frame. This event was high impact and somewhat desirable. Four of the seven events identified as mid-range were considered very high impact. Two were thought to be desirable and two somewhat desirable.

The final category contained ten events related to the image of career and technical education. Three events were deemed immediate time frame, with two being very high impact. One was believed very desirable and one undesirable. Each of the seven mid-range events was rated very high impact. Six of the events were believed to be very desirable and one desirable.

Table 11 summarizes the data collected in the study. The majority of events fell in the immediate to mid-range time frames. Only two events were determined to be long-range and there were no events listed as beyond 20 years or never. The 40 very high impact events were used to construct scenarios for the purpose of strategic planning for career and technical education leaders. 
Table 11

Event Summary

\begin{tabular}{|c|c|c|c|c|c|}
\hline Topic Area & Total Events & $\begin{array}{c}\text { Immediate } \\
\text { Time Frame }\end{array}$ & $\begin{array}{c}\text { Mid-range } \\
\text { Time Frame }\end{array}$ & $\begin{array}{l}\text { Long-range } \\
\text { Time Frame }\end{array}$ & $\begin{array}{c}\text { Very High } \\
\text { Impact } \\
\end{array}$ \\
\hline Curriculum & 28 & 12 & 16 & 0 & 5 \\
\hline $\begin{array}{l}21^{\text {st }} \text { Century } \\
\text { Components }\end{array}$ & 18 & 9 & 8 & 1 & 2 \\
\hline $\begin{array}{l}\text { Political } \\
\text { Issues }\end{array}$ & 10 & 4 & 6 & 0 & 3 \\
\hline $\begin{array}{l}\text { Personnel } \\
\text { Issues }\end{array}$ & 14 & 2 & 12 & 0 & 4 \\
\hline $\begin{array}{l}\text { Relationship } \\
\text { with Business } \\
\text { \& Industry }\end{array}$ & 10 & 5 & 5 & 1 & 5 \\
\hline $\begin{array}{l}\text { Relationship } \\
\text { with Higher } \\
\text { Education }\end{array}$ & 10 & 0 & 9 & 0 & 6 \\
\hline Funding & 6 & 1 & 5 & 0 & 2 \\
\hline Accountability & 8 & 1 & 7 & 0 & 4 \\
\hline Image & 10 & 3 & 7 & 0 & 9 \\
\hline
\end{tabular}

This chapter presented the data identified by the research study. The data is interpreted and analyzed in Chapter 5. The very high impact events are used to develop scenarios for the nine topic clusters. 


\section{CHAPTER 5}

\section{SCENARIO, CONCLUSIONS, DISCUSSION AND RECOMMENDATIONS}

Chapter 5 summarizes the data presented in the previous chapter. Scenarios representing issue clusters for each time frame will be presented in this chapter. Additionally, discussion regarding issue clusters and program concerns as indicated by the literature review in Chapter 2 will be addressed. The analysis and conclusions focus on nine broad topic areas: curriculum,

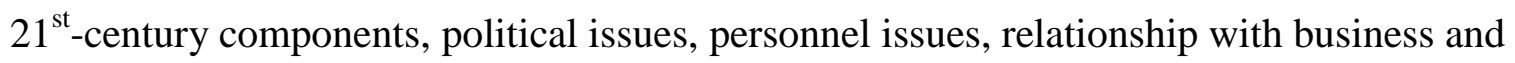
industry, relationship with higher education, funding, accountability, and image.

\section{Scenarios}

Stead (1975) described a scenario as a systematic, analytical discussion of selected occurrences (events) by designated time frames representing short-range, intermediate-range, and long-range forecasts in conjunction with an impact/desirability rating. Appropriate for education, explorative scenarios are multiple and present how different the future may become. Exploratory scenarios should be plausible, relevant, divergent and challenging (Iversen, 2006). The scenarios presented in this chapter present plausible, relevant, divergent and challenging strategies for career and technical education leaders to consider.

According to Iversen (2006), the process of creating scenarios should move through the following phases: (a) identifying drivers and trends through a process such as the Delphi method; (b) consolidating trends or putting ideas into generic categories; (c) prioritizing trends or rating them according to impact; (d) identifying the scenario structure in which the many drivers are used to create possible outcomes; and (e) actor analysis where the investigator determines if the scenarios are plausible and usable tools. 
The results generated from the three rounds of the Delphi were used to create scenarios for the purpose of strategic planning by CTE leaders. Events deemed very high impact were used to construct the scenarios. The events were arranged according to time frame and organized by topic area. Information referenced in the review of literature was used to validate and support responses from the expert panel as scenarios were developed. The desirability and minority opinions from the panelists were taken into consideration during the process. Practical experience of the investigator also played a part as the scenario structure was shaped.

\section{Curriculum}

According to the experts in this research study, career and technical education will be experiencing significant changes in the future. The results suggest imminent change in career and technical education curriculum throughout the immediate and mid-range time frames.

\section{Immediate Time Frame}

Consensus was reached in the one-to-three-year time frame for CTE to lead the validation of the career-ready status of every high school graduate. Requirements that include internship, shadowing, or work in the technical area before graduation, will augment job readiness skills. Hans Meeder (2006) cites CTE in high schools as engaging students in specific career-related learning experiences and preparing them to enter the workforce directly after high school with levels of skill and knowledge that will be valued in the workplace. West Virginia concurs, with a supporting mission statement to better prepare students for the world of work and higher education through programs and training offered at the CTE sites throughout the state (West Virginia Department of Education, 2009a). One minority opinion expressed concern about the feasibility of this conclusion; "I don't believe that most schools could ensure that students have 
the opportunity to participate. Think of small rural areas or small urban areas with not much industry or business."

Experts agree that there will be an increase in the use of instruments that measure the skills employers' value. Nationally standardized industry certifications will assure consistent certificate requirements and provide assurance of skilled workers. Agreeing with the concept, one panelist conveyed reservations stating, "I am a proponent of a broader education for high school students, reflecting all aspects of the industry. I am in favor of credentials being part of a high school program at the advanced levels, but also think we must recognize that many credential exams are not necessarily appropriate for high school students."

Traditionally, educators have viewed high school career-focused education as an option for those who do not intend to pursue post-secondary education. The panel foresees an impending transformation in the future of CTE with an enhanced interest in career areas. Research supports this idea as indicated in Chapter 2. Hull (2003) stated that while some CTE programs are preparing students for the future, many are viewed as a "dumping ground" for the students who are struggling academically.

\section{Mid-range Time Frame}

Career and technical education programs will solidify their position as a partner contributing to the academic success of students. CTE will support an academically rigorous and relevant part of education reform and play a major role in providing $21^{\text {st }}$-century education for the next generation of high school students (Lynch, 2000a). According to Daggett (2002), there is little room for the academically inept in today's contemporary workplace. Curricular changes will include the blending of CTE and academic education, resulting in a considerable overlap of each. As discussed in Chapter 2, in order to secure America's place in the global economy, 
federal investment in CTE must continue to support the improvement of academic and occupational skills resulting in the expansion of access for all students in these programs (Gordon, 2008). Blending the two will not be an easy task. One panelist points out, "blending will hold significant implications for the characteristics and makeup of both educational realms, all of which will face substantial resistance from the players."

The panel agreed that ultimately, CTE concentrations will increase interest of career areas and become a part of graduation requirements for all students. This will require educational reform which encompasses a change in practice at all levels (Fullan, 2001). According to Fullan's research, there are three dimensions associated with educational change and the implementation of new ideas, policies, or practices: (a) the possible use of new materials (technologies), (b) the possible use of new teaching approaches (strategies or activities), and (c) the possible alterations of beliefs (pedagogical assumptions and underlying theories). A strong understanding of these dimensions will be the foundation for CTE leaders at the forefront of reform efforts. Two minority opinions expressed doubt that this will happen. According to one panelist, "I believe the general population still believes that CTE is only for 'certain' students and many in academia fail to see the benefit and caliber of the CTE curriculum. Another had similar thoughts stating, "Some districts are so academically oriented that vocational education is only for other people's children."

\section{$21^{\text {st }}$ Century Components}

Considering the issues in $21^{\text {st }}$-century components and CTE, experts perceive two events as having the potential of very high impact. The events are expected to occur in the immediate and mid-range time frames. Considering the focus many states have placed on $21^{\text {st }}$-century learning, this finding created potential new inquiry for future study. Questions regarding why 
experts found only two of the eighteen $21^{\text {st }}$-century events as very high impact should be considered for further investigation.

\section{Immediate Time Frame}

Consensus was reached that one very high impact event would occur in the one-to-three year time frame. Career and technical education will play a major role in STEM (Science, Technology, Engineering and Mathematics) education. According to the National Science Board (2010), science, technology, engineering, and mathematics fields are collectively considered core technological underpinnings of an advanced society. Their research also attributes the strength of the STEM workforce as an indicator of a nation's ability to sustain itself.

Although most of the panel agreed that CTE centers will increase their role in STEM education, one minority opinion disagreed, "I predict the community colleges and academic high schools will be more successful in adopting and promoting STEM programs."

\section{Mid-range Time Frame}

Considering the issues in CTE, experts perceive modernizing CTE centers as vital in maintaining an edge in the labor market in the mid-range time frame. As discussed in Chapter 2, the nature of student experiences in career and technical education has potential implications for the workforce and our nation's place in the global economy (Silverberg et al., 2004). It is reasonable to surmise that facilities equipped with up-to-date tools and technology will assist in providing the training necessary for students to compete in such an economy. One minority opinion differed, and placed instructional improvement over facilities stating, "I believe instructional strategy improvements are the first priority and are most desirable over and above facility improvements." 


\section{Political Issues}

Career and technical education and politics are inseparable. Federal, state and local concerns have helped shape CTE throughout the years. The expert panel predicts this trend will continue. Consensus was reached regarding three events classified as political in nature would have very high impact on CTE.

\section{Immediate Time Frame}

The experts believe that in the one-to-three year time frame, policy makers will come to realize the gravity of allowing CTE to continue as the dumping ground for students who cannot succeed in the general education classroom. Career and technical education has achieved great improvement in the $21^{\text {st }}$ Century by offering a more challenging curriculum with a greater focus on academics. However, as noted in Chapter 2, many negative perceptions still exist (Hull, 2003). At least two panelists agree that this will be a difficult barrier to conquer. One stated, "I have been in this field for forty years and have heard this is an issue with no movement. Not going to happen." The other was somewhat more optimistic, saying that "while high on the radar now, I don't know that this will change that quickly."

Also in the immediate time frame, panel members expect China and India will take economic control of the world, resulting in an increased United States interest to get very serious about creating, implementing, and marketing innovation. Friedman (2005), in his book It's a Flat World After All, brought to the forefront the concept of globalization. People began to realize that high school and college students today will be competing for jobs against the best students from a much wider range of countries than any previous generation. Career and technical education will play an important role in this process. One panelist stated that "from my 
reading of national press I think it will take longer than one to three years especially with the current economic situation."

\section{Mid-range Time Frame}

Career and technical education facilities and programs will have a strong, vocal and informed voice on Capitol Hill in the four-to-ten year time frame according to the experts. Beginning with the Smith-Hughes Act of 1917 and continuing through The Carl D. Perkins Career and Technical Education Improvement Act of 2006, the federal government has exerted major influence over CTE. Survival of many CTE programs depends on continued federal support. One panelist expressed strong views on this subject stating, "I don't believe this will happen until more people get involved in the ACTE organization. Until CTE educators are willing to stand up and be counted, they will never have the ear of the folks on Capitol Hill. Too many teachers are waiting for 'someone else' to take the lead. If we are to change the current thinking, we will have to have many more people willing to take a stand!"

\section{Personnel Issues}

Recruitment and retention of qualified CTE personnel continues to challenge administrators across the nation. While federal and state mandates have transformed the requirements and expectations of CTE, decisions regarding personnel qualifications and hiring practices are established locally. Four events classified as personnel issues were identified as having very high impact.

\section{Immediate Time Frame}

The panel predicts that career and technical education programs will have great teachers who foster passion and curiosity in the one-to-three year time frame. According to Dr. Jerry Valentine's national research on student engagement, CTE programs are high on the spectrum 
and continue to increase student depth of knowledge (Valentine, 2010). According to Gray and Daugherty (2004) research found that over 50 percent of all technology teachers were over the age of 50, resulting in a shortage of qualified CTE teachers. In 2000, one out of fifteen schools was unable to fill its CTE teacher vacancies (Levesque, 2004). The increased demand for CTE teachers provides an opportunity for administrators to recruit the caliber of teacher identified by the panel.

\section{Mid-range Time Frame}

Identified to occur in the four-to-ten year time frame, the demand for CTE teachers will increase. This is supported by the research as stated in the above scenario. A minority opinion expressed concern regarding the challenges of attracting qualified teachers to the profession. "I am already seeing it. Career and technical education teachers can make a lot more money doing their trade rather than teaching it."

Another area recognized by the expert panel involves CTE teacher preparation programs. Teacher education preparation programs will change significantly as a result of the blending of technical and academic delivery. As stated in the literature review in Chapter 2, integrating academics into CTE programs requires a significant investment in professional development. States must set standards for acceptable levels of knowledge for CTE teachers, requiring development of a national policy regarding standards for CTE teacher preparation programs (Silverberg, et al., 2004). One minority opinion identified the challenges of incorporating academic rigor into CTE teacher professional development.

Secondary guidance counselors influence student attitudes and perceptions regarding CTE programs. Counselors are key players in developing student schedules which may hinder student participation in CTE programs. Experts predict secondary school counselors will 
become informed and cognizant of the opportunities awaiting students in CTE programming. High school counselors are on the front lines when students are at the pinnacle of the career decision-making process (Herr, 2002). One minority opinion expressed strong concern regarding the nature of guidance counselor graduate and undergraduate education programs:

With all of the lip-service and "additions" at the state level which have been purportedly designed to increase the knowledge base, appreciation for, and capacity to guide capable students to the appropriate CTE programming, the nature of guidance counselor undergraduate and graduate education is such that the effective counseling and guidance for high school students cannot and will not improve much, if any, in most schools and areas of the state. Even the individuals who are being charged with seeing this wish to fruition are largely uninformed and do not have the background necessary to see this monumental transition take place.

\section{Relationship with Business and Industry}

From its inception, the mission of vocational or career and technical education focused on providing a well-trained workforce. This role is more critical as CTE works to ensure America's future competitiveness in the world economy. A close relationship with leaders of business and industry is essential in providing students with the skills valued by employers. A positive relationship with business leaders increases the likelihood of economic success. The panel predicts that four events will have very high impact on the relationship between business and industry and CTE. 


\section{Immediate Time Frame}

The demand for skilled workers will increase in the one-to-three year time frame. Globalization and a changing economy have resulted in a shift from a less skilled workforce to one with more specialized skills. In order to train workers with needed skills, it is imperative that CTE work with business and industry to assure success. As noted in Chapter 2, to secure America's place in the global economy, CTE must continue to strive for improvement of academic and occupational skills and expand access for all students in its programs (Gordon, 2008).

\section{Mid-range Time Frame}

It appears that in the four to ten year time frame career and technical education will be called upon to retrain America's workforce. Congress signaled interest in preparing students for the changing $21^{\text {st }}$-century workforce with passage of the Vocational and Applied Technology Act (Perkins II, P.L. 101-392) in 1990. As noted earlier, the focal point of CTE continues to be that of providing a well-trained workforce. One minority opinion states that this is occurring at the present time.

A highly desirable event includes forecasting that all students will seek more specific technical skills training in order to be more competitive in the workplace. A minority opinion states, "I think it would be great if they did, but I don't think people plan ahead like that,

especially the people who need it most." Another minority opinion concludes that the time frame would be shorter.

In a related forecast, there was consensus that CTE will serve as the change agent in building existing governance structures to bring state, regional, and local leaders in education, 
workforce, and economic development together to support and grow each state's economy. The experts agreed that this was a very desirable event.

\section{Relationship with Higher Education}

The increased demand for workers with more specialized skills has lead to occupations that include postsecondary skill requirements. The Carl D. Perkins Career and Technical Education Improvement Act, passed in 2006, calls for a secondary and postsecondary connection (Gordon, 2008). The mission of CTE has expanded to incorporate students' preparation for postsecondary training. The expert panel reached consensus that six events will have very high impact on the relationship between CTE and higher education.

\section{Mid-range Time Frame}

Panel members predicted that postsecondary CTE programs will be absorbed in the community college system. This has potential to become a challenge, as indicated by two minority opinions. One stated, "Here in our state I do not see the community college system taking over all of the CTE programs. Sure - they might like the Health Programs, but would not want the other CTE programs." The other said, "With the increase in for-profit options, I don't believe this will happen." The panel reached consensus that this would be an undesirable event. Several panel members disagreed. One minority opinion stated, "Where will postsecondary programs be absorbed if not in the community college system? If one takes a look around, the universities and four-year colleges are not rushing to the aid of CTE." Another declared, "There are both positive and negative implications that would occur as a result of changes." Finally, "both conditions in and out of the postsecondary system could work well depending on the attitudes and systems supporting the conditions." These strong statements indicate an infectious 
and competitive attitude that has existed throughout the history of CTE. More productive and mutually beneficial is the collaborative relationship between CTE and higher education.

The expert panel indicated a very high impact and very desirable event in the mid-range time frame as career and technical education being recognized as a credible choice for collegebound high school students. This will represent a change in attitude toward CTE being used as a last resort for marginalized students. As referenced in Chapter 2, statistics confirm a great number of students have an increased desire to pursue a college education. Career and technical education is working diligently to be included in that equation. A shift in philosophy to incorporate an increased focus on academic skills and preparation for post-secondary education is taking place (Cohen \& Besharov, 2002). One minority opinion reported, "It is already seen as a credible choice in our region and therefore is not having a very high impact."

The panel predicted that worldwide articulation agreements will be implemented to assure smooth transition of students from high school to college and from college to college. Articulation between secondary and post-secondary programs has been a focus of CTE since educational reform initiatives of the 1990s (Rojewski, 2002). Worldwide agreements would be a major task as indicated by one minority opinion: "This is a coordination issue second to none and is not going to happen."

The experts expect that in the one-to-three year time frame CTE will be a valuable part of all students' overall high school experience and will be used to help prepare them for postsecondary education and/or training and career success. The panel also predicted that CTE will drive innovation and creativity in the states' high schools by transforming the culture of education in order for every school to produce lifelong learners who are both academically skilled and career ready. Both events were deemed very desirable. A minority opinion stated, 
"There is a division that exists between academic and vocational preparation. I have not seen any sign that that is disappearing." Another minority opinion was, "In over 30 total years in CTE related work, I have not seen any indication that such a transition could or would occur so quickly in our current political and educational climate. I think that $15-20$ years is being extremely optimistic."

\section{Long-term Time Frame}

Panel members anticipate learning centers will exist and traditional schools will be obsolete in the 11 to 20 year time frame. This was judged to be somewhat desirable. A panelist who disagreed stated "This would require a political change and would have to be driven from the ground up. Most people are not interested."

\section{Funding}

Funding for CTE at the federal, state and local levels has been secure over recent years. With the number of programs competing for federal and state dollars, the face of stable funding means that those monies need to be stretched. Although CTE has seen small increases in federal funding over the years, these increases have not kept pace with inflation. According to a recent report from the National Center for Education Statistics, federal funding for CTE has realized a 19 percent decrease in real dollars over the last decade (NCES, 2000). State and local funding is decreasing in West Virginia, making these challenges even more evident.

In many small states the only funding received for CTE comes from the federal government. Without those funds, these states would have difficulty in providing CTE to their students. The expert panel concurs and found that two events will have very high impact on future CTE funding. 


\section{Immediate Time Frame}

Federal funding will be the key to survival or demise of CTE in the one-to-three year time frame. Career and technical education has been dependent on federal dollars from its inception. Historically, CTE funding has been secured based on the premise that CTE would provide a trained workforce for the nation. The emphasis of federal funding in vocational education changed from program expansion to program improvement with a focus on at-risk populations in 1984 with passage of the Carl D. Perkins Vocational Education Act (Perkins I, P.L. 98-524). This assured federal money would establish programs emphasizing the acquisition of job skills. One minority opinion alluded that CTE instructors and administrators will need to utilize federal, state or local grants in order maintain CTE programming.

\section{Mid-range Time Frame}

There will not be re-authorization of the Carl D. Perkins Career and Technical Education Act of 2006 beyond 2018 according to the expert panel. This prediction is certain to bring to the forefront many challenges at both the state and federal level. As cited in Chapter 2, there were four prevailing themes under the latest Perkins reauthorization: accountability and program improvement, secondary and postsecondary connections, links to rigorous academics, and finally, a greater focus on business and industry (Gordon, 2008). Developing a well-trained and highly motivated work force requires state-of-the art equipment and CTE centers that meet current industry standards, along with the curriculum materials needed to keep the graduates competitive in the work force.

The existing United States workforce commands the respect of the world. It is a product of federal investment, which ideally, will support the development of world-class career and technical education systems. This system will continue to succeed and improve only with greater 
federal investment in preparing the nation's future workforce. A minority opinion noted, "It all depends how the issue is addressed. For instance, what if new legislation required CTE as part of Title I ESEA activities?” In order to identify and promote national career and technical education delivery models that ensure youth and adults have the opportunity to attain knowledge and skills needed for further training and careers, funding sources must be secured by current state and federal leadership. Career and technical education must find ways to plan for the future and adapt programming to embrace the $21^{\text {st }}$ Century. Anticipating future needs will assure viability and enhance curriculum design for generations to come. In order to promote reform, research can assist in anticipating events that could significantly impact CTE in the $21^{\text {st }}$ Century and prepare for funding challenges.

\section{Accountability}

Under the regulations of federal Perkins legislation and No Child Left Behind, CTE initiated increased accountability standards mandated for public education in the United States. This system of accountability, academic attainment and graduation rates of students enrolled in CTE at the secondary level are measured annually according to these guidelines. Subsequent sanctions are included in the event states fail to meet predefined indicators.

With increased spending on education at the federal, state, and local levels, high stakes accountability has moved to the forefront. Education and political leaders are now looking for a return of investment similar to what industry has employed throughout the years. The expert panel agreed that four events will have very high impact on career and technical education accountability. 


\section{Mid-range Time Frame}

In the four-to-ten year time frame high stakes testing will be replaced by portfolio-type assessments that will include firsthand works, tests, and experiences. Employers today are seeking employees who have the ability to think critically, to apply knowledge to new situations, to analyze information, and the skills to communicate effectively, collaborate with others, solve problems, and make decisions. Higher level thinking skills are increasing in importance in today's workplace (Business Coalition for Education Reform, 2001). A career portfolio is a tool used to give employers a complete picture of the prospective employee. The portfolio highlights experience, education, accomplishments, skill sets, and ultimately the potential of the student. This tool can also be used to illustrate the depth of skills and experience, which is especially important for the CTE student. A portfolio is the ideal instrument to document CTE skills. According to one panelist, "This is happening already in some areas and should increase. I don't think it will stretch out for 10 years."

Another very high impact event suggested by the consensus of the expert panel was that enhanced accountability will include longitudinal data systems designed to improve collection and data integrity. These systems will aid in data-driven decision making. The event was deemed desirable. One panelist suggested this would occur sooner than the four-to-ten year time frame. "I believe we are headed to increased accountability standards and I believe our collection methods will improve, which will help aid in data-driven decision making."

The panel predicted that lifelong learning will become more important due to the fact that people will live longer, work longer, and need more frequent training. This is already occurring according to one panelist. "I am already seeing many folks (of retirement age) returning to school and work in order to maintain a living. Many folks are realizing the importance of 
lifelong learning, and with the onset of advanced technology, it will be necessary to upgrade skills. I do not believe we will be able to count on social security for years to come."

A somewhat desirable scenario suggested by the experts focused on the emphasis on accountability in all secondary education programs. The experts agreed this will continue with career and technical education at great risk to prove that their contribution is worth the expense. As noted in Chapter 2, in the 38-year time span between 1965 and 2003, the federal government invested more than 242 billion dollars on education (U.S. Department of Education, 2003). Although government funding for education consistently increased, an achievement gap continued to exist between the rich and poor, and white and minority students. Disturbing statistics such as this has lead to increased demand for CTE accountability and in all areas and subgroups of education.

\section{Image}

Research and experts agree that image will crystallize the future of career and technical education. Traditionally, CTE has suffered from an image problem, often thought to be a placement for students who are less academically inclined, and focused on teaching entry level job skills for those who are not college bound. Reforming such a system will require a paradigm shift, educational advocacy for CTE programs, and policy realignment to assure advancement of student career and academic achievement (Lynch, 2000b).

Perceptions about CTE are influenced by a number of factors which may include parental views and peer approval. Research also indicates that the image of CTE is dependent upon exposing the myth that all students attend college. According to the Bureau of Labor Statistics (2002), the majority of jobs do not require a college degree. In order to improve the image of 
CTE, diligent work and visionary leadership must include a heightened focus on including academic skills in current CTE programs.

Most agree that more academic rigor is an essential condition for CTE's survival in the $21^{\text {st }}$ Century (Medrich, 2005). However, substantive work must occur in order to change the perception of current programming. The panel of experts predicts many very high impact events that will contribute to the evolution of the image of CTE.

\section{Immediate Time Frame}

Panelists agree that the contribution to economic development must be recognized or CTE will continue to be marginalized. This event was viewed as very desirable. Traditionally, career and technical education was called upon to prepare individuals for their destined occupations. As stated in Chapter 2, many parents and academic educators have the elitist view that CTE courses are not appropriate for students wishing to attend a four-year college (Lynch, 2000b). In its earliest days CTE was driven by the fundamental objective of improving training for the American workforce. During the 1980s educational reform began to recognize vocational education as an essential component in the United States' venture to compete in the everincreasing technological workplace.

In order to improve the image of CTE, programs must be perceived as meeting the needs of students and the employer. Many states are beginning to establish criteria regarding the format components for a $21^{\text {st }}$-century version of career-focused education. To avoid being marginalized, career and technical education leadership has the obligation of responding to the economic trends of the $21^{\text {st }}$-century global economy, making prudent programmatic decisions.

Another event the expert panel rated as having very high impact and being somewhat desirable is the expectation that career and technical education will address the needs of the 
lowest quartile and the difficult-to-educate children. As discussed in Chapter 2, this has been an ongoing reality for CTE. The National Assessment of Vocational Education (1994) reported that a number of vocational schools were focused on teaching entry level job skills to students who are educationally disadvantaged. Lewis, in a study conducted in 2001, found that those surveyed assumed that CTE offered inferior curriculum, appropriate only for students who were unable to meet the demands of a college preparatory program (2001). As noted by Lynch (2000b), reforming this system will require a paradigm shift, educational advocacy for CTE programs, and policy realignment to assure advancement of student career and academic achievement. These efforts will assist in furthering the cause of improving CTE's image.

Panelists suggested that education funding will plateau in the states or decline due to a lack of understanding of the need to be educated and employed to compete in a worldwide economy. Experts evidenced concern regarding this event, as demonstrated by the undesirable rating. Championing CTE's role in providing a skilled workforce for the $21^{\text {st }}$ Century will aid in avoiding this forecast.

\section{Mid-range Time Frame}

Consensus was reached in the four-to-ten year time frame regarding the decrease in high school dropout rates as enrollment in CTE classes increase. This directly related to the students finding relevancy in their learning environments. This was deemed a very desirable event by the panel. The literature review in Chapter 2 cited several studies that support this assumption. A study conducted by Bishop and Mane (2004) established a positive correlation in the number of secondary students enrolled in career technical programs and an increase in high school graduation rates. Plank (2001) concluded that the risk of dropping out was four times higher when students were enrolled exclusively in academic subjects absent CTE courses. Establishing 
programmatic value will be the impending challenge for CTE leaders. Stakeholders will be called upon to demonstrate programs are contributing to the academic success of students, and that the courses are serving as a motivation to remain in school, helping them perform better in academic courses and preparing them to prosper as postsecondary students, as workers and as citizens (Daggett, 2002).

The experts forecast an additional very high impact and very desirable event for the midrange time frame. The "trades" will once again be positions of respect and education will be tied to economic development. Historically, vocational or career and technical education has been called upon to meet the needs of a changing nation. States were encouraged to offer programs and training to support national defense efforts (1920s), reduce unemployment problems (1930s), assist the war effort (1940s), incorporate programming within junior colleges in the 1950s, and shift industries to peacetime economic development in the 1950s and 1960s. The main goal of federal policy and funding was to train young men and women for jobs in the economy (Lynch, 2000b). The panel of experts predicts that CTE will once again rise to the challenge and meet the needs of the new economy.

Also considered very desirable, the panel predicted that CTE will move from the elective side to the required core side of high school graduation requirements. Two adamant minority opinions resulted from this prediction. One panelist suggested, “As long as professional educators are in control of education it will never happen." The other stated, "Based on historical time lines, and considering the substantial lack of understanding and need for education of the policy and decision makers, the years required for a possible transition of this magnitude will be much greater than 10 years." 
Another scenario suggested for the four-to-ten year time frame is that students will need to apply to be accepted into CTE programs. One panelist stated that this was already occurring for some programs in some areas. Another confirmed a required application process in their state. Consensus concluded this to be a desirable event. One minority opinion stated, "I honestly believe if students have to choose CTE, CTE will advance and become more desirable. Students who decide to take the CTE track will want to do it and I believe they will be more successful." Another panelist suggested that an application process may limit accessibility for certain populations. "While this is desirable for some reasons, many students need access to CTE and applying for the programming will prevent access to some.”

The panel of experts reached consensus pertaining to parents recognizing career and technical education as paramount to achieving education and career goals. Gordon (2008) suggested the importance of CTE educators establishing constant communication with parents as paramount in overcoming the obstacles that exist. As referenced in Chapter 2, many parents deemed CTE courses inappropriate for four-year college bound students (Lynch 2000b). Daggett (2002) suggests that CTE must move from the long-held perception that it is a good program "for somebody else's child" to one of providing a viable option for a meaningful education for all students. One minority opinion predicts a much longer time frame; "CTE has difficulty competing with the marketing strategies and communication of worth from general education, and the fundamental lack of CTE friendly counseling and guidance will require a complete restructuring of the mind set of higher education and administrative preparation programming coordinators and developers. We will not see this accomplished in the next few years."

Another very high impact event suggested by consensus of the panel was that the location of CTE will move from behind the scenes of the school to a front showcase. Further, it will 
become the hub in which all high school knowledge revolves. Several panelists disagreed. One stated, "Not going to happen due to what the population in general thinks about career and technical education (vocational education)." Another suggested, "This may be accomplished on a regional basis in the United States, but not in our local area due to the politics of education." This was deemed a very desirable event by the experts. However, one panelist said that due to current politics, the event is not likely to occur in the foreseeable future.

An event expected to be part of the mid-range time frame scenario was that students who complete a secondary CTE program, become employed, and continue to learn (on the job or through employer-provided training) will be valued as much as a person who has a degree. The panel reached consensus and considered this as very desirable. One minority opinion expressed a different view stating, "Not in our society unless there is some change that I am not aware of."

\section{Scenario Summary}

A structured process was used to collect and refine the knowledge from a group of experts by means of a series of questionnaires, combined with controlled opinion response. According to the issues that emerged from the three rounds of the Delphi study, the scenario was established and organized. Nine topic clusters emerged from the first round responses regarding the future events that will impact career and technical education. Within each topic area, events were organized based on immediacy, utilizing the time frames of immediate (one-to-three years), mid-range (four-to-ten years), and long-range (11 to 10 years). The responses of the experts did not generate a scenario of never occurring or occurring beyond 20 years. Encompassed in each time frame, events were organized according to impact and desirability.

Panelists agree that CTE must solidify their position as a partner contributing to the academic success of students. Curricular changes will include the blending of CTE and 
academic education programs. Increasing rigor will include the use of industry-recognized certifications to assure consistent certificate requirements and provide assurance of skills.

Experts regard the issues in the $21^{\text {st }}$-century components as having very high impact and great potential for the future of career and technical education. Panelists agreed that CTE will play a major role in STEM (Science, Technology, Engineering and Mathematics) education. The panelists determined that in order to maintain an edge in the labor market, modernizing CTE centers is essential. Facilities equipped with up-to-date tools and technology will assure that students are provided the necessary training in order to compete in a global economy.

The panelists agreed that politics and CTE are inseparable. The panel evidenced concern for the magnitude of allowing career and technical education to continue as a dumping ground for students who are unable to succeed in the general education classroom. They further expressed concern for the United States losing its place as the world economic leader. Given these issues the panelists agreed that CTE must have a strong, vocal and informed voice on Capitol Hill.

Panelists suggested that CTE will experience an increase in demand for qualified teachers in the near future. Integrating academics into CTE programs will result in significant changes to teacher education programs. They further expect secondary counselors to play an important role in attitudes, perceptions and advisement of students regarding career and technical education programs. Experts agreed that CTE will continue to attract exemplary teachers who inspire passion and curiosity in their students.

Panelists demonstrated the realization of the critical role of business and industry as CTE moves into a global economy. They agree that CTE will be a central element in training a $21^{\text {st }}$ century workforce with specialized skills. They further expect career and technical education to 
serve as a change agent in developing a political structure that will bring a team of stakeholders together in order to support economic development.

The expert panel suggested that postsecondary CTE programs will be absorbed into the community system and agreed this would be undesirable. Panelists further agreed that truly collaborative relationships between CTE and higher education are mutually beneficial. In addition, experts concur that CTE must be recognized as a creditable choice for college-bound students. This will require a philosophical and practical change in order to incorporate academic skills and preparation for post-secondary education.

The panel predicated that world-wide articulation agreements will be implemented between secondary and post-secondary programs. Career and technical education will become a valuable part of all students overall high school experience by producing life-long learners who are both academically skilled and career-ready. Given these issues, panelists anticipate learning centers will exist and traditional schools will become obsolete.

Panelists agree that federal funding will be vital to survival of CTE in the future. They further predict that the Carl D. Perkins Career and Technical Act of 2006 will not be reauthorized beyond 2018. Additionally, the panel concurred that federal dollars are crucial in creating state-of-the-art CTE centers that meet current industry standards, as well as providing curriculum material needed to assure graduates are competitive in the workforce.

Panelists agree that accountability measures will increase and be utilized to assess the effectiveness of CTE programs. Moreover, high stakes testing will be replaced by portfolio-type assessment utilizing first hand works, tests, and experiences to give employers a complete picture of the prospective employee. The panel expects that enhanced accountability will include longitudinal data systems designed to improve collection and data integrity. They further expect 
this practice to aid in data-driven decision making. Life-long learning will continue to increase in importance as people live longer and require more frequent training.

The panelists agreed that the fate of CTE will hinge on improved image. Furthermore, in order to avoid being marginalized, CTE leaders have an obligation to respond to the economic trends of the $21^{\text {st }}$-century global economy and make prudent programmatic decisions. Essential components include increased academic rigor, advocacy for CTE programs, and policy realignment to reassure advancement of student career and academic achievement. The panel predicted that career and technical education will move from the elective side to the core side of high school graduation requirements. Finally, the panel of experts reached consensus that parents will recognize that CTE is important to achieving career and education goals in the $21^{\text {st }}$ Century.

\section{Summary}

The aim of this research project was to apply a three-round modified Delphi technique to forecast the future of career and technical education. In addition, the goal was to construct a scenario for investigating the implications to career and technical education.

Data collection for the study consisted of three rounds. The first round generated 252 possible events. The investigator synthesized the responses into a 114-item survey for Round Two. In Round Two, the expert panel rated each item according to time frame in which each event was likely to occur, degree of impact on career and technical education and the degree of desirability. The Round Two responses were compiled and the median for each variable for each event was calculated. In Round Three, the panelists were given the opportunity to change each of their responses to the median or to justify why their response was more appropriate than the median. New medians were determined from the third-round replies. 
The events generated by the expert panel fell generally into nine broad topic clusters. The investigator arranged all responses in the context of these topic clusters and ordered them according to immediacy, impact, and desirability within each category. The data was utilized to construct scenarios for each time frame within the context of the topic areas. The scenarios reflect the views of the expert panelists regarding the future of career and technical education.

Among the most significant issues facing career and technical education in the near future will be the demand for CTE students to exit programs with a nationally recognized industry certification. There will be a blending of academic and technical programs of study. Enhanced curriculum will lead to increased interest in career and technical education.

Embracing the ideas and issues of the $21^{\text {st }}$ Century, CTE will play a major role in STEM (Science, Technology, Engineering and Mathematics) education. A key to providing the foundation for this growth will include modernizing CTE centers in order to maintain an edge in the labor market.

It is imperative for leadership to recognize the conjoined nature of politics and career and technical education. In order for CTE to demonstrate improvement, policy and practice must begin to address the issue of allowing CTE to continue as the dumping ground for students who cannot succeed in the general education classroom. With the expectation that China and India will be taking economic control of the world, it is crucial for CTE to have a strong, vocal and informed voice on Capitol Hill. Strengthening the infrastructure of CTE will involve reformation of policies and programs at the local and state levels.

As in any great organization, CTE must have great teachers who foster passion and curiosity among the students. The demand for high quality CTE teachers will increase, resulting 
in a restructuring of teacher education preparation programs. This is a direct result of the blending of technical and academic delivery within the school system.

The increased demand for skilled workers in the $21^{\text {st }}$ Century will require a renewed commitment of cooperation between CTE and business and industry. Globalization and a changing economy will necessitate a concerted effort to retrain America's workforce. The quality of this effort will directly relate to America's reemergence as the world economic leader.

New directions and contexts will require a truly collaborative relationship between CTE and the community college system. Additionally, career and technical education will be recognized as a credible choice for college bound high school students.

Although competition for federal dollars will continue to increase, this funding will be crucial to the survival of CTE. There will not be reauthorization of the Carl D. Perkins Act beyond 2018, thus requiring leadership to seek alternate funding sources.

High stakes accountability will move to the forefront, with educational and political leaders looking for a return of their investment. Rather than high stakes testing, the criteria for high quality employees will involve a portfolio that demonstrates the ability to think critically, analyze, synthesize, collaborate, communicate and apply knowledge to new situations. As a glimpse of the new era of accountability is gained, life-long learning will become more important due to increased longevity and the need to constantly improve skills.

The starting point for changing the image of career and technical education will include a strong contribution to economic development. In an effort to address the needs of the student and employer, CTE must place emphasis on establishment of criterions regarding a $21^{\text {st }}$-century version of career-focused education. In short, a comprehensive, high quality CTE system is essential in order to address the needs of the lowest quartile and difficult-to-educate children, as 
well as the college-bound students. Career and technical education will continue play an important role in decreasing high school dropout rates as interest in CTE programming increases. In order to become a force of the future, CTE must demonstrate its worth and strengthen its positive image.

Based on the opinions of experts in career and technical education, a number of conclusions seem reasonable.

\section{Conclusions}

With the limitations of this study and the expert panel opinions, the information generated by the study would suggest that the following events will impact career and technical education in the next 20 years:

- The demand for CTE students to exit programs with a nationally recognized industry certification will become the norm.

- There will be a blending of academic and technical programs of study which will result in an increased interest in CTE.

- Career and technical education will play a major role in STEM education.

- A key to providing growth and maintaining an edge in the labor market will be ensuring CTE facilities are modern and equipped with up-to-date tools and technology.

- Policy and practice must begin to address the issue of allowing CTE to continue as the dumping ground for students who cannot succeed in the general education classroom.

- Career and technical education must have a strong, vocal and informed voice on Capitol Hill to remain strong and help the United States regain its position as the world economic leader. 
- Career and technical education will continue to have great teachers who foster passion and curiosity among the students.

- The demand for high quality CTE teachers will increase, resulting in a restructuring of teacher education preparation programs.

- Career and technical education will be called upon to retrain America's workforce as the economy continues to change.

- The relationship between CTE and the community college system will continue to evolve.

- Career and technical education will be recognized as a credible choice for college bound high school students.

- The Perkins Act will not be reauthorized beyond 2018, therefore increasing competition for vital federal dollars. Thus, leadership will be required to seek alternate funding sources.

- High stakes accountability will increase. Rather than high stakes testing, portfolio assessment will be the means which employers measure career readiness.

- Life-long learning will become important due to increased longevity and the requirement to constantly improve skills.

- Improved image will be the foundation for building CTE recognition as a vital contributor to economic development.

- Career and technical education will establish criterions regarding a $21^{\text {st }}$-century version of career-focused education. 
- In order to address the needs of diverse groups such as the lowest quartile and difficultto-educate student, potential high school dropout, as well as the college bound student, CTE must develop a comprehensive and high quality system.

- Image will improve as CTE moves to become a force of the future and demonstrates its worth in the overall educational system.

\section{Discussion}

The Delphi technique appeared to be an effective and appropriate instrument for exploration of the future of career and technical education. The level of response indicated enthusiasm and interest in projecting future events of career and technical education. The $100 \%$ response rate for all three rounds of the survey and the degree of comments demonstrated a willingness to devote ample time to this pursuit. The responses provided the researcher adequate information in order to develop topic clusters from which to generate a scenario.

The research method and procedures used in this Delphi study were effective in obtaining relevant opinions for projecting future events. The study included projections of top level administrators of professional organizations, as well as, prominent practitioners and researchers in the profession. Because these individuals are the most active in the profession, the study was representative and complete.

The study used forced-choice time frames, allowing development and calculation of median estimates of occurrence, impact and desirability. This promoted consistent treatment of the data and generated information for scenario development. The scenario organized the projections according to topic and immediacy, providing a structural basis for future planning and decision-making. The Delphi proved to be a viable research method for obtaining, organizing and presenting information as a resource for future planning efforts or study. 


\section{Recommendations}

Based on the results of this study, the following recommendations should be considered:

- That career and technical education should remain highly involved in the validation of the career ready status of every high school student by requiring all programs to offer a standardized, nationally recognized industry certification. The findings of this study suggest that CTE will support an academically rigorous and relevant part of education reform. Martin Scaglione, President of ACT's Workforce Division, agrees that development of a career readiness certification is important. Through the use of assessments, a joint research and policy-making initiative, Mr. Scaglione has been instrumental in establishing curricula for craft accreditation. By partnering with industry and academia, the National Center for Construction Education and Research (NCCER) has developed a system for certifying core, foundational and learning skills employees need in order to be successful in the construction industry (NCCER, 2010).

- That CTE will implement curricular changes which will result in the blending of technical and academic education in order to play a major role in providing $21^{\text {st }}$-century education for the next generation of high school students. Career and technical education concentrations will become a part of graduation requirements for all students. Marc Prensky (2008), author and speaker, refers to $21^{\text {st }}$-century learners as "digital natives" and urges educators to move from the traditional lecture method to the new pedagogy of students teaching themselves with teacher guidance. Pearlman (2009) put research into action by creating true learner-centered schoolplaces/workplaces. These New Tech schools begin by defining eight primary learner outcomes: content standards, collaboration, critical thinking, oral communication, written communication, career 
preparation, citizenship and ethics, and technology literacy. These are embedded in all projects which are primarily problem based learning. Career and technical education demonstrates that this can be implemented successfully into $21^{\text {st }}$-century schools.

- That in order for CTE to play a major role in STEM (Science, Technology, Engineering, Mathematics) education facilities must be equipped with up-to-date and state of the art equipment and technology. An example of a successful career and technical education STEM program, Project Lead the Way (PLTW) was launched in 1997 as an independent, not-for-profit organization with 12 participating high schools. This program has grown to approximately 3,000 middle and high schools with 250,000 students enrolled. Courses include engineering and biomedical sciences with the goal of producing 400,000 scientists and engineers annually (Hyslop, 2010).

- That CTE educators at all levels become actively involved in state, local and national professional organizations in order to advocate for career and technical education programs. A strong professional organization is important for influencing CTE legislation as well as providing professional support to its members. Administrators and educators alike must urge their legislators at the state and national levels to support CTE initiatives.

- That qualified CTE personnel will be recruited and retained in the field by improving the established requirements and expectations regarding personnel qualifications and hiring practices. As impending retirements begin to transpire, the demand for great teachers who foster the passion and curiosity in their students will increase.

- That teacher education preparation programs will change significantly as a result of the blending of academic and technical curriculum. In order to accomplish this, states must 
set standards for acceptable levels of knowledge for CTE teachers, developing a national policy regarding requirements for CTE teacher preparation programs.

- That high school guidance counselors will become informed and cognizant of the opportunities awaiting students in CTE programs. In order to increase the knowledge base, appreciation for and capacity to guide capable students to the appropriate CTE programming, counselors must receive intense professional development regarding these programs. This may include visits to CTE centers and hands-on learning activities. Additionally, counselor preparation programs should include a CTE component.

- That CTE will foster a close relationship with leaders of business and industry in order to ensure America's future competitiveness in the world economy. The study suggests that to ensure a well trained workforce, input from business and industry is crucial. Improved use of advisory councils and empowerment of site base decision making will assure the voice of business and industry is heard.

- That CTE and higher education develop a truly collaborative effort focused on creating a mutually beneficial relationship rather than the current competitive and territorial attitudes. This will require a change in attitude toward CTE as being used as a last resort for marginalized students. Articulation agreements will provide smooth transition of students from high school to college and college to college. Dr. Brenda Dann-Messier, Assistant Secretary for Vocational and Adult Education, agrees with the vision of a cradle-to-career education system. Dr. Messier places emphasis on academically rigorous, well articulated pathways between high school and college. Additionally, preparing all students for $21^{\text {st }}$-century careers will make this vision a reality. In her Association for Career and Technical Education (ACTE) convention speech, she 
challenged all CTE stakeholders to build more innovative and academically rigorous programs of study, pathways that transition students seamlessly from secondary to postsecondary and assure their progress and completion and lead to rewarding careers. Furthermore, she encouraged them to become part of the national dialogue that engages secondary and postsecondary institutions and includes business and industry communities (Dann-Messier, 2010).

- That CTE will drive innovation and creativity in high schools by transforming the culture of education in order for every school to produce life-long learners that are both academically-skilled and career ready. Career and technical education programs can lead the way in providing $21^{\text {st }}$-century learning opportunities and serving as an example for traditional education.

- That CTE educators explore opportunities for external and alternative funding to enhance the financial feasibility of technical programs. Partnerships with business and industry should be explored to help alleviate the financial burden of creating new programs as well as anticipating future needs. An example would include Secretary of Labor Hilda L. Solis's announcement of nearly $\$ 100$ million in green jobs training grants, as authorized by the American Recovery and Reinvestment Act of 2009. These grants will support job training programs to help dislocated workers and others, including veterans, women, African Americans and Latinos, find jobs in expanding green industries and occupations. In the midst of an economic recession, CTE has an opportunity to provide training programs to meet the need of green job skills and knowledge built on concepts of sustainability, green technology, green standards, green processes and life cycle analysis which apply to every current CTE program in existence (Stone, 2010). 
- That CTE will respond to high stakes accountability through an improved data collection system. Similar to industry, education and political leaders are now looking for a return on their investment. This system of accountability should include rates of academic attainment and graduation of students involved in CTE programs. West Virginia became a leader in the field by implementing Global 21 Performance Assessments for all students completing a CTE concentration. The assessments were designed to judge student abilities to apply specific knowledge and research skills in a "hands-on" setting. Performance evaluations require the student to operate specialized equipment to solve a problem or make an analysis. The aim of performance assessments is to reveal a number of problem solving approaches, thus providing insight into a student's level of conceptual and procedural knowledge (West Virginia Department of Education, 2010).

- That CTE will develop programming designed to address life-long learning based on the premise that people will live longer, work longer and need more frequent training. Additionally, with the onset of advanced technology, it will be necessary to continually upgrade skills.

- That CTE will improve its image through a number of measures. A comprehensive marketing strategy to educate all stakeholders on the benefits of a career and technical education should be developed.

- That a follow-up study should be considered after ten years to determine the reliability and validity of the projections and to extend the time frames for continued future planning.

- That a survey be conducted among the practicing CTE administrators and teachers to assess agreement with the expert panel. 
- Future research may consider utilization of the research agenda established by the ACTE (Association for Career and Technical Education) in order to collect quantitative data regarding CTE director and teacher perceptions.

\section{Coda}

The underlying goal of this study was to answer the essential question, "Will CTE survive in the future?" The expert panel appeared to answer in the affirmative. Not only will CTE survive the next 20 years, it is poised to take an even larger role in the overall educational system.

The study explored career and technical education at a national level through the opinions of an expert panel. Using a modified Delphi study to generate information for developing a plan that will help school officials ensure program graduates will attain the skills needed to enter the workforce or a postsecondary institution. The results should also be of interest to both local and state administrators who plan and set policy for CTE programming.

Career and technical education is at a crossroad. Survival depends on making changes to meet the demands of a new economy, addressing the increased expectations of stakeholders, and defining the role of CTE in overall school reform. There is agreement that change is imperative, and the expert panel in this study has provided direction. Decisions regarding curriculum, $21^{\text {st }}$ century components, political issues, personnel issues, and relationship with business and industry, relationship with higher education, funding, accountability and image are addressed in this research. Future planning is an important responsibility for educators and has been made more difficult during these changing times. The results of this study should provide a tool and information in this planning process. 
Although career and technical education is sure to face increasing challenges, it will adapt to the changes and emerge as a force focused on providing students with the skills necessary to succeed in the $21^{\text {st }}$ Century. In spite of economic challenge, personnel shortages, technological advancement, image issues, curricular changes, and political concerns, CTE will evolve as a leader in the educational reform efforts. 


\section{REFERENCES}

Adler, M. \& Ziglio, E. (1996). Gazing into the oracle: The Delphi method and its application to social policy and public health. London: Kingsley Publishers.

Andrews, C. \& Allen, J. (2002). Utilization of technology-enhanced Delphi techniques. Workforce Education Forum, 29(1), 1-15.

Association for Career and Technical Education (ACTE). (2006, October). Career and technical education's role in American competitiveness (Issue Brief). Alexandria, VA.

Bardecki, M. J. (1984). Participants' response to the Delphi method: An attitudinal perspective. Technological Forecasting and Social Change, 25(3), 281-292.

Barlow, M. L. (1967). History of industrial education in the United States. Peoria, IL: Chas. A. Bennett.

Barnes, J. L. (1987). An international study of curricular organizers for the study of technology. (Unpublished doctoral dissertation), Virginia Polytechnic Institute and State University, Blacksburg, Virginia.

Bishop, J. H. \& Mane, F. (2004). The impacts of career technical education on high school labor market success. Economics of Education Review, 23. 381-402.

Bjil, R. (1992). Delphi in a future scenario study on mental health and mental health care. Futures, 24(3). 232-250.

Boesel, D., Hudson, L., Deich, S., \& Masten, C. (1994) Participation in and quality of vocational education, national assessment of vocational education, Vol. II. Washington, DC: U. S. Department of Education, Office of Educational Research and Improvement. Bottoms, G. (2005). The SREB model: academic rigor, technical relevance, and a head start on a career. In Remaking Career and Technical Education for the $21{ }^{\text {st }}$ Century: What Role for High School Programs. Washington, D.C.: The Aspen Institute, April 2005. 
Broyles, T. W. (2004). Curriculum and facilities for agricultural education: An agriscience approach. (Unpublished doctoral dissertation). Virginia Polytechnic Institute and State University, Blacksburg, Virginia.

Bruening, T. H., Schanlon, D. C., Hodes, C., Dhital, P., Shao, X., \& Liu, S. T. (2001). The status of the career and technical education teacher preparation program. University Park: National Research Center for Career and Technical Education, Pennsylvania State University.

Business Coalition for Education Reform, (2001). Why Business Cares about Education. Available at http://www.bcer.org.

Camp, W. G. \& Hillison, J. H. (1984). Prosser's sixteen theorems: Time for reconsideration. Journal of Vocational and Technical Education, 1(1), 13-15.

Carl D. Perkins Vocational Education Act. (1984). Public Law 98-524, 98 Stat. 2437.

Carl D. Perkins Vocational and Applied Technology Education Act. (1990). Public Law 101392, 104 Stat. 753.

Carl D. Perkins Vocational and Technical Education Act. (1998). Public Law 105-332, 112 Stat. 3076.

Carl D. Perkins Career and Technical Education Act. (2006). Public Law 109-270, 120 Stat. 683.

Carman, W. H. (1999). An application of the Delphi method of forecasting to the future of technology infrastructure in West Virginia high schools (Doctoral dissertation). Retrieved from http://wvuscholar.wvu.edu.

Castellano, M., Stringfield, S., \& Stone, J. (2003). Secondary career and technical education and comprehensive school reform: Implications for research and practice. Review of Educational Research. 73(2), 231-272. 
Cohen, M., \& Besharov, D. J. (2002). The role of career and technical education: Implications for the federal government. Retrieved April 9, 2008, from http://www.ed.gov/ about/offices/list/ovae/pi/hs/besharov.doc.

Courtney, J., Croasdell, D. \& Paradice, D., (1998). Foundations of information systems. Texas A \& M University. Retrieved November 3, 2009 from http://www.bauer.uh.edu/parks/ fis/inqorg.htm\#ref on.

Cradler, J. (1994). School-based technology use planning. Educational IRM Quarterly, 3(3-4), $12-16$.

Custer, R. L., Scarcella, J. A., \& Stewart, B. R. (1999). The modified Delphi technique: A rotational modification. Journal of Vocational and Technical Education, 15 (2), 1-10.

Daggett, W. R. (2002). The future of career and technical education. International Center for Leadership in Education. Rexford, NY.

Daggett, W. R. (2005). A central role for cte in high school restructuring. Techniques, April. 5658.

Dalkey, N. C., (1969). The Delphi method: An experimental study of group opinion. United States Air Force Project Rand. Santa Monica, CA.

Dalkey, N. C., \& Helmer, O. (1963). An experimental application of the Delphi method to the use of experts. Management Science, 9(3), 458-467.

Dann-Messier, B. (2010, December). Address to national ACTE conference. Las Vegas, NV.

Darling-Hammond, L. (2004). From "separate but equal" to "no child left behind": The collision of new standards and old inequalities. In D. Meier and G. Wood (Eds.) Many Children Left Behind (pp. 3-32). Boston: Beacon Press.

Delbecq, A. L., Van de Ven, A. H., \& Gustafson, D. H. (1975). Group techniques for program planning. Glenview, IL: Scott, Foresman, and Co. 
Dewey, J. (1900). Psychology and social practice. Psychological Review, 7, 105-124.

Dewey, J. (1915). Education vs. Trade-training. The New Republic, 28, 42.

Dewey, J. (1916). Democracy and education. New York: MacMillan.

Dobbins, T. R. (1999). Clinical experiences for agricultural teacher education programs in North Carolina, South Carolina, and Virginia. (Unpublished doctoral dissertation), Virginia Polytechnic Institute and State University, Blacksburg, Virginia.

Dutton, S. T. \& Snedden, D. (1916). The administration of public education in the United States. New York: Macmillan.

Freidman, T. L. (2005). It's a flat world, after all. Retrieved July 6, 2007 from http://www.nytimes.com/2005/04/03/magazine/03DOMINANCE.html?ei=5090\&en=cc2 a003cd936d374\&ex=1270267200\&pagewa...

Friebel, C. H. (1999). An application of the Delphi method of forecasting to the future of public education in West Virginia. (Doctoral dissertation). Retrieved from http://wvuscholar.wvu.edu.

Fullan, M. G. \& Miles, M. B. (1992). What works and what doesn't. Phi Delta Kappan, 211-218.

Fullan, M. (2001). The new meaning of educational change. New York: Teachers College Press.

Gaunt, D. P. (2005). High school seniors' perceptions of career and technical education and factors influencing their decision to attend an area career technical center. (Unpublished doctoral dissertation). Western Michigan University, Kalamazoo, Michigan.

Goldschmidt, P. G. (1975). Scientific inquiry or political critique? Remarks on Delphi assessment, expert opinion, forecasting, and group process by H. Sackman. Technological Forecasting and Social Change, 7, 195-213. 
Gordon, H. R. (2008). The history and growth of career and technical education in America. Long Grove, IL: Waveland Press, Inc.

Gould, Marge C. (2002). Developing literacy and workplace skills: Teaching for $21^{\text {st }}$ century employment. National Education Service, Bloomington, Ind., 2002.

Gray, K. (1991, February). "Vocational Education in High School: A Modern Phoenix?” Phi Delta Kappan 71(6), 437-445. (ERIC No. EJ 421 308).

Gray, M. \& Daugherty, M. (2004, Spring). Factors that influence students to enroll in technology education programs. Journal of Technology Education, 15(2), 5-19.

Hall, G. E., Loucks, S. F., Rutherford, W. L., \& Newlove, B. W. (1975). Levels of use of the innovation: A framework for analyzing innovation adoption. Journal of Teacher Education, 26(1), 52-56.

Herr, E. (2002). School reform and perspectives on the role of school counselors: A century of proposals for change. Professional School Counseling, 5(4), 220-234.

Hsu, C. \& Sanford, B. (2007). The Delphi Technique: Making Sense of Consensus. Practical Assessment, Research \& Evaluation 10(12). Available at http://pareonline.net/pdf/ v12n10.pdf.

Hull, D. (2003). Redefining career and technical education: Seizing a unique opportunity to help “neglected majority" become world-class students, workers and citizens. Techniques, 78(5), 30-36.

Hughes, K. L. \& Karp, M. M. (2004). “School-based Career Development: A Synthesis of the Literature." IEE Brief, 30, 1-42.

Hyslop, A. (2010, March). CTE's role in science, technology, engineering and mathematics. Techniques. Retrieved from http://www.acteonline.org/tech_march10.aspx. 
Iverson, J. S. (2006). Futures thinking methodologies and options relevant for education. In Organization for Economic Co-operation and Development Centre for Educational Research and Innovation (Ed.), Think scenarios, rethink education (pp. 107-120). Paris: OECD.

Johnson, B. \& Christensen, L. (2000). Educational research: Quantitative and qualitative approaches. Needham Heights, MA: A Pearson Education Company.

Judd, R. C. (1972). Delphi decision methods in higher education administration. Eric Document Reproduction Service No. ED 109941.

Kazis, R. (2005). Remaking career and technical education for the $21^{\text {st }}$ century: What role for high school programs? Aspen Institute.

Kirby, B. A. (2007). The future of clinical laboratory science: A Delphi study. (Doctoral dissertation). Retrieved from http://wvuscholar.wvu.edu.

Kleiner, B. H., \& Corrigan, W. A. (1989). Understanding organizational change. Leadership and Organization Development Journal, 10(3), 25-31.

Lam, J. (1982). Determinants of educational plans of the indeterminant high school graduates. The Journal of Educational Administration, 20(2), 213-229.

Lang, T. (1998). An overview of four futures methodologies. Retrieved June 30, 2009, from http://www.soc.hamaii.edu/ future/j7/LANG.html.

Levesque, K. (2004). Teacher quality in vocational education. A Report Prepared by MPR Associates for the National Assessment of Vocational Education. Washington, DC: U.S. Department of Education, Office of the Under Secretary. 
Levesque, K., Lauen, D., Teitelbaum, P., Alt, M., Librera, S., \& Nelson, D. (2000). Vocational education in the United States: Toward the Year 2000. Washington, DC: U. S. Department of Education, Office of Educational Research and Improvement.

Lewis, M. V. (2001). Major needs of career and technical education in the year 2000: Views from the field. Columbus: National Dissemination Center for Career and Technical Education, The Ohio State University.

Lindeman, C. A. (1981). Priorities within the health care system: A Delphi survey. Kansas City, MO: American Nurses’ Association.

Linstone, H., \& Turoff, M. (Eds.). (1975). The Delphi method: Techniques and applications. Reading, MA: Addison-Wesley Pub. Co.

Ludwig, B. (1997). Predicting the future: Have you considered using the Delphi methodology? Journal of Extension, 35(5), 1-4. Retrieved November 5, 2009, from http://www.joe.org/joe/1997october/tt2.php.

Lynch, R. L. (2000a). High school career and technical education for the first decade of the $21^{\text {st }}$ century. Journal of Vocational Education Research, 25(2) 155-198.

Lynch, R. L. (2000b). New directions for high school career and technical education in the 21st Century. (Ed-99-CO-0013). Columbus, OH: Center on Education and Training.

Martino, J. P. (1983). Technological forecasting for decision making. New York: North-Holland. Masser, I., \& Foley, P. (1987). Delphi revisited: Expert opinion in urban analysis. Urban Studies, 24(3), 217-225.

Medrich, E. A. (2005). Change or die: The challenge facing career and technical education today. In Remaking Career and Technical Education for the $21^{\text {st }}$ Century: What Role for High School Programs. Washington, D.C.: The Aspen Institute, April 2005. 
Meeder, H. (2006). Reinventing the American High School for the 21st Century: Strengthening a New Vision for the American High School through the Experiences and Resources of Career and Technical Education. (Position Paper). Retrieved from Association of Career and Technical Education website: http://www.acteonline.org/uploadedFiles/ Issues_and_Advocacy/files/ACTEHSReform_Full.pdf.

Miller, M. M. (1993). Enhancing regional analysis with the Delphi method. Review of Regional Studies 23(2), 191-212.

Mirra, D. R. (2004). The role of the school superintendent as a technology leader: A Delphi study. (Unpublished doctorial dissertation). Virginia Polytechnic Institute and State University, Blacksburg, Virginia.

Mitroff. I. I. \& Turoff, M. Philosophical and methodological foundations of Delphi. In Linstone, H. A.\& Turoff, M. (Eds.), The Delphi method: Techniques and applications (pp.17-36). Reading, MA: Addison-Wesley Publishing Company.

Murane, R. J., \& Levy, F. (1996). Teaching the new basic skills: Principles for educating children to thrive in a changing economy. New York: Free Press.

Na, S. (2006). A Delphi study to identify teaching competencies of teacher education faculty in 2015 (Doctoral dissertation). Retrieved from http://wvuscholar.wvu.edu.

Nagel, D. (2009, April). The $21^{\text {st }}$ century learning imperative. The Journal. Retrieved December 16, 2009 from http://thejournal.com/articles/2009/04/24/the-21st-century-learningimperative.aspx.

National Association of State Directors of Career Technical Education Consortium. (2009). Silver Spring, MD. Retrieved from http://www.careertech.org/ on November 11, 2009. 
National Center for Educational Statistics, U. S. Department of Education. (1997). Time spent teaching core academic subjects in elementary schools: Statistical Analysis Report, February, 1997. Available at www.nces.ed.gov/pubs/97293.pdf.

National Center for Education Statistics (NCES). (2000). “Changes in High School Vocational Course taking in a Larger Perspective," Stats in Brief, October.

National Employer Leadership Council. (1999). Institutions confirmed: the bottom-line return on school-to-work investment for students and employers. Washington, DC: KSA Group, Inc.

National Endowment for Financial Education. (2002). Financial literacy in America: Individual choices, national consequences. A white paper from a symposium, October 2002.

National Science Board. (2010). Preparing the next generation of STEM innovators: Identifying and developing our nation's human capital. (NSB Publication No. 10-33). Retrieved from http://www.nsf.gov/nsb/publications/2010/nsb1033.pdf.

NCCER and ACT partner to build construction industry careers. (2010, Spring). Activity, 48(2). Retrieved from http://www.act.org/activity/spring2010/nccer.html.

Olson, L. (2003, April 23). Quality of coursework rises since 1983. Education Week. O’Neil, J. (1995). On schools as learning organizations: A conversation with Peter Senge. Educational Leadership, 52(7), 20-23.

Parente, F. J., Anderson, J. K., Myers P., \& O’Brin, T. (1984). An examination of factors contributing to Delphi accuracy. Journal of Forecasting, 3(2), 173-182.

Partnership for $21^{\text {st }}$ Century Skills. (2009). The MILE Guide, Milestones for Improving Learning \& Education. Learning for the $21^{\text {st }}$ Century. Retrieved January 21, 2010 from http://www.21stcenturyskills.org/documents/MILE_Guide_091101.pdf. 
Pearlman, B. (2009, September-October). Making $21^{\text {st }}$ century schools: Creating learnercentered schoolplaces/workplaces for a new culture of students at work. Educational Technology. Retrieved from http://www.bobpearlman.org/Articles/ET\%20Bob\% 20Pearlman\%20article.pdf.

Pfeiffer, J. (1968). New look at education. Poughkeepsie, NY: Odyssey Press.

Plank, S. (2001). Career and technical education in the balance. St. Paul. National Research Center for Career and Technical Education, University of Minnesota.

Prensky, M. (2008). The role of technology in teaching and the classroom. Educational Technology. Retrieved from http://www.marcprensky.com/writing/PrenskyThe_Role_of_Technology-ET-11-12-08.pdf.

Roberts, R. W. (1957). Vocational and Practical Arts Education. New York: Harper and Row Publishers, 1957.

Rojewski, J. (2002). Preparing the workforce of tomorrow: A conceptual framework for career and technical education. Journal of Vocational Educational Research, 27(1), Retrieved from http://scholar.lib.vt.edu/ejournals/JVER/v27n1/rojewski.html.

Rossetti, R. (1989). Reasons high school students are not enrolling in vocational education and people influencing students' decisions. Columbus, OH: Ohio State University Department of Agricultural Education. (ERIC Document Reproduction Service No. ED $305445)$.

Russell, M., Goldberg, A. \& O’Connor, K. (2003). Computer-based testing and validity: a look back and into the future. Technology and Assessment Study Collaborative, Boston College, August 2003. 
Sandrey, M. A., \& Bulger, S. M. (2008). The Delphi method: an approach for facilitating evidence based practice in athletic training. Athletic Training Education Journal. 3(4), 135-142. Retrieved from http://206.211.148.195/ atej/vol3/no4/EJ60\%202\% 20Delphi\%20Method_Sandrey.pdf.

Sahakian C. E. (1997). The Delphi Method. Skokie, IL: The Corporate Partnering Institute.

Scheele, D. S. (1975). Reality construction as a product of Delphi interaction. In H. A. Linstone \& M. Turoff (Eds.), The Delphi method: Techniques and applications (pp.37-71). Reading, MA: Addison-Wesley Publishing Company.

Silverberg, M., Warner, E., Fong, M., \& Goodwin, D. (2004). National Assessment of Vocational Education: Final Report to Congress. Washington: U.S. Department of Education, Office of the Undersecretary.

Stasz, C., \& Bodilly, S. (2004). Efforts to improve the quality of vocational in secondary schools: Impact of federal and state policies. Santa Monica, CA: RAND.

Stead, F. L. (1975). An application of the Delphi method of forecasting to nursing education planning in West Virginia (Doctoral dissertation, West Virginia University, 1975).

Stone, III, J. R. (2010, March). It isn't easy being green or is it? Techniques. Retrieved from http://www.acteonline.org/tech_march10.aspx.

Swanson, J. C. (1951). Development of Federal Legislation for Vocational Education. Chicago, IL: American Technical Society.

Tyack, D. (1974). The one best system: A history of American urban education. Cambridge, MA: Harvard University Press.

U. S. Department of Education. (2003). No Child Left Behind: A parent's guide. Office of the Secretary, Office of Public Affairs, Washington, D.C. 
U. S. Department of Labor. (2009), Working in the $21^{\text {st }}$ Century. Bureau of Labor Statistics, Washington, D.C. Available at http://www.bls.gov/opub/working/home.htm.

Valentine, J. (2010, August). Student engagement: Measuring and studying this critical factor for school improvement and student achievement. RESA 7 Administrator's Forum. Presented at meeting of RESA 7, Clarksburg, WV.

Walonick, D. (1993). An Overview of Forcasting Metodology. StatPac, Retrieved January 26, 2010 from http://statpac.com/reearhpaperforcating.htm.

Weaver, W. T. (1971). The Delphi forecasting method. Phi Delta Kappan, 52(5), 267-273.

West Virginia Department of Education. (2009a). About West Virginia career and technical education. Available at http://careertech.k12.wv.us/about.html.

West Virginia Department of Education. (2009b). West Virginia State Plan for Career and Technical Education. Retrieved November 17, 2009 from http://careertech.k12.wv.us/ documents/FinalStatePlan.pdf.

West Virginia Department of Education. (2010). Career and Technical Education Performance Assessment. Retrieved January 11, 2011 from http://careertech.k12.wv.us/global21performance-assessments.html.

Witkin, B. R., \& Altschuld, J. W. (1995). Planning and conducting needs assessment: A practical guide. Thousand Oaks, CA: Sage Publications, Inc.

Woudenberg, F. (1991). An evaluation of Delphi. Technological Forecasting and Social Change, $40,131-150$.

Young, S. J., \& Jamieson, L. M. (2001). Delivery methodology of the Delphi: A comparison of two approaches. Journal of Park and Recreation Administration, 19(1), 42-58.

Yousuf, M. I., (Spring 2007). The Delphi technique. Essays in Education, 20, 80-89. 
APPENDIXES 
Appendix A

Notice of IRB Protocol Exemption 


\title{
WestVrrginiaUniversity. \\ Office of Research Compliance
}

\section{Expedited-IRB Protocol-Exemption}

\author{
To: $\quad$ Chapman, Paul \\ From: $\quad$ WVU Office of Research Compliance \\ Date: $\quad$ Friday, February 26, 2010 \\ Subject: Exemption Acknowledgement
}

Tracking \#: $\mathrm{H}-22293$

Title: $\quad$ Career and Technical Education at a Crossroads: A Delphi Study

The above-referenced study was reviewed by the West Virginia University Institutional Review Board (IRB) and was granted exemption in accordance with 45 CFR 46.101(2).

This protocol was reviewed using the following:

Exemption Checklist (210r)

This research study was granted an exemption in accordance with Research that involves educational tests, survey procedures, interview procedures or observation of public behavior [45 CFR 46.101(2)].

The following documents have been acknowledged for use in this study and are available in the BRAAN system:

Surveys, Questionnaires, Interviews

Attachments

Round 1 Survey.doc Round 1 survey attached. Results from Round 1 are needed to prepare Round 2 survey.

Miscellaneous Attachments

Attachments

Email Message with Cover Letter.doc Email message with cover letter. Email Message withRound 1.doc Email message to be sent with Round 1 survey.

Informational Cover Letter.doc Informational Cover Letter.

Invitation message.doc Invitation message.

Professional Data Sheet.doc Professional data sheet. 
Thank you.

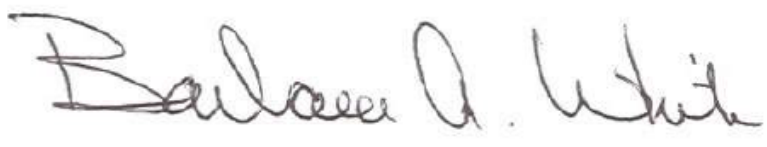

Board Designee: White, Barbara

Letter Sent By: White, Barbara, 2/26/2010 2:44 PM

Once you begin your human subject research, the following regulations apply:

1. Any modifications to the study protocol must be reviewed and acknowledged by the IRB prior to implementation.

2. You may not use a modified form until it has been acknowledged by the IRB. 


\section{WestVrrginiaUniversity. \\ Office of Research Compliance}

\section{Expedited - Amendment - Exemption}

To: $\quad$ Chapman, Paul

From: $\quad$ WVU Office of Research Compliance

Date: $\quad$ Thursday, April 29, 2010

Subject: No action required

Tracking \#: AMEND-2232 (H-22293)

Title: $\quad$ Career and Technical Education at a Crossroads: A Delphi Study

On 4/29/2010 the following changes to the study were reviewed and approved:

This amendment was reviewed using the following:

Exemption Checklist (210r)

This amendment is to include the Round 2 survey which could not be created until round 1 was completed.

The following attached documents have been reviewed and acknowledged:

Surveys, Questionnaires, Interviews

Attachments

Round 1 Survey.doc Round 1 survey attached. Results from Round 1 are needed to prepare Round 2 survey.

Round 2 Survey.doc Round 2 survey.

Miscellaneous Attachments

Attachments

Email Message with Cover Letter.doc Email message with cover letter.

Email Message withRound 1.doc Email message to be sent with Round 1 survey.

Informational Cover Letter.doc Informational Cover Letter.

Invitation message.doc Invitation message.

Professional Data Sheet.doc Professional data sheet. 
The above-referenced study was granted exemption in accordance with 45 CFR 46.101 (2).

Thank you.

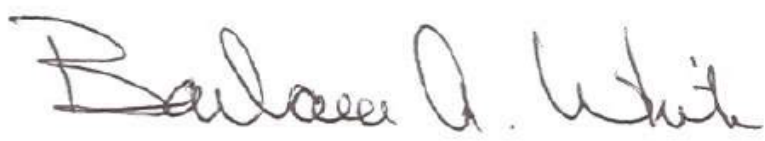

Board Designee: White, Barbara

Letter Sent By: White, Barbara, 4/29/2010 9:19 AM 


\section{W. WestVirginiaUniversity.}

Office of Research Compliance

\section{Expedited - Amendment - Exemption}

To: $\quad$ Chapman, Paul

From: $\quad$ WVU Office of Research Compliance

Date: $\quad$ Monday, June 14, 2010

Subject: No action required

Tracking \#: AMEND-2319 (H-22293)

Title: $\quad$ Career and Technical Education at a Crossroads: A Delphi Study

On $6 / 14 / 2010$ the following changes to the study were reviewed and approved:

Submitting Round 3 survey which is based on results from Round 2.

Exempt Research Checklist (210r)

The above-referenced study was granted exemption in accordance with 45 CFR 46.101 (2).

Thank you.

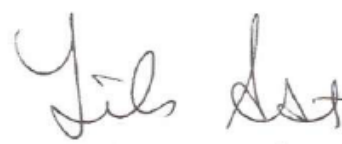

Board Designee: Ast, Lilo

Letter Sent By: Ast, Lilo, 6/14/2010 2:12 PM 
Appendix B

Participant Qualifications 


\section{Expert Panel Qualifications}

\begin{tabular}{|c|c|c|c|c|c|}
\hline $\begin{array}{c}\text { Expert } \\
\text { Panel } \\
\text { Member }\end{array}$ & Position & $\begin{array}{c}\text { Degree } \\
\text { Level }\end{array}$ & $\begin{array}{c}\text { Years of } \\
\text { CTE } \\
\text { Experience }\end{array}$ & $\begin{array}{l}\text { Professional } \\
\text { Organization } \\
\text { Membership }\end{array}$ & $\begin{array}{l}\text { Materials } \\
\text { Published }\end{array}$ \\
\hline 1 & $\begin{array}{l}\text { CTE District } \\
\text { Superintendent }\end{array}$ & Ph.D. & 23 & Yes & Yes \\
\hline 2 & $\begin{array}{c}\text { Assistant State CTE } \\
\text { Director }\end{array}$ & MA & 39 & Yes & No \\
\hline 3 & State CTE Director & MA & 20 & Yes & No \\
\hline 4 & $\begin{array}{l}\text { State Level Executive } \\
\text { Director }\end{array}$ & Ph.D. & 10 & Yes & Yes \\
\hline 5 & $\begin{array}{l}\text { State Level Program } \\
\text { Director }\end{array}$ & $\mathrm{MA}+45$ & 31 & Yes & Yes \\
\hline 6 & Local CTE Director & MS & 32 & Yes & No \\
\hline 7 & Department Chair & Ed.D. & 31 & Yes & Yes \\
\hline 8 & $\begin{array}{l}\text { District Level CTE } \\
\text { Administrator }\end{array}$ & $\mathrm{MA}+45$ & 36 & No & No \\
\hline 9 & $\begin{array}{l}\text { District Level CTE } \\
\text { Director }\end{array}$ & MA & 35 & Yes & No \\
\hline 10 & State CTE Director & Ph.D. & 10 & Yes & No \\
\hline 11 & State CTE Director & $\mathrm{MA}+$ & 45 & Yes & Yes \\
\hline 12 & $\begin{array}{l}\text { State Level Program } \\
\text { Specialist }\end{array}$ & Ed.D. & 41 & Yes & Yes \\
\hline 13 & $\begin{array}{l}\text { District Level CTE } \\
\text { Director }\end{array}$ & Ph. D. & 40 & Yes & No \\
\hline 14 & $\begin{array}{l}\text { District Level CTE } \\
\text { Director }\end{array}$ & MS & 24 & Yes & Yes \\
\hline 15 & $\begin{array}{c}\text { CTE District } \\
\text { Superintendent }\end{array}$ & $\mathrm{MA}+$ & 6 & Yes & No \\
\hline 16 & $\begin{array}{l}\text { Senior Staff CTE } \\
\text { Association }\end{array}$ & BA & 6 & Yes & Yes \\
\hline 17 & $\begin{array}{l}\text { State Level CTE } \\
\text { Section Supervisor }\end{array}$ & Ed.S. & 24 & Yes & Yes \\
\hline 18 & $\begin{array}{l}\text { Faculty State CTE } \\
\text { Certification Program }\end{array}$ & Ed.S. & 26 & Yes & Yes \\
\hline 19 & $\begin{array}{l}\text { National Association } \\
\text { Director }\end{array}$ & BS & 3 & Yes & Yes \\
\hline
\end{tabular}


Appendix C

Correspondence 
W. WestVirginiaUniversity。

College of Human

Resources \& Education

\section{Dear CTE Colleague:}

I would like to invite you to participate in a research study that may benefit career and technical education. Your participation is voluntary.

I am asking you to be a member of an expert panel of CTE professionals because of your experience and expertise. The panel will include approximately 25 individuals who are practitioners, researchers, policy makers and leaders in the field. The study is part of my doctoral dissertation in Educational Leadership Studies at West Virginia University. The project is being supervised by Dr. Paul Chapman, an assistant professor in the College of Human Resources and Education.

The study will utilize the Delphi method of forecasting which relies upon expert opinion to reach a consensus about events in the future. There will be three rounds. In the first round, you will be asked to identify events that you believe will have an impact on career and technical education. You will be provided with a list of all first round responses in the second round. You will be asked to indicate when you think each event might occur and the desirability of the event. In the final round, all second round responses will be compared. In an attempt of achieve consensus, you will be asked to change your response or defend it as a minority opinion.

Your identity as a panel member will be held in strict confidence. Correspondence will be identified only by number. A copy of the final summary report will be provided to each panel member.

The success of this study depends upon the input of experts. Your participation will help provide scenarios for which to prepare. Planning is essential for the continued success of CTE as we move into the future.

Thank you for considering my study. I trust that your commitment to CTE will encourage you to participate. I will follow up with an email during the week of to confirm your decision to participate. If you have any questions, please feel free to contact me at (304)614-6630 or by email at mcutrigh@ access.k12.wv.us. I look forward to a positive response.

Sincerely,

Michael W. Cutright, M.A. 
W. WestVirginiaUniversity。

College of Human

Resources \& Education

\section{Dear CTE Colleague:}

This is a follow up to the message I sent last week requesting your participation in a research study that I believe will benefit career and technical education.

Again, the study will utilize the Delphi method of forecasting which relies upon expert opinion to reach a consensus about events in the future. There will be three rounds. In the first round, you will be asked to identify events that you believe will have an impact on career and technical education. You will be provided with a list of all first round responses in the second round. You will be asked to indicate when you think each event might occur and the desirability of the event. In the final round, all second round responses will be compared. In an attempt of achieve consensus, you will be asked to change your response or defend it as a minority opinion.

Please respond to this message to confirm your decision to participate. I am anxious to get the study started and discover what the experts think. If you have any questions, please feel free to contact me at (304)614-6630 or by email at mcutrigh@access.k12.wv.us. I look forward to a positive response.

Sincerely,

Michael Cutright 
(Email Message with Informational Cover Letter and Professional Data Sheet)

Dear Colleague:

Thank you for agreeing to serve as a member of the expert panel for my study on the future of career and technical education. Your input will be extremely valuable for career and technical educators as they plan for the future.

I have attached the informational cover letter. Please read it and confirm your agreement to participate by replying to this email.

I have also attached a professional data sheet for you to complete and return via email attachment. The information collected is for informational purposes only.

Your participation and commitment to career and technical education is greatly appreciated.

Sincerely,

Michael Cutright 


\section{WestVrrginiaUniversity。 \\ College of Human \\ Resources \& Education}

\section{Informational Cover Letter}

\section{Career and Technical Education at a Crossroads: A Delphi Study}

Introduction: I have been invited to participate in this research study by Michael Cutright, who is conducting the study to fill the requirements for his doctoral dissertation in Educational Leadership Studies at West Virginia University. Mr. Cutright has explained the study to me. The West Virginia University Institutional Review Board (IRB) has acknowledgement of this study on file.

Purpose of the Study: The purpose of the study is to learn more about how the experts view the future of career and technical education.

Description of Procedure: This study consists of a three-round survey process. I will be asked my opinions about the future of career and technical education in the first round. The second round will consist of a survey generated by the responses to the first round. I will be asked to indicate an appropriate time frame and degree of impact and desirability for each event listed. I will receive a personalized survey instrument comparing my responses to the median responses of the panel. I will be asked to change my responses to agree with the consensus of the group or to justify my responses as minority opinions.

Risks and Discomforts: There are no known or expected risks from participating in this study.

Alternative: I understand that I do not have to participate in this study.

Benefits: I understand that this study is not expected to be of direct benefit to me, but the knowledge gained may be of benefit to others.

Contact Persons: For more information about this research, I can contact Michael Cutright at (304) 472-1259 (office), (304) 636-8758 (home) or (304) 614-6630 (cell) or I can contact his advisor, Dr. Paul Chapman, Assistant Professor in the College of Human Resources and Education at (304) 293-2147. For more information about my rights as a research subject, I may contact the Executive Secretary of the Institutional Review Board at (304) 293-7073.

Confidentiality: I understand that any information about me obtained as a result of my participation in this research will be kept as confidential as legally possible. I also understand that my research records, like hospital records, may be subpoenaed by court order or may be inspected by federal regulatory authorities. In any publications that may 
result from this research, neither my name nor any information from which I might be identified will be published without my consent.

Voluntary Participation: Participation in this study is voluntary. I understand that I am free to withdraw my consent to participate in this study at any time. Refusal to participate or withdrawal will involve no penalty or loss of benefits. I have been given the opportunity to ask questions about the research and I have received answers concerning areas I did not understand. 


\section{Professional Data Sheet}

Please provide the information requested below. The information collected is for informational purposes only. It will not be used to reveal your identity.

1. What is your position? (Be general, for example, State Director, local administrator, etc.)

2. How many years of experience do you have in CTE?

3. What is your degree level?

4. What (if any) professional organizations do you belong to?

5. Have you been published? 
(Email Message to accompany Round 1 Survey)

Dear Colleague:

Attached is the Round 1 survey instrument for the Delphi study on the future of career and technical education. Directions for completing the survey are located at the top of the form.

Your prompt response is critical to the success of this study. I would appreciate it if you would return the completed survey by Please return it as an email attachment.

Please do not hesitate to call me if you have any questions or concerns about the Round 1 survey. You can reach me by calling my cell phone (304) $614-6630$ or by emailing me at mcutrigh@access.k12.wv.us.

Thank you in advance for completing this survey.

Sincerely,

Michael Cutright 


\section{Career and Technical Education at a Crossroads: A Delphi Study \\ Round 1 Survey}

Directions: Please respond to the following question by listing the events that you believe will impact career and technical education. Use as many pages as needed.

As I view the future of career and technical education in the next 20 years, the following events might occur. 


\section{ROUND TWO SURVEY}

Thank you for the great responses to Round One of my study. It was very interesting to see what you think is in store for the future of career and technical education.

Your responses have been compiled into this Round Two survey. Please indicate your response to each of the questions. I would appreciate it if you could complete the survey by

Survey Instructions:

- Each question below consists of an event derived from the responses of the panel to the first round survey and three response items.

- The first response item consists of five time frames. Please indicate which time frame you believe corresponds with the event.

The choices are: (1) Never; (2) Immediate (1-3 years); (3) Mid-Range (4-10 years); (4) Long-Range (11-20 years); and (5) Beyond 20 years.

- The second response item of each of the questions is a five-point scale to rate the impact you believe the event will have on career and technical education.

The three indicator points are (1) Very Low Impact; (3) Moderate Impact; and (5) Very High Impact. Additional gradients fall between the indicator points.

(If you answered Never to the time frame item, you do not need to rank the second response item. The perception that an event will not happen indicates that it will not impact the profession.)

- The third response item is a five-point scale to rate the desirability of the event.

The indicator points are (1) Very Undesirable and (5) Very Desirable with additional gradients between the points. This item will help determine if the impact will be positive or negative for career and technical education.

\section{To access the survey click on this link:}

\section{http://www.zoomerang.com/Survey/WEB22AKKZBRQPH}


Round 2 Survey

\section{Curriculum}

Question 1

Entrepreneurship will become a part of all career and technical education programs.

Please select the time frame you believe is most appropriate.

$\begin{array}{lllll}\circ & \circ & \circ & \circ & \circ \\ \text { Never } & \text { Immediate } & \text { Mid-Range } & \text { Long-Range } & \text { Beyond 20 Years } \\ & (1-3 \text { years }) & (4-10 \text { years }) & (11-20 \text { years }) & \end{array}$

If you believe the event will occur, please rate the degree of impact to Career and Technical Education.

\begin{tabular}{|c|c|c|c|c|}
\hline ○ & O & O & & 0 \\
\hline Very & & Moderate & & Very \\
\hline Low & & Impact & & High \\
\hline Impact & & & & Impac \\
\hline
\end{tabular}

Please rate your perception of the desirability of the event.

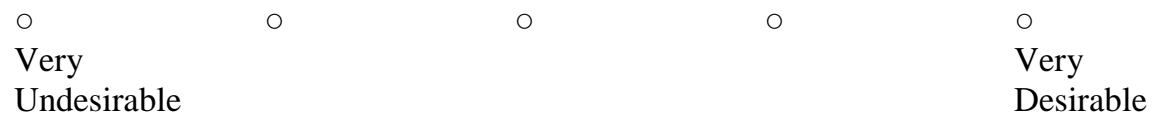

Question 2

Health Occupations CTE programs will be more closely connected with identified health care providers and/or facilities: there will be a more pronounced OJT/co-op component required for CTE program completion.

Please select the time frame you believe is most appropriate.

$\begin{array}{lllll}\circ & \circ & \circ & \circ & \circ \\ \text { Never } & \text { Immediate } & \text { Mid-Range } & \text { Long-Range } & \text { Beyond 20 Years } \\ & (1-3 \text { years }) & (4-10 \text { years }) & (11-20 \text { years }) & \end{array}$

If you believe the event will occur, please rate the degree of impact to Career and Technical Education.

\begin{tabular}{|c|c|c|c|c|}
\hline 0 & 0 & 0 & 0 & 0 \\
\hline Very & & Moderate & & Very \\
\hline Low & & Impact & & High \\
\hline Impact & & & & Impact \\
\hline
\end{tabular}

Please rate your perception of the desirability of the event.

\begin{tabular}{|c|c|c|c|c|}
\hline 0 & 0 & 0 & 0 & 0 \\
\hline Very & & & & Very \\
\hline Undesirable & & & & Desirable \\
\hline
\end{tabular}




\section{Question 3}

National Security concerns will continue and career preparation programs in Criminal Justice, Bio-Security will continue to grow.

Please select the time frame you believe is most appropriate.

$\begin{array}{lllll}\circ & \circ & \circ & \circ & \circ \\ \text { Never } & \begin{array}{l}\text { Immediate } \\ \text { (1-3 years })\end{array} & \begin{array}{l}\text { Mid-Range } \\ (4-10 \text { years })\end{array} & \begin{array}{l}\text { Long-Range } \\ (11-20 \text { years })\end{array} & \text { Beyond } 20 \text { Years }\end{array}$

If you believe the event will occur, please rate the degree of impact to Career and Technical Education.

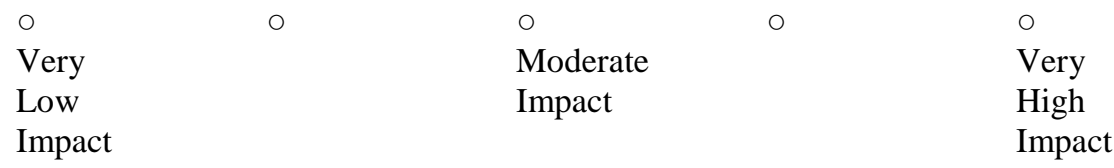

Please rate your perception of the desirability of the event.

$\begin{array}{lllll}\circ & 0 & 0 & 0 & 0\end{array}$

Very Very

Undesirable Desirable

Question 4

The teaching of languages will become part of a complete and effective CTE program.

Please select the time frame you believe is most appropriate.

$\begin{array}{lllll}\circ & \circ & \circ & \circ & \circ \\ \text { Never } & \begin{array}{l}\text { Immediate } \\ \text { (1-3 years })\end{array} & \begin{array}{l}\text { Mid-Range } \\ (4-10 \text { years })\end{array} & \begin{array}{l}\text { Long-Range } \\ (11-20 \text { years })\end{array} & \text { Beyond } 20 \text { Years }\end{array}$

If you believe the event will occur, please rate the degree of impact to Career and Technical Education.

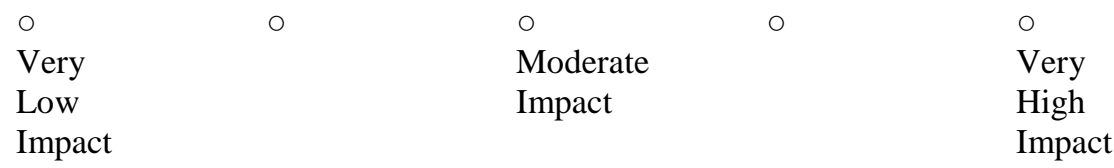

Please rate your perception of the desirability of the event.

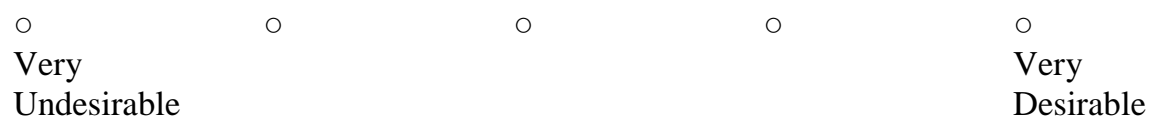


Question 5

Students must do an internship, shadow, or work in the technical area before they graduate high school.

Please select the time frame you believe is most appropriate.

$\begin{array}{lllll}\circ \text { Never } & \circ & \circ & \circ & \circ \\ & \begin{array}{l}\text { Immediate } \\ (1-3 \text { years })\end{array} & \begin{array}{l}\text { Mid-Range } \\ (4-10 \text { years })\end{array} & \begin{array}{l}\text { Long-Range } \\ (11-20 \text { years })\end{array} & \text { Beyond } 20 \text { Years }\end{array}$

If you believe the event will occur, please rate the degree of impact to Career and Technical Education.

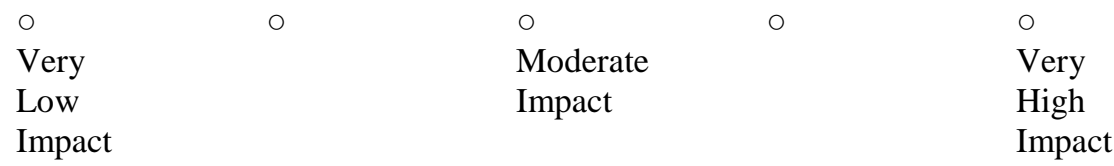

Please rate your perception of the desirability of the event.

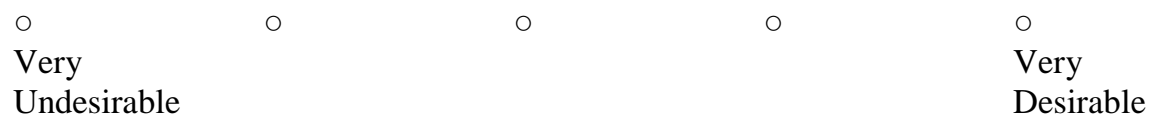

Question 6

CTE leads the validation of career-ready status of every high school graduate by increasing the use of instruments that measure skills employers' value (industry recognized certifications).

Please select the time frame you believe is most appropriate.

$\begin{array}{lllll}\circ & \circ & \circ & \circ & \circ \\ \text { Never } & \begin{array}{l}\text { Immediate } \\ (1-3 \text { years })\end{array} & \begin{array}{l}\text { Mid-Range } \\ (4-10 \text { years })\end{array} & \begin{array}{l}\text { Long-Range } \\ (11-20 \text { years })\end{array} & \text { Beyond 20 Years }\end{array}$

If you believe the event will occur, please rate the degree of impact to Career and Technical Education.

$\begin{array}{llll}\circ & \circ & \circ & \circ \\ \text { Very } & \text { Moderate } & \\ \text { Low } & \text { Impact } & \text { Very } \\ \text { Impact } & & \text { High } \\ & & \text { Impact }\end{array}$

Please rate your perception of the desirability of the event.

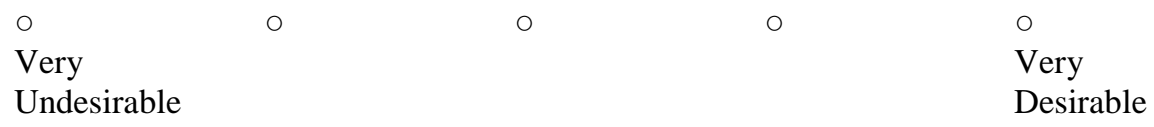




\section{Question 7}

Simultaneously, as career and technical education tries to address the needs of the hard-to-reach student, there will be a rebirth of interest in occupations that will stay local and provide a good living.

Please select the time frame you believe is most appropriate.

$\begin{array}{lllll}\circ & \circ & \circ & \circ & \circ \\ \text { Never } & \begin{array}{l}\text { Immediate } \\ \text { (1-3 years })\end{array} & \begin{array}{l}\text { Mid-Range } \\ (4-10 \text { years })\end{array} & \begin{array}{l}\text { Long-Range } \\ (11-20 \text { years })\end{array} & \text { Beyond } 20 \text { Years }\end{array}$

If you believe the event will occur, please rate the degree of impact to Career and Technical Education.

$\begin{array}{llll}\circ & \circ & \circ & \circ \\ \text { Very } & \text { Moderate } & \text { Very } \\ \text { Low } & \text { Impact } & \text { High } \\ \text { Impact } & & \text { Impact }\end{array}$

Please rate your perception of the desirability of the event.

$\begin{array}{lllll}0 & 0 & 0 & 0\end{array}$

Very Very

Undesirable Desirable

Question 8

Software and machine management will become new basics of education in CTE while standardized tests and other forms of testing will disappear.

Please select the time frame you believe is most appropriate.

$\begin{array}{lllll}\circ & \circ & \circ & \circ & \circ \\ \text { Never } & \begin{array}{l}\text { Immediate } \\ \text { (1-3 years })\end{array} & \begin{array}{l}\text { Mid-Range } \\ (4-10 \text { years })\end{array} & \begin{array}{l}\text { Long-Range } \\ (11-20 \text { years })\end{array} & \text { Beyond } 20 \text { Years }\end{array}$

If you believe the event will occur, please rate the degree of impact to Career and Technical Education.

$\begin{array}{llll}\circ & \circ & \circ & \circ \\ \text { Very } & \text { Moderate } & \text { Very } \\ \text { Low } & \text { Impact } & \text { High } \\ \text { Impact } & & \text { Impact }\end{array}$

Please rate your perception of the desirability of the event.

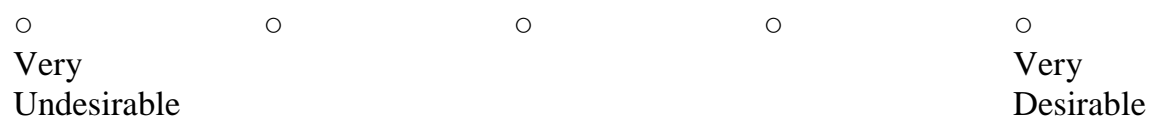


Question 9

Career and technical education will be driven by a common national vision, mission and set of core values.

Please select the time frame you believe is most appropriate.

$\begin{array}{lllll}\circ & \circ & \circ & \circ & \circ \\ \text { Never } & \begin{array}{l}\text { Immediate } \\ (1-3 \text { years })\end{array} & \begin{array}{l}\text { Mid-Range } \\ (4-10 \text { years })\end{array} & \begin{array}{l}\text { Long-Range } \\ (11-20 \text { years })\end{array} & \text { Beyond } 20 \text { Years }\end{array}$

If you believe the event will occur, please rate the degree of impact to Career and Technical Education.

\begin{tabular}{|c|c|c|}
\hline \multirow{2}{*}{$\begin{array}{l}\text { O } \\
\text { Very } \\
\text { Low }\end{array}$} & \multirow[t]{2}{*}{0} & $\begin{array}{l}\circ \\
\text { Moderate }\end{array}$ \\
\hline & & Impact \\
\hline
\end{tabular}

Please rate your perception of the desirability of the event.

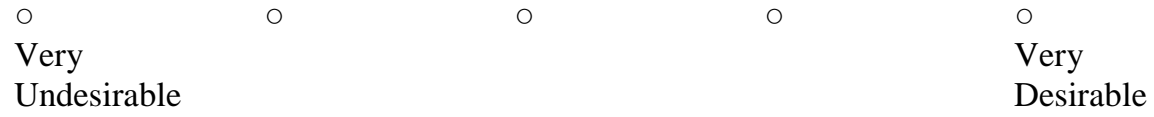

Question 10

CTE leads the Career Clusters initiative by emerging and aligning with economic development industry sectors/clusters.

Please select the time frame you believe is most appropriate.

$\begin{array}{lllll}\circ & \circ & \circ & \circ & \circ \\ \text { Never } & \begin{array}{l}\text { Immediate } \\ (1-3 \text { years })\end{array} & \begin{array}{l}\text { Mid-Range } \\ (4-10 \text { years })\end{array} & \begin{array}{l}\text { Long-Range } \\ (11-20 \text { years })\end{array} & \text { Beyond 20 Years }\end{array}$

If you believe the event will occur, please rate the degree of impact to Career and Technical Education.

$\begin{array}{llll}\circ & \circ & \circ & \circ \\ \text { Very } & \text { Moderate } & \text { Very } \\ \text { Low } & \text { Impact } & \text { High } \\ \text { Impact } & & \text { Impact }\end{array}$

Please rate your perception of the desirability of the event.

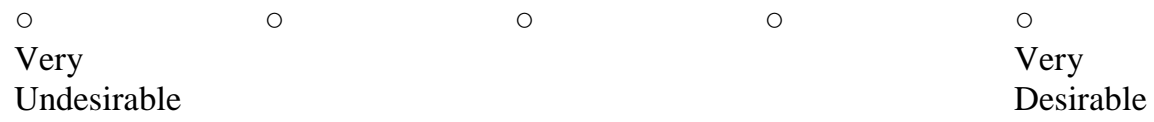




\section{Question 11}

Content standard objectives (CSOs) and similar standards in other states will undergo a major overhaul, as research shows the futility of trying to make a one-size-fits-all list of criteria for completion. Programs of the same name, in different places, under different industry/business needs, will look different.

Please select the time frame you believe is most appropriate.

$\begin{array}{lllll}\circ \text { Never } & \circ & \circ & \circ & \circ \\ & \begin{array}{l}\text { Immediate } \\ (1-3 \text { years })\end{array} & \begin{array}{l}\text { Mid-Range } \\ (4-10 \text { years })\end{array} & \begin{array}{l}\text { Long-Range } \\ (11-20 \text { years })\end{array} & \text { Beyond } 20 \text { Years }\end{array}$

If you believe the event will occur, please rate the degree of impact to Career and Technical Education.

\begin{tabular}{|c|c|c|}
\hline 0 & 0 & 0 \\
\hline Very & Moderate & Very \\
\hline Low & Impact & High \\
\hline Impact & & Impact \\
\hline
\end{tabular}

Please rate your perception of the desirability of the event.

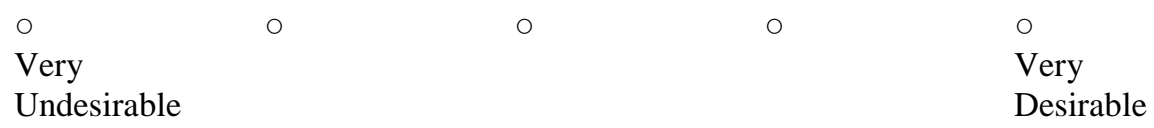

Question 12

Grade-level tracking will be replaced with content learning, where students can build on their knowledge and abilities, and leave the grade classification behind allowing more time for the CTE effort.

Please select the time frame you believe is most appropriate.

$\begin{array}{lllll}\circ & \circ & \circ & \circ & \circ \\ \text { Never } & \text { Immediate } & \begin{array}{l}\text { Mid-Range } \\ (1-3 \text { years })\end{array} & \begin{array}{l}\text { Long-Range } \\ (1-10 \text { years })\end{array} & \text { Beyond 20 Years } \\ & & \end{array}$

If you believe the event will occur, please rate the degree of impact to Career and Technical Education.

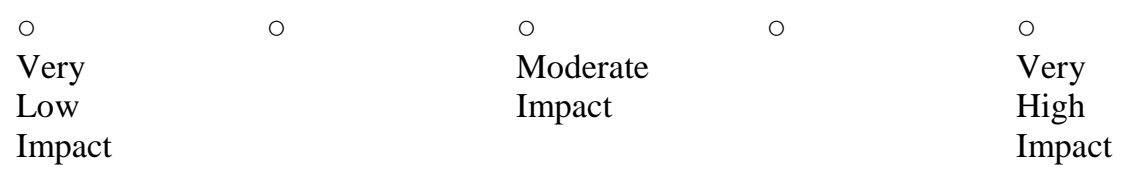

Please rate your perception of the desirability of the event.

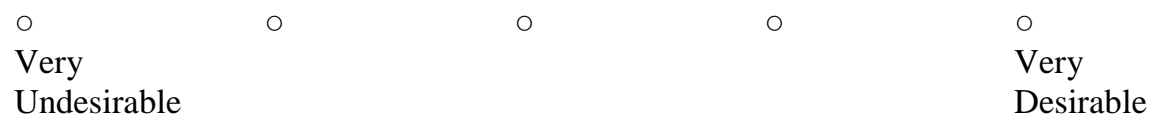




\section{Question 13}

CTE is the catalyst that expands the assistance available to all high school students to enable them to make both wise academic and career choices and achieve their goals for the future.

Please select the time frame you believe is most appropriate.

$\begin{array}{lllll}\circ & \circ & \circ & \circ & \circ \\ \text { Never } & \begin{array}{l}\text { Immediate } \\ \text { (1-3 years })\end{array} & \begin{array}{l}\text { Mid-Range } \\ (4-10 \text { years })\end{array} & \begin{array}{l}\text { Long-Range } \\ (11-20 \text { years })\end{array} & \text { Beyond } 20 \text { Years }\end{array}$

If you believe the event will occur, please rate the degree of impact to Career and Technical Education.

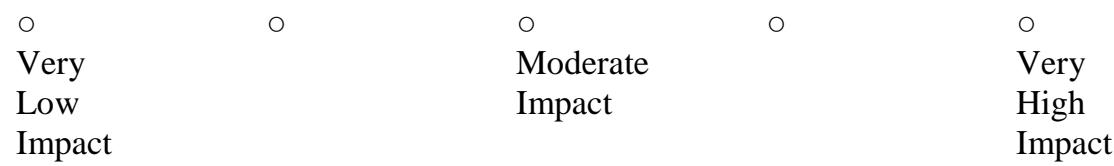

Please rate your perception of the desirability of the event.

$\begin{array}{lllll}0 & 0 & 0 & 0\end{array}$

Very Very

Undesirable Desirable

Question 14

There will be an increase in the interest of CTE career areas.

Please select the time frame you believe is most appropriate.

$\begin{array}{lllll}\circ \text { Never } & \circ & \circ & \circ & \circ \\ & \begin{array}{l}\text { Immediate } \\ (1-3 \text { years })\end{array} & \begin{array}{l}\text { Mid-Range } \\ (4-10 \text { years })\end{array} & \begin{array}{l}\text { Long-Range } \\ (11-20 \text { years })\end{array} & \text { Beyond } 20 \text { Years }\end{array}$

If you believe the event will occur, please rate the degree of impact to Career and Technical Education.

$\begin{array}{llll}\circ & \circ & \circ & \circ \\ \text { Very } & \text { Moderate } & \\ \text { Low } & \text { Impact } & \text { Very } \\ \text { Impact } & & \text { High } \\ & & \text { Impact }\end{array}$

Please rate your perception of the desirability of the event.

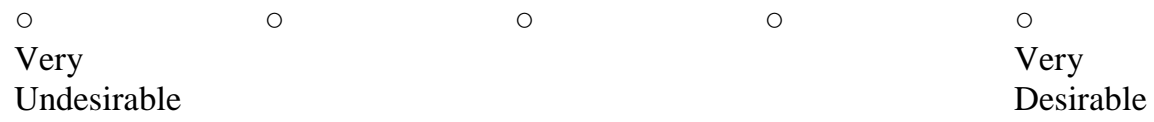




\section{Question 15}

Secondary CTE programs will all offer a minimum of two tracts, one for highly capable and a different level for those students recognized as less achieving or challenged.

Please select the time frame you believe is most appropriate.

$\begin{array}{lllll}\circ \text { Never } & \circ & \circ & \circ & \circ \\ & \begin{array}{l}\text { Immediate } \\ (1-3 \text { years })\end{array} & \begin{array}{l}\text { Mid-Range } \\ (4-10 \text { years })\end{array} & \begin{array}{l}\text { Long-Range } \\ (11-20 \text { years })\end{array} & \text { Beyond } 20 \text { Years }\end{array}$

If you believe the event will occur, please rate the degree of impact to Career and Technical Education.

$\begin{array}{llll}\circ & \circ & \circ & \circ \\ \text { Very } & \text { Moderate } & \\ \text { Low } & \text { Impact } & \text { Very } \\ \text { Impact } & & \text { High } \\ & & \text { Impact }\end{array}$

Please rate your perception of the desirability of the event.

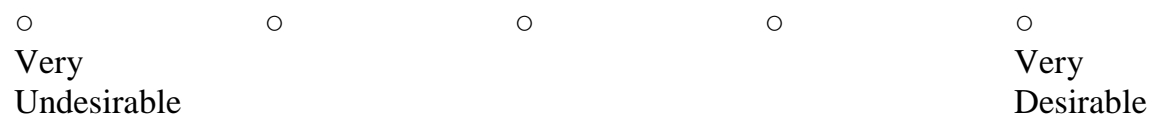

Question 16

Rigor and relevance of content and delivery will be increased significantly in CTE curriculum and instruction.

Please select the time frame you believe is most appropriate.

$\begin{array}{lllll}\circ & \circ & \circ & \circ & \circ \\ \text { Never } & \begin{array}{l}\text { Immediate } \\ \text { (1-3 years })\end{array} & \begin{array}{l}\text { Mid-Range } \\ (4-10 \text { years })\end{array} & \begin{array}{l}\text { Long-Range } \\ (11-20 \text { years })\end{array} & \text { Beyond } 20 \text { Years }\end{array}$

If you believe the event will occur, please rate the degree of impact to Career and Technical Education.

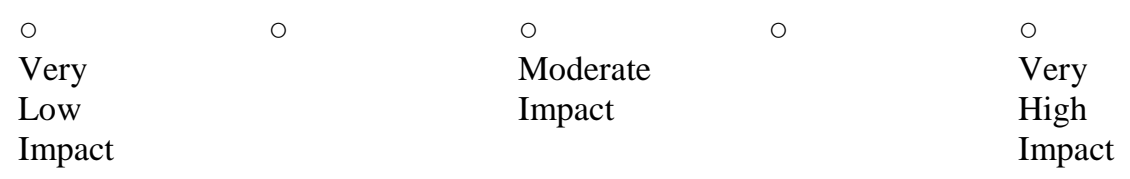

Please rate your perception of the desirability of the event.

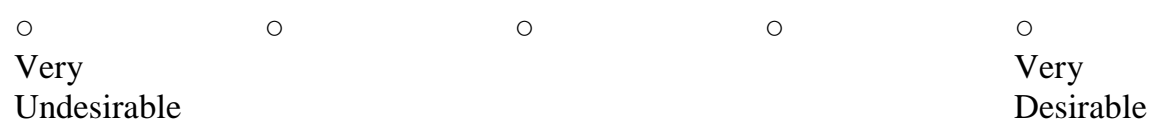




\section{Question 17}

The blending of career and technical education and academic education will overlap considerably—it will no longer be an either/or situation.

Please select the time frame you believe is most appropriate.

$\begin{array}{lllll}\circ \text { Never } & \circ & \circ & \circ & \circ \\ & \begin{array}{l}\text { Immediate } \\ (1-3 \text { years })\end{array} & \begin{array}{l}\text { Mid-Range } \\ (4-10 \text { years })\end{array} & \begin{array}{l}\text { Long-Range } \\ (11-20 \text { years })\end{array} & \text { Beyond } 20 \text { Years }\end{array}$

If you believe the event will occur, please rate the degree of impact to Career and Technical Education.

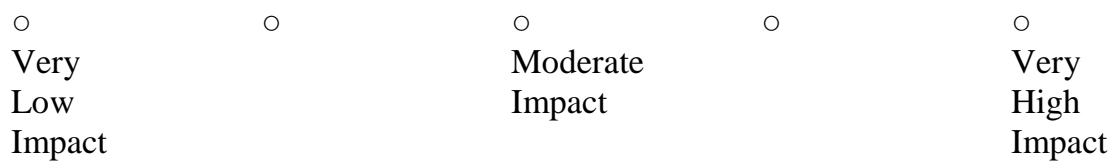

Please rate your perception of the desirability of the event.

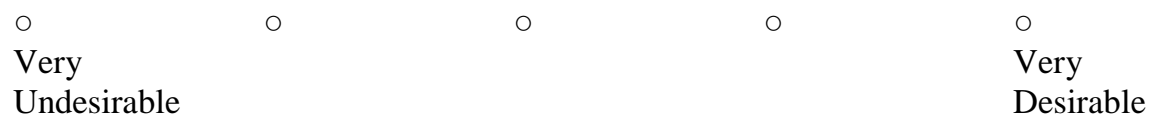

Question 18

Career academies and small learning communities will replace the comprehensive high school setting.

Please select the time frame you believe is most appropriate.

$\begin{array}{lllll}\circ & \circ & \circ & \circ & \circ \\ \text { Never } & \begin{array}{l}\text { Immediate } \\ (1-3 \text { years })\end{array} & \begin{array}{l}\text { Mid-Range } \\ (4-10 \text { years })\end{array} & \begin{array}{l}\text { Long-Range } \\ (11-20 \text { years })\end{array} & \text { Beyond 20 Years }\end{array}$

If you believe the event will occur, please rate the degree of impact to Career and Technical Education.

$\begin{array}{llll}\circ & \circ & \circ & \circ \\ \text { Very } & \text { Moderate } & \text { Very } \\ \text { Low } & \text { Impact } & \text { High } \\ \text { Impact } & & \text { Impact }\end{array}$

Please rate your perception of the desirability of the event.

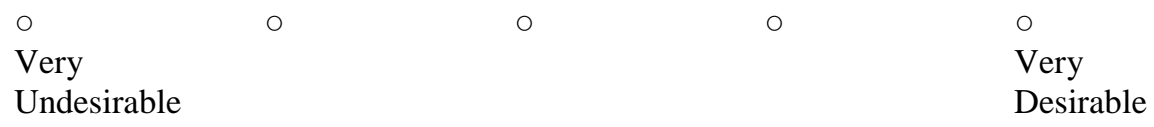




\section{Question 19}

CTE will be offered in elementary schools.

Please select the time frame you believe is most appropriate.

$\begin{array}{lllll}\circ & \circ & \circ & \circ & \circ \\ \text { Never } & \text { Immediate } & \text { Mid-Range } & \text { Long-Range } & \text { Beyond 20 Years } \\ & (1-3 \text { years }) & (4-10 \text { years }) & (11-20 \text { years }) & \end{array}$

If you believe the event will occur, please rate the degree of impact to Career and Technical Education.

\begin{tabular}{|c|c|c|c|c|}
\hline 0 & 0 & 0 & 0 & 0 \\
\hline Very & & Moderate & & Very \\
\hline Low & & Impact & & High \\
\hline
\end{tabular}

Please rate your perception of the desirability of the event.

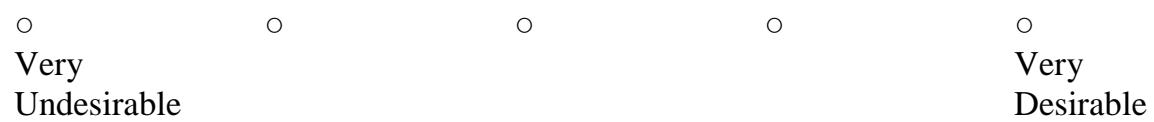

Question 20

The Carnegie unit will be replaced with something new which is not seat-time based.

Please select the time frame you believe is most appropriate.

$\begin{array}{lllll}\circ & \circ & \circ & \circ & \circ \\ \text { Never } & \text { Immediate } & \text { Mid-Range } & \text { Long-Range } & \text { Beyond 20 Years } \\ & (1-3 \text { years }) & (4-10 \text { years }) & (11-20 \text { years }) & \end{array}$

If you believe the event will occur, please rate the degree of impact to Career and Technical Education.

\begin{tabular}{|c|c|c|c|c|}
\hline o & 0 & 0 & o & 0 \\
\hline Very & & Moderate & & Very \\
\hline Low & & Impact & & High \\
\hline Impact & & & & Impact \\
\hline
\end{tabular}

Please rate your perception of the desirability of the event.

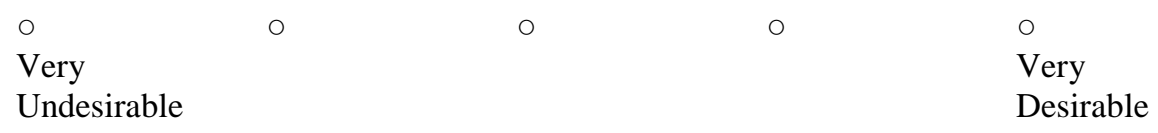




\section{Question 21}

The school calendar will change drastically, perhaps even becoming individualized depending on geographic area of the state(s).

Please select the time frame you believe is most appropriate.

$\begin{array}{lllll}\circ \text { Never } & \circ & \circ & \circ & \circ \\ & \begin{array}{l}\text { Immediate } \\ \text { (1-3 years })\end{array} & \begin{array}{l}\text { Mid-Range } \\ (4-10 \text { years })\end{array} & \begin{array}{l}\text { Long-Range } \\ (11-20 \text { years })\end{array} & \text { Beyond } 20 \text { Years }\end{array}$

If you believe the event will occur, please rate the degree of impact to Career and Technical Education.

$\begin{array}{llll}\circ & \circ & \circ & \circ \\ \text { Very } & \text { Moderate } & \text { Very } \\ \text { Low } & \text { Impact } & \text { High } \\ \text { Impact } & & \text { Impact }\end{array}$

Please rate your perception of the desirability of the event.

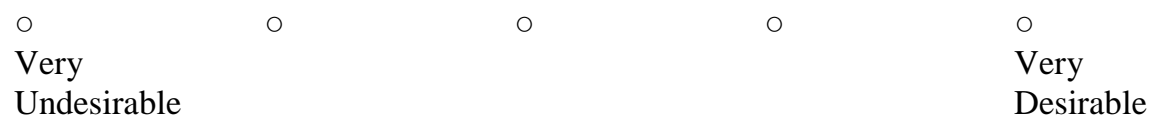

Question 22

Active participation in Career and Technical Student Organizations (CTSO'S) will be a requirement to complete the CTE course with students routinely attending leadership and competitive events.

Please select the time frame you believe is most appropriate.

$\begin{array}{lllll}\circ & \circ & \circ & \circ & \circ \\ \text { Never } & \begin{array}{l}\text { Immediate } \\ (1-3 \text { years })\end{array} & \begin{array}{l}\text { Mid-Range } \\ (4-10 \text { years })\end{array} & \begin{array}{l}\text { Long-Range } \\ (11-20 \text { years })\end{array} & \text { Beyond 20 Years }\end{array}$

If you believe the event will occur, please rate the degree of impact to Career and Technical Education.

$\begin{array}{llll}\circ & \circ & \circ & \circ \\ \text { Very } & \text { Moderate } & \\ \text { Low } & \text { Impact } & \text { Very } \\ \text { Impact } & & \text { High } \\ & & \text { Impact }\end{array}$

Please rate your perception of the desirability of the event.

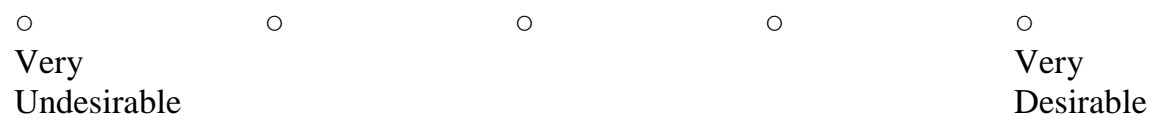




\section{Question 23}

Career and Technical Education will be renamed to Technical Skills Achievement (TSA), meaning there is more of the industry certification focus than what we have now.

Please select the time frame you believe is most appropriate.

$\begin{array}{lllll}\circ \text { Never } & \circ & \circ & \circ & \circ \\ & \begin{array}{l}\text { Immediate } \\ (1-3 \text { years })\end{array} & \begin{array}{l}\text { Mid-Range } \\ (4-10 \text { years })\end{array} & \begin{array}{l}\text { Long-Range } \\ (11-20 \text { years })\end{array} & \text { Beyond } 20 \text { Years }\end{array}$

If you believe the event will occur, please rate the degree of impact to Career and Technical Education.

$\begin{array}{llll}\circ & \circ & \circ & \circ \\ \text { Very } & \text { Moderate } & \\ \text { Low } & \text { Impact } & \text { Very } \\ \text { Impact } & & \text { High } \\ & & \text { Impact }\end{array}$

Please rate your perception of the desirability of the event.

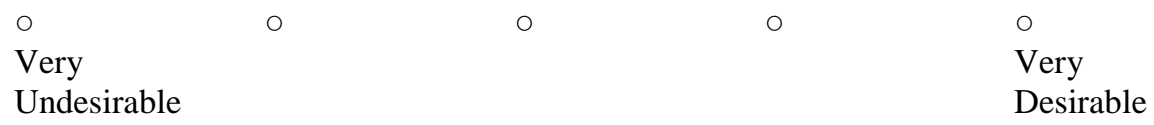

Question 24

All stand-alone, academy and area CTE centers will have counselors, core-subject teachers and a student health center on campus.

Please select the time frame you believe is most appropriate.

$\begin{array}{lllll}\circ & \circ & \circ & \circ & \circ \\ \text { Never } & \begin{array}{l}\text { Immediate } \\ (1-3 \text { years })\end{array} & \begin{array}{l}\text { Mid-Range } \\ (4-10 \text { years })\end{array} & \begin{array}{l}\text { Long-Range } \\ (11-20 \text { years })\end{array} & \text { Beyond 20 Years }\end{array}$

If you believe the event will occur, please rate the degree of impact to Career and Technical Education.

$\begin{array}{llll}\circ & \circ & \circ & \circ \\ \text { Very } & \text { Moderate } & \text { Very } \\ \text { Low } & \text { Impact } & \text { High } \\ \text { Impact } & & \text { Impact }\end{array}$

Please rate your perception of the desirability of the event.

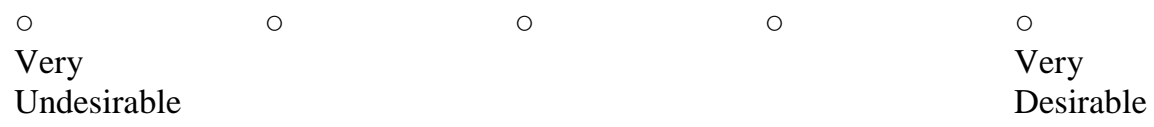




\section{Question 25}

CTE concentrations will be part of graduation requirements for all students.

Please select the time frame you believe is most appropriate.

$\begin{array}{lllll}\circ & \circ & \circ & \circ & \circ \\ \text { Never } & \text { Immediate } & \text { Mid-Range } & \text { Long-Range } & \text { Beyond 20 Years } \\ & (1-3 \text { years }) & (4-10 \text { years }) & (11-20 \text { years }) & \end{array}$

If you believe the event will occur, please rate the degree of impact to Career and Technical Education.

\begin{tabular}{|c|c|c|c|c|}
\hline 0 & 0 & 0 & 0 & 0 \\
\hline Very & & Moderate & & Very \\
\hline Low & & Impact & & High \\
\hline
\end{tabular}

Please rate your perception of the desirability of the event.

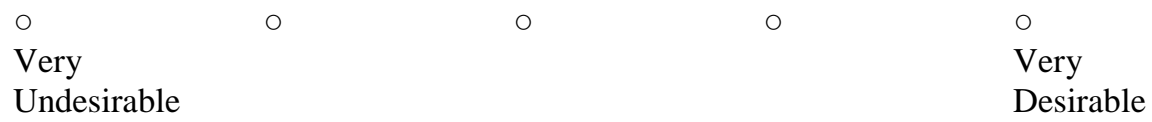

\section{Question 26}

Global standardization of education, accreditation will occur.

Please select the time frame you believe is most appropriate.

$\begin{array}{lllll}\circ & \circ & \circ & \circ & \circ \\ \text { Never } & \text { Immediate } & \text { Mid-Range } & \text { Long-Range } & \text { Beyond 20 Years } \\ & (1-3 \text { years }) & (4-10 \text { years }) & (11-20 \text { years }) & \end{array}$

If you believe the event will occur, please rate the degree of impact to Career and Technical Education.

\begin{tabular}{|c|c|c|c|}
\hline 0 & 0 & 0 & 0 \\
\hline Very & & Moderate & Very \\
\hline Low & & Impact & High \\
\hline Impact & & & Impact \\
\hline
\end{tabular}

Please rate your perception of the desirability of the event.

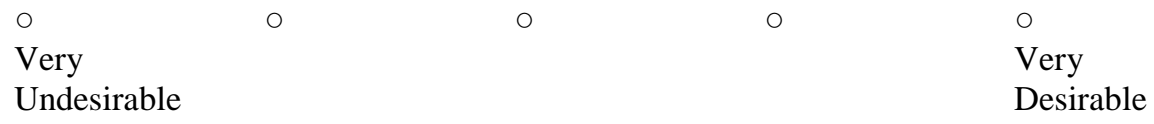




\section{Question 27}

Those secondary programs that were called "practical"; e.g., technology education will receive decreasing support until they no longer exist.

Please select the time frame you believe is most appropriate.

$\begin{array}{lllll}\circ \text { Never } & \circ & \circ & \circ & \circ \\ & \begin{array}{l}\text { Immediate } \\ (1-3 \text { years })\end{array} & \begin{array}{l}\text { Mid-Range } \\ (4-10 \text { years })\end{array} & \begin{array}{l}\text { Long-Range } \\ (11-20 \text { years })\end{array} & \text { Beyond } 20 \text { Years }\end{array}$

If you believe the event will occur, please rate the degree of impact to Career and Technical Education.

$\begin{array}{llll}\circ & \circ & \circ & \circ \\ \text { Very } & \text { Moderate } & \text { Very } \\ \text { Low } & \text { Impact } & \text { High } \\ \text { Impact } & & \text { Impact }\end{array}$

Please rate your perception of the desirability of the event.

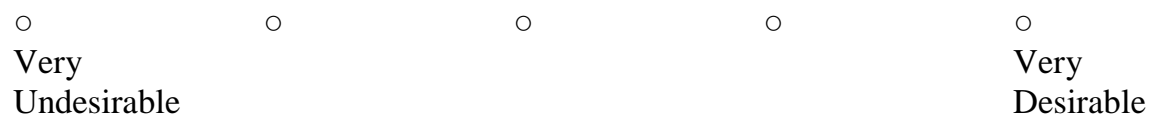

Question 28

Traditional lines of schools, districts and institutions will blur.

Please select the time frame you believe is most appropriate.

$\begin{array}{lllll}\circ & \circ & \circ & \circ & \circ \\ \text { Never } & \begin{array}{l}\text { Immediate } \\ \text { (1-3 years })\end{array} & \begin{array}{l}\text { Mid-Range } \\ (4-10 \text { years })\end{array} & \begin{array}{l}\text { Long-Range } \\ (11-20 \text { years })\end{array} & \text { Beyond } 20 \text { Years }\end{array}$

If you believe the event will occur, please rate the degree of impact to Career and Technical Education.

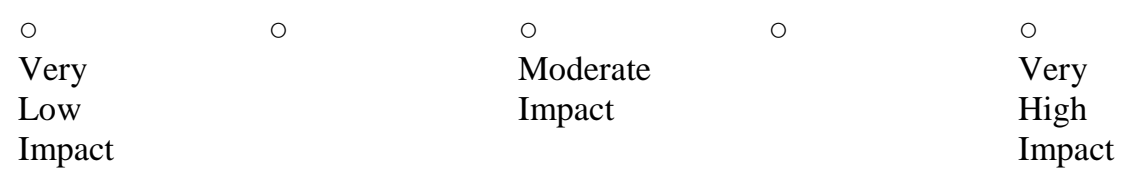

Please rate your perception of the desirability of the event.

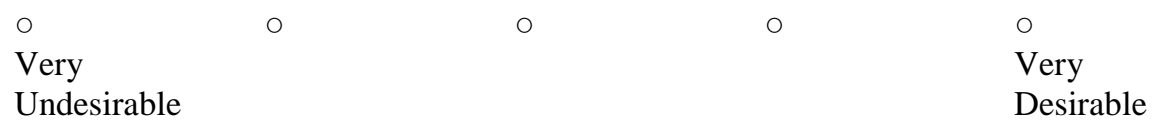




\section{Technology}

Question 29

The United States and other advanced societies will move toward continuous innovation to meet job market demand, which is founded by information technology.

Please select the time frame you believe is most appropriate.

$\begin{array}{lllll}\circ & \circ & \circ & \circ & \circ \\ \text { Never } & \text { Immediate } & \begin{array}{l}\text { Mid-Range } \\ (1-3 \text { years })\end{array} & \begin{array}{l}\text { Long-Range } \\ (1-10 \text { years })\end{array} & \text { Beyond 20 Years } \\ & \text { (11-20 years }) & \end{array}$

If you believe the event will occur, please rate the degree of impact to Career and Technical Education.

\begin{tabular}{|c|c|c|}
\hline 0 & 0 & 0 \\
\hline Very & Moderate & Very \\
\hline Low & Impact & High \\
\hline Impact & & Impact \\
\hline
\end{tabular}

Please rate your perception of the desirability of the event.

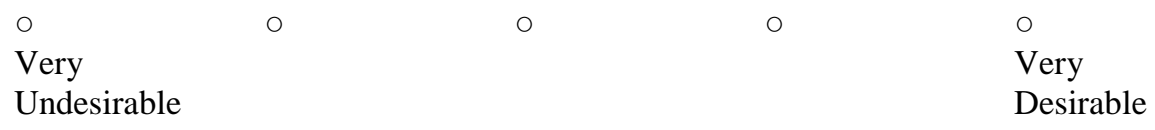

Question 30

The development of the right side of the brain will be fostered by activities that require synthesis and holistic thinking.

Please select the time frame you believe is most appropriate.

$\begin{array}{lllll}\circ \text { Never } & \circ & \circ & \circ & \circ \\ & \begin{array}{l}\text { Immediate } \\ \text { (1-3 years })\end{array} & \begin{array}{l}\text { Mid-Range } \\ (4-10 \text { years })\end{array} & \begin{array}{l}\text { Long-Range } \\ (11-20 \text { years })\end{array} & \text { Beyond } 20 \text { Years }\end{array}$

If you believe the event will occur, please rate the degree of impact to Career and Technical Education.

$\begin{array}{lll}\circ & \circ & \circ \\ \text { Very } & \text { Moderate } & \circ \\ \text { Low } & \text { Impact } & \text { Very } \\ \text { Impact } & & \text { High } \\ & & \text { Impact }\end{array}$

Please rate your perception of the desirability of the event.

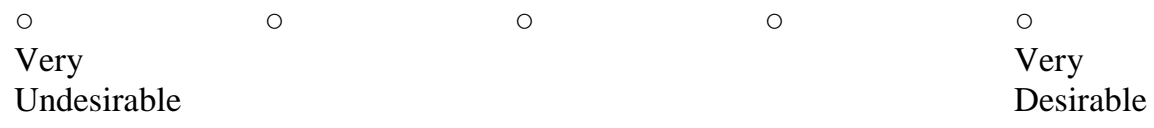




\section{Question 31}

Continued globalization will result in multi-national education programs.

Please select the time frame you believe is most appropriate.

$\begin{array}{lllll}\circ & \circ & \circ & \circ & \circ \\ \text { Never } & \text { Immediate } & \text { Mid-Range } & \text { Long-Range } & \text { Beyond 20 Years } \\ & (1-3 \text { years }) & (4-10 \text { years }) & (11-20 \text { years }) & \end{array}$

If you believe the event will occur, please rate the degree of impact to Career and Technical Education.

\begin{tabular}{|c|c|c|c|c|}
\hline 0 & 0 & 0 & 0 & 0 \\
\hline Very & & Moderate & & Very \\
\hline Low & & Impact & & High \\
\hline
\end{tabular}

Please rate your perception of the desirability of the event.

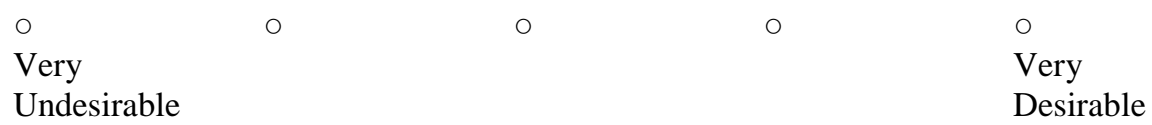

\section{Question 32}

The goal of career technical education systems in 20 years will be to produce flexible, resilient, software-supported students, workers and citizens who can successfully compete, thrive, and live with dignity in a technology-driven Continuous Innovation Society capable of embracing constantly changing goods and services of consumer needs.

Please select the time frame you believe is most appropriate.

$\begin{array}{lllll}\circ & \circ & \circ & \circ & \circ \\ \text { Never } & \text { Immediate } & \text { Mid-Range } & \text { Long-Range } & \text { Beyond 20 Years } \\ & (1-3 \text { years }) & (4-10 \text { years }) & (11-20 \text { years }) & \end{array}$

If you believe the event will occur, please rate the degree of impact to Career and Technical Education.

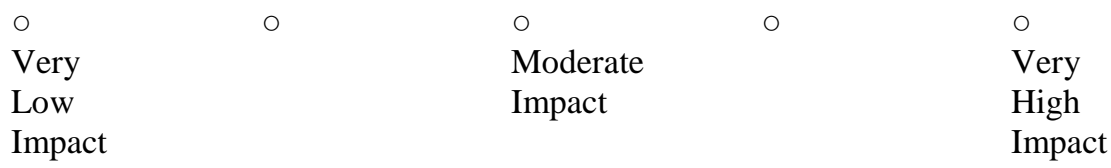

Please rate your perception of the desirability of the event.

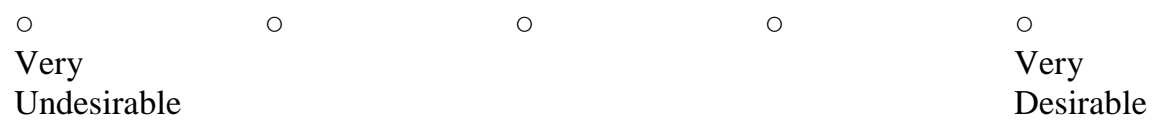




\section{Question 33}

Learning in career and technical education will be performance and innovation based.

Please select the time frame you believe is most appropriate.

$\begin{array}{lllll}\circ & \circ & \circ & \circ & \circ \\ \text { Never } & \text { Immediate } & \text { Mid-Range } & \text { Long-Range } & \text { Beyond 20 Years } \\ & (1-3 \text { years }) & (4-10 \text { years }) & (11-20 \text { years }) & \end{array}$

If you believe the event will occur, please rate the degree of impact to Career and Technical Education.

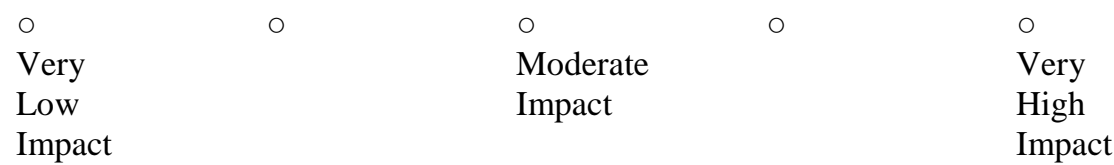

Please rate your perception of the desirability of the event.

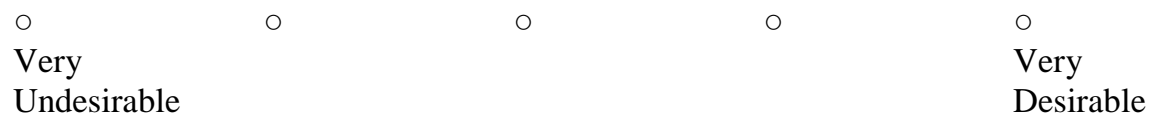

\section{Question 34}

Rural America with no access to high speed internet will get access.

Please select the time frame you believe is most appropriate.

$\begin{array}{lllll}\circ & \circ & \circ & \circ & \circ \\ \text { Never } & \text { Immediate } & \text { Mid-Range } & \text { Long-Range } & \text { Beyond 20 Years } \\ & (1-3 \text { years }) & (4-10 \text { years }) & (11-20 \text { years }) & \end{array}$

If you believe the event will occur, please rate the degree of impact to Career and Technical Education.

\begin{tabular}{|c|c|c|c|}
\hline 0 & 0 & 0 & 0 \\
\hline Very & & Moderate & Very \\
\hline Low & & Impact & High \\
\hline Impact & & & Impact \\
\hline
\end{tabular}

Please rate your perception of the desirability of the event.

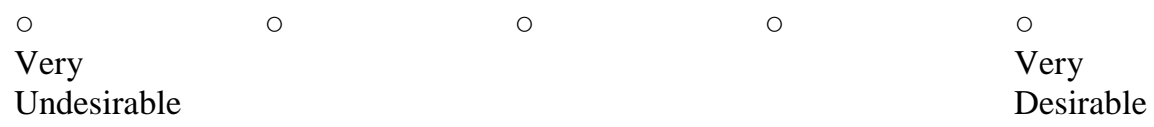




\section{Question 35}

International Business will be added to programming in CTE.

Please select the time frame you believe is most appropriate.

$\begin{array}{lllll}\circ & \circ & \circ & \circ & \circ \\ \text { Never } & \text { Immediate } & \text { Mid-Range } & \text { Long-Range } & \text { Beyond 20 Years } \\ & (1-3 \text { years }) & (4-10 \text { years }) & (11-20 \text { years }) & \end{array}$

If you believe the event will occur, please rate the degree of impact to Career and Technical Education.

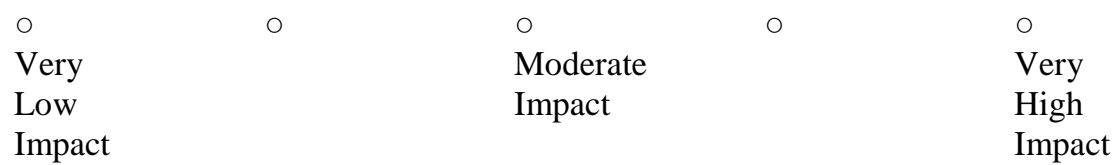

Please rate your perception of the desirability of the event.

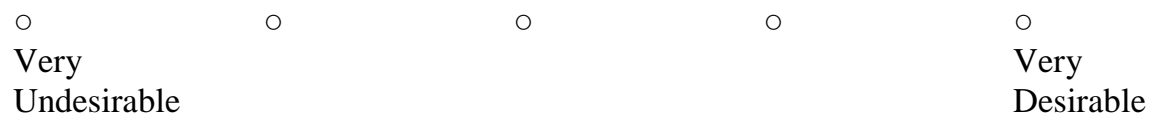

Question 36

Green technology initiatives emerge as new CTE programs.

Please select the time frame you believe is most appropriate.

$\begin{array}{lllll}\circ & \circ & \circ & \circ & \circ \\ \text { Never } & \text { Immediate } & \text { Mid-Range } & \text { Long-Range } & \text { Beyond 20 Years } \\ & (1-3 \text { years }) & (4-10 \text { years }) & (11-20 \text { years }) & \end{array}$

If you believe the event will occur, please rate the degree of impact to Career and Technical Education.

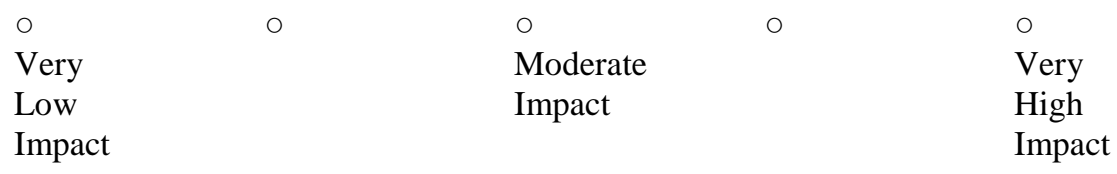

Please rate your perception of the desirability of the event.

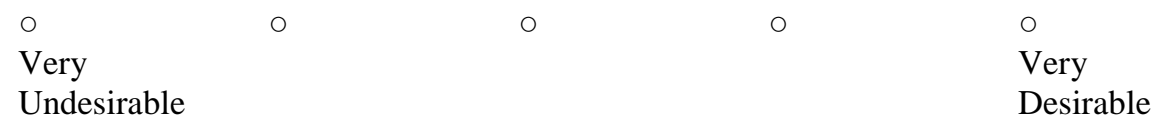




\section{Question 37}

Modernizing CTE centers will be vital in maintaining an edge in the labor market.

Please select the time frame you believe is most appropriate.

$\begin{array}{lllll}\circ & \circ & \circ & \circ & \circ \\ \text { Never } & \text { Immediate } & \text { Mid-Range } & \text { Long-Range } & \text { Beyond 20 Years } \\ & (1-3 \text { years }) & (4-10 \text { years }) & (11-20 \text { years }) & \end{array}$

If you believe the event will occur, please rate the degree of impact to Career and Technical Education.

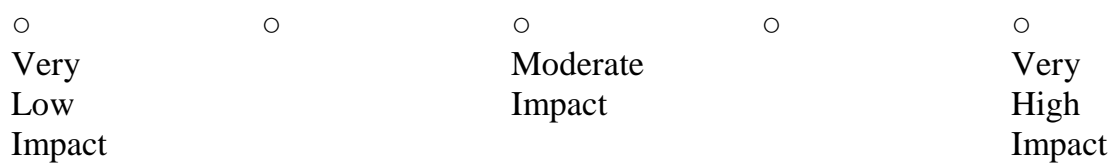

Please rate your perception of the desirability of the event.

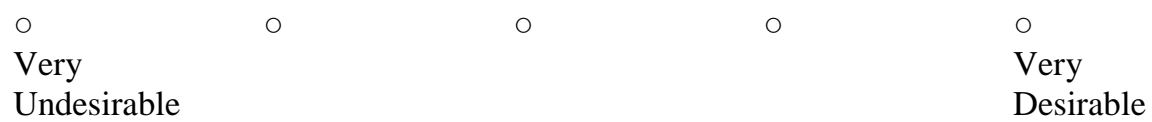

Question 38

Career and technical education will play a major role in STEM (Science, Technology, Engineering and Mathematics) education.

Please select the time frame you believe is most appropriate.

$\begin{array}{lllll}\circ & \circ & \circ & \circ & \circ \\ \text { Never } & \text { Immediate } & \text { Mid-Range } & \text { Long-Range } & \text { Beyond 20 Years } \\ & (1-3 \text { years }) & (4-10 \text { years }) & (11-20 \text { years }) & \end{array}$

If you believe the event will occur, please rate the degree of impact to Career and Technical Education.

\begin{tabular}{|c|c|c|c|c|}
\hline 0 & 0 & 0 & 0 & 0 \\
\hline Very & & Moderate & & Very \\
\hline Low & & Impact & & High \\
\hline Impact & & & & Impact \\
\hline
\end{tabular}

Please rate your perception of the desirability of the event.

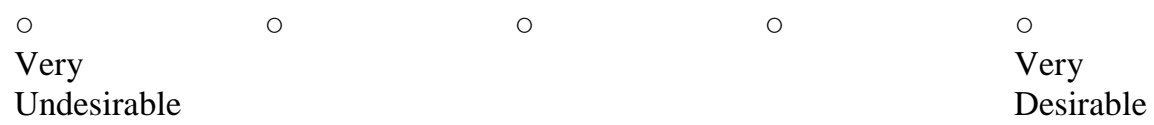




\section{Question 39}

Career and technical education will include the teaching of soft skills such as the ability to work well together in its programming.

Please select the time frame you believe is most appropriate.

$\begin{array}{lllll}\circ \text { Never } & \circ & \circ & \circ & \circ \\ & \begin{array}{l}\text { Immediate } \\ (1-3 \text { years })\end{array} & \begin{array}{l}\text { Mid-Range } \\ (4-10 \text { years })\end{array} & \begin{array}{l}\text { Long-Range } \\ (11-20 \text { years })\end{array} & \text { Beyond } 20 \text { Years }\end{array}$

If you believe the event will occur, please rate the degree of impact to Career and Technical Education.

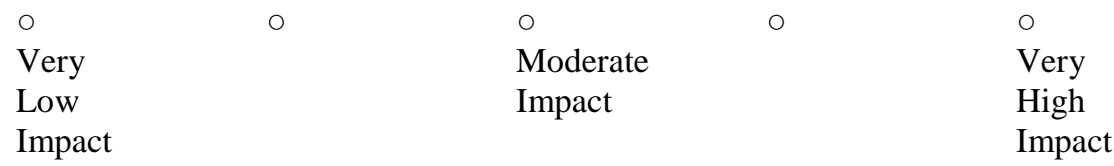

Please rate your perception of the desirability of the event.

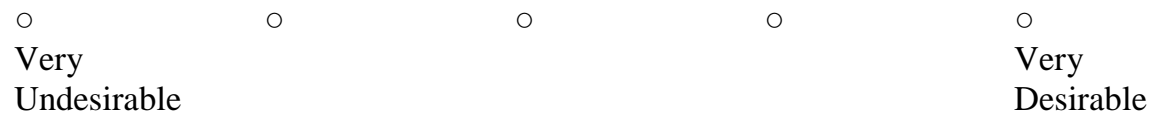

Question 40

Career development of life-long learners at ALL levels will become very important as we move from the manufacturing model to individualization.

Please select the time frame you believe is most appropriate.

$\begin{array}{lllll}\circ & \circ & \circ & \circ & \circ \\ \text { Never } & \begin{array}{l}\text { Immediate } \\ (1-3 \text { years })\end{array} & \begin{array}{l}\text { Mid-Range } \\ (4-10 \text { years })\end{array} & \begin{array}{l}\text { Long-Range } \\ (11-20 \text { years })\end{array} & \text { Beyond 20 Years }\end{array}$

If you believe the event will occur, please rate the degree of impact to Career and Technical Education.

$\begin{array}{llll}\circ & \circ & \circ & \circ \\ \text { Very } & \text { Moderate } & \text { Very } \\ \text { Low } & \text { Impact } & \text { High } \\ \text { Impact } & & \text { Impact }\end{array}$

Please rate your perception of the desirability of the event.

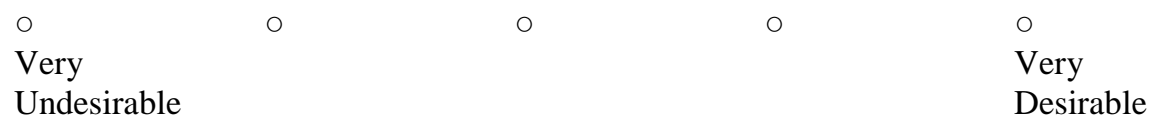




\section{Question 41}

Societal changes and more ethnic diversity will occur at a faster rate thus increasing the need to understand and tolerate the cultural needs and function of others amongst us.

Please select the time frame you believe is most appropriate.

$\begin{array}{lllll}\circ & \circ & \circ & \circ & \circ \\ \text { Never } & \text { Immediate } & \begin{array}{l}\text { Mid-Range } \\ (1-3 \text { years })\end{array} & \begin{array}{l}\text { Long-Range } \\ (1-10 \text { years })\end{array} & \text { Beyond 20 Years } \\ & & \end{array}$

If you believe the event will occur, please rate the degree of impact to Career and Technical Education.

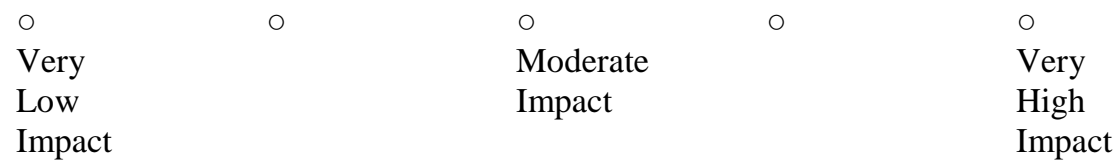

Please rate your perception of the desirability of the event.

$\begin{array}{llll}\circ & \circ & 0 & \circ \\ \text { Very } & & & 0 \\ \text { Undesirable } & & & \text { Very } \\ & & \text { Desirable }\end{array}$

Question 42

Instructional technology (ex. virtual learning) will increase its presence as a course delivery component.

Please select the time frame you believe is most appropriate.

$\begin{array}{lllll}\circ & \circ & \circ & \circ & \circ \\ \text { Never } & \text { Immediate } & \text { Mid-Range } & \text { Long-Range } & \text { Beyond 20 Years } \\ & (1-3 \text { years }) & (4-10 \text { years }) & (11-20 \text { years }) & \end{array}$

If you believe the event will occur, please rate the degree of impact to Career and Technical Education.

\begin{tabular}{|c|c|c|c|c|}
\hline 0 & 0 & 0 & 0 & 0 \\
\hline Very & & Moderate & & Very \\
\hline Low & & Impact & & High \\
\hline Impact & & & & Impact \\
\hline
\end{tabular}

Please rate your perception of the desirability of the event.

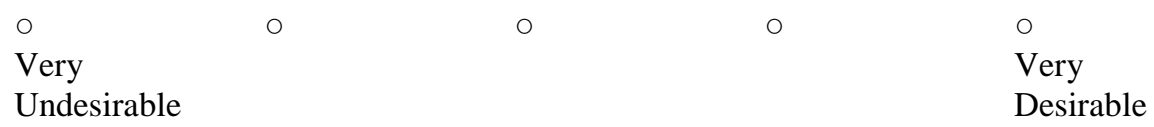




\section{Question 43}

Technology advances will continue to drive curriculum and program changes increasing learning outside of the brick walls at all levels.

Please select the time frame you believe is most appropriate.

$\begin{array}{lllll}\circ \text { Never } & \circ & \circ & \circ & \circ \\ & \begin{array}{l}\text { Immediate } \\ (1-3 \text { years })\end{array} & \begin{array}{l}\text { Mid-Range } \\ (4-10 \text { years })\end{array} & \begin{array}{l}\text { Long-Range } \\ (11-20 \text { years })\end{array} & \text { Beyond } 20 \text { Years }\end{array}$

If you believe the event will occur, please rate the degree of impact to Career and Technical Education.

$\begin{array}{llll}\circ & \circ & \circ & \circ \\ \text { Very } & \text { Moderate } & \text { Very } \\ \text { Low } & \text { Impact } & \text { High } \\ \text { Impact } & & \text { Impact }\end{array}$

Please rate your perception of the desirability of the event.

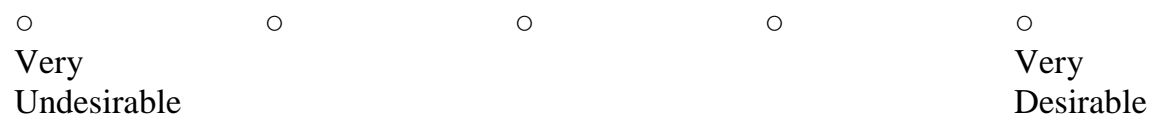

Question 44

Change in public education will be strongly influenced by outside innovators.

Please select the time frame you believe is most appropriate.

$\begin{array}{lllll}\circ & \circ & \circ & \circ & \circ \\ \text { Never } & \begin{array}{l}\text { Immediate } \\ \text { (1-3 years })\end{array} & \begin{array}{l}\text { Mid-Range } \\ (4-10 \text { years })\end{array} & \begin{array}{l}\text { Long-Range } \\ (11-20 \text { years })\end{array} & \text { Beyond } 20 \text { Years }\end{array}$

If you believe the event will occur, please rate the degree of impact to Career and Technical Education.

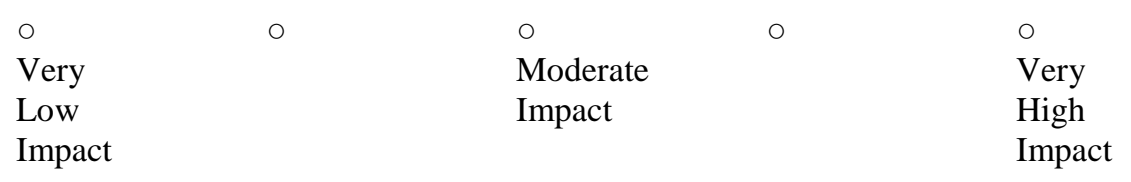

Please rate your perception of the desirability of the event.

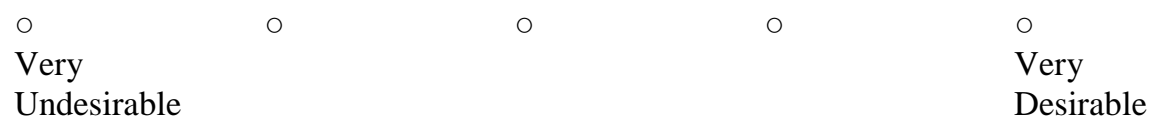




\section{Question 45}

Project-based and work-based learning will become more common.

Please select the time frame you believe is most appropriate.

$\begin{array}{lllll}\circ & \circ & \circ & \circ & \circ \\ \text { Never } & \text { Immediate } & \text { Mid-Range } & \text { Long-Range } & \text { Beyond 20 Years } \\ & (1-3 \text { years }) & (4-10 \text { years }) & (11-20 \text { years }) & \end{array}$

If you believe the event will occur, please rate the degree of impact to Career and Technical Education.

\begin{tabular}{|c|c|c|c|c|}
\hline 0 & 0 & 0 & 0 & 0 \\
\hline Very & & Moderate & & Very \\
\hline Low & & Impact & & High \\
\hline
\end{tabular}

Please rate your perception of the desirability of the event.

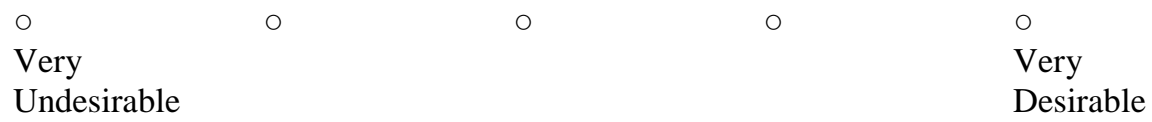

\section{Question 46}

The use of technology to drive the teaching and learning process will become common place.

Please select the time frame you believe is most appropriate.

$\begin{array}{lllll}\circ & \circ & \circ & \circ & \circ \\ \text { Never } & \text { Immediate } & \text { Mid-Range } & \text { Long-Range } & \text { Beyond 20 Years } \\ & (1-3 \text { years }) & (4-10 \text { years }) & (11-20 \text { years }) & \end{array}$

If you believe the event will occur, please rate the degree of impact to Career and Technical Education.

\begin{tabular}{|c|c|c|c|}
\hline 0 & 0 & 0 & 0 \\
\hline Very & & Moderate & Very \\
\hline Low & & Impact & High \\
\hline Impact & & & Impact \\
\hline
\end{tabular}

Please rate your perception of the desirability of the event.

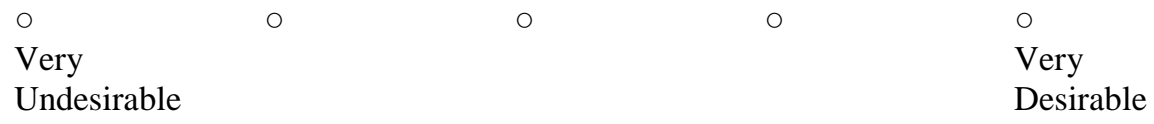




\section{Political Issues}

\section{Question 47}

Student flight from low performance public schools to other viable options will occur.

Please select the time frame you believe is most appropriate.

$\begin{array}{lllll}\circ & \circ & \circ & \circ & \circ \\ \text { Never } & \begin{array}{l}\text { Immediate } \\ (1-3 \text { years })\end{array} & \begin{array}{l}\text { Mid-Range } \\ (4-10 \text { years })\end{array} & \begin{array}{l}\text { Long-Range } \\ (11-20 \text { years })\end{array} & \text { Beyond } 20 \text { Years }\end{array}$

If you believe the event will occur, please rate the degree of impact to Career and Technical Education.

$\begin{array}{llll}\circ & \circ & \circ & \circ \\ \text { Very } & \text { Moderate } & \text { Very } \\ \text { Low } & \text { Impact } & \text { High } \\ \text { Impact } & & \text { Impact }\end{array}$

Please rate your perception of the desirability of the event.

$\begin{array}{lllll}0 & 0 & 0 & 0\end{array}$

Very Very

Undesirable Desirable

Question 48

Current education hierarchies will be challenged, especially the school board authority, will be eliminated as an archaic way of running a school system.

Please select the time frame you believe is most appropriate.

$\begin{array}{lllll}\circ & \circ & \circ & \circ & \circ \\ \text { Never } & \begin{array}{l}\text { Immediate } \\ (1-3 \text { years })\end{array} & \begin{array}{l}\text { Mid-Range } \\ (4-10 \text { years })\end{array} & \begin{array}{l}\text { Long-Range } \\ (11-20 \text { years })\end{array} & \text { Beyond } 20 \text { Years }\end{array}$

If you believe the event will occur, please rate the degree of impact to Career and Technical Education.

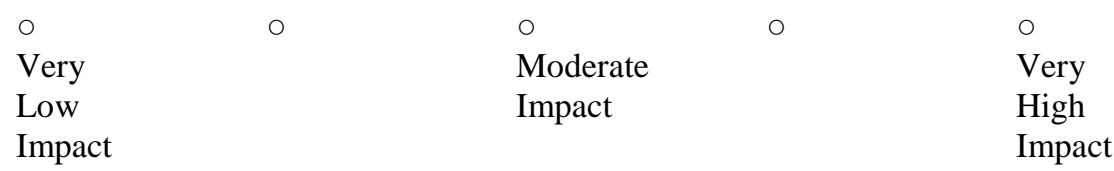

Please rate your perception of the desirability of the event.

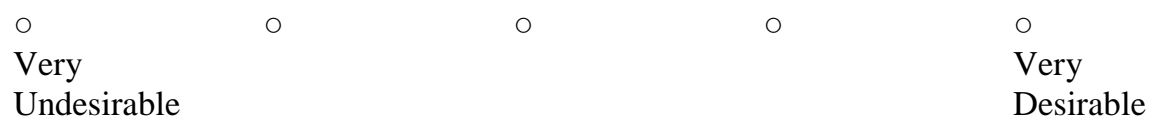




\section{Question 49}

There will be a concentrated evaluation of the qualifications for County (or Regional) Board of Education membership---there will be a requirement that individuals have some interest in or value for education and the public schools - and, perhaps, even some education themselves, which will take the credibility and influence of Board Members up several notches.

Please select the time frame you believe is most appropriate.

$\begin{array}{lllll}\circ & \circ & \circ & \circ & \circ \\ \text { Never } & \text { Immediate } & \begin{array}{l}\text { Mid-Range } \\ (1-3 \text { years })\end{array} & \begin{array}{l}\text { Long-Range } \\ (1-10 \text { years })\end{array} & \text { Beyond 20 Years } \\ & \text { (11-20 years }) & \end{array}$

If you believe the event will occur, please rate the degree of impact to Career and Technical Education.

$\begin{array}{llll}\circ & \circ & \circ & \circ \\ \text { Very } & \text { Moderate } & \\ \text { Low } & \text { Impact } & \text { Very } \\ \text { Impact } & & \text { High } \\ & & \text { Impact }\end{array}$

Please rate your perception of the desirability of the event.

O

Very

Undesirable
○

0

$\begin{array}{ll}\circ & \\ \text { Very } \\ \text { Desirable }\end{array}$

Question 50

Decision and policy makers will realize the gravity of allowing CTE to continue as the dumping ground for students who cannot succeed in the general education classroom.

Please select the time frame you believe is most appropriate.

$\begin{array}{lllll}\circ \text { Never } & \circ & \circ & \circ & \circ \\ & \begin{array}{l}\text { Immediate } \\ (1-3 \text { years })\end{array} & \begin{array}{l}\text { Mid-Range } \\ (4-10 \text { years })\end{array} & \begin{array}{l}\text { Long-Range } \\ (11-20 \text { years })\end{array} & \text { Beyond } 20 \text { Years }\end{array}$

If you believe the event will occur, please rate the degree of impact to Career and Technical Education.

$\begin{array}{llll}\circ & \circ & \circ & \circ \\ \text { Very } & \text { Moderate } & \\ \text { Low } & \text { Impact } & \text { Very } \\ \text { Impact } & & \text { High } \\ & & \text { Impact }\end{array}$

Please rate your perception of the desirability of the event.

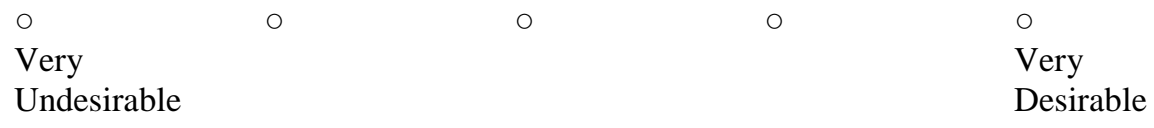




\section{Question 51}

Public education will remain but there will be expansion of private sector education and new hybrids of publicprivate sector partnerships.

Please select the time frame you believe is most appropriate.

$\begin{array}{lllll}\circ & \circ & \circ & \circ & \circ \\ \text { Never } & \begin{array}{l}\text { Immediate } \\ (1-3 \text { years })\end{array} & \begin{array}{l}\text { Mid-Range } \\ (4-10 \text { years })\end{array} & \begin{array}{l}\text { Long-Range } \\ (11-20 \text { years })\end{array} & \text { Beyond 20 Years }\end{array}$

If you believe the event will occur, please rate the degree of impact to Career and Technical Education.

$\begin{array}{llll}\circ & \circ & \circ & \circ \\ \text { Very } & \text { Moderate } & \text { Very } \\ \text { Low } & \text { Impact } & \text { High } \\ \text { Impact } & & \text { Impact }\end{array}$

Please rate your perception of the desirability of the event.

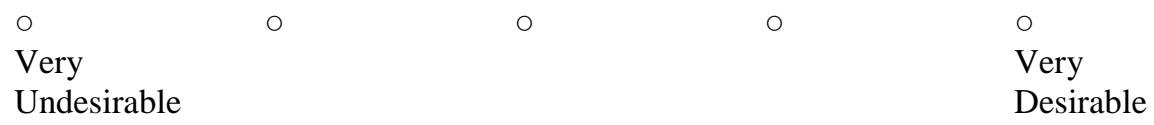

Question 52

High school dropout rates will continue to climb due to a disengaged student population from middle school upward.

Please select the time frame you believe is most appropriate.

$\begin{array}{lllll}\circ & \circ & \circ & \circ & \circ \\ \text { Never } & \begin{array}{l}\text { Immediate } \\ (1-3 \text { years })\end{array} & \begin{array}{l}\text { Mid-Range } \\ (4-10 \text { years })\end{array} & \begin{array}{l}\text { Long-Range } \\ (11-20 \text { years })\end{array} & \text { Beyond } 20 \text { Years }\end{array}$

If you believe the event will occur, please rate the degree of impact to Career and Technical Education.

$\begin{array}{llll}\circ & \circ & \circ & \circ \\ \text { Very } & \text { Moderate } & \\ \text { Low } & \text { Impact } & \text { Very } \\ \text { Impact } & & \text { High } \\ & & \text { Impact }\end{array}$

Please rate your perception of the desirability of the event.

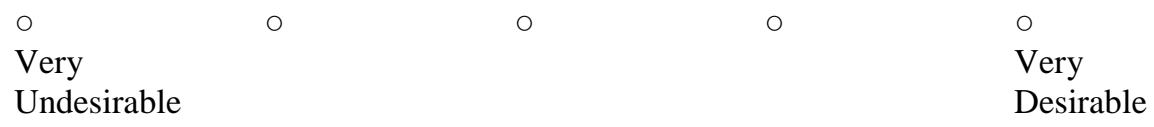




\section{Question 53}

Career and technical education facilities and programs will have a strong, vocal and informed voice on Capitol Hill.

Please select the time frame you believe is most appropriate.

\begin{tabular}{|c|c|c|c|c|}
\hline 0 & 0 & 0 & 0 & 0 \\
\hline Never & $\begin{array}{l}\text { Immediate } \\
\text { (1-3 years) }\end{array}$ & $\begin{array}{l}\text { Mid-Range } \\
\text { (4-10 years) }\end{array}$ & $\begin{array}{l}\text { Long-Range } \\
\text { (11-20 years) }\end{array}$ & Beyond 20 Years \\
\hline
\end{tabular}

If you believe the event will occur, please rate the degree of impact to Career and Technical Education.

\begin{tabular}{|c|c|c|}
\hline \multirow[b]{3}{*}{ Low } & 0 & 0 \\
\hline & & Moderate \\
\hline & & Impact \\
\hline
\end{tabular}

Please rate your perception of the desirability of the event.

$\begin{array}{llll}\circ & \circ & 0 & \circ \\ \text { Very } & & & 0 \\ \text { Undesirable } & & & \text { Very } \\ & & \text { Desirable }\end{array}$

\section{Question 54}

Global, national, state, regional and local economic changes cause greater shifts in the wealth of populations.

Please select the time frame you believe is most appropriate.

$\begin{array}{lllll}\circ & \circ & \circ & \circ & \circ \\ \text { Never } & \text { Immediate } & \text { Mid-Range } & \text { Long-Range } & \text { Beyond 20 Years } \\ & (1-3 \text { years }) & (4-10 \text { years }) & (11-20 \text { years }) & \end{array}$

If you believe the event will occur, please rate the degree of impact to Career and Technical Education.

\begin{tabular}{|c|c|c|c|c|}
\hline 0 & 0 & 0 & 0 & 0 \\
\hline Very & & Moderate & & Very \\
\hline Low & & Impact & & High \\
\hline Impact & & & & Impact \\
\hline
\end{tabular}

Please rate your perception of the desirability of the event.

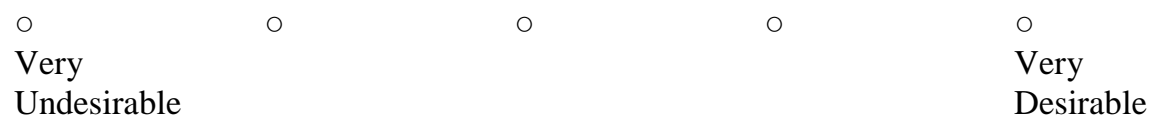




\section{Question 55}

China and India will control the world economically pushing the United States to get very serious about creating, implementing and marketing innovation.

Please select the time frame you believe is most appropriate.

$\begin{array}{lllll}\circ \text { Never } & \circ & \circ & \circ & \circ \\ & \begin{array}{l}\text { Immediate } \\ (1-3 \text { years })\end{array} & \begin{array}{l}\text { Mid-Range } \\ (4-10 \text { years })\end{array} & \begin{array}{l}\text { Long-Range } \\ (11-20 \text { years })\end{array} & \text { Beyond } 20 \text { Years }\end{array}$

If you believe the event will occur, please rate the degree of impact to Career and Technical Education.

$\begin{array}{llll}\circ & \circ & \circ & \circ \\ \text { Very } & \text { Moderate } & \text { Very } \\ \text { Low } & \text { Impact } & \text { High } \\ \text { Impact } & & \text { Impact }\end{array}$

Please rate your perception of the desirability of the event.

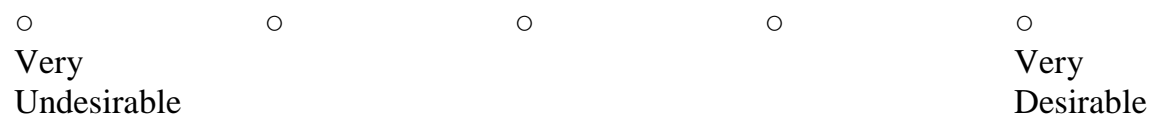

Question 56

Social systems move from the old manufacturing models of education, work and life to one where individuals decide what path they want to follow to fit in the global scheme.

Please select the time frame you believe is most appropriate.

$\begin{array}{lllll}\circ & \circ & \circ & \circ & \circ \\ \text { Never } & \begin{array}{l}\text { Immediate } \\ (1-3 \text { years })\end{array} & \begin{array}{l}\text { Mid-Range } \\ (4-10 \text { years })\end{array} & \begin{array}{l}\text { Long-Range } \\ (11-20 \text { years })\end{array} & \text { Beyond 20 Years }\end{array}$

If you believe the event will occur, please rate the degree of impact to Career and Technical Education.

$\begin{array}{llll}\circ & \circ & \circ & \circ \\ \text { Very } & \text { Moderate } & \\ \text { Low } & \text { Impact } & \text { Very } \\ \text { Impact } & & \text { High } \\ & & \text { Impact }\end{array}$

Please rate your perception of the desirability of the event.

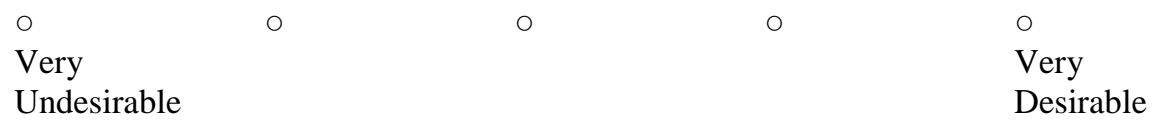




\section{Personnel}

Question 57

Educators in career and technical education fields will be required to hold postsecondary degrees (associate, bachelor or master).

Please select the time frame you believe is most appropriate.

$\begin{array}{lllll}\circ & \circ & \circ & \circ & \circ \\ \text { Never } & \text { Immediate } & \begin{array}{l}\text { Mid-Range } \\ (1-3 \text { years })\end{array} & \begin{array}{l}\text { Long-Range } \\ (1-10 \text { years })\end{array} & \text { Beyond 20 Years } \\ & \text { (11-20 years }) & \end{array}$

If you believe the event will occur, please rate the degree of impact to Career and Technical Education.

$\begin{array}{lll}\circ & \circ & \circ \\ \text { Very } & \text { Moderate } & \circ \\ \text { Low } & \text { Impact } & \text { Very } \\ \text { Impact } & & \text { High } \\ & & \text { Impact }\end{array}$

Please rate your perception of the desirability of the event.

O

Very

Undesirable
○

0
○ $\quad 0$

Very

Desirable

Question 58

Career and technical education teachers will be required to hold industry certification.

Please select the time frame you believe is most appropriate.

\begin{tabular}{|c|c|c|c|c|}
\hline 0 & 0 & o & o & 0 \\
\hline Never & $\begin{array}{l}\text { Immediate } \\
\text { (1-3 years) }\end{array}$ & $\begin{array}{l}\text { Mid-Range } \\
(4-10 \text { years) }\end{array}$ & $\begin{array}{l}\text { Long-Range } \\
\text { (11-20 years) }\end{array}$ & Beyond 20 Years \\
\hline
\end{tabular}

If you believe the event will occur, please rate the degree of impact to Career and Technical Education.

\begin{tabular}{|c|c|c|c|}
\hline \multirow{4}{*}{$\begin{array}{l}\text { O } \\
\text { Very } \\
\text { Low } \\
\text { Impa }\end{array}$} & 0 & 0 & 0 \\
\hline & & Moderate & \\
\hline & & Impact & \\
\hline & & & \\
\hline
\end{tabular}

Please rate your perception of the desirability of the event.

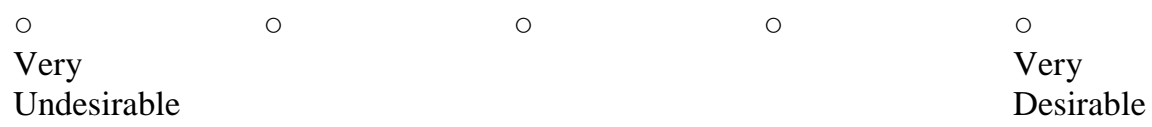




\section{Question 59}

The demand for CTE teachers will increase.

Please select the time frame you believe is most appropriate.

$\begin{array}{lllll}\circ & \circ & \circ & \circ & \circ \\ \text { Never } & \text { Immediate } & \text { Mid-Range } & \text { Long-Range } & \text { Beyond 20 Years } \\ & (1-3 \text { years }) & (4-10 \text { years }) & (11-20 \text { years }) & \end{array}$

If you believe the event will occur, please rate the degree of impact to Career and Technical Education.

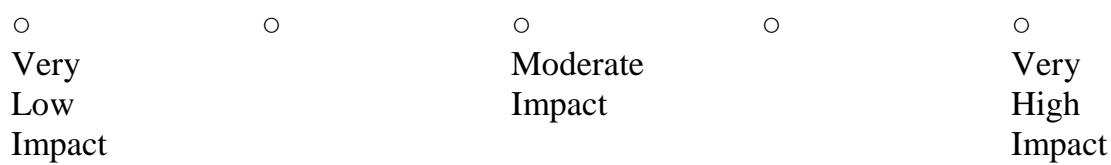

Please rate your perception of the desirability of the event.

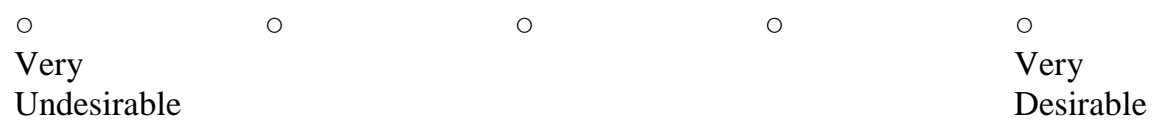

Question 60

Teacher education programs for CTE teachers will change significantly as a result of the blending of technical and academic delivery.

Please select the time frame you believe is most appropriate.

$\begin{array}{lllll}\circ & \circ & \circ & \circ & \circ \\ \text { Never } & \text { Immediate } & \text { Mid-Range } & \text { Long-Range } & \text { Beyond 20 Years } \\ & (1-3 \text { years }) & (4-10 \text { years }) & (11-20 \text { years }) & \end{array}$

If you believe the event will occur, please rate the degree of impact to Career and Technical Education.

\begin{tabular}{|c|c|c|c|c|}
\hline 0 & 0 & 0 & 0 & 0 \\
\hline Very & & Moderate & & Very \\
\hline Low & & Impact & & High \\
\hline Impact & & & & Impact \\
\hline
\end{tabular}

Please rate your perception of the desirability of the event.

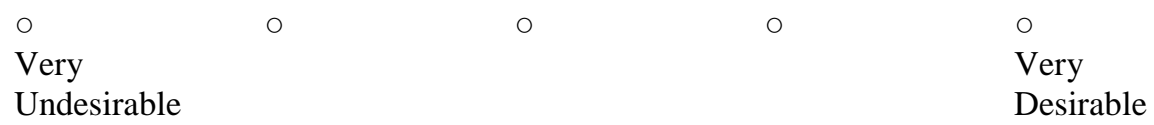




\section{Question 61}

There will be a teacher education tract in higher education for those wishing to pursue a career in industrial, technical or health occupations education much like regular education fields.

Please select the time frame you believe is most appropriate.

$\begin{array}{lllll}\circ & \circ & \circ & \circ & \circ \\ \text { Never } & \begin{array}{l}\text { Immediate } \\ (1-3 \text { years })\end{array} & \begin{array}{l}\text { Mid-Range } \\ (4-10 \text { years })\end{array} & \begin{array}{l}\text { Long-Range } \\ (11-20 \text { years })\end{array} & \text { Beyond 20 Years }\end{array}$

If you believe the event will occur, please rate the degree of impact to Career and Technical Education.

$\begin{array}{llll}\circ & \circ & \circ & \circ \\ \text { Very } & \text { Moderate } & \text { Very } \\ \text { Low } & \text { Impact } & \text { High } \\ \text { Impact } & & \text { Impact }\end{array}$

Please rate your perception of the desirability of the event.

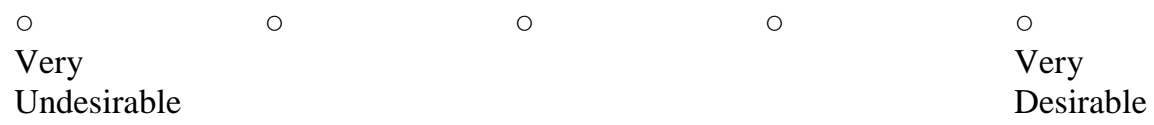

\section{Question 62}

Many teachers will be part-time as opposed to full-time.

Please select the time frame you believe is most appropriate.

$\begin{array}{lllll}\circ & \circ & \circ & \circ & \circ \\ \text { Never } & \begin{array}{l}\text { Immediate } \\ \text { (1-3 years })\end{array} & \begin{array}{l}\text { Mid-Range } \\ (4-10 \text { years })\end{array} & \begin{array}{l}\text { Long-Range } \\ (11-20 \text { years })\end{array} & \text { Beyond } 20 \text { Years }\end{array}$

If you believe the event will occur, please rate the degree of impact to Career and Technical Education.

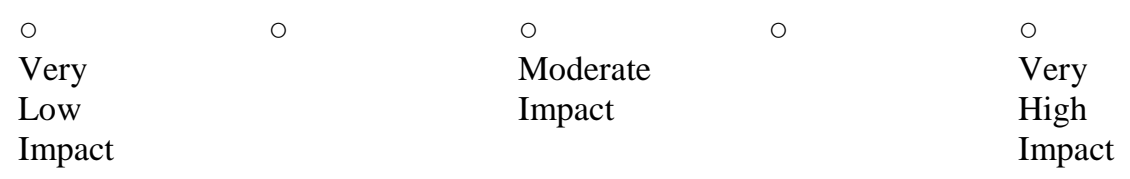

Please rate your perception of the desirability of the event.

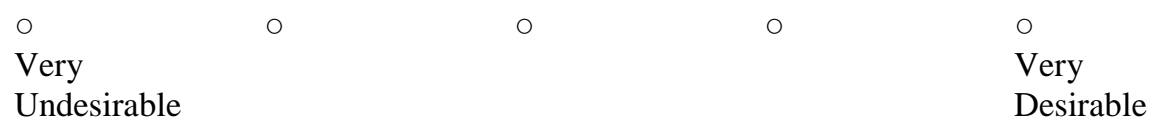




\section{Question 63}

CTE performance based educator pay will come to the forefront.

Please select the time frame you believe is most appropriate.

$\begin{array}{lllll}\circ & \circ & \circ & \circ & \circ \\ \text { Never } & \text { Immediate } & \text { Mid-Range } & \text { Long-Range } & \text { Beyond 20 Years } \\ & (1-3 \text { years }) & (4-10 \text { years }) & (11-20 \text { years }) & \end{array}$

If you believe the event will occur, please rate the degree of impact to Career and Technical Education.

\begin{tabular}{|c|c|c|c|c|}
\hline 0 & 0 & 0 & 0 & 0 \\
\hline Very & & Moderate & & Very \\
\hline Low & & Impact & & High \\
\hline
\end{tabular}

Please rate your perception of the desirability of the event.

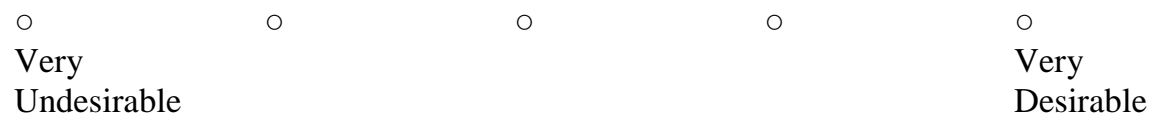

\section{Question 64}

CTE instructors must understand and participate in professional development activities to prepare them for the subjects being taught and with a variety of strategies.

Please select the time frame you believe is most appropriate.

$\begin{array}{lllll}\circ & \circ & \circ & \circ & \circ \\ \text { Never } & \text { Immediate } & \text { Mid-Range } & \text { Long-Range } & \text { Beyond 20 Years } \\ & (1-3 \text { years }) & (4-10 \text { years }) & (11-20 \text { years }) & \end{array}$

If you believe the event will occur, please rate the degree of impact to Career and Technical Education.

\begin{tabular}{|c|c|c|c|c|}
\hline 0 & 0 & 0 & 0 & 0 \\
\hline Very & & Moderate & & Very \\
\hline Low & & Impact & & High \\
\hline Impact & & & & Impact \\
\hline
\end{tabular}

Please rate your perception of the desirability of the event.

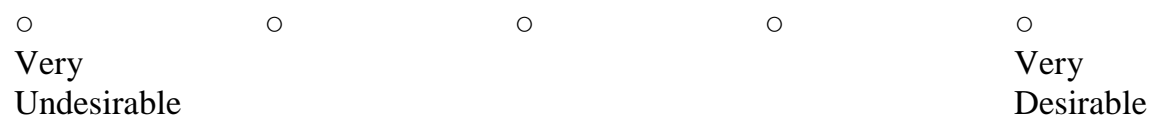




\section{Question 65}

CTE programs will have great teachers who foster passion and curiosity.

Please select the time frame you believe is most appropriate.

$\begin{array}{lllll}\circ & \circ & \circ & \circ & \circ \\ \text { Never } & \text { Immediate } & \text { Mid-Range } & \text { Long-Range } & \text { Beyond 20 Years } \\ & (1-3 \text { years }) & (4-10 \text { years }) & (11-20 \text { years }) & \end{array}$

If you believe the event will occur, please rate the degree of impact to Career and Technical Education.

\begin{tabular}{|c|c|c|c|c|}
\hline 0 & 0 & 0 & 0 & 0 \\
\hline Very & & Moderate & & Very \\
\hline Low & & Impact & & High \\
\hline
\end{tabular}

Please rate your perception of the desirability of the event.

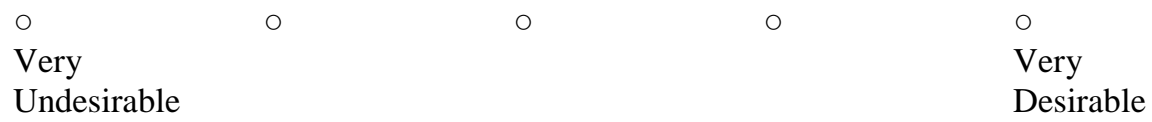

\section{Question 66}

Secondary school counselors will be informed and cognizant of the opportunities awaiting students in CTE programming.

Please select the time frame you believe is most appropriate.

$\begin{array}{lllll}\circ & \circ & \circ & \circ & \circ \\ \text { Never } & \text { Immediate } & \text { Mid-Range } & \text { Long-Range } & \text { Beyond 20 Years } \\ & (1-3 \text { years }) & (4-10 \text { years }) & (11-20 \text { years }) & \end{array}$

If you believe the event will occur, please rate the degree of impact to Career and Technical Education.

\begin{tabular}{|c|c|c|c|c|}
\hline 0 & 0 & 0 & 0 & 0 \\
\hline Very & & Moderate & & Very \\
\hline Low & & Impact & & High \\
\hline Impact & & & & Impact \\
\hline
\end{tabular}

Please rate your perception of the desirability of the event.

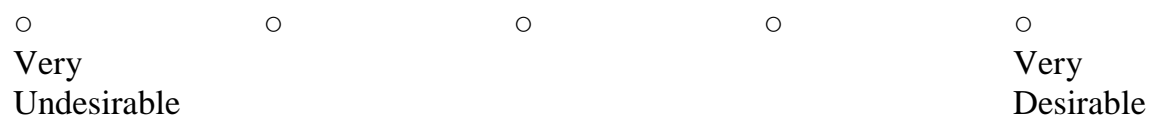




\section{Question 67}

Stakeholders in various realms of education (CTE, secondary, post-secondary, general secondary, higher ed) will emerge steadily as important informants and collaborators in not only evaluating, but also planning and execution instructional programs.

Please select the time frame you believe is most appropriate.

$\begin{array}{lllll}\circ & \circ & \circ & \circ & \circ \\ \text { Never } & \begin{array}{l}\text { Immediate } \\ \text { (1-3 years })\end{array} & \begin{array}{l}\text { Mid-Range } \\ (4-10 \text { years })\end{array} & \begin{array}{l}\text { Long-Range } \\ (11-20 \text { years })\end{array} & \text { Beyond } 20 \text { Years }\end{array}$

If you believe the event will occur, please rate the degree of impact to Career and Technical Education.

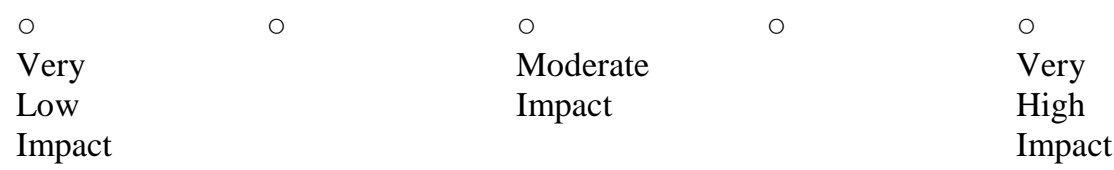

Please rate your perception of the desirability of the event.

$\begin{array}{lllll}0 & 0 & 0 & 0\end{array}$

Very Very

Undesirable Desirable

Question 68

CTE Administrator preparation programs will be designed to better equip principals in the career and technical education realm.

Please select the time frame you believe is most appropriate.

$\begin{array}{lllll}\circ & \circ & \circ & \circ & \circ \\ \text { Never } & \begin{array}{l}\text { Immediate } \\ (1-3 \text { years })\end{array} & \begin{array}{l}\text { Mid-Range } \\ (4-10 \text { years })\end{array} & \begin{array}{l}\text { Long-Range } \\ (11-20 \text { years })\end{array} & \text { Beyond } 20 \text { Years }\end{array}$

If you believe the event will occur, please rate the degree of impact to Career and Technical Education.

$\begin{array}{llll}\circ & \circ & \circ & \circ \\ \text { Very } & \text { Moderate } & \text { Very } \\ \text { Low } & \text { Impact } & \text { High } \\ \text { Impact } & & \text { Impact }\end{array}$

Please rate your perception of the desirability of the event.

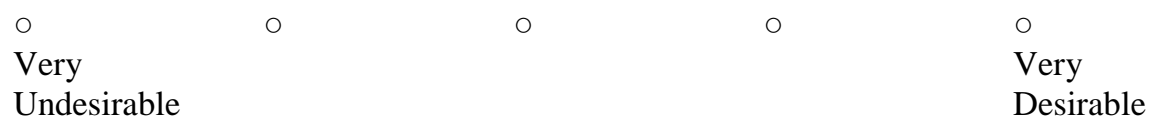




\section{Question 69}

There will be a shift in CTE governance resulting in an increase in contact between local educators and state/regional leaders.

Please select the time frame you believe is most appropriate.

$\begin{array}{lllll}\circ \text { Never } & \circ & \circ & \circ & \circ \\ & \begin{array}{l}\text { Immediate } \\ (1-3 \text { years })\end{array} & \begin{array}{l}\text { Mid-Range } \\ (4-10 \text { years })\end{array} & \begin{array}{l}\text { Long-Range } \\ (11-20 \text { years })\end{array} & \text { Beyond } 20 \text { Years }\end{array}$

If you believe the event will occur, please rate the degree of impact to Career and Technical Education.

$\begin{array}{llll}\circ & \circ & \circ & \circ \\ \text { Very } & \text { Moderate } & \\ \text { Low } & \text { Impact } & \text { Very } \\ \text { Impact } & & \text { High } \\ & & \text { Impact }\end{array}$

Please rate your perception of the desirability of the event.

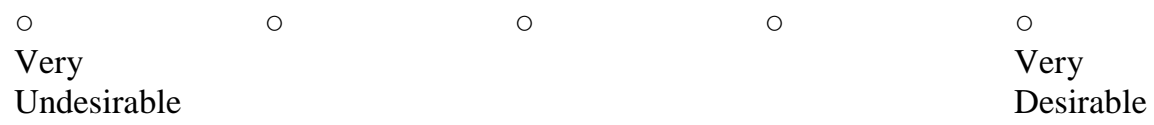

Question 70

Faculty will become consultants to students, who will become clients, while the students will become innovators and entrepreneurs.

Please select the time frame you believe is most appropriate.

$\begin{array}{lllll}\circ & \circ & \circ & \circ & \circ \\ \text { Never } & \begin{array}{l}\text { Immediate } \\ (1-3 \text { years })\end{array} & \begin{array}{l}\text { Mid-Range } \\ (4-10 \text { years })\end{array} & \begin{array}{l}\text { Long-Range } \\ (11-20 \text { years })\end{array} & \text { Beyond 20 Years }\end{array}$

If you believe the event will occur, please rate the degree of impact to Career and Technical Education.

$\begin{array}{llll}\circ & \circ & \circ & \circ \\ \text { Very } & \text { Moderate } & \text { Very } \\ \text { Low } & \text { Impact } & \text { High } \\ \text { Impact } & & \text { Impact }\end{array}$

Please rate your perception of the desirability of the event.

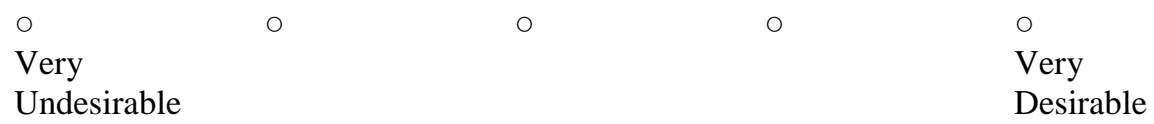




\section{Relationship with Business and Industry}

\section{Question 71}

The local industry advisory council will play a bigger role in ensuring that the lab tools and equipment are updated to meet and/or exceed the requirements of the workplace.

Please select the time frame you believe is most appropriate.

$\begin{array}{lllll}\circ \text { Never } & \circ & \circ & \circ & \circ \\ & \begin{array}{l}\text { Immediate } \\ (1-3 \text { years })\end{array} & \begin{array}{l}\text { Mid-Range } \\ (4-10 \text { years })\end{array} & \begin{array}{l}\text { Long-Range } \\ (11-20 \text { years })\end{array} & \text { Beyond } 20 \text { Years }\end{array}$

If you believe the event will occur, please rate the degree of impact to Career and Technical Education.

\begin{tabular}{|c|c|c|}
\hline 0 & 0 & 0 \\
\hline Very & Moderate & Very \\
\hline Low & Impact & High \\
\hline Impact & & Impact \\
\hline
\end{tabular}

Please rate your perception of the desirability of the event.

○

Very

Undesirable
O

C 0
O

Very

Desirable

Question 72

The demand for skilled workers will increase.

Please select the time frame you believe is most appropriate.

$\begin{array}{lllll}\circ & \circ & \circ & \circ & \circ \\ \text { Never } & \begin{array}{l}\text { Immediate } \\ \text { (1-3 years })\end{array} & \begin{array}{l}\text { Mid-Range } \\ (4-10 \text { years })\end{array} & \begin{array}{l}\text { Long-Range } \\ (11-20 \text { years })\end{array} & \text { Beyond } 20 \text { Years }\end{array}$

If you believe the event will occur, please rate the degree of impact to Career and Technical Education.

$\begin{array}{llll}\circ & \circ & \circ & \circ \\ \text { Very } & \text { Moderate } & \text { Very } \\ \text { Low } & \text { Impact } & \text { High } \\ \text { Impact } & & \text { Impact }\end{array}$

Please rate your perception of the desirability of the event.

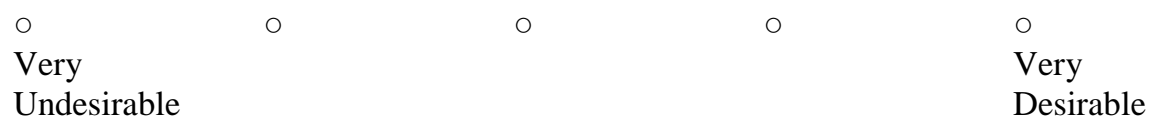




\section{Question 73}

Collaboration between stakeholders and CTE will increase.

Please select the time frame you believe is most appropriate.

$\begin{array}{lllll}\circ & \circ & \circ & \circ & \circ \\ \text { Never } & \text { Immediate } & \text { Mid-Range } & \text { Long-Range } & \text { Beyond 20 Years } \\ & (1-3 \text { years }) & (4-10 \text { years }) & (11-20 \text { years }) & \end{array}$

If you believe the event will occur, please rate the degree of impact to Career and Technical Education.

\begin{tabular}{|c|c|c|c|c|}
\hline 0 & 0 & 0 & 0 & 0 \\
\hline Very & & Moderate & & Very \\
\hline Low & & Impact & & High \\
\hline
\end{tabular}

Please rate your perception of the desirability of the event.

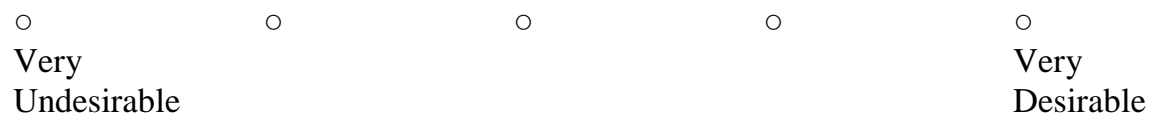

\section{Question 74}

The demand for workers with postsecondary education will increase.

Please select the time frame you believe is most appropriate.

$\begin{array}{lllll}\circ & \circ & \circ & \circ & \circ \\ \text { Never } & \text { Immediate } & \text { Mid-Range } & \text { Long-Range } & \text { Beyond 20 Years } \\ & (1-3 \text { years }) & (4-10 \text { years }) & (11-20 \text { years }) & \end{array}$

If you believe the event will occur, please rate the degree of impact to Career and Technical Education.

\begin{tabular}{|c|c|c|c|}
\hline 0 & 0 & 0 & 0 \\
\hline Very & & Moderate & Very \\
\hline Low & & Impact & High \\
\hline Impact & & & Impact \\
\hline
\end{tabular}

Please rate your perception of the desirability of the event.

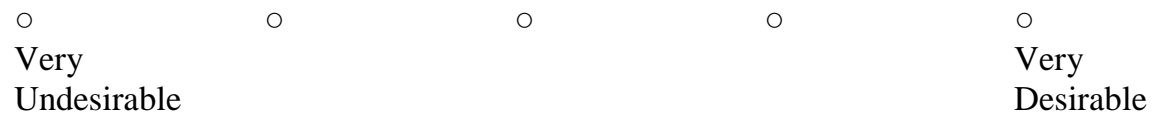




\section{Question 75}

Career and technical education will be called upon to retrain America's workforce.

Please select the time frame you believe is most appropriate.

$\begin{array}{lllll}\circ & \circ & \circ & \circ & \circ \\ \text { Never } & \text { Immediate } & \text { Mid-Range } & \text { Long-Range } & \text { Beyond 20 Years } \\ & (1-3 \text { years }) & (4-10 \text { years }) & (11-20 \text { years }) & \end{array}$

If you believe the event will occur, please rate the degree of impact to Career and Technical Education.

\begin{tabular}{|c|c|c|c|c|}
\hline 0 & 0 & 0 & 0 & 0 \\
\hline Very & & Moderate & & Very \\
\hline Low & & Impact & & High \\
\hline
\end{tabular}

Please rate your perception of the desirability of the event.

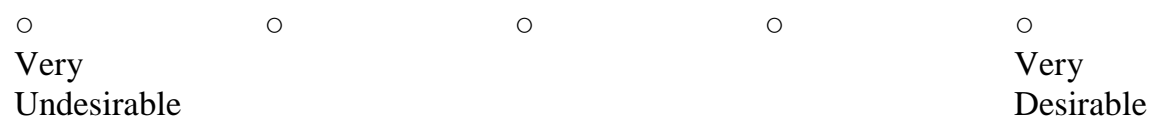

\section{Question 76}

The focus of education will be on workforce development, which will mean the alignment of education and work and the use of data to develop what programs are offered.

Please select the time frame you believe is most appropriate.

$\begin{array}{lllll}\circ & \circ & \circ & \circ & \circ \\ \text { Never } & \text { Immediate } & \text { Mid-Range } & \text { Long-Range } & \text { Beyond 20 Years } \\ & (1-3 \text { years }) & (4-10 \text { years }) & (11-20 \text { years }) & \end{array}$

If you believe the event will occur, please rate the degree of impact to Career and Technical Education.

\begin{tabular}{|c|c|c|c|c|}
\hline 0 & 0 & 0 & 0 & 0 \\
\hline Very & & Moderate & & Very \\
\hline Low & & Impact & & High \\
\hline Impact & & & & Impact \\
\hline
\end{tabular}

Please rate your perception of the desirability of the event.

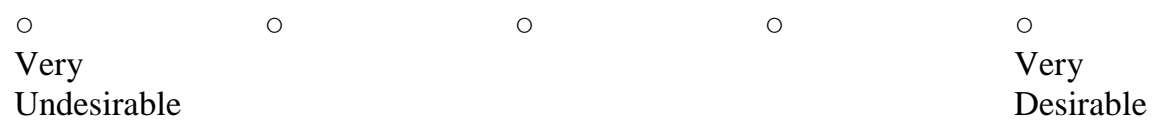




\section{Question 77}

CTE is the link that connects business leaders with educators in a unified effort to help all students understand the relevance of their education to their future goals and prepare them with the knowledge, talent and skills valued and needed in today's workplace.

Please select the time frame you believe is most appropriate.

$\begin{array}{lllll}\circ & \circ & \circ & \circ & \circ \\ \text { Never } & \begin{array}{l}\text { Immediate } \\ \text { (1-3 years })\end{array} & \begin{array}{l}\text { Mid-Range } \\ (4-10 \text { years })\end{array} & \begin{array}{l}\text { Long-Range } \\ (11-20 \text { years })\end{array} & \text { Beyond } 20 \text { Years }\end{array}$

If you believe the event will occur, please rate the degree of impact to Career and Technical Education.

$\begin{array}{llll}\circ & \circ & \circ & \circ \\ \text { Very } & \text { Moderate } & \text { Very } \\ \text { Low } & \text { Impact } & \text { High } \\ \text { Impact } & & \text { Impact }\end{array}$

Please rate your perception of the desirability of the event.

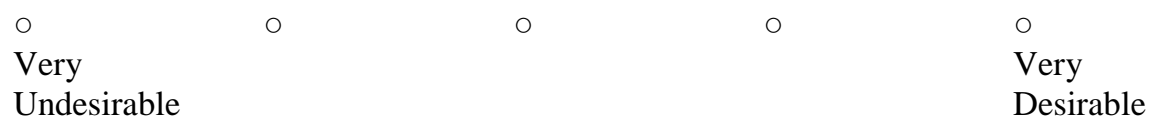

\section{Question 78}

Jobs will constantly evolve to meet workforce demand forcing constant updating for career technical education in America formulating an Innovation Society driven by continuously enhanced human capital.

Please select the time frame you believe is most appropriate.

$\begin{array}{lllll}\circ & \circ & \circ & \circ & \circ \\ \text { Never } & \begin{array}{l}\text { Immediate } \\ \text { (1-3 years })\end{array} & \begin{array}{l}\text { Mid-Range } \\ (4-10 \text { years })\end{array} & \begin{array}{l}\text { Long-Range } \\ (11-20 \text { years })\end{array} & \text { Beyond } 20 \text { Years }\end{array}$

If you believe the event will occur, please rate the degree of impact to Career and Technical Education.

$\begin{array}{llll}\circ & \circ & \circ & \circ \\ \text { Very } & \text { Moderate } & \text { Very } \\ \text { Low } & \text { Impact } & \text { High } \\ \text { Impact } & & \text { Impact }\end{array}$

Please rate your perception of the desirability of the event.

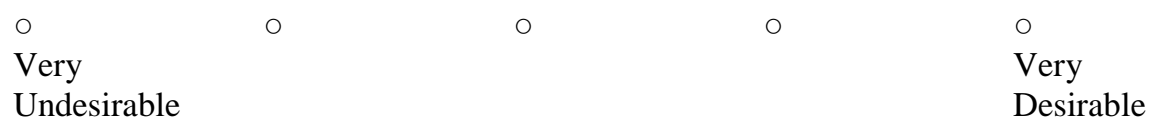




\section{Question 79}

All students will seek more specific technical skills training in order to be more competitive in the workplace.

Please select the time frame you believe is most appropriate.

$\begin{array}{lllll}\circ & \circ & \circ & \circ & \circ \\ \text { Never } & \text { Immediate } & \text { Mid-Range } & \text { Long-Range } & \text { Beyond 20 Years } \\ & (1-3 \text { years }) & (4-10 \text { years }) & (11-20 \text { years }) & \end{array}$

If you believe the event will occur, please rate the degree of impact to Career and Technical Education.

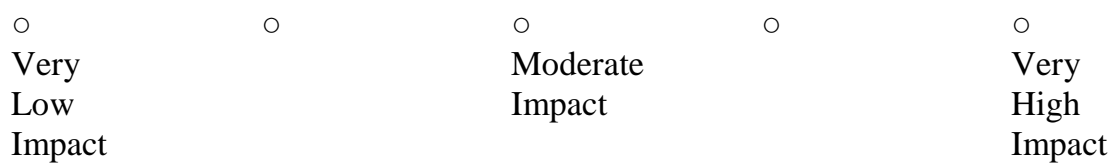

Please rate your perception of the desirability of the event.

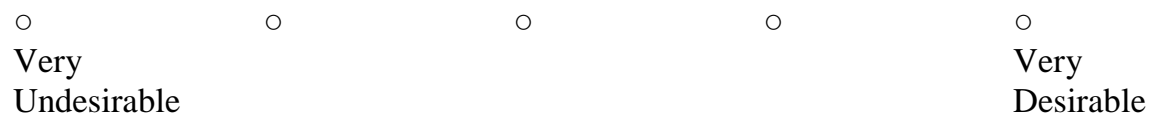

\section{Question 80}

CTE will serve as the change agent in building existing governance structures to bring state, regional and local leaders in education, workforce and economic development together to support and grow each state's economy.

Please select the time frame you believe is most appropriate.

$\begin{array}{lllll}\circ & \circ & \circ & \circ & \circ \\ \text { Never } & \text { Immediate } & \text { Mid-Range } & \text { Long-Range } & \text { Beyond 20 Years } \\ & (1-3 \text { years }) & (4-10 \text { years }) & (11-20 \text { years }) & \end{array}$

If you believe the event will occur, please rate the degree of impact to Career and Technical Education.

\begin{tabular}{|c|c|c|c|c|}
\hline 0 & 0 & 0 & 0 & 0 \\
\hline Very & & Moderate & & Very \\
\hline Low & & Impact & & High \\
\hline Impact & & & & Impact \\
\hline
\end{tabular}

Please rate your perception of the desirability of the event.

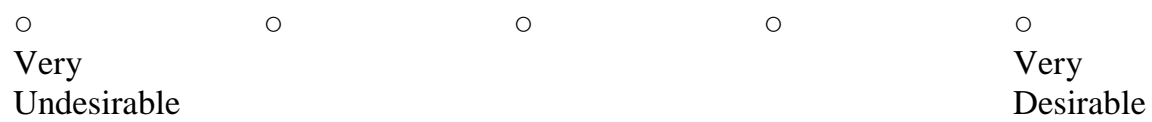




\section{Relationship with Higher Education}

Question 81

Post secondary CTE programs will be absorbed in the community college system.

Please select the time frame you believe is most appropriate.

$\begin{array}{lllll}\circ & \circ & \circ & \circ & \circ \\ \text { Never } & \begin{array}{l}\text { Immediate } \\ \text { (1-3 years })\end{array} & \begin{array}{l}\text { Mid-Range } \\ (4-10 \text { years })\end{array} & \begin{array}{l}\text { Long-Range } \\ (11-20 \text { years })\end{array} & \text { Beyond } 20 \text { Years }\end{array}$

If you believe the event will occur, please rate the degree of impact to Career and Technical Education.

$\begin{array}{llll}\circ & \circ & \circ & \circ \\ \text { Very } & \text { Moderate } & \text { Very } \\ \text { Low } & \text { Impact } & \text { High } \\ \text { Impact } & & \text { Impact }\end{array}$

Please rate your perception of the desirability of the event.

$\begin{array}{lllll}0 & 0 & 0 & 0\end{array}$

Very Very

Undesirable Desirable

Question 82

Career and Technical Education will be recognized as a credible choice for college-bound high school students, rather than as a last resort for marginalized students.

Please select the time frame you believe is most appropriate.

$\begin{array}{lllll}\circ & \circ & \circ & \circ & \circ \\ \text { Never } & \begin{array}{l}\text { Immediate } \\ (1-3 \text { years })\end{array} & \begin{array}{l}\text { Mid-Range } \\ (4-10 \text { years })\end{array} & \begin{array}{l}\text { Long-Range } \\ (11-20 \text { years })\end{array} & \text { Beyond } 20 \text { Years }\end{array}$

If you believe the event will occur, please rate the degree of impact to Career and Technical Education.

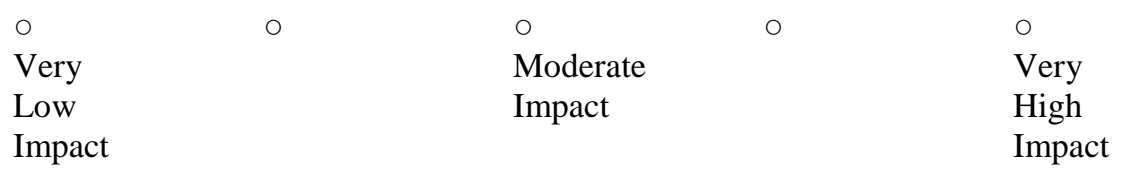

Please rate your perception of the desirability of the event.

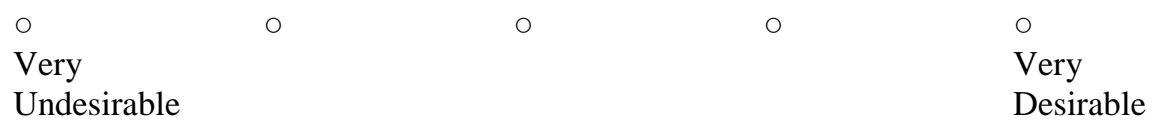




\section{Question 83}

There will be better program alignment with community colleges enabling a much more seamless transition to post secondary education.

Please select the time frame you believe is most appropriate.

$\begin{array}{lllll}\circ \text { Never } & \circ & \circ & \circ & \circ \\ & \begin{array}{l}\text { Immediate } \\ (1-3 \text { years })\end{array} & \begin{array}{l}\text { Mid-Range } \\ (4-10 \text { years })\end{array} & \begin{array}{l}\text { Long-Range } \\ (11-20 \text { years })\end{array} & \text { Beyond } 20 \text { Years }\end{array}$

If you believe the event will occur, please rate the degree of impact to Career and Technical Education.

$\begin{array}{llll}\circ & \circ & \circ & \circ \\ \text { Very } & \text { Moderate } & \text { Very } \\ \text { Low } & \text { Impact } & \text { High } \\ \text { Impact } & & \text { Impact }\end{array}$

Please rate your perception of the desirability of the event.

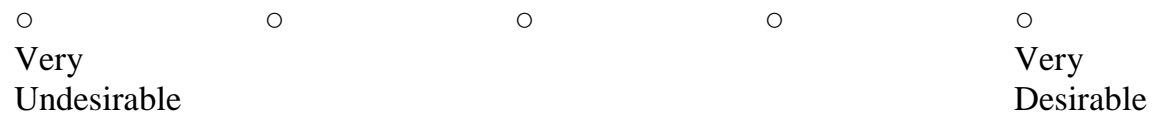

\section{Question 84}

Higher education will offer multiple tracks for advancement through the degree process for students entering from Career and Technical Education with certifications/completions in similar career fields.

Please select the time frame you believe is most appropriate.

$\begin{array}{lllll}\circ & \circ & \circ & \circ & \circ \\ \text { Never } & \begin{array}{l}\text { Immediate } \\ \text { (1-3 years })\end{array} & \begin{array}{l}\text { Mid-Range } \\ (4-10 \text { years })\end{array} & \begin{array}{l}\text { Long-Range } \\ (11-20 \text { years })\end{array} & \text { Beyond } 20 \text { Years }\end{array}$

If you believe the event will occur, please rate the degree of impact to Career and Technical Education.

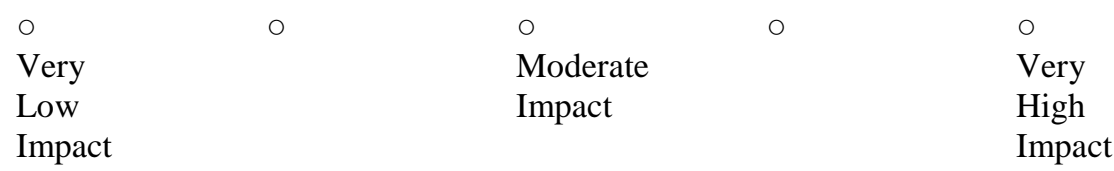

Please rate your perception of the desirability of the event.

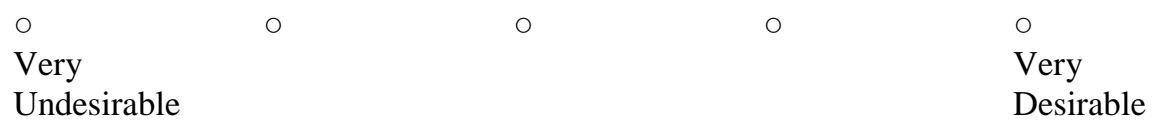




\section{Question 85}

Worldwide articulation agreements will be implemented to assure smooth transition of students from high school to college and from college to college.

Please select the time frame you believe is most appropriate.

\begin{tabular}{|c|c|c|c|c|}
\hline 0 & 0 & 0 & 0 & 0 \\
\hline Never & $\begin{array}{l}\text { Immediate } \\
\text { (1-3 years) }\end{array}$ & $\begin{array}{l}\text { Mid-Range } \\
\text { (4-10 years) }\end{array}$ & $\begin{array}{l}\text { Long-Range } \\
\text { (11-20 years) }\end{array}$ & Beyond 20 Years \\
\hline
\end{tabular}

If you believe the event will occur, please rate the degree of impact to Career and Technical Education.

\begin{tabular}{|c|c|c|}
\hline \multirow[b]{3}{*}{ Low } & 0 & 0 \\
\hline & & Moderate \\
\hline & & Impact \\
\hline
\end{tabular}

Please rate your perception of the desirability of the event.

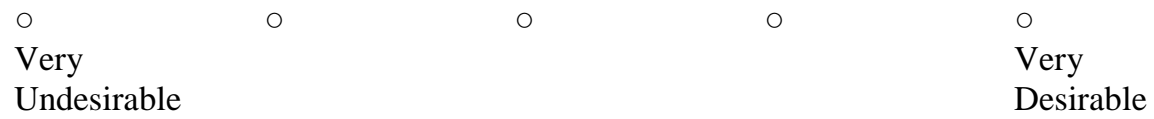

\section{Question 86}

Learning centers will exist and traditional schools will be obsolete.

Please select the time frame you believe is most appropriate.

$\begin{array}{lllll}\circ & \circ & \circ & \circ & \circ \\ \text { Never } & \text { Immediate } & \text { Mid-Range } & \text { Long-Range } & \text { Beyond 20 Years } \\ & (1-3 \text { years }) & (4-10 \text { years }) & (11-20 \text { years }) & \end{array}$

If you believe the event will occur, please rate the degree of impact to Career and Technical Education.

\begin{tabular}{|c|c|c|c|c|}
\hline 0 & 0 & 0 & 0 & 0 \\
\hline Very & & Moderate & & Very \\
\hline Low & & Impact & & High \\
\hline Impact & & & & Impact \\
\hline
\end{tabular}

Please rate your perception of the desirability of the event.

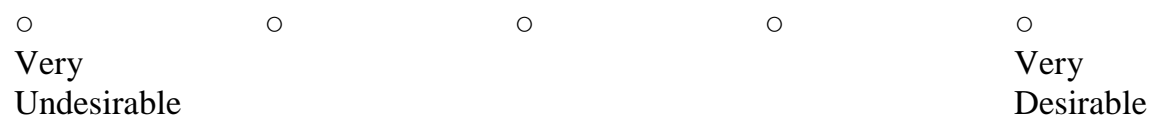




\section{Question 87}

The chasm between secondary and postsecondary career and technical education will either get smaller or be eliminated with the implementation of programs of study.

Please select the time frame you believe is most appropriate.

$\begin{array}{lllll}\circ \text { Never } & \circ & \circ & \circ & \circ \\ & \begin{array}{l}\text { Immediate } \\ (1-3 \text { years })\end{array} & \begin{array}{l}\text { Mid-Range } \\ (4-10 \text { years })\end{array} & \begin{array}{l}\text { Long-Range } \\ (11-20 \text { years })\end{array} & \text { Beyond } 20 \text { Years }\end{array}$

If you believe the event will occur, please rate the degree of impact to Career and Technical Education.

$\begin{array}{llll}\circ & \circ & \circ & \circ \\ \text { Very } & \text { Moderate } & \text { Very } \\ \text { Low } & \text { Impact } & \text { High } \\ \text { Impact } & & \text { Impact }\end{array}$

Please rate your perception of the desirability of the event.

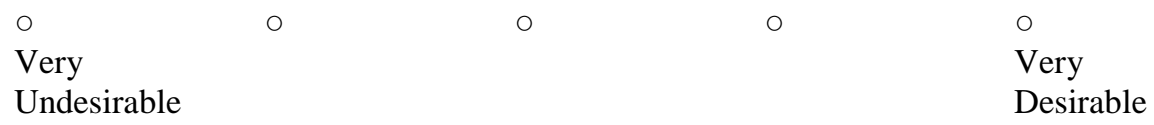

\section{Question 88}

High school CTE will become more agile and focused on supporting transitions to higher education that support the local, regional, state, national and GLOBAL workforce and economic needs.

Please select the time frame you believe is most appropriate.

$\begin{array}{lllll}\circ & \circ & \circ & \circ & \circ \\ \text { Never } & \begin{array}{l}\text { Immediate } \\ (1-3 \text { years })\end{array} & \begin{array}{l}\text { Mid-Range } \\ (4-10 \text { years })\end{array} & \begin{array}{l}\text { Long-Range } \\ (11-20 \text { years })\end{array} & \text { Beyond 20 Years }\end{array}$

If you believe the event will occur, please rate the degree of impact to Career and Technical Education.

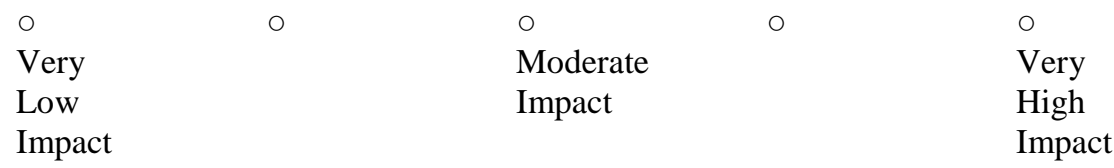

Please rate your perception of the desirability of the event.

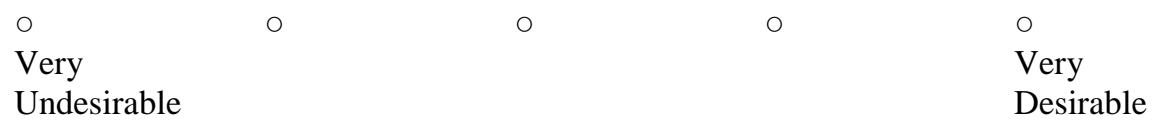




\section{Question 89}

CTE will be a valuable part of all students' overall high school experience and is used to help them prepare for postsecondary education and/or training and career success.

Please select the time frame you believe is most appropriate.

$\begin{array}{lllll}\circ \text { Never } & \circ & \circ & \circ & \circ \\ & \begin{array}{l}\text { Immediate } \\ (1-3 \text { years })\end{array} & \begin{array}{l}\text { Mid-Range } \\ (4-10 \text { years })\end{array} & \begin{array}{l}\text { Long-Range } \\ (11-20 \text { years })\end{array} & \text { Beyond } 20 \text { Years }\end{array}$

If you believe the event will occur, please rate the degree of impact to Career and Technical Education.

$\begin{array}{llll}\circ & \circ & \circ & \circ \\ \text { Very } & \text { Moderate } & \text { Very } \\ \text { Low } & \text { Impact } & \text { High } \\ \text { Impact } & & \text { Impact }\end{array}$

Please rate your perception of the desirability of the event.

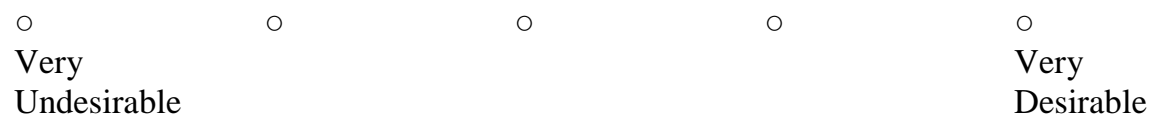

\section{Question 90}

CTE drives innovation and creativity in the state's high schools by transforming the culture of education so every school produces lifelong learners that are both academically-skilled and career-ready.

Please select the time frame you believe is most appropriate.

$\begin{array}{lllll}\circ & \circ & \circ & \circ & \circ \\ \text { Never } & \begin{array}{l}\text { Immediate } \\ (1-3 \text { years })\end{array} & \begin{array}{l}\text { Mid-Range } \\ (4-10 \text { years })\end{array} & \begin{array}{l}\text { Long-Range } \\ (11-20 \text { years })\end{array} & \text { Beyond 20 Years }\end{array}$

If you believe the event will occur, please rate the degree of impact to Career and Technical Education.

$\begin{array}{llll}\circ & \circ & \circ & \circ \\ \text { Very } & \text { Moderate } & \text { Very } \\ \text { Low } & \text { Impact } & \text { High } \\ \text { Impact } & & \text { Impact }\end{array}$

Please rate your perception of the desirability of the event.

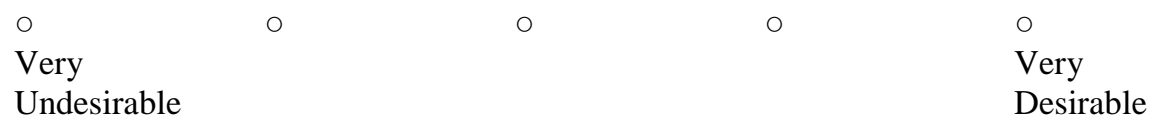




\section{Funding}

Question 91

CTE funding will become more dependent on "competitive grants" which would require additional "proof" that programs are valid.

Please select the time frame you believe is most appropriate.

$\begin{array}{lllll}\circ & \circ & \circ & \circ & \circ \\ \text { Never } & \text { Immediate } & \begin{array}{l}\text { Mid-Range } \\ (1-3 \text { years })\end{array} & \begin{array}{l}\text { Long-Range } \\ (1-10 \text { years })\end{array} & \text { Beyond 20 Years } \\ & \text { (11-20 years }) & \end{array}$

If you believe the event will occur, please rate the degree of impact to Career and Technical Education.

\begin{tabular}{|c|c|c|}
\hline 0 & 0 & 0 \\
\hline Very & Moderate & Very \\
\hline Low & Impact & High \\
\hline Impact & & Impact \\
\hline
\end{tabular}

Please rate your perception of the desirability of the event.

$\circ$

Very

Undesirable
○

0 $\circ$

Very

Desirable

\section{Question 92}

Federal funding will be the key to the survival or demise of career and technical education.

Please select the time frame you believe is most appropriate.

$\begin{array}{lllll}\circ & \circ & \circ & \circ & \circ \\ \text { Never } & \begin{array}{l}\text { Immediate } \\ (1-3 \text { years })\end{array} & \begin{array}{l}\text { Mid-Range } \\ (4-10 \text { years })\end{array} & \begin{array}{l}\text { Long-Range } \\ (11-20 \text { years })\end{array} & \text { Beyond } 20 \text { Years }\end{array}$

If you believe the event will occur, please rate the degree of impact to Career and Technical Education.

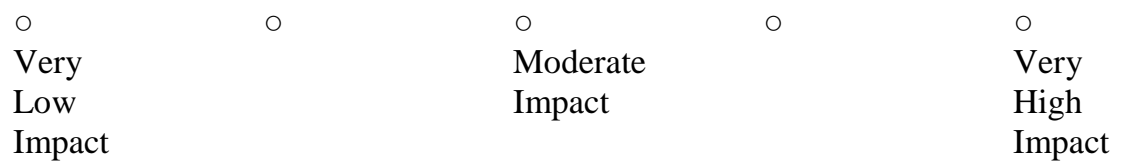

Please rate your perception of the desirability of the event.

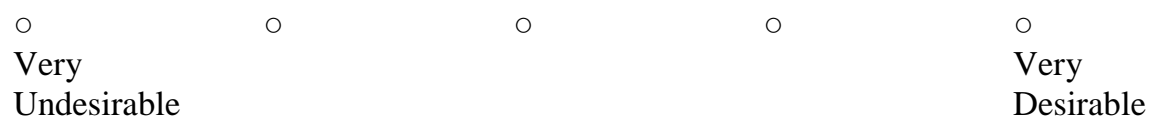




\section{Question 93}

Career and technical education research database will grow significantly, providing a valid and substantial foundation for increasing and stabilizing funding for higher quality CTE teachers and higher quality CTE programming.

Please select the time frame you believe is most appropriate.

$\begin{array}{lllll}\circ & \circ & \circ & \circ & \circ \\ \text { Never } & \begin{array}{l}\text { Immediate } \\ (1-3 \text { years })\end{array} & \begin{array}{l}\text { Mid-Range } \\ (4-10 \text { years })\end{array} & \begin{array}{l}\text { Long-Range } \\ (11-20 \text { years })\end{array} & \text { Beyond 20 Years }\end{array}$

If you believe the event will occur, please rate the degree of impact to Career and Technical Education.

$\begin{array}{llll}\circ & \circ & \circ & \circ \\ \text { Very } & \text { Moderate } & \text { Very } \\ \text { Low } & \text { Impact } & \text { High } \\ \text { Impact } & & \text { Impact }\end{array}$

Please rate your perception of the desirability of the event.

$\begin{array}{lllll}0 & 0 & 0 & 0\end{array}$

Very Very

Undesirable Desirable

Question 94

CTE programs will be certified or recognized by industry, professional, trade associations, or state licensing agencies and that will lead to Performance Based Program support dollars.

Please select the time frame you believe is most appropriate.

$\begin{array}{lllll}\circ & \circ & \circ & \circ & \circ \\ \text { Never } & \begin{array}{l}\text { Immediate } \\ \text { (1-3 years })\end{array} & \begin{array}{l}\text { Mid-Range } \\ (4-10 \text { years })\end{array} & \begin{array}{l}\text { Long-Range } \\ (11-20 \text { years })\end{array} & \text { Beyond } 20 \text { Years }\end{array}$

If you believe the event will occur, please rate the degree of impact to Career and Technical Education.

$\begin{array}{llll}\circ & \circ & \circ & \circ \\ \text { Very } & \text { Moderate } & \text { Very } \\ \text { Low } & \text { Impact } & \text { High } \\ \text { Impact } & & \text { Impact }\end{array}$

Please rate your perception of the desirability of the event.

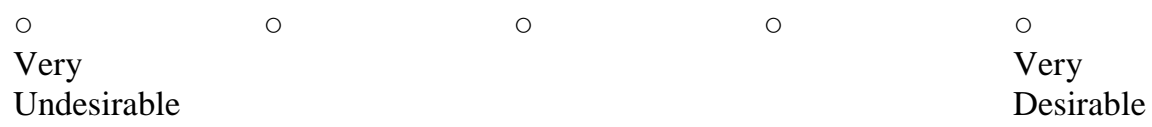




\section{Question 95}

Perkins funding may be replaced or greatly modified as CTE merges with general education, higher education and community colleges.

Please select the time frame you believe is most appropriate.

$\begin{array}{lllll}\circ \text { Never } & \circ & \circ & \circ & \circ \\ & \begin{array}{l}\text { Immediate } \\ (1-3 \text { years })\end{array} & \begin{array}{l}\text { Mid-Range } \\ (4-10 \text { years })\end{array} & \begin{array}{l}\text { Long-Range } \\ (11-20 \text { years })\end{array} & \text { Beyond } 20 \text { Years }\end{array}$

If you believe the event will occur, please rate the degree of impact to Career and Technical Education.

$\begin{array}{llll}\circ & \circ & \circ & \circ \\ \text { Very } & \text { Moderate } & \text { Very } \\ \text { Low } & \text { Impact } & \text { High } \\ \text { Impact } & & \text { Impact }\end{array}$

Please rate your perception of the desirability of the event.

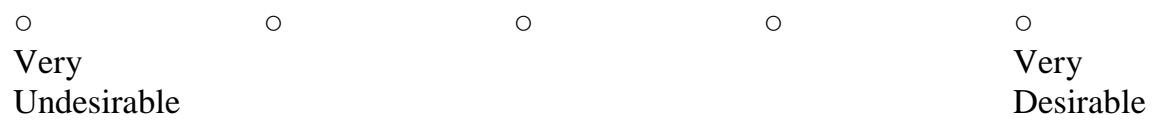

Question 96

There will not be a re-authorization of the Carl D. Perkins Career and Technical Education Act of 2006 beyond 2018.

Please select the time frame you believe is most appropriate.

$\begin{array}{lllll}\circ & \circ & \circ & \circ & \circ \\ \text { Never } & \begin{array}{l}\text { Immediate } \\ (1-3 \text { years })\end{array} & \begin{array}{l}\text { Mid-Range } \\ (4-10 \text { years })\end{array} & \begin{array}{l}\text { Long-Range } \\ (11-20 \text { years })\end{array} & \text { Beyond 20 Years }\end{array}$

If you believe the event will occur, please rate the degree of impact to Career and Technical Education.

$\begin{array}{llll}\circ & \circ & \circ & \circ \\ \text { Very } & \text { Moderate } & \text { Very } \\ \text { Low } & \text { Impact } & \text { High } \\ \text { Impact } & & \text { Impact }\end{array}$

Please rate your perception of the desirability of the event.

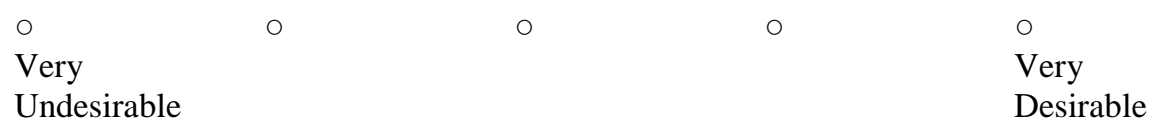




\section{Accountability}

Question 97

The focus on research-based and test driven education will increase.

Please select the time frame you believe is most appropriate.

$\begin{array}{lllll}\circ & \circ & \circ & \circ & \circ \\ \text { Never } & \begin{array}{l}\text { Immediate } \\ \text { (1-3 years })\end{array} & \begin{array}{l}\text { Mid-Range } \\ (4-10 \text { years })\end{array} & \begin{array}{l}\text { Long-Range } \\ (11-20 \text { years })\end{array} & \text { Beyond } 20 \text { Years }\end{array}$

If you believe the event will occur, please rate the degree of impact to Career and Technical Education.

$\begin{array}{llll}\circ & \circ & \circ & \circ \\ \text { Very } & \text { Moderate } & \text { Very } \\ \text { Low } & \text { Impact } & \text { High } \\ \text { Impact } & & \text { Impact }\end{array}$

Please rate your perception of the desirability of the event.

$\begin{array}{lllll}\circ & 0 & 0 & 0 & 0\end{array}$

Very Very

Undesirable Desirable

Question 98

Performance-based assessment will replace degrees and diplomas. Student competencies will be observable and documented on a Certificate of Achievement.

Please select the time frame you believe is most appropriate.

$\begin{array}{lllll}\circ & \circ & \circ & \circ & \circ \\ \text { Never } & \begin{array}{l}\text { Immediate } \\ \text { (1-3 years })\end{array} & \begin{array}{l}\text { Mid-Range } \\ (4-10 \text { years })\end{array} & \begin{array}{l}\text { Long-Range } \\ (11-20 \text { years })\end{array} & \text { Beyond } 20 \text { Years }\end{array}$

If you believe the event will occur, please rate the degree of impact to Career and Technical Education.

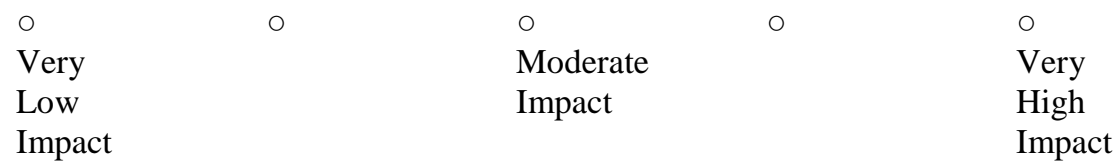

Please rate your perception of the desirability of the event.

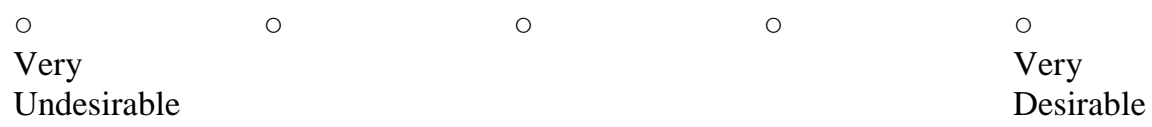




\section{Question 99}

High-stakes testing will be replaced by portfolio-type of assessments that will include firsthand works, tests and experiences.

Please select the time frame you believe is most appropriate.

\begin{tabular}{|c|c|c|c|c|}
\hline 0 & 0 & 0 & 0 & 0 \\
\hline Never & $\begin{array}{l}\text { Immediate } \\
\text { (1-3 years) }\end{array}$ & $\begin{array}{l}\text { Mid-Range } \\
\text { (4-10 years) }\end{array}$ & $\begin{array}{l}\text { Long-Range } \\
\text { (11-20 years) }\end{array}$ & Beyond 20 Years \\
\hline
\end{tabular}

If you believe the event will occur, please rate the degree of impact to Career and Technical Education.

\begin{tabular}{|c|c|c|}
\hline \multirow[b]{3}{*}{ Low } & 0 & 0 \\
\hline & & Moderate \\
\hline & & Impact \\
\hline
\end{tabular}

Please rate your perception of the desirability of the event.

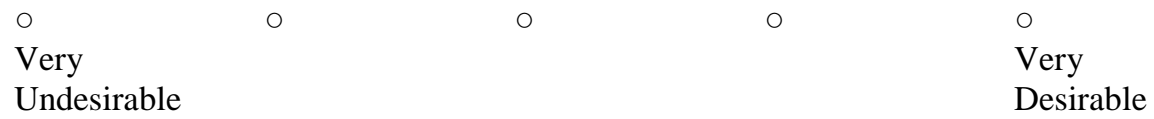

Question 100

More educational assessments will be measured through the ability to access knowledge and not retain knowledge.

Please select the time frame you believe is most appropriate.

$\begin{array}{lllll}\circ & \circ & \circ & \circ & \circ \\ \text { Never } & \text { Immediate } & \text { Mid-Range } & \text { Long-Range } & \text { Beyond 20 Years } \\ & (1-3 \text { years }) & (4-10 \text { years }) & (11-20 \text { years }) & \end{array}$

If you believe the event will occur, please rate the degree of impact to Career and Technical Education.

\begin{tabular}{|c|c|c|c|c|}
\hline 0 & 0 & 0 & 0 & 0 \\
\hline Very & & Moderate & & Very \\
\hline Low & & Impact & & High \\
\hline Impact & & & & Impact \\
\hline
\end{tabular}

Please rate your perception of the desirability of the event.

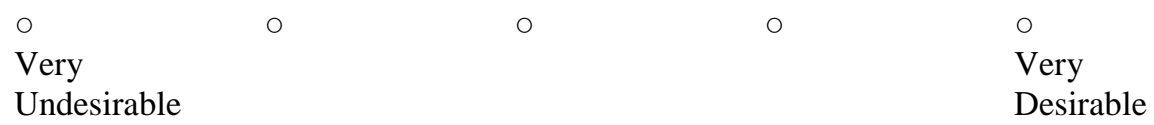




\section{Question 101}

There will be national CTE assessments.

Please select the time frame you believe is most appropriate.

$\begin{array}{lllll}\circ & \circ & \circ & \circ & \circ \\ \text { Never } & \text { Immediate } & \text { Mid-Range } & \text { Long-Range } & \text { Beyond 20 Years } \\ & (1-3 \text { years }) & (4-10 \text { years }) & (11-20 \text { years }) & \end{array}$

If you believe the event will occur, please rate the degree of impact to Career and Technical Education.

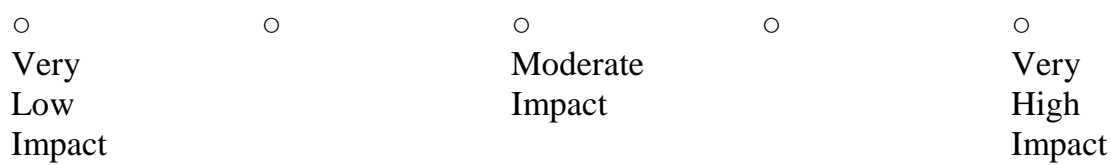

Please rate your perception of the desirability of the event.

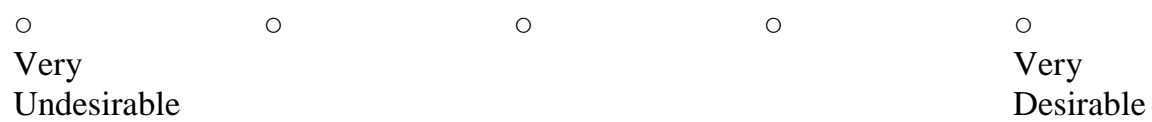

\section{Question 102}

Enhanced accountability will include longitudinal data systems designed to improve collection and data integrity which will aid in data-driven decision making.

Please select the time frame you believe is most appropriate.

$\begin{array}{lllll}\circ & \circ & \circ & \circ & \circ \\ \text { Never } & \text { Immediate } & \text { Mid-Range } & \text { Long-Range } & \text { Beyond 20 Years } \\ & (1-3 \text { years }) & (4-10 \text { years }) & (11-20 \text { years }) & \end{array}$

If you believe the event will occur, please rate the degree of impact to Career and Technical Education.

\begin{tabular}{|c|c|c|c|c|}
\hline 0 & 0 & 0 & 0 & 0 \\
\hline Very & & Moderate & & Very \\
\hline Low & & Impact & & High \\
\hline Impact & & & & Impact \\
\hline
\end{tabular}

Please rate your perception of the desirability of the event.

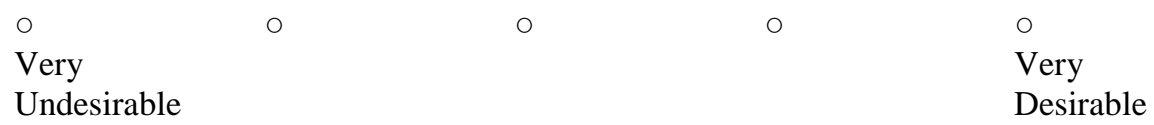




\section{Question 103}

Lifelong learning will become more important because people will live longer, work longer and need more frequent training.

Please select the time frame you believe is most appropriate.

$\begin{array}{lllll}\circ \text { Never } & \circ & \circ & \circ & \circ \\ & \begin{array}{l}\text { Immediate } \\ (1-3 \text { years })\end{array} & \begin{array}{l}\text { Mid-Range } \\ (4-10 \text { years })\end{array} & \begin{array}{l}\text { Long-Range } \\ (11-20 \text { years })\end{array} & \text { Beyond } 20 \text { Years }\end{array}$

If you believe the event will occur, please rate the degree of impact to Career and Technical Education.

$\begin{array}{llll}\circ & \circ & \circ & \circ \\ \text { Very } & \text { Moderate } & \\ \text { Low } & \text { Impact } & \text { Very } \\ \text { Impact } & & \text { High } \\ & & \text { Impact }\end{array}$

Please rate your perception of the desirability of the event.

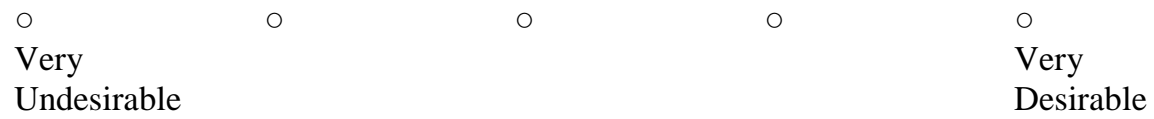

\section{Question 104}

The emphasis on accountability in all secondary education programs will continue with career and technical education at great risk to prove that their contribution is worth the expense.

Please select the time frame you believe is most appropriate.

$\begin{array}{lllll}\circ & \circ & \circ & \circ & \circ \\ \text { Never } & \begin{array}{l}\text { Immediate } \\ (1-3 \text { years })\end{array} & \begin{array}{l}\text { Mid-Range } \\ (4-10 \text { years })\end{array} & \begin{array}{l}\text { Long-Range } \\ (11-20 \text { years })\end{array} & \text { Beyond 20 Years }\end{array}$

If you believe the event will occur, please rate the degree of impact to Career and Technical Education.

$\begin{array}{llll}\circ & \circ & \circ & \circ \\ \text { Very } & \text { Moderate } & \text { Very } \\ \text { Low } & \text { Impact } & \text { High } \\ \text { Impact } & & \text { Impact }\end{array}$

Please rate your perception of the desirability of the event.

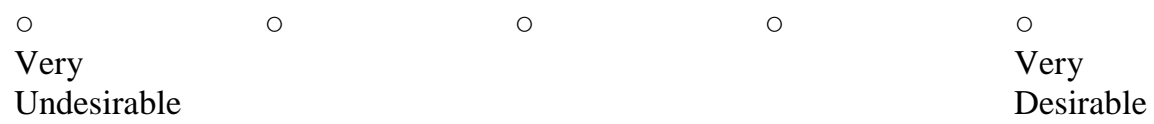




\section{Image}

\section{Question 105}

The contribution to economic development must be recognized or career and technical education will continue to be marginalized.

Please select the time frame you believe is most appropriate.

$\begin{array}{lllll}\circ & \circ & \circ & \circ & \circ \\ \text { Never } & \text { Immediate } & \text { Mid-Range } & \text { Long-Range } & \text { Beyond 20 Years } \\ & (1-3 \text { years }) & (4-10 \text { years }) & (11-20 \text { years }) & \end{array}$

If you believe the event will occur, please rate the degree of impact to Career and Technical Education.

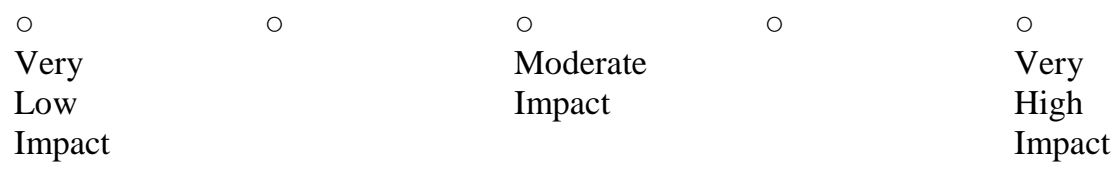

Please rate your perception of the desirability of the event.

○

Very

Undesirable
○

-

○

0

Very

Desirable

Question 106

The high school dropout rates will decrease as enrollment in CTE classes increase because students see relevancy in their learning environment.

Please select the time frame you believe is most appropriate.

$\begin{array}{lllll}\circ & \circ & \circ & \circ & \circ \\ \text { Never } & \text { Immediate } & \text { Mid-Range } & \text { Long-Range } & \text { Beyond 20 Years } \\ & (1-3 \text { years }) & (4-10 \text { years }) & (11-20 \text { years }) & \end{array}$

If you believe the event will occur, please rate the degree of impact to Career and Technical Education.

\begin{tabular}{|c|c|c|c|}
\hline O & O & O & O \\
\hline Very & & Moderate & Very \\
\hline Low & & Impact & High \\
\hline Impact & & & Impact \\
\hline
\end{tabular}

Please rate your perception of the desirability of the event.

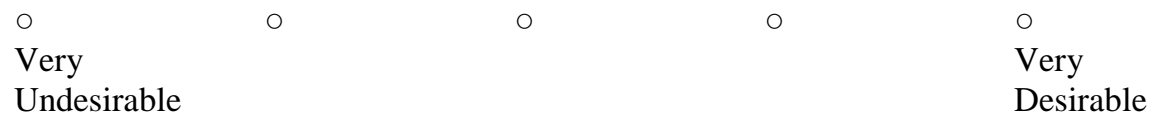




\section{Question 109}

CTE will move from the elective side of the high school graduation requirements to the required core side of high school graduation.

Please select the time frame you believe is most appropriate.

$\begin{array}{lllll}\circ & \circ & \circ & \circ & \circ \\ \text { Never } & \begin{array}{l}\text { Immediate } \\ (1-3 \text { years })\end{array} & \begin{array}{l}\text { Mid-Range } \\ (4-10 \text { years })\end{array} & \begin{array}{l}\text { Long-Range } \\ (11-20 \text { years })\end{array} & \text { Beyond 20 Years }\end{array}$

If you believe the event will occur, please rate the degree of impact to Career and Technical Education.

$\begin{array}{llll}\circ & \circ & \circ & \circ \\ \text { Very } & \text { Moderate } & \text { Very } \\ \text { Low } & \text { Impact } & \text { High } \\ \text { Impact } & & \text { Impact }\end{array}$

Please rate your perception of the desirability of the event.

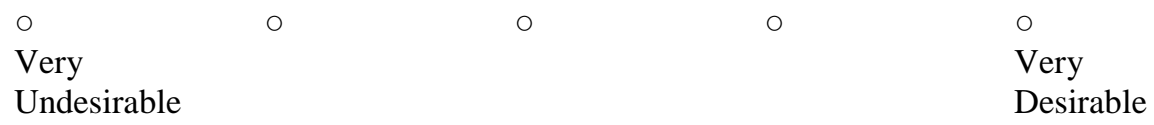

Question 110

Students will need to apply to be accepted into CTE programs.

Please select the time frame you believe is most appropriate.

$\begin{array}{lllll}\circ & \circ & \circ & \circ & \circ \\ \text { Never } & \begin{array}{l}\text { Immediate } \\ \text { (1-3 years })\end{array} & \begin{array}{l}\text { Mid-Range } \\ (4-10 \text { years })\end{array} & \begin{array}{l}\text { Long-Range } \\ (11-20 \text { years })\end{array} & \text { Beyond } 20 \text { Years }\end{array}$

If you believe the event will occur, please rate the degree of impact to Career and Technical Education.

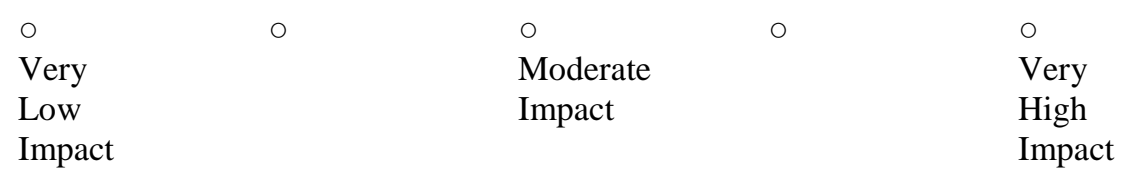

Please rate your perception of the desirability of the event.

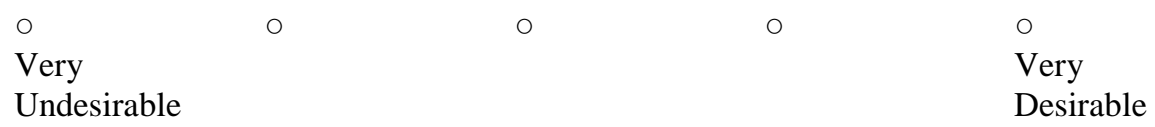




\section{Question 111}

Parents will recognize that CTE is paramount to achieving education and career goals.

Please select the time frame you believe is most appropriate.

$\begin{array}{lllll}\circ & \circ & \circ & \circ & \circ \\ \text { Never } & \text { Immediate } & \text { Mid-Range } & \text { Long-Range } & \text { Beyond 20 Years } \\ & (1-3 \text { years }) & (4-10 \text { years }) & (11-20 \text { years }) & \end{array}$

If you believe the event will occur, please rate the degree of impact to Career and Technical Education.

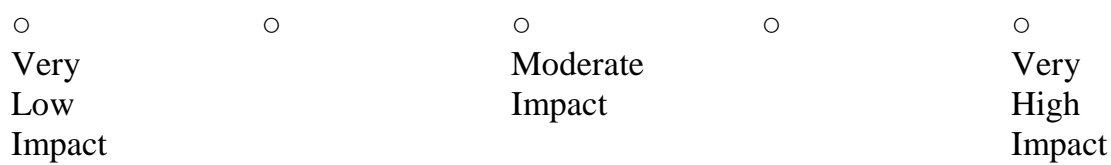

Please rate your perception of the desirability of the event.

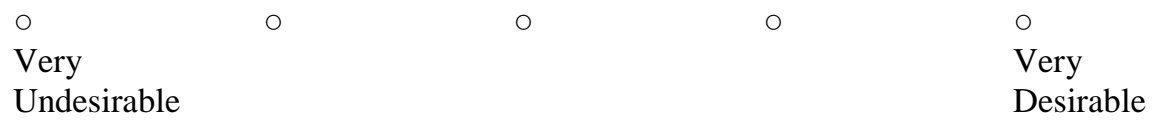

\section{Question 112}

The location of CTE will move from behind the scenes of the school to a front showcase and become the hub in which all high school knowledge revolves.

Please select the time frame you believe is most appropriate.

$\begin{array}{lllll}\circ & \circ & \circ & \circ & \circ \\ \text { Never } & \text { Immediate } & \text { Mid-Range } & \text { Long-Range } & \text { Beyond 20 Years } \\ & (1-3 \text { years }) & (4-10 \text { years }) & (11-20 \text { years }) & \end{array}$

If you believe the event will occur, please rate the degree of impact to Career and Technical Education.

\begin{tabular}{|c|c|c|c|c|}
\hline 0 & 0 & 0 & 0 & 0 \\
\hline Very & & Moderate & & Very \\
\hline Low & & Impact & & High \\
\hline Impact & & & & Impact \\
\hline
\end{tabular}

Please rate your perception of the desirability of the event.

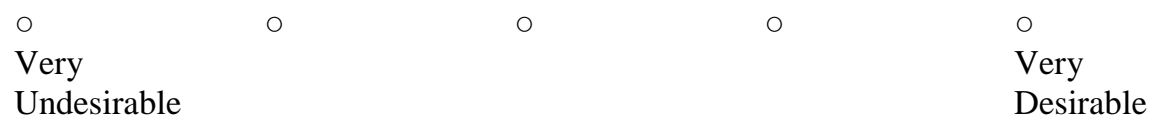




\section{Question 113}

Students who complete a secondary program, go to work, and continue to learn either on the job and/or receive training provided by the employer will be valued as much as a person who has a degree.

Please select the time frame you believe is most appropriate.

$\begin{array}{lllll}\circ \text { Never } & \circ & \circ & \circ & \circ \\ & \begin{array}{l}\text { Immediate } \\ (1-3 \text { years })\end{array} & \begin{array}{l}\text { Mid-Range } \\ (4-10 \text { years })\end{array} & \begin{array}{l}\text { Long-Range } \\ (11-20 \text { years })\end{array} & \text { Beyond } 20 \text { Years }\end{array}$

If you believe the event will occur, please rate the degree of impact to Career and Technical Education.

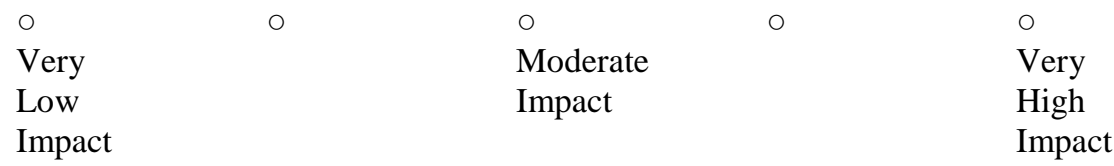

Please rate your perception of the desirability of the event.

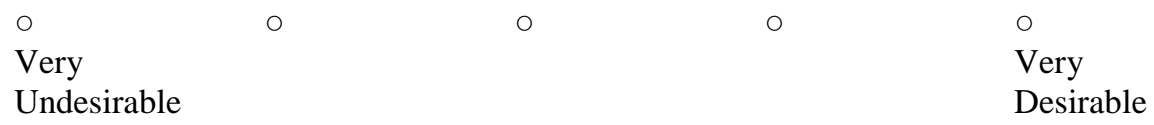

\section{Question 114}

Education funding will plateau in the states or decline due to a lack of understanding of the need to be educated and employed to compete in a world-wide economy.

Please select the time frame you believe is most appropriate.

$\begin{array}{lllll}\circ & \circ & \circ & \circ & \circ \\ \text { Never } & \begin{array}{l}\text { Immediate } \\ (1-3 \text { years })\end{array} & \begin{array}{l}\text { Mid-Range } \\ (4-10 \text { years })\end{array} & \begin{array}{l}\text { Long-Range } \\ (11-20 \text { years })\end{array} & \text { Beyond 20 Years }\end{array}$

If you believe the event will occur, please rate the degree of impact to Career and Technical Education.

$\begin{array}{llll}\circ & \circ & \circ & \circ \\ \text { Very } & \text { Moderate } & \text { Very } \\ \text { Low } & \text { Impact } & \text { High } \\ \text { Impact } & & \text { Impact }\end{array}$

Please rate your perception of the desirability of the event.

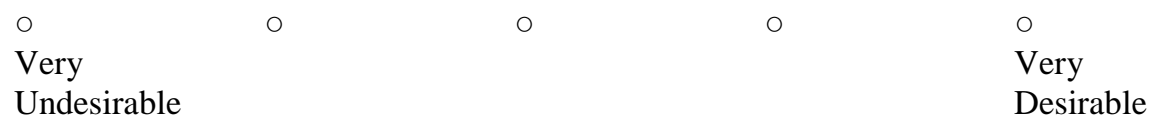




\section{Dear Expert Panelist:}

Thank you for your hard work in the first two rounds. This is the third and final round. I sincerely appreciate your expert opinions and the dedication you have to career and technical education.

The first page includes a question that asks if you are willing to be named as a panelist when the survey results are made public. Names will not be connected with individual data in any way. You are under no obligation to agree to have your name publicly listed.

The instrument in this round consists of individualized responses. It has only those questions for which your responses differed from the group median. For each question, you are asked to either change your response to equal the median, or to write a sentence explaining why your response is a better choice than the median. Responses that are not defended will be automatically changed to the median.

The format for this round has changed. Simply record your responses on this document and save it. Return it to me as an email attachment.

I would very much appreciate it if you could return it to me by

Again, thank you for your expert opinions.

Sincerely,

Michael Cutright 


\section{ROUND THREE SURVEY}

Do you agree to have your name released for publication/presentation as a panelist for this study?

Yes

No

Note: Click on the box beside your choice. The response box will expand as you type in it. (A blank on "Your response" indicates that you did not answer in Round 2.)

\section{Curriculum}

\section{Question 1}

\section{Entrepreneurship will become a part of all career and technical education programs.}

Q1-Time Frame (Please select the time frame you believe is most appropriate.)

Your response:

Median response: 2-Immediate (1-3 years)

Change to reflect median

I do not wish to change my response because: Type Response Here

Q1-Impact (Please rate the degree of impact to career and technical education.)

$1=$ Very Low Impact and $6=$ Very High Impact

Your response:

Median response: 3

Change to reflect median

I do not wish to change my response because: Type Response Here

Q1-Desirability (Please rate your perception of the desirability of the event.) $1=$ Very Undesirable and $5=$ Very Desirable

Your response:

Median response: 4

Change to reflect median

I do not wish to change my response because: Type Response Here 
Question 2

Health Occupations CTE programs will be more closely connected with identified health care providers and/or facilities: there will be a more pronounced OJT/co-op component required for CTE program completion.

Q2-Time Frame (Please select the time frame you believe is most appropriate.)

Your response:

Median response: 2-Immediate (1-3 years)

Change to reflect median

I do not wish to change my response because: Type Response Here

Q2-Impact (Please rate the degree of impact to career and technical education.) $1=$ Very Low Impact and $6=$ Very High Impact

Your response:

Median response: 3

Change to reflect median

I do not wish to change my response because: Type Response Here

Q2-Desirability (Please rate your perception of the desirability of the event.) $1=$ Very Undesirable and $5=$ Very Desirable

Your response:

Median response: 4

Change to reflect median

I do not wish to change my response because: Type Response Here 
Question 3

National Security concerns will continue and career preparation programs in Criminal Justice, Bio-Security will continue to grow.

Q3-Time Frame (Please select the time frame you believe is most appropriate.)

Your response:

Median response: 2-Immediate (1-3 years)

Change to reflect median

I do not wish to change my response because: Type Response Here

Q3-Impact (Please rate the degree of impact to career and technical education.) $1=$ Very Low Impact and $6=$ Very High Impact

Your response:

Median response: 4

Change to reflect median

I do not wish to change my response because: Type Response Here

Q3-Desirability (Please rate your perception of the desirability of the event.) $1=$ Very Undesirable and $5=$ Very Desirable

Your response:

Median response: 4

Change to reflect median

I do not wish to change my response because: Type Response Here 


\section{Question 4}

The teaching of languages will become part of a complete and effective CTE program.

Q4-Time Frame (Please select the time frame you believe is most appropriate.)

Your response:

Median response: 3-Mid-range (4-10 years)

Change to reflect median

I do not wish to change my response because: Type Response Here

Q4-Impact (Please rate the degree of impact to career and technical education.) $1=$ Very Low Impact and $6=$ Very High Impact

Your response:

Median response: 3

Change to reflect median

I do not wish to change my response because: Type Response Here

Q4-Desirability (Please rate your perception of the desirability of the event.) $1=$ Very Undesirable and $5=$ Very Desirable

Your response:

Median response: 2

Change to reflect median

I do not wish to change my response because: Type Response Here 


\section{Question 5}

Students must do an internship, shadow, or work in the technical area before they graduate high school.

Q5-Time Frame (Please select the time frame you believe is most appropriate.)

Your response:

Median response: 2-Mid-range (4-10 years)

Change to reflect median

I do not wish to change my response because: Type Response Here

Q5-Impact (Please rate the degree of impact to career and technical education.) $1=$ Very Low Impact and $6=$ Very High Impact

Your response:

Median response: 5

Change to reflect median

I do not wish to change my response because: Type Response Here

Q5-Desirability (Please rate your perception of the desirability of the event.) $1=$ Very Undesirable and $5=$ Very Desirable

Your response:

Median response: 4

Change to reflect median

I do not wish to change my response because: Type Response Here 


\section{Question 6}

CTE leads the validation of career-ready status of every high school graduate by increasing the use of instruments that measure skills employers' value (industry recognized certifications).

Q6-Time Frame (Please select the time frame you believe is most appropriate.)

Your response:

Median response: 2-Mid-range (4-10 years)

Change to reflect median

I do not wish to change my response because: Type Response Here

Q6-Impact (Please rate the degree of impact to career and technical education.) $1=$ Very Low Impact and $6=$ Very High Impact

Your response:

Median response: 5

Change to reflect median

I do not wish to change my response because: Type Response Here

Q6-Desirability (Please rate your perception of the desirability of the event.) $1=$ Very Undesirable and $5=$ Very Desirable

Your response:

Median response: 5

Change to reflect median

I do not wish to change my response because: Type Response Here 


\section{Question 7}

Simultaneously, as career and technical education tries to address the needs of the hard-to-reach student, there will be a rebirth of interest in occupations that will stay local and provide a good living.

Q7-Time Frame (Please select the time frame you believe is most appropriate.)

Your response:

Median response: 3-Long-range (11-20 years)

Change to reflect median

I do not wish to change my response because: Type Response Here

Q7-Impact (Please rate the degree of impact to career and technical education.) $1=$ Very Low Impact and $6=$ Very High Impact

Your response:

Median response: 4

Change to reflect median

I do not wish to change my response because: Type Response Here

Q7-Desirability (Please rate your perception of the desirability of the event.) $1=$ Very Undesirable and $5=$ Very Desirable

Your response:

Median response: 4

Change to reflect median

I do not wish to change my response because: Type Response Here 


\section{Question 8}

Software and machine management will become new basics of education in CTE while standardized tests and other forms of testing will disappear.

Q8-Time Frame (Please select the time frame you believe is most appropriate.)

Your response:

Median response: 2-Immediate (1-3 years)

Change to reflect median

I do not wish to change my response because: Type Response Here

Q8-Impact (Please rate the degree of impact to career and technical education.) $1=$ Very Low Impact and $6=$ Very High Impact

Your response:

Median response: 4

Change to reflect median

I do not wish to change my response because: Type Response Here

Q8-Desirability (Please rate your perception of the desirability of the event.) $1=$ Very Undesirable and $5=$ Very Desirable

Your response:

Median response: 3

Change to reflect median

I do not wish to change my response because: Type Response Here 


\section{Question 9}

Career and technical education will be driven by a common national vision, mission and set of core values.

Q9-Time Frame (Please select the time frame you believe is most appropriate.)

Your response:

Median response: 3-Mid-range (4-10 years)

Change to reflect median

I do not wish to change my response because: Type Response Here

Q9-Impact (Please rate the degree of impact to career and technical education.) $1=$ Very Low Impact and $6=$ Very High Impact

Your response:

Median response: 4

Change to reflect median

I do not wish to change my response because: Type Response Here

Q9-Desirability (Please rate your perception of the desirability of the event.) $1=$ Very Undesirable and $5=$ Very Desirable

Your response:

Median response: 4

Change to reflect median

I do not wish to change my response because: Type Response Here 


\section{Question 10}

CTE leads the Career Clusters initiative by emerging and aligning with economic development industry sectors/clusters.

Q10-Time Frame (Please select the time frame you believe is most appropriate.)

Your response:

Median response: 2-Immediate (1-3 years)

Change to reflect median

I do not wish to change my response because: Type Response Here

Q10-Impact (Please rate the degree of impact to career and technical education.) $1=$ Very Low Impact and $6=$ Very High Impact

Your response:

Median response: 4

Change to reflect median

I do not wish to change my response because: Type Response Here

Q10-Desirability (Please rate your perception of the desirability of the event.) $1=$ Very Undesirable and $5=$ Very Desirable

Your response:

Median response: 5

Change to reflect median

I do not wish to change my response because: Type Response Here 


\section{Question 11}

Content standard objectives (CSOs) and similar standards in other states will undergo a major overhaul, as research shows the futility of trying to make a one-size-fits-all list of criteria for completion. Programs of the same name, in different places, under different industry/business needs, will look different.

Q11-Time Frame (Please select the time frame you believe is most appropriate.)

Your response:

Median response: 3-Mid-range (4-10 years)

Change to reflect median

I do not wish to change my response because: Type Response Here

Q11-Impact (Please rate the degree of impact to career and technical education.) $1=$ Very Low Impact and $6=$ Very High Impact

Your response:

Median response: 4

Change to reflect median

I do not wish to change my response because: Type Response Here

Q11-Desirability (Please rate your perception of the desirability of the event.) $1=$ Very Undesirable and $5=$ Very Desirable

Your response:

Median response: 3

Change to reflect median

I do not wish to change my response because: Type Response Here 


\section{Question 12}

Grade-level tracking will be replaced with content learning, where students can build on their knowledge and abilities, and leave the grade classification behind allowing more time for the CTE effort.

Q12-Time Frame (Please select the time frame you believe is most appropriate.)

Your response:

Median response: 3-Mid-range (4-10 years)

Change to reflect median

I do not wish to change my response because: Type Response Here

Q12-Impact (Please rate the degree of impact to career and technical education.) $1=$ Very Low Impact and $6=$ Very High Impact

Your response:

Median response: 4

Change to reflect median

I do not wish to change my response because: Type Response Here

Q12-Desirability (Please rate your perception of the desirability of the event.) $1=$ Very Undesirable and $5=$ Very Desirable

Your response:

Median response: 4

Change to reflect median

I do not wish to change my response because: Type Response Here 


\section{Question 13}

CTE is the catalyst that expands the assistance available to all high school students to enable them to make both wise academic and career choices and achieve their goals for the future.

Q13-Time Frame (Please select the time frame you believe is most appropriate.)

Your response:

Median response: 2-Immediate (1-3 years)

Change to reflect median

I do not wish to change my response because: Type Response Here

Q13-Impact (Please rate the degree of impact to career and technical education.) $1=$ Very Low Impact and $6=$ Very High Impact

Your response:

Median response: 4

Change to reflect median

I do not wish to change my response because: Type Response Here

Q13-Desirability (Please rate your perception of the desirability of the event.) $1=$ Very Undesirable and $5=$ Very Desirable

Your response:

Median response: 5

Change to reflect median

I do not wish to change my response because: Type Response Here 


\section{Question 14}

\section{There will be an increase in the interest of CTE career areas.}

Q14-Time Frame (Please select the time frame you believe is most appropriate.)

Your response:

Median response: 2-Immediate (1-3 years)

Change to reflect median

I do not wish to change my response because: Type Response Here

Q14-Impact (Please rate the degree of impact to career and technical education.) $1=$ Very Low Impact and $6=$ Very High Impact

Your response:

Median response: 5

Change to reflect median

I do not wish to change my response because: Type Response Here

Q14-Desirability (Please rate your perception of the desirability of the event.) $1=$ Very Undesirable and $5=$ Very Desirable

Your response:

Median response: 5

Change to reflect median

I do not wish to change my response because: Type Response Here 


\section{Question 15}

Secondary CTE programs will all offer a minimum of two tracts, one for highly capable and a different level for those students recognized as less achieving or challenged.

Q15-Time Frame (Please select the time frame you believe is most appropriate.)

Your response:

Median response: 2-Immediate (1-3 years)

Change to reflect median

I do not wish to change my response because: Type Response Here

Q15-Impact (Please rate the degree of impact to career and technical education.) $1=$ Very Low Impact and $6=$ Very High Impact

Your response:

Median response: 4

Change to reflect median

I do not wish to change my response because: Type Response Here

Q15-Desirability (Please rate your perception of the desirability of the event.) $1=$ Very Undesirable and $5=$ Very Desirable

Your response:

Median response: 3

Change to reflect median

I do not wish to change my response because: Type Response Here 
Question 16

Rigor and relevance of content and delivery will be increased significantly in CTE curriculum and instruction.

Q16-Time Frame (Please select the time frame you believe is most appropriate.)

Your response:

Median response: 2-Immediate (1-3 years)

Change to reflect median

I do not wish to change my response because: Type Response Here

Q16-Impact (Please rate the degree of impact to career and technical education.) $1=$ Very Low Impact and $6=$ Very High Impact

Your response:

Median response: 4

Change to reflect median

I do not wish to change my response because: Type Response Here

Q16-Desirability (Please rate your perception of the desirability of the event.) $1=$ Very Undesirable and $5=$ Very Desirable

Your response:

Median response: 2

Change to reflect median

I do not wish to change my response because: Type Response Here 
Question 17

The blending of career and technical education and academic education will overlap considerably -it will no longer be an either/or situation.

Q17-Time Frame (Please select the time frame you believe is most appropriate.)

Your response:

Median response: 3-Mid-range (4-10 years)

Change to reflect median

I do not wish to change my response because: Type Response Here

Q17-Impact (Please rate the degree of impact to career and technical education.) $1=$ Very Low Impact and $6=$ Very High Impact

Your response:

Median response: 5

Change to reflect median

I do not wish to change my response because: Type Response Here

Q17-Desirability (Please rate your perception of the desirability of the event.) $1=$ Very Undesirable and $5=$ Very Desirable

Your response:

Median response: 7

Change to reflect median

I do not wish to change my response because: Type Response Here 


\section{Question 18}

Career academies and small learning communities will replace the comprehensive high school setting.

Q18-Time Frame (Please select the time frame you believe is most appropriate.)

Your response:

Median response: 3-Mid-range (4-10 years)

Change to reflect median

I do not wish to change my response because: Type Response Here

Q18-Impact (Please rate the degree of impact to career and technical education.) $1=$ Very Low Impact and $6=$ Very High Impact

Your response:

Median response: 4

Change to reflect median

I do not wish to change my response because: Type Response Here

Q18-Desirability (Please rate your perception of the desirability of the event.) $1=$ Very Undesirable and $5=$ Very Desirable

Your response:

Median response: 4

Change to reflect median

I do not wish to change my response because: Type Response Here 


\section{Question 19}

\section{CTE will be offered in elementary schools.}

Q19-Time Frame (Please select the time frame you believe is most appropriate.)

Your response:

Median response: 3-Mid-range (4-10 years)

Change to reflect median

I do not wish to change my response because: Type Response Here

Q19-Impact (Please rate the degree of impact to career and technical education.) $1=$ Very Low Impact and $6=$ Very High Impact

Your response:

Median response: 3

Change to reflect median

I do not wish to change my response because: Type Response Here

Q19-Desirability (Please rate your perception of the desirability of the event.) $1=$ Very Undesirable and $5=$ Very Desirable

Your response:

Median response: 4

Change to reflect median

I do not wish to change my response because: Type Response Here 


\section{Question 20}

The Carnegie unit will be replaced with something new which is not seat-time based.

Q20-Time Frame (Please select the time frame you believe is most appropriate.)

Your response:

Median response: 3-Mid-range (4-10 years)

Change to reflect median

I do not wish to change my response because: Type Response Here

Q20-Impact (Please rate the degree of impact to career and technical education.) $1=$ Very Low Impact and $6=$ Very High Impact

Your response:

Median response: 4

Change to reflect median

I do not wish to change my response because: Type Response Here

Q20-Desirability (Please rate your perception of the desirability of the event.) $1=$ Very Undesirable and $5=$ Very Desirable

Your response:

Median response: 4

Change to reflect median

I do not wish to change my response because: Type Response Here 


\section{Question 21}

The school calendar will change drastically, perhaps even becoming individualized depending on geographic area of the state(s).

Q21-Time Frame (Please select the time frame you believe is most appropriate.)

Your response:

Median response: 3-Mid-range (4-10 years)

Change to reflect median

I do not wish to change my response because: Type Response Here

Q21-Impact (Please rate the degree of impact to career and technical education.) $1=$ Very Low Impact and $6=$ Very High Impact

Your response:

Median response: 3

Change to reflect median

I do not wish to change my response because: Type Response Here

Q21-Desirability (Please rate your perception of the desirability of the event.) $1=$ Very Undesirable and $5=$ Very Desirable

Your response:

Median response: 4

Change to reflect median

I do not wish to change my response because: Type Response Here 


\section{Question 22}

Active participation in Career and Technical Student Organizations (CTSO'S) will be a requirement to complete the CTE course with students routinely attending leadership and competitive events.

Q22-Time Frame (Please select the time frame you believe is most appropriate.)

Your response:

Median response: 3-Mid-range (4-10 years)

Change to reflect median

I do not wish to change my response because: Type Response Here

Q22-Impact (Please rate the degree of impact to career and technical education.) $1=$ Very Low Impact and $6=$ Very High Impact

Your response:

Median response: 4

Change to reflect median

I do not wish to change my response because: Type Response Here

Q22-Desirability (Please rate your perception of the desirability of the event.) $1=$ Very Undesirable and $5=$ Very Desirable

Your response:

Median response: 4

Change to reflect median

I do not wish to change my response because: Type Response Here 


\section{Question 23}

Career and Technical Education will be renamed to Technical Skills Achievement (TSA), meaning there is more of the industry certification focus than what we have now.

Q23-Time Frame (Please select the time frame you believe is most appropriate.)

Your response:

Median response: 3-Mid-range (4-10 years)

Change to reflect median

I do not wish to change my response because: Type Response Here

Q23-Impact (Please rate the degree of impact to career and technical education.) $1=$ Very Low Impact and $6=$ Very High Impact

Your response:

Median response: 4

Change to reflect median

I do not wish to change my response because: Type Response Here

Q23-Desirability (Please rate your perception of the desirability of the event.) $1=$ Very Undesirable and $5=$ Very Desirable

Your response:

Median response: 2

Change to reflect median

I do not wish to change my response because: Type Response Here 


\section{Question 24}

All stand-alone, academy and area CTE centers will have counselors, core-subject teachers and a student health center on campus.

Q24-Time Frame (Please select the time frame you believe is most appropriate.)

Your response:

Median response: 3-Mid-range (4-10 years)

Change to reflect median

I do not wish to change my response because: Type Response Here

Q24-Impact (Please rate the degree of impact to career and technical education.) $1=$ Very Low Impact and $6=$ Very High Impact

Your response:

Median response: 4

Change to reflect median

I do not wish to change my response because: Type Response Here

Q24-Desirability (Please rate your perception of the desirability of the event.) $1=$ Very Undesirable and $5=$ Very Desirable

Your response:

Median response: 5

Change to reflect median

I do not wish to change my response because: Type Response Here 
Question 25

CTE concentrations will be part of graduation requirements for all students.

Q25-Time Frame (Please select the time frame you believe is most appropriate.)

Your response:

Median response: 3-Mid-range (4-10 years)

Change to reflect median

I do not wish to change my response because: Type Response Here

Q25-Impact (Please rate the degree of impact to career and technical education.) $1=$ Very Low Impact and $6=$ Very High Impact

Your response:

Median response: 5

Change to reflect median

I do not wish to change my response because: Type Response Here

Q25-Desirability (Please rate your perception of the desirability of the event.) $1=$ Very Undesirable and $5=$ Very Desirable

Your response:

Median response: 5

Change to reflect median

I do not wish to change my response because: Type Response Here 


\section{Question 26}

\section{Global standardization of education, accreditation will occur.}

Q26-Time Frame (Please select the time frame you believe is most appropriate.)

Your response:

Median response: 3-Mid-range (4-10 years)

Change to reflect median

I do not wish to change my response because: Type Response Here

Q26-Impact (Please rate the degree of impact to career and technical education.) $1=$ Very Low Impact and $6=$ Very High Impact

Your response:

Median response: 4

Change to reflect median

I do not wish to change my response because: Type Response Here

Q26-Desirability (Please rate your perception of the desirability of the event.) $1=$ Very Undesirable and $5=$ Very Desirable

Your response:

Median response: 3

Change to reflect median

I do not wish to change my response because: Type Response Here 
Question 27

Those secondary programs that were called "practical"; e.g., technology education will receive decreasing support until they no longer exist.

Q27-Time Frame (Please select the time frame you believe is most appropriate.)

Your response:

Median response: 2-Immediate (1-3 years)

Change to reflect median

I do not wish to change my response because: Type Response Here

Q27-Impact (Please rate the degree of impact to career and technical education.) $1=$ Very Low Impact and $6=$ Very High Impact

Your response:

Median response: 3

Change to reflect median

I do not wish to change my response because: Type Response Here

Q27-Desirability (Please rate your perception of the desirability of the event.) $1=$ Very Undesirable and $5=$ Very Desirable

Your response:

Median response: 2

Change to reflect median

I do not wish to change my response because: Type Response Here 


\section{Question 28}

\section{Traditional lines of schools, districts and institutions will blur.}

Q28-Time Frame (Please select the time frame you believe is most appropriate.)

Your response:

Median response: 3-Mid-range (4-10 years)

Change to reflect median

I do not wish to change my response because: Type Response Here

Q28-Impact (Please rate the degree of impact to career and technical education.) $1=$ Very Low Impact and $6=$ Very High Impact

Your response:

Median response: 4

Change to reflect median

I do not wish to change my response because: Type Response Here

Q28-Desirability (Please rate your perception of the desirability of the event.) $1=$ Very Undesirable and $5=$ Very Desirable

Your response:

Median response: 4

Change to reflect median

I do not wish to change my response because: Type Response Here 


\section{Technology}

Question 29

The United States and other advanced societies will move toward continuous innovation to meet job market demand, which is founded by information technology.

Q29-Time Frame (Please select the time frame you believe is most appropriate.)

Your response:

Median response: 3-Mid-range (4-10 years)

Change to reflect median

I do not wish to change my response because: Type Response Here

Q29-Impact (Please rate the degree of impact to career and technical education.) $1=$ Very Low Impact and $6=$ Very High Impact

Your response:

Median response: 4

Change to reflect median

I do not wish to change my response because: Type Response Here

Q29-Desirability (Please rate your perception of the desirability of the event.) $1=$ Very Undesirable and $5=$ Very Desirable

Your response:

Median response: 4

Change to reflect median

I do not wish to change my response because: Type Response Here 


\section{Question 30}

The development of the right side of the brain will be fostered by activities that require synthesis and holistic thinking.

Q30-Time Frame (Please select the time frame you believe is most appropriate.)

Your response:

Median response: 2-Immediate (1-3 years)

Change to reflect median

I do not wish to change my response because: Type Response Here

Q30-Impact (Please rate the degree of impact to career and technical education.) $1=$ Very Low Impact and $6=$ Very High Impact

Your response:

Median response: 4

Change to reflect median

I do not wish to change my response because: Type Response Here

Q30-Desirability (Please rate your perception of the desirability of the event.) $1=$ Very Undesirable and $5=$ Very Desirable

Your response:

Median response: 4

Change to reflect median

I do not wish to change my response because: Type Response Here 


\section{Question 31}

\section{Continued globalization will result in multi-national education programs.}

Q31-Time Frame (Please select the time frame you believe is most appropriate.)

Your response:

Median response: 3-Mid-range (4-10 years)

Change to reflect median

I do not wish to change my response because: Type Response Here

Q31-Impact (Please rate the degree of impact to career and technical education.) $1=$ Very Low Impact and $6=$ Very High Impact

Your response:

Median response: 4

Change to reflect median

I do not wish to change my response because: Type Response Here

Q31-Desirability (Please rate your perception of the desirability of the event.) $1=$ Very Undesirable and $5=$ Very Desirable

Your response:

Median response: 3

Change to reflect median

I do not wish to change my response because: Type Response Here 


\section{Question 32}

The goal of career technical education systems in 20 years will be to produce flexible, resilient, softwaresupported students, workers and citizens who can successfully compete, thrive, and live with dignity in a technology-driven Continuous Innovation Society capable of embracing constantly changing goods and services of consumer needs.

Q32-Time Frame (Please select the time frame you believe is most appropriate.)

Your response:

Median response: 4-Long-range (11-20 years)

Change to reflect median

I do not wish to change my response because: Type Response Here

Q32-Impact (Please rate the degree of impact to career and technical education.) $1=$ Very Low Impact and $6=$ Very High Impact

Your response:

Median response: 4

Change to reflect median

I do not wish to change my response because: Type Response Here

Q32-Desirability (Please rate your perception of the desirability of the event.) $1=$ Very Undesirable and $5=$ Very Desirable

Your response:

Median response: 4

Change to reflect median

I do not wish to change my response because: Type Response Here 


\section{Question 33}

Learning in career and technical education will be performance and innovation based.

Q33-Time Frame (Please select the time frame you believe is most appropriate.)

Your response:

Median response: 3-Mid-range (4-10 years)

Change to reflect median

I do not wish to change my response because: Type Response Here

Q33-Impact (Please rate the degree of impact to career and technical education.) $1=$ Very Low Impact and $6=$ Very High Impact

Your response:

Median response: 4

Change to reflect median

I do not wish to change my response because: Type Response Here

Q33-Desirability (Please rate your perception of the desirability of the event.) $1=$ Very Undesirable and $5=$ Very Desirable

Your response:

Median response: 5

Change to reflect median

I do not wish to change my response because: Type Response Here 


\section{Question 34}

Rural America with no access to high speed internet will get access.

Q34-Time Frame (Please select the time frame you believe is most appropriate.)

Your response:

Median response: 3-Mid-range (4-10 years)

Change to reflect median

I do not wish to change my response because: Type Response Here

Q34-Impact (Please rate the degree of impact to career and technical education.) $1=$ Very Low Impact and $6=$ Very High Impact

Your response:

Median response: 3

Change to reflect median

I do not wish to change my response because: Type Response Here

Q34-Desirability (Please rate your perception of the desirability of the event.) $1=$ Very Undesirable and $5=$ Very Desirable

Your response:

Median response: 5

Change to reflect median

I do not wish to change my response because: Type Response Here 


\section{Question 35}

International Business will be added to programming in CTE.

Q35-Time Frame (Please select the time frame you believe is most appropriate.)

Your response:

Median response: 3-Mid-range (4-10 years)

Change to reflect median

I do not wish to change my response because: Type Response Here

Q35-Impact (Please rate the degree of impact to career and technical education.) $1=$ Very Low Impact and $6=$ Very High Impact

Your response:

Median response: 4

Change to reflect median

I do not wish to change my response because: Type Response Here

Q35-Desirability (Please rate your perception of the desirability of the event.) $1=$ Very Undesirable and $5=$ Very Desirable

Your response:

Median response: 4

Change to reflect median

I do not wish to change my response because: Type Response Here 


\section{Question 36}

Green technology initiatives emerge as new CTE programs.

Q36-Time Frame (Please select the time frame you believe is most appropriate.)

Your response:

Median response: 2-Immediate (1-3 years)

Change to reflect median

I do not wish to change my response because: Type Response Here

Q36-Impact (Please rate the degree of impact to career and technical education.) $1=$ Very Low Impact and $6=$ Very High Impact

Your response:

Median response: 4

Change to reflect median

I do not wish to change my response because: Type Response Here

Q36-Desirability (Please rate your perception of the desirability of the event.) $1=$ Very Undesirable and $5=$ Very Desirable

Your response:

Median response: 5

Change to reflect median

I do not wish to change my response because: Type Response Here 
Question 37

Modernizing CTE centers will be vital in maintaining an edge in the labor market.

Q37-Time Frame (Please select the time frame you believe is most appropriate.)

Your response:

Median response: 3-Mid-range (4-10 years)

Change to reflect median

I do not wish to change my response because: Type Response Here

Q37-Impact (Please rate the degree of impact to career and technical education.) $1=$ Very Low Impact and $6=$ Very High Impact

Your response:

Median response: 5

Change to reflect median

I do not wish to change my response because: Type Response Here

Q37-Desirability (Please rate your perception of the desirability of the event.) $1=$ Very Undesirable and $5=$ Very Desirable

Your response:

Median response: 5

Change to reflect median

I do not wish to change my response because: Type Response Here 


\section{Question 38}

Career and technical education will play a major role in STEM (Science, Technology, Engineering and Mathematics) education.

Q38-Time Frame (Please select the time frame you believe is most appropriate.)

Your response:

Median response: 2-Immediate (1-3 years)

Change to reflect median

I do not wish to change my response because: Type Response Here

Q38-Impact (Please rate the degree of impact to career and technical education.) $1=$ Very Low Impact and $6=$ Very High Impact

Your response:

Median response: 5

Change to reflect median

I do not wish to change my response because: Type Response Here

Q38-Desirability (Please rate your perception of the desirability of the event.) $1=$ Very Undesirable and $5=$ Very Desirable

Your response:

Median response: 5

Change to reflect median

I do not wish to change my response because: Type Response Here 
Question 39

Career and technical education will include the teaching of soft skills such as the ability to work well together in its programming.

Q39-Time Frame (Please select the time frame you believe is most appropriate.)

Your response:

Median response: 2-Immediate (1-3 years)

Change to reflect median

I do not wish to change my response because: Type Response Here

Q39-Impact (Please rate the degree of impact to career and technical education.) $1=$ Very Low Impact and $6=$ Very High Impact

Your response:

Median response: 4

Change to reflect median

I do not wish to change my response because: Type Response Here

Q39-Desirability (Please rate your perception of the desirability of the event.) $1=$ Very Undesirable and $5=$ Very Desirable

Your response:

Median response: 5

Change to reflect median

I do not wish to change my response because: Type Response Here 


\section{Question 40}

Career development of life-long learners at ALL levels will become very important as we move from the manufacturing model to individualization.

Q40-Time Frame (Please select the time frame you believe is most appropriate.)

Your response:

Median response: 3-Mid-range (4-10 years)

Change to reflect median

I do not wish to change my response because: Type Response Here

Q40-Impact (Please rate the degree of impact to career and technical education.) $1=$ Very Low Impact and $6=$ Very High Impact

Your response:

Median response: 4

Change to reflect median

I do not wish to change my response because: Type Response Here

Q40-Desirability (Please rate your perception of the desirability of the event.) $1=$ Very Undesirable and $5=$ Very Desirable

Your response:

Median response: 4

Change to reflect median

I do not wish to change my response because: Type Response Here 


\section{Question 41}

Societal changes and more ethnic diversity will occur at a faster rate thus increasing the need to understand and tolerate the cultural needs and function of others amongst us.

Q41-Time Frame (Please select the time frame you believe is most appropriate.)

Your response:

Median response: 2-Immediate $(1=3$ years $)$

Change to reflect median

I do not wish to change my response because: Type Response Here

Q41-Impact (Please rate the degree of impact to career and technical education.) $1=$ Very Low Impact and $6=$ Very High Impact

Your response:

Median response: 4

Change to reflect median

I do not wish to change my response because: Type Response Here

Q41-Desirability (Please rate your perception of the desirability of the event.) $1=$ Very Undesirable and $5=$ Very Desirable

Your response:

Median response: 4

Change to reflect median

I do not wish to change my response because: Type Response Here 


\section{Question 42}

Instructional technology (ex. virtual learning) will increase its presence as a course delivery component.

Q42-Time Frame (Please select the time frame you believe is most appropriate.)

Your response:

Median response: 2-Immediate (1-3 years)

Change to reflect median

I do not wish to change my response because: Type Response Here

Q1-Impact (Please rate the degree of impact to career and technical education.) $1=$ Very Low Impact and $6=$ Very High Impact

Your response:

Median response: 4

Change to reflect median

I do not wish to change my response because: Type Response Here

Q1-Desirability (Please rate your perception of the desirability of the event.) $1=$ Very Undesirable and $5=$ Very Desirable

Your response:

Median response: 4

Change to reflect median

I do not wish to change my response because: Type Response Here 


\section{Question 43}

Technology advances will continue to drive curriculum and program changes increasing learning outside of the brick walls at all levels.

Q43-Time Frame (Please select the time frame you believe is most appropriate.)

Your response:

Median response: 2-Immediate (1-3 years)

Change to reflect median

I do not wish to change my response because: Type Response Here

Q43-Impact (Please rate the degree of impact to career and technical education.) $1=$ Very Low Impact and $6=$ Very High Impact

Your response:

Median response: 4

Change to reflect median

I do not wish to change my response because: Type Response Here

Q43-Desirability (Please rate your perception of the desirability of the event.) $1=$ Very Undesirable and $5=$ Very Desirable

Your response:

Median response: 4

Change to reflect median

I do not wish to change my response because: Type Response Here 


\section{Question 44}

Change in public education will be strongly influenced by outside innovators.

Q44-Time Frame (Please select the time frame you believe is most appropriate.)

Your response:

Median response: 3-Mid-range (4-10 years)

Change to reflect median

I do not wish to change my response because: Type Response Here

Q44-Impact (Please rate the degree of impact to career and technical education.) $1=$ Very Low Impact and $6=$ Very High Impact

Your response:

Median response: 4

Change to reflect median

I do not wish to change my response because: Type Response Here

Q44-Desirability (Please rate your perception of the desirability of the event.) $1=$ Very Undesirable and $5=$ Very Desirable

Your response:

Median response: 3

Change to reflect median

I do not wish to change my response because: Type Response Here 


\section{Question 45}

Project-based and work-based learning will become more common.

Q45-Time Frame (Please select the time frame you believe is most appropriate.)

Your response:

Median response: 2-Immediate (1-2 years)

Change to reflect median

I do not wish to change my response because: Type Response Here

Q1-Impact (Please rate the degree of impact to career and technical education.) $1=$ Very Low Impact and $6=$ Very High Impact

Your response:

Median response: 4

Change to reflect median

I do not wish to change my response because: Type Response Here

Q45-Desirability (Please rate your perception of the desirability of the event.) $1=$ Very Undesirable and $5=$ Very Desirable

Your response:

Median response: 5

Change to reflect median

I do not wish to change my response because: Type Response Here 


\section{Question 46}

The use of technology to drive the teaching and learning process will become common place.

Q46-Time Frame (Please select the time frame you believe is most appropriate.)

Your response:

Median response: 2-Immediate (1-3 years)

Change to reflect median

I do not wish to change my response because: Type Response Here

Q46-Impact (Please rate the degree of impact to career and technical education.) $1=$ Very Low Impact and $6=$ Very High Impact

Your response:

Median response: 4

Change to reflect median

I do not wish to change my response because: Type Response Here

Q46-Desirability (Please rate your perception of the desirability of the event.) $1=$ Very Undesirable and $5=$ Very Desirable

Your response:

Median response: 5

Change to reflect median

I do not wish to change my response because: Type Response Here 


\section{Political Issues}

\section{Question 47}

Student flight from low performance public schools to other viable options will occur.

Q47-Time Frame (Please select the time frame you believe is most appropriate.)

Your response:

Median response: 3-Mid-range (4-10 years)

Change to reflect median

I do not wish to change my response because: Type Response Here

Q47-Impact (Please rate the degree of impact to career and technical education.) $1=$ Very Low Impact and $6=$ Very High Impact

Your response:

Median response: 4

Change to reflect median

I do not wish to change my response because: Type Response Here

Q47-Desirability (Please rate your perception of the desirability of the event.) $1=$ Very Undesirable and $5=$ Very Desirable

Your response:

Median response: 3

Change to reflect median

I do not wish to change my response because: Type Response Here 


\section{Question 48}

Current education hierarchies will be challenged, especially the school board authority, will be eliminated as an archaic way of running a school system.

Q48-Time Frame (Please select the time frame you believe is most appropriate.)

Your response:

Median response: 3-Mid-range (4-10 years)

Change to reflect median

I do not wish to change my response because: Type Response Here

Q48-Impact (Please rate the degree of impact to career and technical education.) $1=$ Very Low Impact and $6=$ Very High Impact

Your response:

Median response: 3

Change to reflect median

I do not wish to change my response because: Type Response Here

Q48-Desirability (Please rate your perception of the desirability of the event.) $1=$ Very Undesirable and $5=$ Very Desirable

Your response:

Median response: 3

Change to reflect median

I do not wish to change my response because: Type Response Here 


\section{Question 49}

There will be a concentrated evaluation of the qualifications for County (or Regional) Board of Education membership---there will be a requirement that individuals have some interest in or value for education and the public schools - and, perhaps, even some education themselves, which will take the credibility and influence of Board Members up several notches.

Q49-Time Frame (Please select the time frame you believe is most appropriate.)

Your response:

Median response: 3-Mid-range (4-10 years)

Change to reflect median

I do not wish to change my response because: Type Response Here

Q49-Impact (Please rate the degree of impact to career and technical education.) $1=$ Very Low Impact and $6=$ Very High Impact

Your response:

Median response: 4

Change to reflect median

I do not wish to change my response because: Type Response Here

Q49-Desirability (Please rate your perception of the desirability of the event.) $1=$ Very Undesirable and $5=$ Very Desirable

Your response:

Median response: 4

Change to reflect median

I do not wish to change my response because: Type Response Here 
Question 50

Decision and policy makers will realize the gravity of allowing CTE to continue as the dumping ground for students who cannot succeed in the general education classroom.

Q50-Time Frame (Please select the time frame you believe is most appropriate.)

Your response:

Median response: 2-Immediate (1-3 years)

Change to reflect median

I do not wish to change my response because: Type Response Here

Q50-Impact (Please rate the degree of impact to career and technical education.) $1=$ Very Low Impact and $6=$ Very High Impact

Your response:

Median response: 5

Change to reflect median

I do not wish to change my response because: Type Response Here

Q50-Desirability (Please rate your perception of the desirability of the event.) $1=$ Very Undesirable and $5=$ Very Desirable

Your response:

Median response: 5

Change to reflect median

I do not wish to change my response because: Type Response Here 


\section{Question 51}

Public education will remain but there will be expansion of private sector education and new hybrids of publicprivate sector partnerships.

Q51-Time Frame (Please select the time frame you believe is most appropriate.)

Your response:

Median response: 3-Mid-range (4-10 years)

Change to reflect median

I do not wish to change my response because: Type Response Here

Q51-Impact (Please rate the degree of impact to career and technical education.) $1=$ Very Low Impact and $6=$ Very High Impact

Your response:

Median response: 4

Change to reflect median

I do not wish to change my response because: Type Response Here

Q51-Desirability (Please rate your perception of the desirability of the event.) $1=$ Very Undesirable and $5=$ Very Desirable

Your response:

Median response: 3

Change to reflect median

I do not wish to change my response because: Type Response Here 


\section{Question 52}

High school dropout rates will continue to climb due to a disengaged student population from middle school upward.

Q52-Time Frame (Please select the time frame you believe is most appropriate.)

Your response:

Median response: 2-Immediate (1-3 years)

Change to reflect median

I do not wish to change my response because: Type Response Here

Q52-Impact (Please rate the degree of impact to career and technical education.) $1=$ Very Low Impact and $6=$ Very High Impact

Your response:

Median response: 4

Change to reflect median

I do not wish to change my response because: Type Response Here

Q52-Desirability (Please rate your perception of the desirability of the event.) $1=$ Very Undesirable and $5=$ Very Desirable

Your response:

Median response: 2

Change to reflect median

I do not wish to change my response because: Type Response Here 


\section{Question 53}

Career and technical education facilities and programs will have a strong, vocal and informed voice on Capitol Hill.

Q53-Time Frame (Please select the time frame you believe is most appropriate.)

Your response:

Median response: 3-Mid-range (4-10 years)

Change to reflect median

I do not wish to change my response because: Type Response Here

Q53-Impact (Please rate the degree of impact to career and technical education.) $1=$ Very Low Impact and $6=$ Very High Impact

Your response:

Median response: 5

Change to reflect median

I do not wish to change my response because: Type Response Here

Q53-Desirability (Please rate your perception of the desirability of the event.) $1=$ Very Undesirable and $5=$ Very Desirable

Your response:

Median response: 5

Change to reflect median

I do not wish to change my response because: Type Response Here 


\section{Question 54}

Global, national, state, regional and local economic changes cause greater shifts in the wealth of populations.

Q54-Time Frame (Please select the time frame you believe is most appropriate.)

Your response:

Median response: 3-Mid-range (4-10 years)

Change to reflect median

I do not wish to change my response because: Type Response Here

Q54-Impact (Please rate the degree of impact to career and technical education.) $1=$ Very Low Impact and $6=$ Very High Impact

Your response:

Median response: 4

Change to reflect median

I do not wish to change my response because: Type Response Here

Q54-Desirability (Please rate your perception of the desirability of the event.) $1=$ Very Undesirable and $5=$ Very Desirable

Your response:

Median response: 3

Change to reflect median

I do not wish to change my response because: Type Response Here 


\section{Question 55}

China and India will control the world economically pushing the United States to get very serious about creating, implementing and marketing innovation.

Q55-Time Frame (Please select the time frame you believe is most appropriate.)

Your response:

Median response: 2-Immediate (1-3 years)

Change to reflect median

I do not wish to change my response because: Type Response Here

Q55-Impact (Please rate the degree of impact to career and technical education.) $1=$ Very Low Impact and $6=$ Very High Impact

Your response:

Median response: 5

Change to reflect median

I do not wish to change my response because: Type Response Here

Q55-Desirability (Please rate your perception of the desirability of the event.) $1=$ Very Undesirable and $5=$ Very Desirable

Your response:

Median response: 2

Change to reflect median

I do not wish to change my response because: Type Response Here 


\section{Question 56}

Social systems move from the old manufacturing models of education, work and life to one where individuals decide what path they want to follow to fit in the global scheme.

Q56-Time Frame (Please select the time frame you believe is most appropriate.)

Your response:

Median response: 3-Mid-range (4-10 years)

Change to reflect median

I do not wish to change my response because: Type Response Here

Q56-Impact (Please rate the degree of impact to career and technical education.) $1=$ Very Low Impact and $6=$ Very High Impact

Your response:

Median response: 4

Change to reflect median

I do not wish to change my response because: Type Response Here

Q56-Desirability (Please rate your perception of the desirability of the event.) $1=$ Very Undesirable and $5=$ Very Desirable

Your response:

Median response: 4

Change to reflect median

I do not wish to change my response because: Type Response Here 


\section{Personnel}

\section{Question 57}

Educators in career and technical education fields will be required to hold postsecondary degrees (associate, bachelor or master).

Q57-Time Frame (Please select the time frame you believe is most appropriate.)

Your response:

Median response: 3-Mid-range (4-10 years)

Change to reflect median

I do not wish to change my response because: Type Response Here

Q57-Impact (Please rate the degree of impact to career and technical education.) $1=$ Very Low Impact and $6=$ Very High Impact

Your response:

Median response: 4

Change to reflect median

I do not wish to change my response because: Type Response Here

Q57-Desirability (Please rate your perception of the desirability of the event.) $1=$ Very Undesirable and $5=$ Very Desirable

Your response:

Median response: 4

Change to reflect median

I do not wish to change my response because: Type Response Here 


\section{Question 58}

\section{Career and technical education teachers will be required to hold industry certification.}

Q58-Time Frame (Please select the time frame you believe is most appropriate.)

Your response:

Median response: 3-Mid-range (4-10 years)

Change to reflect median

I do not wish to change my response because: Type Response Here

Q58-Impact (Please rate the degree of impact to career and technical education.) $1=$ Very Low Impact and $6=$ Very High Impact

Your response:

Median response: 4

Change to reflect median

I do not wish to change my response because: Type Response Here

Q58-Desirability (Please rate your perception of the desirability of the event.) $1=$ Very Undesirable and $5=$ Very Desirable

Your response:

Median response: 5

Change to reflect median

I do not wish to change my response because: Type Response Here 


\section{Question 59}

\section{The demand for CTE teachers will increase.}

Q59-Time Frame (Please select the time frame you believe is most appropriate.)

Your response:

Median response: 3-Mid-range (4-10 years)

Change to reflect median

I do not wish to change my response because: Type Response Here

Q59-Impact (Please rate the degree of impact to career and technical education.) $1=$ Very Low Impact and $6=$ Very High Impact

Your response:

Median response: 5

Change to reflect median

I do not wish to change my response because: Type Response Here

Q59-Desirability (Please rate your perception of the desirability of the event.) $1=$ Very Undesirable and $5=$ Very Desirable

Your response:

Median response: 5

Change to reflect median

I do not wish to change my response because: Type Response Here 


\section{Question 60}

Teacher education programs for CTE teachers will change significantly as a result of the blending of technical and academic delivery.

Q60-Time Frame (Please select the time frame you believe is most appropriate.)

Your response:

Median response: 3-Mid-range (4-10 years)

Change to reflect median

I do not wish to change my response because: Type Response Here

Q60-Impact (Please rate the degree of impact to career and technical education.) $1=$ Very Low Impact and $6=$ Very High Impact

Your response:

Median response: 5

Change to reflect median

I do not wish to change my response because: Type Response Here

Q60-Desirability (Please rate your perception of the desirability of the event.) $1=$ Very Undesirable and $5=$ Very Desirable

Your response:

Median response: 5

Change to reflect median

I do not wish to change my response because: Type Response Here 


\section{Question 61}

There will be a teacher education tract in higher education for those wishing to pursue a career in industrial, technical or health occupations education much like regular education fields.

Q61-Time Frame (Please select the time frame you believe is most appropriate.)

Your response:

Median response: 3-Mid-range (4-10 years)

Change to reflect median

I do not wish to change my response because: Type Response Here

Q61-Impact (Please rate the degree of impact to career and technical education.) $1=$ Very Low Impact and $6=$ Very High Impact

Your response:

Median response: 4

Change to reflect median

I do not wish to change my response because: Type Response Here

Q61-Desirability (Please rate your perception of the desirability of the event.) $1=$ Very Undesirable and $5=$ Very Desirable

Your response:

Median response: 4

Change to reflect median

I do not wish to change my response because: Type Response Here 


\section{Question 62}

Many teachers will be part-time as opposed to full-time.

Q62-Time Frame (Please select the time frame you believe is most appropriate.)

Your response:

Median response: 3-Mid-range (4-10 years)

Change to reflect median

I do not wish to change my response because: Type Response Here

Q62-Impact (Please rate the degree of impact to career and technical education.) $1=$ Very Low Impact and $6=$ Very High Impact

Your response:

Median response: 4

Change to reflect median

I do not wish to change my response because: Type Response Here

Q62-Desirability (Please rate your perception of the desirability of the event.) $1=$ Very Undesirable and $5=$ Very Desirable

Your response:

Median response: 3

Change to reflect median

I do not wish to change my response because: Type Response Here 


\section{Question 63}

\section{CTE performance based educator pay will come to the forefront.}

Q63-Time Frame (Please select the time frame you believe is most appropriate.)

Your response:

Median response: 3-Mid-range (4-10 years)

Change to reflect median

I do not wish to change my response because: Type Response Here

Q63-Impact (Please rate the degree of impact to career and technical education.) $1=$ Very Low Impact and $6=$ Very High Impact

Your response:

Median response: 4

Change to reflect median

I do not wish to change my response because: Type Response Here

Q63-Desirability (Please rate your perception of the desirability of the event.) $1=$ Very Undesirable and $5=$ Very Desirable

Your response:

Median response: 3

Change to reflect median

I do not wish to change my response because: Type Response Here 


\section{Question 64}

CTE instructors must understand and participate in professional development activities to prepare them for the subjects being taught and with a variety of strategies.

Q64-Time Frame (Please select the time frame you believe is most appropriate.)

Your response:

Median response: 2-Immediate (1-3 years)

Change to reflect median

I do not wish to change my response because: Type Response Here

Q64-Impact (Please rate the degree of impact to career and technical education.) $1=$ Very Low Impact and $6=$ Very High Impact

Your response:

Median response: 4

Change to reflect median

I do not wish to change my response because: Type Response Here

Q64-Desirability (Please rate your perception of the desirability of the event.) $1=$ Very Undesirable and $5=$ Very Desirable

Your response:

Median response: 5

Change to reflect median

I do not wish to change my response because: Type Response Here 


\section{Question 65}

\section{CTE programs will have great teachers who foster passion and curiosity.}

Q65-Time Frame (Please select the time frame you believe is most appropriate.)

Your response:

Median response: 2-Immediate (1-3 years)

Change to reflect median

I do not wish to change my response because: Type Response Here

Q65-Impact (Please rate the degree of impact to career and technical education.) $1=$ Very Low Impact and $6=$ Very High Impact

Your response:

Median response: 5

Change to reflect median

I do not wish to change my response because: Type Response Here

Q65-Desirability (Please rate your perception of the desirability of the event.) $1=$ Very Undesirable and $5=$ Very Desirable

Your response:

Median response: 5

Change to reflect median

I do not wish to change my response because: Type Response Here 


\section{Question 66}

Secondary school counselors will be informed and cognizant of the opportunities awaiting students in CTE programming.

Q66-Time Frame (Please select the time frame you believe is most appropriate.)

Your response:

Median response: 3-Mid-range (4-10 years)

Change to reflect median

I do not wish to change my response because: Type Response Here

Q66-Impact (Please rate the degree of impact to career and technical education.) $1=$ Very Low Impact and $6=$ Very High Impact

Your response:

Median response: 5

Change to reflect median

I do not wish to change my response because: Type Response Here

Q66-Desirability (Please rate your perception of the desirability of the event.) $1=$ Very Undesirable and $5=$ Very Desirable

Your response:

Median response: 5

Change to reflect median

I do not wish to change my response because: Type Response Here 


\section{Question 67}

Stakeholders in various realms of education (CTE, secondary, post-secondary, general secondary, higher ed) will emerge steadily as important informants and collaborators in not only evaluating, but also planning and execution instructional programs.

Q67-Time Frame (Please select the time frame you believe is most appropriate.)

Your response:

Median response: 3-Mid-range (4-10 years)

Change to reflect median

I do not wish to change my response because: Type Response Here

Q67-Impact (Please rate the degree of impact to career and technical education.) $1=$ Very Low Impact and $6=$ Very High Impact

Your response:

Median response: 4

Change to reflect median

I do not wish to change my response because: Type Response Here

Q67-Desirability (Please rate your perception of the desirability of the event.) $1=$ Very Undesirable and $5=$ Very Desirable

Your response:

Median response: 5

Change to reflect median

I do not wish to change my response because: Type Response Here 


\section{Question 68}

CTE Administrator preparation programs will be designed to better equip principals in the career and technical education realm.

Q68-Time Frame (Please select the time frame you believe is most appropriate.)

Your response:

Median response: 3-Mid-range (4-10 years)

Change to reflect median

I do not wish to change my response because: Type Response Here

Q68-Impact (Please rate the degree of impact to career and technical education.) $1=$ Very Low Impact and $6=$ Very High Impact

Your response:

Median response: 4

Change to reflect median

I do not wish to change my response because: Type Response Here

Q68-Desirability (Please rate your perception of the desirability of the event.) $1=$ Very Undesirable and $5=$ Very Desirable

Your response:

Median response: 5

Change to reflect median

I do not wish to change my response because: Type Response Here 


\section{Question 69}

There will be a shift in CTE governance resulting in an increase in contact between local educators and state/regional leaders.

Q69-Time Frame (Please select the time frame you believe is most appropriate.)

Your response:

Median response: 3-Mid-range (4-10 years)

Change to reflect median

I do not wish to change my response because: Type Response Here

Q69-Impact (Please rate the degree of impact to career and technical education.) $1=$ Very Low Impact and $6=$ Very High Impact

Your response:

Median response: 4

Change to reflect median

I do not wish to change my response because: Type Response Here

Q69-Desirability (Please rate your perception of the desirability of the event.) $1=$ Very Undesirable and $5=$ Very Desirable

Your response:

Median response: 4

Change to reflect median

I do not wish to change my response because: Type Response Here 


\section{Question 70}

Faculty will become consultants to students, who will become clients, while the students will become innovators and entrepreneurs.

Q70-Time Frame (Please select the time frame you believe is most appropriate.)

Your response:

Median response: 3-Mid-range (4-10 years)

Change to reflect median

I do not wish to change my response because: Type Response Here

Q70-Impact (Please rate the degree of impact to career and technical education.) $1=$ Very Low Impact and $6=$ Very High Impact

Your response:

Median response: 4

Change to reflect median

I do not wish to change my response because: Type Response Here

Q70-Desirability (Please rate your perception of the desirability of the event.) $1=$ Very Undesirable and $5=$ Very Desirable

Your response:

Median response: 4

Change to reflect median

I do not wish to change my response because: Type Response Here 


\section{Relationship with Business and Industry}

\section{Question 71}

The local industry advisory council will play a bigger role in ensuring that the lab tools and equipment are updated to meet and/or exceed the requirements of the workplace.

Q71-Time Frame (Please select the time frame you believe is most appropriate.)

Your response:

Median response: 3-Mid-range (4-10 years)

Change to reflect median

I do not wish to change my response because: Type Response Here

Q71-Impact (Please rate the degree of impact to career and technical education.) $1=$ Very Low Impact and $6=$ Very High Impact

Your response:

Median response: 4

Change to reflect median

I do not wish to change my response because: Type Response Here

Q71-Desirability (Please rate your perception of the desirability of the event.) $1=$ Very Undesirable and $5=$ Very Desirable

Your response:

Median response: 4

Change to reflect median

I do not wish to change my response because: Type Response Here 


\section{Question 72}

\section{The demand for skilled workers will increase.}

Q72-Time Frame (Please select the time frame you believe is most appropriate.)

Your response:

Median response: 2-Immediate (1-3 years)

Change to reflect median

I do not wish to change my response because: Type Response Here

Q72-Impact (Please rate the degree of impact to career and technical education.) $1=$ Very Low Impact and $6=$ Very High Impact

Your response:

Median response: 5

Change to reflect median

I do not wish to change my response because: Type Response Here

Q72-Desirability (Please rate your perception of the desirability of the event.) $1=$ Very Undesirable and $5=$ Very Desirable

Your response:

Median response: 5

Change to reflect median

I do not wish to change my response because: Type Response Here 


\section{Question 73}

\section{Collaboration between stakeholders and CTE will increase.}

Q73-Time Frame (Please select the time frame you believe is most appropriate.)

Your response:

Median response: 2-Immediate (1-3 years)

Change to reflect median

I do not wish to change my response because: Type Response Here

Q73-Impact (Please rate the degree of impact to career and technical education.) $1=$ Very Low Impact and $6=$ Very High Impact

Your response:

Median response: 4

Change to reflect median

I do not wish to change my response because: Type Response Here

Q73-Desirability (Please rate your perception of the desirability of the event.) $1=$ Very Undesirable and $5=$ Very Desirable

Your response:

Median response: 5

Change to reflect median

I do not wish to change my response because: Type Response Here 


\section{Question 74}

The demand for workers with postsecondary education will increase.

Q74-Time Frame (Please select the time frame you believe is most appropriate.)

Your response:

Median response: 2-Immediate (1-3 years)

Change to reflect median

I do not wish to change my response because: Type Response Here

Q74-Impact (Please rate the degree of impact to career and technical education.) $1=$ Very Low Impact and $6=$ Very High Impact

Your response:

Median response: 4

Change to reflect median

I do not wish to change my response because: Type Response Here

Q74-Desirability (Please rate your perception of the desirability of the event.) $1=$ Very Undesirable and $5=$ Very Desirable

Your response:

Median response: 5

Change to reflect median

I do not wish to change my response because: Type Response Here 
Question 75

Career and technical education will be called upon to retrain America's workforce.

Q75-Time Frame (Please select the time frame you believe is most appropriate.)

Your response:

Median response: 3-Mid-range (4-10 years)

Change to reflect median

I do not wish to change my response because: Type Response Here

Q75-Impact (Please rate the degree of impact to career and technical education.) $1=$ Very Low Impact and $6=$ Very High Impact

Your response:

Median response: 5

Change to reflect median

I do not wish to change my response because: Type Response Here

Q75-Desirability (Please rate your perception of the desirability of the event.) $1=$ Very Undesirable and $5=$ Very Desirable

Your response:

Median response: 5

Change to reflect median

I do not wish to change my response because: Type Response Here 


\section{Question 76}

The focus of education will be on workforce development, which will mean the alignment of education and work and the use of data to develop what programs are offered.

Q76-Time Frame (Please select the time frame you believe is most appropriate.)

Your response:

Median response: 3-Mid-range (4-10 years)

Change to reflect median

I do not wish to change my response because: Type Response Here

Q76-Impact (Please rate the degree of impact to career and technical education.) $1=$ Very Low Impact and $6=$ Very High Impact

Your response:

Median response: 4

Change to reflect median

I do not wish to change my response because: Type Response Here

Q76-Desirability (Please rate your perception of the desirability of the event.) $1=$ Very Undesirable and $5=$ Very Desirable

Your response:

Median response: 4

Change to reflect median

I do not wish to change my response because: Type Response Here 


\section{Question 77}

CTE is the link that connects business leaders with educators in a unified effort to help all students understand the relevance of their education to their future goals and prepare them with the knowledge, talent and skills valued and needed in today's workplace.

Q77-Time Frame (Please select the time frame you believe is most appropriate.)

Your response:

Median response: 2-Immediate (1-3 years)

Change to reflect median

I do not wish to change my response because: Type Response Here

Q77-Impact (Please rate the degree of impact to career and technical education.) $1=$ Very Low Impact and $6=$ Very High Impact

Your response:

Median response: 4

Change to reflect median

I do not wish to change my response because: Type Response Here

Q77-Desirability (Please rate your perception of the desirability of the event.) $1=$ Very Undesirable and $5=$ Very Desirable

Your response:

Median response: 4

Change to reflect median

I do not wish to change my response because: Type Response Here 


\section{Question 78}

Jobs will constantly evolve to meet workforce demand forcing constant updating for career technical education in America formulating an Innovation Society driven by continuously enhanced human capital.

Q78-Time Frame (Please select the time frame you believe is most appropriate.)

Your response:

Median response: 2-Immediate (1-3 years)

Change to reflect median

I do not wish to change my response because: Type Response Here

Q78-Impact (Please rate the degree of impact to career and technical education.) $1=$ Very Low Impact and $6=$ Very High Impact

Your response:

Median response: 5

Change to reflect median

I do not wish to change my response because: Type Response Here

Q78-Desirability (Please rate your perception of the desirability of the event.) $1=$ Very Undesirable and $5=$ Very Desirable

Your response:

Median response: 5

Change to reflect median

I do not wish to change my response because: Type Response Here 


\section{Question 79}

All students will seek more specific technical skills training in order to be more competitive in the workplace.

Q79-Time Frame (Please select the time frame you believe is most appropriate.)

Your response:

Median response: 3-Mid-range (4-10 years)

Change to reflect median

I do not wish to change my response because: Type Response Here

Q79-Impact (Please rate the degree of impact to career and technical education.) $1=$ Very Low Impact and $6=$ Very High Impact

Your response:

Median response: 5

Change to reflect median

I do not wish to change my response because: Type Response Here

Q79-Desirability (Please rate your perception of the desirability of the event.) $1=$ Very Undesirable and $5=$ Very Desirable

Your response:

Median response: 5

Change to reflect median

I do not wish to change my response because: Type Response Here 


\section{Question 80}

CTE will serve as the change agent in building existing governance structures to bring state, regional and local leaders in education, workforce and economic development together to support and grow each state's economy.

Q80-Time Frame (Please select the time frame you believe is most appropriate.)

Your response:

Median response: 3-Mid-range (4-10 years)

Change to reflect median

I do not wish to change my response because: Type Response Here

Q80-Impact (Please rate the degree of impact to career and technical education.) $1=$ Very Low Impact and $6=$ Very High Impact

Your response:

Median response: 5

Change to reflect median

I do not wish to change my response because: Type Response Here

Q80-Desirability (Please rate your perception of the desirability of the event.) $1=$ Very Undesirable and $5=$ Very Desirable

Your response:

Median response: 5

Change to reflect median

I do not wish to change my response because: Type Response Here 


\section{Relationship with Higher Education}

\section{Question 81}

Post secondary CTE programs will be absorbed in the community college system.

Q81-Time Frame (Please select the time frame you believe is most appropriate.)

Your response:

Median response: 3-Mid-range (4-10 years)

Change to reflect median

I do not wish to change my response because: Type Response Here

Q81-Impact (Please rate the degree of impact to career and technical education.) $1=$ Very Low Impact and $6=$ Very High Impact

Your response:

Median response: 5

Change to reflect median

I do not wish to change my response because: Type Response Here

Q81-Desirability (Please rate your perception of the desirability of the event.) $1=$ Very Undesirable and $5=$ Very Desirable

Your response:

Median response: 5

Change to reflect median

I do not wish to change my response because: Type Response Here 


\section{Question 82}

Career and Technical Education will be recognized as a credible choice for college-bound high school students, rather than as a last resort for marginalized students.

Q82-Time Frame (Please select the time frame you believe is most appropriate.)

Your response:

Median response: 3-Mid-range (4-10 years)

Change to reflect median

I do not wish to change my response because: Type Response Here

Q82-Impact (Please rate the degree of impact to career and technical education.) $1=$ Very Low Impact and $6=$ Very High Impact

Your response:

Median response: 5

Change to reflect median

I do not wish to change my response because: Type Response Here

Q82-Desirability (Please rate your perception of the desirability of the event.) $1=$ Very Undesirable and $5=$ Very Desirable

Your response:

Median response: 5

Change to reflect median

I do not wish to change my response because: Type Response Here 


\section{Question 83}

There will be better program alignment with community colleges enabling a much more seamless transition to post secondary education.

Q83-Time Frame (Please select the time frame you believe is most appropriate.)

Your response:

Median response: 3-Mid-range (4-10 years)

Change to reflect median

I do not wish to change my response because: Type Response Here

Q83-Impact (Please rate the degree of impact to career and technical education.) $1=$ Very Low Impact and $6=$ Very High Impact

Your response:

Median response: 4

Change to reflect median

I do not wish to change my response because: Type Response Here

Q83-Desirability (Please rate your perception of the desirability of the event.) $1=$ Very Undesirable and $5=$ Very Desirable

Your response:

Median response: 4

Change to reflect median

I do not wish to change my response because: Type Response Here 


\section{Question 84}

Higher education will offer multiple tracks for advancement through the degree process for students entering from Career and Technical Education with certifications/completions in similar career fields.

Q84-Time Frame (Please select the time frame you believe is most appropriate.)

Your response:

Median response: 3-Mid-range (4-10 years)

Change to reflect median

I do not wish to change my response because: Type Response Here

Q84-Impact (Please rate the degree of impact to career and technical education.) $1=$ Very Low Impact and $6=$ Very High Impact

Your response:

Median response: 4

Change to reflect median

I do not wish to change my response because: Type Response Here

Q84-Desirability (Please rate your perception of the desirability of the event.) $1=$ Very Undesirable and $5=$ Very Desirable

Your response:

Median response: 5

Change to reflect median

I do not wish to change my response because: Type Response Here 


\section{Question 85}

Worldwide articulation agreements will be implemented to assure smooth transition of students from high school to college and from college to college.

Q85-Time Frame (Please select the time frame you believe is most appropriate.)

Your response:

Median response: 3-Mid-range (4-10 years)

Change to reflect median

I do not wish to change my response because: Type Response Here

Q85-Impact (Please rate the degree of impact to career and technical education.) $1=$ Very Low Impact and $6=$ Very High Impact

Your response:

Median response: 5

Change to reflect median

I do not wish to change my response because: Type Response Here

Q85-Desirability (Please rate your perception of the desirability of the event.) $1=$ Very Undesirable and $5=$ Very Desirable

Your response:

Median response: 5

Change to reflect median

I do not wish to change my response because: Type Response Here 


\section{Question 86}

Learning centers will exist and traditional schools will be obsolete.

Q86-Time Frame (Please select the time frame you believe is most appropriate.)

Your response:

Median response: 4-Long-range (11-20 years)

Change to reflect median

I do not wish to change my response because: Type Response Here

Q86-Impact (Please rate the degree of impact to career and technical education.) $1=$ Very Low Impact and $6=$ Very High Impact

Your response:

Median response: 5

Change to reflect median

I do not wish to change my response because: Type Response Here

Q86-Desirability (Please rate your perception of the desirability of the event.) $1=$ Very Undesirable and $5=$ Very Desirable

Your response:

Median response: 3

Change to reflect median

I do not wish to change my response because: Type Response Here 


\section{Question 87}

The chasm between secondary and postsecondary career and technical education will either get smaller or be eliminated with the implementation of programs of study.

Q87-Time Frame (Please select the time frame you believe is most appropriate.)

Your response:

Median response: 3-Mid-range (4-10 years)

Change to reflect median

I do not wish to change my response because: Type Response Here

Q87-Impact (Please rate the degree of impact to career and technical education.) $1=$ Very Low Impact and $6=$ Very High Impact

Your response:

Median response: 4

Change to reflect median

I do not wish to change my response because: Type Response Here

Q87-Desirability (Please rate your perception of the desirability of the event.) $1=$ Very Undesirable and $5=$ Very Desirable

Your response:

Median response: 4

Change to reflect median

I do not wish to change my response because: Type Response Here 


\section{Question 88}

High school CTE will become more agile and focused on supporting transitions to higher education that support the local, regional, state, national and GLOBAL workforce and economic needs.

Q88-Time Frame (Please select the time frame you believe is most appropriate.)

Your response:

Median response: 3-Mid-range (4-10 years)

Change to reflect median

I do not wish to change my response because: Type Response Here

Q88-Impact (Please rate the degree of impact to career and technical education.) $1=$ Very Low Impact and $6=$ Very High Impact

Your response:

Median response: 4

Change to reflect median

I do not wish to change my response because: Type Response Here

Q88-Desirability (Please rate your perception of the desirability of the event.) $1=$ Very Undesirable and $5=$ Very Desirable

Your response:

Median response: 4

Change to reflect median

I do not wish to change my response because: Type Response Here 


\section{Question 89}

CTE will be a valuable part of all students' overall high school experience and is used to help them prepare for postsecondary education and/or training and career success.

Q89-Time Frame (Please select the time frame you believe is most appropriate.)

Your response:

Median response: 3-Mid-range (4-10 years)

Change to reflect median

I do not wish to change my response because: Type Response Here

Q89-Impact (Please rate the degree of impact to career and technical education.) $1=$ Very Low Impact and $6=$ Very High Impact

Your response:

Median response: 5

Change to reflect median

I do not wish to change my response because: Type Response Here

Q89-Desirability (Please rate your perception of the desirability of the event.) $1=$ Very Undesirable and $5=$ Very Desirable

Your response:

Median response: 5

Change to reflect median

I do not wish to change my response because: Type Response Here 


\section{Question 90}

CTE drives innovation and creativity in the state's high schools by transforming the culture of education so every school produces lifelong learners that are both academically-skilled and career-ready.

Q90-Time Frame (Please select the time frame you believe is most appropriate.)

Your response:

Median response: 3-Mid-range (4-10 years)

Change to reflect median

I do not wish to change my response because: Type Response Here

Q90-Impact (Please rate the degree of impact to career and technical education.) $1=$ Very Low Impact and $6=$ Very High Impact

Your response:

Median response: 5

Change to reflect median

I do not wish to change my response because: Type Response Here

Q90-Desirability (Please rate your perception of the desirability of the event.) $1=$ Very Undesirable and $5=$ Very Desirable

Your response:

Median response: 5

Change to reflect median

I do not wish to change my response because: Type Response Here 


\section{Funding}

\section{Question 91}

CTE funding will become more dependent on "competitive grants" which would require additional "proof" that programs are valid.

Q91-Time Frame (Please select the time frame you believe is most appropriate.)

Your response:

Median response: 3-Mid-range (4-10 years)

Change to reflect median

I do not wish to change my response because: Type Response Here

Q91-Impact (Please rate the degree of impact to career and technical education.) $1=$ Very Low Impact and $6=$ Very High Impact

Your response:

Median response: 4

Change to reflect median

I do not wish to change my response because: Type Response Here

Q91-Desirability (Please rate your perception of the desirability of the event.) $1=$ Very Undesirable and $5=$ Very Desirable

Your response:

Median response: 3

Change to reflect median

I do not wish to change my response because: Type Response Here 


\section{Question 92}

Federal funding will be the key to the survival or demise of career and technical education.

Q92-Time Frame (Please select the time frame you believe is most appropriate.)

Your response:

Median response: 2-Immediate (1-3 years)

Change to reflect median

I do not wish to change my response because: Type Response Here

Q92-Impact (Please rate the degree of impact to career and technical education.) $1=$ Very Low Impact and $6=$ Very High Impact

Your response:

Median response: 5

Change to reflect median

I do not wish to change my response because: Type Response Here

Q92-Desirability (Please rate your perception of the desirability of the event.) $1=$ Very Undesirable and $5=$ Very Desirable

Your response:

Median response: 3

Change to reflect median

I do not wish to change my response because: Type Response Here 


\section{Question 93}

Career and technical education research database will grow significantly, providing a valid and substantial foundation for increasing and stabilizing funding for higher quality CTE teachers and higher quality CTE programming.

Q93-Time Frame (Please select the time frame you believe is most appropriate.)

Your response:

Median response: 3-Mid-range (4-10 years)

Change to reflect median

I do not wish to change my response because: Type Response Here

Q93-Impact (Please rate the degree of impact to career and technical education.) $1=$ Very Low Impact and $6=$ Very High Impact

Your response:

Median response: 4

Change to reflect median

I do not wish to change my response because: Type Response Here

Q93-Desirability (Please rate your perception of the desirability of the event.) $1=$ Very Undesirable and $5=$ Very Desirable

Your response:

Median response: 5

Change to reflect median

I do not wish to change my response because: Type Response Here 


\section{Question 94}

CTE programs will be certified or recognized by industry, professional, trade associations, or state licensing agencies and that will lead to Performance Based Program support dollars.

Q94-Time Frame (Please select the time frame you believe is most appropriate.)

Your response:

Median response: 3-Mid-range (4-10 years)

Change to reflect median

I do not wish to change my response because: Type Response Here

Q94-Impact (Please rate the degree of impact to career and technical education.) $1=$ Very Low Impact and $6=$ Very High Impact

Your response:

Median response: 4

Change to reflect median

I do not wish to change my response because: Type Response Here

Q94-Desirability (Please rate your perception of the desirability of the event.) $1=$ Very Undesirable and $5=$ Very Desirable

Your response:

Median response: 4

Change to reflect median

I do not wish to change my response because: Type Response Here 


\section{Question 95}

Perkins funding may be replaced or greatly modified as CTE merges with general education, higher education and community colleges.

Q95-Time Frame (Please select the time frame you believe is most appropriate.)

Your response:

Median response: 3-Mid-range (4-10 years)

Change to reflect median

I do not wish to change my response because: Type Response Here

Q95-Impact (Please rate the degree of impact to career and technical education.) $1=$ Very Low Impact and $6=$ Very High Impact

Your response:

Median response: 4

Change to reflect median

I do not wish to change my response because: Type Response Here

Q95-Desirability (Please rate your perception of the desirability of the event.) $1=$ Very Undesirable and $5=$ Very Desirable

Your response:

Median response: 3

Change to reflect median

I do not wish to change my response because: Type Response Here 


\section{Question 96}

There will not be a re-authorization of the Carl D. Perkins Career and Technical Education Act of 2006 beyond 2018.

Q96-Time Frame (Please select the time frame you believe is most appropriate.)

Your response:

Median response: 3-Mid-range (4-10 years)

Change to reflect median

I do not wish to change my response because: Type Response Here

Q96-Impact (Please rate the degree of impact to career and technical education.) $1=$ Very Low Impact and $6=$ Very High Impact

Your response:

Median response: 5

Change to reflect median

I do not wish to change my response because: Type Response Here

Q96-Desirability (Please rate your perception of the desirability of the event.) $1=$ Very Undesirable and $5=$ Very Desirable

Your response:

Median response: 3

Change to reflect median

I do not wish to change my response because: Type Response Here 


\section{Accountability}

\section{Question 97}

The focus on research-based and test driven education will increase.

Q97-Time Frame (Please select the time frame you believe is most appropriate.)

Your response:

Median response: 2-Immediate (1-3 years)

Change to reflect median

I do not wish to change my response because: Type Response Here

Q97-Impact (Please rate the degree of impact to career and technical education.) $1=$ Very Low Impact and $6=$ Very High Impact

Your response:

Median response: 4

Change to reflect median

I do not wish to change my response because: Type Response Here

Q97-Desirability (Please rate your perception of the desirability of the event.) $1=$ Very Undesirable and $5=$ Very Desirable

Your response:

Median response: 3

Change to reflect median

I do not wish to change my response because: Type Response Here 


\section{Question 98}

Performance-based assessment will replace degrees and diplomas. Student competencies will be observable and documented on a Certificate of Achievement.

Q98-Time Frame (Please select the time frame you believe is most appropriate.)

Your response:

Median response: 3-Mid-range (4-10 years)

Change to reflect median

I do not wish to change my response because: Type Response Here

Q98-Impact (Please rate the degree of impact to career and technical education.) $1=$ Very Low Impact and $6=$ Very High Impact

Your response:

Median response: 4

Change to reflect median

I do not wish to change my response because: Type Response Here

Q98-Desirability (Please rate your perception of the desirability of the event.) $1=$ Very Undesirable and $5=$ Very Desirable

Your response:

Median response: 5

Change to reflect median

I do not wish to change my response because: Type Response Here 


\section{Question 99}

High-stakes testing will be replaced by portfolio-type of assessments that will include firsthand works, tests and experiences.

Q99-Time Frame (Please select the time frame you believe is most appropriate.)

Your response:

Median response: 3-Mid-range (4-10 years)

Change to reflect median

I do not wish to change my response because: Type Response Here

Q99-Impact (Please rate the degree of impact to career and technical education.) $1=$ Very Low Impact and $6=$ Very High Impact

Your response:

Median response: 5

Change to reflect median

I do not wish to change my response because: Type Response Here

Q99-Desirability (Please rate your perception of the desirability of the event.) $1=$ Very Undesirable and $5=$ Very Desirable

Your response:

Median response: 4

Change to reflect median

I do not wish to change my response because: Type Response Here 


\section{Question 100}

More educational assessments will be measured through the ability to access knowledge and not retain knowledge.

Q100-Time Frame (Please select the time frame you believe is most appropriate.)

Your response:

Median response: 3-Mid-range (4-10 years)

Change to reflect median

I do not wish to change my response because: Type Response Here

Q100-Impact (Please rate the degree of impact to career and technical education.) $1=$ Very Low Impact and $6=$ Very High Impact

Your response:

Median response: 4

Change to reflect median

I do not wish to change my response because: Type Response Here

Q100-Desirability (Please rate your perception of the desirability of the event.) $1=$ Very Undesirable and $5=$ Very Desirable

Your response:

Median response: 4

Change to reflect median

I do not wish to change my response because: Type Response Here 


\section{Question 101}

\section{There will be national CTE assessments.}

Q101-Time Frame (Please select the time frame you believe is most appropriate.)

Your response:

Median response: 3-Mid-range (4-10 years)

Change to reflect median

I do not wish to change my response because: Type Response Here

Q101-Impact (Please rate the degree of impact to career and technical education.) $1=$ Very Low Impact and $6=$ Very High Impact

Your response:

Median response: 5

Change to reflect median

I do not wish to change my response because: Type Response Here

Q101-Desirability (Please rate your perception of the desirability of the event.) $1=$ Very Undesirable and $5=$ Very Desirable

Your response:

Median response: 3

Change to reflect median

I do not wish to change my response because: Type Response Here 


\section{Question 102}

Enhanced accountability will include longitudinal data systems designed to improve collection and data integrity which will aid in data-driven decision making.

Q102-Time Frame (Please select the time frame you believe is most appropriate.)

Your response:

Median response: 3-Mid-range (4-10 years)

Change to reflect median

I do not wish to change my response because: Type Response Here

Q102-Impact (Please rate the degree of impact to career and technical education.) $1=$ Very Low Impact and $6=$ Very High Impact

Your response:

Median response: 5

Change to reflect median

I do not wish to change my response because: Type Response Here

Q102-Desirability (Please rate your perception of the desirability of the event.) $1=$ Very Undesirable and $5=$ Very Desirable

Your response:

Median response: 4

Change to reflect median

I do not wish to change my response because: Type Response Here 


\section{Question 103}

Lifelong learning will become more important because people will live longer, work longer and need more frequent training.

Q103-Time Frame (Please select the time frame you believe is most appropriate.)

Your response:

Median response: 3-Mid-range (4-10 years)

Change to reflect median

I do not wish to change my response because: Type Response Here

Q103-Impact (Please rate the degree of impact to career and technical education.) $1=$ Very Low Impact and $6=$ Very High Impact

Your response:

Median response: 4

Change to reflect median

I do not wish to change my response because: Type Response Here

Q103-Desirability (Please rate your perception of the desirability of the event.) $1=$ Very Undesirable and $5=$ Very Desirable

Your response:

Median response: 4

Change to reflect median

I do not wish to change my response because: Type Response Here 


\section{Question 104}

The emphasis on accountability in all secondary education programs will continue with career and technical education at great risk to prove that their contribution is worth the expense.

Q104-Time Frame (Please select the time frame you believe is most appropriate.)

Your response:

Median response: 3-Mid-range (4-10 years)

Change to reflect median

I do not wish to change my response because: Type Response Here

Q104-Impact (Please rate the degree of impact to career and technical education.) $1=$ Very Low Impact and $6=$ Very High Impact

Your response:

Median response: 5

Change to reflect median

I do not wish to change my response because: Type Response Here

Q104-Desirability (Please rate your perception of the desirability of the event.) $1=$ Very Undesirable and $5=$ Very Desirable

Your response:

Median response: 3

Change to reflect median

I do not wish to change my response because: Type Response Here 


\section{Image}

\section{Question 105}

The contribution to economic development must be recognized or career and technical education will continue to be marginalized.

Q105-Time Frame (Please select the time frame you believe is most appropriate.)

Your response:

Median response: 2-Immediate (1-3 years)

Change to reflect median

I do not wish to change my response because: Type Response Here

Q105-Impact (Please rate the degree of impact to career and technical education.) $1=$ Very Low Impact and $6=$ Very High Impact

Your response:

Median response: 5

Change to reflect median

I do not wish to change my response because: Type Response Here

Q105-Desirability (Please rate your perception of the desirability of the event.) $1=$ Very Undesirable and $5=$ Very Desirable

Your response:

Median response: 5

Change to reflect median

I do not wish to change my response because: Type Response Here 


\section{Question 106}

The high school dropout rates will decrease as enrollment in CTE classes increase because students see relevancy in their learning environment.

Q106-Time Frame (Please select the time frame you believe is most appropriate.)

Your response:

Median response: 3-Mid-range (4-10 years)

Change to reflect median

I do not wish to change my response because: Type Response Here

Q106-Impact (Please rate the degree of impact to career and technical education.) $1=$ Very Low Impact and $6=$ Very High Impact

Your response:

Median response: 5

Change to reflect median

I do not wish to change my response because: Type Response Here

Q106-Desirability (Please rate your perception of the desirability of the event.) $1=$ Very Undesirable and $5=$ Very Desirable

Your response:

Median response: 5

Change to reflect median

I do not wish to change my response because: Type Response Here 


\section{Question 107}

Career and technical education will be expected to address the needs of the lowest quartile and the difficult-toeducate children.

Q107-Time Frame (Please select the time frame you believe is most appropriate.)

Your response:

Median response: 2-Immediate (1-3 years)

Change to reflect median

I do not wish to change my response because: Type Response Here

Q107-Impact (Please rate the degree of impact to career and technical education.) $1=$ Very Low Impact and $6=$ Very High Impact

Your response:

Median response: 4

Change to reflect median

I do not wish to change my response because: Type Response Here

Q107-Desirability (Please rate your perception of the desirability of the event.) $1=$ Very Undesirable and $5=$ Very Desirable

Your response:

Median response: 3

Change to reflect median

I do not wish to change my response because: Type Response Here 


\section{Question 108}

The "trades" will once again be positions of respect and education will be tied to economic development.

Q108-Time Frame (Please select the time frame you believe is most appropriate.)

Your response:

Median response: 3-Mid-range (4-10 years)

Change to reflect median

I do not wish to change my response because: Type Response Here

Q108-Impact (Please rate the degree of impact to career and technical education.) $1=$ Very Low Impact and $6=$ Very High Impact

Your response:

Median response: 5

Change to reflect median

I do not wish to change my response because: Type Response Here

Q108-Desirability (Please rate your perception of the desirability of the event.) $1=$ Very Undesirable and $5=$ Very Desirable

Your response:

Median response: 5

Change to reflect median

I do not wish to change my response because: Type Response Here 


\section{Question 109}

CTE will move from the elective side of the high school graduation requirements to the required core side of high school graduation.

Q109-Time Frame (Please select the time frame you believe is most appropriate.)

Your response:

Median response: 3-Mid-range (4-10 years)

Change to reflect median

I do not wish to change my response because: Type Response Here

Q109-Impact (Please rate the degree of impact to career and technical education.) $1=$ Very Low Impact and $6=$ Very High Impact

Your response:

Median response: 5

Change to reflect median

I do not wish to change my response because: Type Response Here

Q109-Desirability (Please rate your perception of the desirability of the event.) $1=$ Very Undesirable and $5=$ Very Desirable

Your response:

Median response: 5

Change to reflect median

I do not wish to change my response because: Type Response Here 


\section{Question 110}

Students will need to apply to be accepted into CTE programs.

Q110-Time Frame (Please select the time frame you believe is most appropriate.)

Your response:

Median response: 3-Mid-range (4-10 years)

Change to reflect median

I do not wish to change my response because: Type Response Here

Q110-Impact (Please rate the degree of impact to career and technical education.) $1=$ Very Low Impact and $6=$ Very High Impact

Your response:

Median response: 5

Change to reflect median

I do not wish to change my response because: Type Response Here

Q110-Desirability (Please rate your perception of the desirability of the event.) $1=$ Very Undesirable and $5=$ Very Desirable

Your response:

Median response: 4

Change to reflect median

I do not wish to change my response because: Type Response Here 


\section{Question 111}

Parents will recognize that CTE is paramount to achieving education and career goals.

Q111-Time Frame (Please select the time frame you believe is most appropriate.)

Your response:

Median response: 3-Mid-range (4-10 years)

Change to reflect median

I do not wish to change my response because: Type Response Here

Q111-Impact (Please rate the degree of impact to career and technical education.) $1=$ Very Low Impact and $6=$ Very High Impact

Your response:

Median response: 5

Change to reflect median

I do not wish to change my response because: Type Response Here

Q111-Desirability (Please rate your perception of the desirability of the event.) $1=$ Very Undesirable and $5=$ Very Desirable

Your response:

Median response: 5

Change to reflect median

I do not wish to change my response because: Type Response Here 


\section{Question 112}

The location of CTE will move from behind the scenes of the school to a front showcase and become the hub in which all high school knowledge revolves.

Q112-Time Frame (Please select the time frame you believe is most appropriate.)

Your response:

Median response: 3-Mid-range (4-10 years)

Change to reflect median

I do not wish to change my response because: Type Response Here

Q112-Impact (Please rate the degree of impact to career and technical education.) $1=$ Very Low Impact and $6=$ Very High Impact

Your response:

Median response: 5

Change to reflect median

I do not wish to change my response because: Type Response Here

Q112-Desirability (Please rate your perception of the desirability of the event.) $1=$ Very Undesirable and $5=$ Very Desirable

Your response:

Median response: 5

Change to reflect median

I do not wish to change my response because: Type Response Here 


\section{Question 113}

Students who complete a secondary program, go to work, and continue to learn either on the job and/or receive training provided by the employer will be valued as much as a person who has a degree.

Q113-Time Frame (Please select the time frame you believe is most appropriate.)

Your response:

Median response: 3-Mid-range (4-10 years)

Change to reflect median

I do not wish to change my response because: Type Response Here

Q113-Impact (Please rate the degree of impact to career and technical education.) $1=$ Very Low Impact and $6=$ Very High Impact

Your response:

Median response: 5

Change to reflect median

I do not wish to change my response because: Type Response Here

Q113-Desirability (Please rate your perception of the desirability of the event.) $1=$ Very Undesirable and $5=$ Very Desirable

Your response:

Median response: 5

Change to reflect median

I do not wish to change my response because: Type Response Here 


\section{Question 114}

Education funding will plateau in the states or decline due to a lack of understanding of the need to be educated and employed to compete in a world-wide economy.

Q114-Time Frame (Please select the time frame you believe is most appropriate.)

Your response:

Median response: 2-Immediate (1-3 years)

Change to reflect median

I do not wish to change my response because: Type Response Here

Q114-Impact (Please rate the degree of impact to career and technical education.) $1=$ Very Low Impact and $6=$ Very High Impact

Your response:

Median response: 5

Change to reflect median

I do not wish to change my response because: Type Response Here

Q114-Desirability (Please rate your perception of the desirability of the event.) $1=$ Very Undesirable and $5=$ Very Desirable

Your response:

Median response: 2

Change to reflect median

I do not wish to change my response because: Type Response Here 
Appendix D

Compilation of All Survey Data 


\section{Appendix D \\ Compilation of All Survey Data}

Time Frame: 1-Never; 2-Immediate (1-3 years); 3-Mid-Range (4-10 years); 4-Long-Range (11-20 years); and 5-beyond 20 years.

Impact: 1-Very Low Impact; 2- Low Impact; 3-Moderate Impact; 4-High Impact and 5-Very High Impact.

Desirability: 1-Very Undesirable; 2-Undesirable; 3-Somewhat Desirable; 4-Desirable and 5-Very Desirable.

\section{Question 1}

\section{Entrepreneurship will become a part of all career and technical education programs.}

Median Time Frame Round 2

Median Impact Round 2

Median Desirability Round 2

Median Time Frame Round 3

Minority Opinion(s)
2

3

3 - There are too many requirements in the current curriculum. In addition to all the academics, which have steadily increased, there are other offerings constantly being added to the curriculum. The school system is being charged with curing all deficiencies, whether they can control those deficiencies or not.

3 - I don't think our state department of education will act that quickly.

3 - While I think this will become part of CTE programs, I think it will take longer than 2 years to accomplish.

1 - Entrepreneurship will never be a part of all CTE programs.

Median Impact Round 3

3

Minority Opinion(s)

5 - Career Technical Education Programs provide skills necessary for individuals to be good employees and to become bunisess owners. It is important for people to realize the ability that each skilled individual has to be self sufficient if the correct entrepreneural skills are taught.

2 - Local and state support for entrepreneurship will vary greatly.

Median Desirability Round 3

4

Minority Opinion(s)

3 - Teachers will need more training to promote Entrepreneurship.

3 - This would be benefitial based on the current economic climate and lack of employment opportunities.

5 - I see entrepreneurship to be the essence of employment in the future, not just self-employment, but employment within companies will also require entrepreneurship around projects, services and products within the company. 


\section{Question 2}

Health Occupations CTE programs will be more closely connected with identified health care providers and/or facilities: there will be a more pronounced OJT/co-op component required for CTE program completion.

Median Time Frame Round 2

Median Impact Round 2

Median Desirability Round 2

Median Time Frame Round 3

Minority Opinion(s)
2

3

3 - I believe there are many co-op programs in existence and we currently have internships within our Career and Technical Structure in Ohio.

Median Impact Round 3

3

Minority Opinion(s)

5 - Health Occupations is probably the \#larea for occupations in most states and it is critical to the health care providers/facilities that there is a more pronounced co-op component.

Median Desirability Round 3

4

\section{Question 3}

National Security concerns will continue and career preparation programs in Criminal Justice, BioSecurity will continue to grow.

Median Time Frame Round 2

2

Median Impact Round 2

4

Median Desirability Round 2

Median Time Frame Round $3 \quad 2$

Minority Opinion(s)

3 - Although it is desirable, I do not believe there is neither the will nor the money to make this a relaity in the immediate future

Median Impact Round 3

4

Minority Opinion(s)

5 - There are increasing issues regarding national security and I believe these courses will continue to grow. Our current enrollment is high with students on a waiting list.

Median Desirability Round 3 


\section{Question 4}

The teaching of languages will become part of a complete and effective CTE program.

Median Time Frame Round 2

Median Impact Round 2

Median Desirability Round 2

Median Time Frame Round 3

Minority Opinion(s)
3

3

1 - I believe this will remain in the academic arena and not be part of CTE.

4 - Who is going to teach the language? We can't get enough foreign language teachers to meet current needs.

4 - While I feel language acquisition is extremely important, I don't see making this a priority on any radar and thus feel if it does come to fruition, the timeframe is longer.

5 - The availability of qualified teachers to support teaching of languages in CTE will be an issue which will present barriers to the likelihood of integration of languages as an integral part of the CTE programming.

Median Impact Round 3

3

Minority Opinion(s)

1 - The more requirements that are added (language or otherwise) to the curriculum will result in the loss of CTE programs I do not think CTE teachers who traditionally come from the trades, will also be versed in other languages.

4 - In reference to the above response, I do not think the impact will be great.

2 - I don't believe language acquisition and CTE will come together any time soon so at this time the impact is pretty low.

5 - With the difficulties currently encountered as CTE tries to find the hours and funding to successfully incorporate the training students need, teaching of languages (other than infused English, Grammar and Writing) will meet with substantial barriers systematic barriers.

5 - Local and regional support for expanded language instruction will promote foreign exchanges in CTE.

Median Desirability Round 3

2

Minority Opinion(s)

5 - Americans, in general, continue to be illiterate on an international basis. Foreign language will be critical to our success on a global basis. Frankly, our arrogance continues-English is not the only language in the world.

5 - It is a topic for discussion and examination, but for most programs, I do not see it as a priority--let's see if we can even come close to meeting the needs of the English-speaking kids and adult students in our programs now--before we presume to be all things to all people. 
5 - This is of local and regional importance.

3 - I believe more and more people will be employed or doing business with people who speak a language other thean their native language. To prosper in the future economy the workforce must be prepared to be part of a global community.

\section{Question 5}

Students must do an internship, shadow, or work in the technical area before they graduate high school.

Median Time Frame Round 2

Median Impact Round 2

Median Desirability Round 2

Median Time Frame Round 3

Minority Opinion(s)

4 - I don't believe that most schools could ensure that students have the opportunity to participate. Think of small rural areas or small urban with not much industry or business.

Median Impact Round 3

5

Minority Opinion(s)

2 - The WVDOE is currently working on changing 2510 and this is one thing that (may) be added.

3 - We are already doing this and it is not impactful.

Median Desirability Round 3

4

Minority Opinion(s)

5 - It is important for students to gain practical experience for on the job training while in high school. Job experience leads to increased exposure in the field of work and increased ability of the student to actually preform job tasks.

5 - Important step to career development/choices.

2 - This would be very desirable since it would put all potential graduates into the workplace.

5 - I don't think it is doable but if every student could get a taste of what it really is like to work I think it would be very desirable. 


\section{Question 6}

CTE leads the validation of career-ready status of every high school graduate by increasing the use of instruments that measure skills employers' value (industry recognized certifications).

Median Time Frame Round 2

Median Impact Round 2

Median Desirability Round 2

Median Time Frame Round 3

Median Impact Round 3

Median Desirability Round 3

Minority Opinion(s)
2

5

2

5

2 - I am a proponent of a broader education for high school students, reflecting all aspects of the industry. I am in favor of credentials being part of a high school program at the advanced levels, but also think we must recognize that many credential exams are not necessarily appropriate for high school students.

\section{Question 7}

Simultaneously, as career and technical education tries to address the needs of the hard-to-reach student, there will be a rebirth of interest in occupations that will stay local and provide a good living.

Median Time Frame Round 2

3

Median Impact Round 2

4

Median Desirability Round 2

Median Time Frame Round 3

Minority Opinion(s)

1 - Although I marked the above box, we should be aware that is not the role of CTE to fuel local jobs that pay minimum wage.

Median Impact Round 3

4

Median Desirability Round 3

4

Minority Opinion(s)

2 - I don't want this to be a form of "tracking" some students into less desirable occupations. 


\section{Question 8 \\ Software and machine management will become new basics of education in CTE while standardized tests and other forms of testing will disappear.}

Median Time Frame Round 2

Median Impact Round 2

Median Desirability Round 2

Median Time Frame Round 3

Minority Opinion(s)
2

\section{4}

4 - Because of current legislation and the existing educational marketplace, I don't see tests disappearing in 1-3 years.

4 - It will take substantial time to transition.

Median Impact Round 3

4

Minority Opinion(s)

2 - The rush toward technology at least in some areas of county is held back by funding issues. It this case a whole culture of how schools operate would have to be altered. Not going to happen any time soon.

1 - As such, the impact is extremely low.

2 - I simply disagree.

Median Desirability Round 3 3

Minority Opinion(s)

5 - Changes in technology and student learning will dictate this area.

5 - This is being discussed with regard to 2510. I'm hopeful that it will happen.

4 - Contextual Learning will always be the most significantcomponent in Career and TEchnical Education.

2 - Software and machine management is more important to some CTE fields than others:.Rather than software and machine management which is speicifc, the new basics is different than the assessments that measure. Perfomrance-based assesmsnets that measure skills rather should be the new assessment rather than stanadardized tests.

\section{Question 9}

Career and technical education will be driven by a common national vision, mission and set of core values.

Median Time Frame Round 2 
$\begin{array}{ll}\text { Median Desirability Round } 2 & 4 \\ \text { Median Time Frame Round 3 } & 3 \\ \text { Median Impact Round 3 } & 4 \\ \text { Median Desirability Round } 3 & \\ \text { Minority Opinion(s) } \\ 2 \text { - Local and Regional CTE Advisory Committees drive the vision and mission, not federal. }\end{array}$

Question 10

CTE leads the Career Clusters initiative by emerging and aligning with economic development industry sectors/clusters.

Median Time Frame Round 2

2

Median Impact Round 2

4

Median Desirability Round $2 \quad 5$

Median Time Frame Round $3 \quad 2$

Minority Opinion(s)

4 - The separation between economic development, workforce education and career and technical education creates silos of language, financial structures and political structures that will take major reorganization to integrate. This integration will take 10 years or more WITH federal leadership.

Median Impact Round 3

4

Median Desirability Round 3

5

\section{Question 11}

Content standard objectives (CSOs) and similar standards in other states will undergo a major overhaul, as research shows the futility of trying to make a one-size-fits-all list of criteria for completion. Programs of the same name, in different places, under different industry/business needs, will look different.

Median Time Frame Round 2

3

Median Impact Round 2

4

Median Desirability Round 2

Median Time Frame Round 3

Minority Opinion(s)

5 - Again, the pace of this kind of change in education I believe is slower than what the median believes.

1 - The discussion about standards does not appear to be going away any time soon based on Common Core State Standards Initiative and other national conversations. 
Median Impact Round 3

Median Desirability Round 3

3

Minority Opinion(s)

4 - I believe that if we don't listen to and follow the trends of economic development, then we will not survive.

Question 12

Grade-level tracking will be replaced with content learning, where students can build on their knowledge and abilities, and leave the grade classification behind allowing more time for the CTE effort.

Median Time Frame Round 2

3

Median Impact Round 2

4

Median Desirability Round 2

Median Time Frame Round 3

Minority Opinion(s)

4 - It would require changing the whole culture of school. Not going to happen anytime soon.

5 - I might be willing to go to a 4, but the pace of this kind of change seems glacial.

5 - Substantial time required for such transition.

Median Impact Round 3

Minority Opinion(s)

3 - Perception of parents/public will determine this along with blended learning through online learning.

Median Desirability Round 3

4

Minority Opinion(s)

5 - Look at the new GED option; it allows this.

\section{Question 13}

CTE is the catalyst that expands the assistance available to all high school students to enable them to make both wise academic and career choices and achieve their goals for the future.

Median Time Frame Round 2

2

Median Impact Round 2

4

Median Desirability Round 2

Median Time Frame Round 3

Median Impact Round 3

4

Median Desirability Round 3 


\section{Question 14}

There will be an increase in the interest of CTE career areas.

Median Time Frame Round 2

Median Impact Round 2

Median Desirability Round 2

Median Time Frame Round 3

Median Impact Round 3

Median Desirability Round 3
2

\section{5}

5

2

5

Question 15

Secondary CTE programs will all offer a minimum of two tracts, one for highly capable and a different level for those students recognized as less achieving or challenged.

Median Time Frame Round 2 2

Median Impact Round 2

4

Median Desirability Round 2

Median Time Frame Round 3

2

Minority Opinion(s)

1 - I am not in favor of tracking students.

3 - Like any government program, this issue will take more time if it is to happen at all.

5 - Again, this is not happening now really and don't think that if this were to occur that it would happen in 1-3 years.

1 - While individual student needs need to be addressed, this sounds too much like tracking students.

4 - I believe those that wish to do this will run into hurdles from those who believe this is going to disadvantage whole populations.

Median Impact Round 3

4

Minority Opinion(s)

1 - Hence the impact.(Again, this is not happening now really and don't think that if this were to occur that it would happen in 1-3 years.)

Median Desirability Round 3

Minority Opinion(s)

1 - There are too many related issues that need to be addressed in the statement. Addressing student needs is a good thing, but will resources be equitable, will capability of the educators be equitable, etc. In the past, these have been issues that negatively impacted student learning. 
1 - I worry about the decision that certain students are not able to learn at a higher level. I believe the program expectations should remain constantly high while the educators strive for better teaching/leraning strategies to reach more students.

\section{Question 16}

Rigor and relevance of content and delivery will be increased significantly in CTE curriculum and instruction.

Median Time Frame Round 2

Median Impact Round 2

Median Desirability Round 2

Median Time Frame Round 3

Minority Opinion(s)
2

4

3 - Too many of these questions people seem to think change comes much quicker than I do. The more different the change the longer it takes. Currently most districts are also suffering from a lack of funding. Most changes at least require some money for staff development or curriculum etc.

Median Impact Round 3

4

Minority Opinion(s)

5 - This is a must for CTE.

Median Desirability Round 3

2

Minority Opinion(s)

5 - CTE instructors/administers must research and become knowledgeable to increase rigor and relevance. Data collection for CTE must reflect changes in instruction.

5 - I believe all curriculum should provide rigor and relevance otherwise we are doing a terrible injustice to our students.

4 - In Ohio this is already around the corner.

4 - While we tout the rigor and relevance I believe it will be increased and brought more to light.

5 - Content is critical to the core of education, along with the way that content is delivered by teachers. It needs to be rigorous and relevant in order to be useful for students.

3 - More rigor will be required to enable student success in future study and in the workplace. 


\section{Question 17 \\ The blending of career and technical education and academic education will overlap considerably-it will no longer be an either/or situation.}

Median Time Frame Round 2

3

Median Impact Round 2

5

Median Desirability Round $2 \quad 5$

Median Time Frame Round 3

Minority Opinion(s)

5 - Blending the two realms will take substantial time due to the politics of education.

4 - This will simply take a long time.

Median Impact Round 3

5

Median Desirability Round 3

5

Minority Opinion(s)

3 - Blending will hold significant implications for the characteristics and makeup of both educational realms, all of which will face substantial resistance from the players.

\section{Question 18}

Career academies and small learning communities will replace the comprehensive high school setting.

Median Time Frame Round 2

Median Impact Round 2

Median Desirability Round 2

Median Time Frame Round 3

Median Impact Round 3

Median Desirability Round 3

Minority Opinion(s)
3

4

4

3

4

1 - A number of studies I have read recently say academies and small learning communities increase student performance. 


\section{Question 19 \\ CTE will be offered in elementary schools.}

Median Time Frame Round 2

Median Impact Round 2

Median Desirability Round 2

Median Time Frame Round 3

Minority Opinion(s)

1 - This may go into middle schools; however, I just don't see it happening in elementary.

1 - With the current emphasis on core academic subjects I don't see it happening at all.

1 - I do not believe that we have the people-power,trainedf professional or money to expand this type of learning at this time in the US.

5 - Not really sure what is meant by the definition of CTE in elementary, but we need to be clear at the secondary and postsecondary levels before we go further down the spectrum.

1 - Elementary schools may experience "CTE counseling" but there is not room in the curriculum set forgradesK1-5 for CTE instruction--neither is it developmentally appropriate. Middle school--yes. Elementary--no. In elementary school, there is and should be exposure to career awareness, but not instruction in career skills--an elementary child is not developmentally ready to choose his or her career path--they are still learning to just be.

Median Impact Round 3

3

\section{Minority Opinion(s)}

2 - Lack of Resources will prevent this from happening.

1 - If it does not happen there is no impact.

1 - I do not believe that we have the people-power,trainedf professional or money to expand this type of learning at this time in the US.

- It will not happen in my lifetime.

Median Desirability Round 3

4

Minority Opinion(s)

1 - I can't see any benefit for students or the profession at this level.

- I do not believe CTE is developmentally appropriate instructional programming for grades K-5. 


\section{Question 20}

The Carnegie unit will be replaced with something new which is not seat-time based.

Median Time Frame Round 2

Median Impact Round 2

Median Desirability Round 2

Median Time Frame Round 3

Minority Opinion(s)

1 - If it ever should happen it will be a long time.

2 - Colleges and Universities will block this strategy.

Median Impact Round 3

4

Minority Opinion(s)

5 - Blended learning through technology and student time will bring this change.

Median Desirability Round 3

4

Question 21

The school calendar will change drastically, perhaps even becoming individualized depending on geographic area of the state(s).

Median Time Frame Round 2

Median Impact Round 2

3

Median Desirability Round 2

Median Time Frame Round 3

4

3

Minority Opinion(s)

1 - The whole expectations of parents and communities would have to change. Not going to happen.

1 - I do not believe school calendars will change significantly across the country.

Median Impact Round 3

3

Minority Opinion(s)

1 - Not going to happen so there is no impact.

1 - CT Education will continue to be flexible and work in any calendar situation.

1 - Since this is already occurring in some areas through distance learning, I don't think it will have a major impact. 
4 - I strongly believe gains in achievement will not happen until we meet the individualized NEEDS of students. Right now we meet the needs of the professors, high school teachers, etc., because they want summers off. The world no longer functions this way.

Median Desirability Round 3

4

Minority Opinion(s)

1 - CT Education will continue to be flexible and work in any calendar situation.

\section{Question 22}

Active participation in Career and Technical Student Organizations (CTSO'S) will be a requirement to complete the CTE course with students routinely attending leadership and competitive events.

Median Time Frame Round 2

3

Median Impact Round 2

4

Median Desirability Round $2 \quad 4$

Median Time Frame Round $3 \quad 3$

Minority Opinion(s)

1 - I just don't think this will become a requirement across the board.

Median Impact Round 3

4

Minority Opinion(s)

5 - Here in Florida CTSO participation is REQUIRED and we are leading the US in CTSO's. Because of it our students have a higher pass rate on CTE assessment than other states, are more competitive for jobs than those from other states and are ready for the real world. This question should be changed to 5 (very high impact).

1 - Hence the impact score. ( I just don't think this will become a requirement across the board.)

Median Desirability Round 3

4

Minority Opinion(s)

5 - Here in Florida CTSO participation is REQUIRED and we are leading the US in CTSO'S. Because of it our students have a higher pass rate on CTE assessment than other states, are more competitive for jobs than those from other states and are ready for the real world. This question should be changed to 5 (very high desirability). 


\section{Question 23}

Career and Technical Education will be renamed to Technical Skills Achievement (TSA), meaning there is more of the industry certification focus than what we have now.

Median Time Frame Round 2

Median Impact Round 2

Median Desirability Round 2

Median Time Frame Round 3

Minority Opinion(s)

\section{3}

4

1 - We do not need another name change!

1 - There was a change from vocational education to Career and Technical Education. Changing the name ever so often won't change people's perception of what vocational education is.

1 - Again, I don't think this will change in that timeframe.

1 - I do not believe this will happen. CTE is very broad and technical skills achievement is but one component.

1 - Do not see and hope this will not happen.

Median Impact Round 3

4

Minority Opinion(s)

3 - CTE is still trying to change the image of the word "vocational" for our profession which still is being used by many who will not accept the name change of the year 2000.

1 - Changing names don't have any impact on what is being taught.

1 - We need to be flexible and a name change will mean little.

1 - I guess if it did happen, it would have an impact, but I don't think it will.

Median Desirability Round 3

2

Minority Opinion(s)

3 - CTE is still trying to change the image of the word "vocational" for our profession which still is being used by many who will not accept the name change of the year 2000. 


\section{Question 24}

All stand-alone, academy and area CTE centers will have counselors, core-subject teachers and a student health center on campus.

Median Time Frame Round 2

Median Impact Round 2

Median Desirability Round 2

Median Time Frame Round 3

Median Impact Round 3

Median Desirability Round $3 \quad 5$

\section{Question 25}

CTE concentrations will be part of graduation requirements for all students.

Median Time Frame Round $2 \quad 3$

Median Impact Round 2

Median Desirability Round 2

Median Time Frame Round 3

Minority Opinion(s)

1 - I believe the general population still believes that CTE is only for "certain" students and many academia fail to see the benefit and caliber of the CTE curriculum.

2 - They already are a part of grad requirements.

1 - Some districts are so academically oriented that vocational education is only for other people's children.

Median Impact Round 3

Minority Opinion(s)

1 - Not going to happen no impact.

Median Desirability Round 3 


\section{Question 26}

Global standardization of education, accreditation will occur.

Median Time Frame Round 2

Median Impact Round 2

Median Desirability Round 2

Median Time Frame Round 3

Minority Opinion(s)

1 - I don't think this will occur in the available timelines.

5 - Change takes longer.

Median Impact Round 3

4

Minority Opinion(s)

1 - Hence the impact score. (I don't think this will occur in the available timelines.)

Median Desirability Round 3

Minority Opinion(s)

5 - As business become even more global if people were trained very young to exist in this kind of environment it would prepare them much better.

5 - Sorry, but education is an international/global necessity. There must be some standardization so our students or those from other countries have some common knowledge and skills to survive.

\section{Question 27}

Those secondary programs that were called "practical"; e.g., technology education will receive decreasing support until they no longer exist.

Median Time Frame Round 2

2

Median Impact Round 2

3

Median Desirability Round 2

Median Time Frame Round 3

2

Minority Opinion(s)

3 - Image.

5 - Unfortunatley, I have already seen the loss of the technology programs in all middle schools, much of their demisedue to lack of funding.

Median Impact Round 3

3
2 


\section{Question 28 \\ Traditional lines of schools, districts and institutions will blur.}

Median Time Frame Round 2

Median Impact Round 2

Median Desirability Round 2

Median Time Frame Round 3

Minority Opinion(s)

1 - Traditions are hard to do anything about and what school your friends and family went to is very important to a large segment of the population.

5 - Again political and financial structures will resist change in the absence of massive federal or state mandates to make these changes.

Median Impact Round 3

4

Minority Opinion(s)

1 - No impact because I don't think it will happen.

Median Desirability Round 3

4

\section{Question 29}

The United States and other advanced societies will move toward continuous innovation to meet job market demand, which is founded by information technology.

Median Time Frame Round 2

3

Median Impact Round 2

4

Median Desirability Round 2

4

Median Time Frame Round 3

3

Median Impact Round 3

4

Median Desirability Round 3

4

Minority Opinion(s)

5 - The United States must move forward.
4

4

3




\section{Question 30 \\ The development of the right side of the brain will be fostered by activities that require synthesis and holistic thinking.}

Median Time Frame Round 2

Median Impact Round 2

Median Desirability Round 2

Median Time Frame Round 3

Minority Opinion(s)
2

\section{4}

2

3 - There are a number of articles that refer to this change. I believe they are leading and forecasting the future even if most people don't.

Median Impact Round 3

4

Median Desirability Round 3

4

Minority Opinion(s)

5 - To remain competitive our country will need to embrace this change.

\section{Question 31}

Continued globalization will result in multi-national education programs.

Median Time Frame Round 2

Median Impact Round 2

Median Desirability Round 2

Median Time Frame Round 3

Minority Opinion(s)

1 - This would take a great deal of coordination from somewhere. this nations schools are not see up for this kind of coordiantion.

1 - Not sure at what level this is geared. As a nation we don't send high school students abroad now and there is not a focus on it, so I just don't see this occuring.

Median Impact Round 3

4

Minority Opinion(s)

1 - I doubt it this is going to happen.

2 - I guess if this did occur, the impact would be high.

Median Desirability Round 3 3

Minority Opinion(s) 
5 - A must for students, and society, to be productive and competitive.

1 - I doubt it this is going to happen.

5 - We must seriously recognize education is becoming a global endeavor. We are not protecting our students if we desire NOT to be willing to work this direction.

Question 32

The goal of career technical education systems in 20 years will be to produce flexible, resilient, softwaresupported students, workers and citizens who can successfully compete, thrive, and live with dignity in a technology-driven Continuous Innovation Society capable of embracing constantly changing goods and services of consumer needs.

Median Time Frame Round 2

Median Impact Round 2

4

Median Desirability Round $2 \quad 4$

Median Time Frame Round $3 \quad 4$

Median Impact Round 3

4

Median Desirability Round 3

4

Question 33

Learning in career and technical education will be performance and innovation based.

Median Time Frame Round 2

3

Median Impact Round 2

4

Median Desirability Round $2 \quad 5$

Median Time Frame Round 3

Minority Opinion(s)

2 - Need to start the movement now for this change but teachers must be supplied with proper tools, technology, and professional development opportunities.

Median Impact Round 3

4

Median Desirability Round 3 


\section{Question 34}

Rural America with no access to high speed internet will get access.

Median Time Frame Round 2

Median Impact Round 2

Median Desirability Round 2

Median Time Frame Round 3

Median Impact Round 3

Minority Opinion(s)
3

5

3

5 - The United States needs to conform to a universal system for broadband; example would be countries such as Africa where access can be found in the more remote places.

5 - As someone who is an educator in "Rural America" I am dis-heartened at our lack of high speed internet today and believe this componenet would impact the cultural situation tremendously but am concerned that there is little desire, at the state or federal level to improve the situation in many rural areas regarding connectivity.

5 - In an information-based society connectedness is critical to a functioning society. The Internet is becoming more of a need as opposed to a want.

Median Desirability Round 3

5

\section{Question 35}

International Business will be added to programming in CTE.

Median Time Frame Round 2

Median Impact Round 2

Median Desirability Round 2

Median Time Frame Round 3

Minority Opinion(s)
3

\section{4}

2 - It already exits in some programs however teachers are not comforta ble with teaching the subject since most have not experienced travel internationally or study or conversations/research in the area.

Median Impact Round 3

4

Median Desirability Round 3 


\section{Question 36}

Green technology initiatives emerge as new CTE programs.

Median Time Frame Round 2

Median Impact Round 2

Median Desirability Round 2

Median Time Frame Round 3

Median Impact Round 3

Minority Opinion(s)
2

4

5

2

5 - There is a move for green technology with Federal grants.

2 - As "green technologies" have not really been defined in a distinctive curriculum framework, the competencies will simply be merged into existing CTE programs such as HVAC, electrical, Plumbing and environmental technologies, not a big impact.

Median Desirability Round 3

5

Question 37

Modernizing CTE centers will be vital in maintaining an edge in the labor market.

Median Time Frame Round 2

Median Impact Round 2

Median Desirability Round 2

Median Time Frame Round 3

Median Impact Round 3

Median Desirability Round 3

Minority Opinion(s)
3

5

3

\section{5}

5

4 - I believe instructional strategy improvements are the first priority and are most desireable over and above facility improvements. 


\section{Question 38}

Career and technical education will play a major role in STEM (Science, Technology, Engineering and Mathematics) education.

Median Time Frame Round 2

Median Impact Round 2

Median Desirability Round $2 \quad 5$

Median Time Frame Round $3 \quad 2$

Median Impact Round 3

5

Minority Opinion(s)

3 - I predict the community colleges and academic high schools will be more successful in adopting and promoting STEM programs.

Median Desirability Round 3

Question 39

Career and technical education will include the teaching of soft skills such as the ability to work well together in its programming.

Median Time Frame Round 2

2

Median Impact Round 2

4

Median Desirability Round $2 \quad 5$

Median Time Frame Round $3 \quad 2$

Median Impact Round 3

4

Median Desirability Round 3

5

\section{Question 40}

Career development of life-long learners at ALL levels will become very important as we move from the manufacturing model to individualization.

Median Time Frame Round 2

3

Median Impact Round 2

4

Median Desirability Round 2

4

Median Time Frame Round 3

Median Impact Round 3

4

Median Desirability Round 3 


\section{Question 41}

Societal changes and more ethnic diversity will occur at a faster rate thus increasing the need to understand and tolerate the cultural needs and function of others amongst us.

Median Time Frame Round 2

2

Median Impact Round 2

4

Median Desirability Round $2 \quad 4$

Median Time Frame Round $3 \quad 2$

Median Impact Round 3

4

Minority Opinion(s)

1 - This is really dependent on the global economy which is not good now. For the time being, I see this as low impact.

Median Desirability Round 3

4

Question 42

Instructional technology (ex. virtual learning) will increase its presence as a course delivery component.

Median Time Frame Round 2 2

Median Impact Round 2

4

Median Desirability Round 2

4

Median Time Frame Round 3

Minority Opinion(s)

3 - I believe it will take longer.

Median Impact Round 3

4

Median Desirability Round 3 


\section{Question 43}

Technology advances will continue to drive curriculum and program changes increasing learning outside of the brick walls at all levels.

Median Time Frame Round 2

Median Impact Round 2

4

Median Desirability Round $2 \quad 4$

Median Time Frame Round $3 \quad 2$

Median Impact Round 3

4

Minority Opinion(s)

5 - It currently is happening and CTE instructors and administrators need to increase their skills.

Median Desirability Round 3

4

Question 44

Change in public education will be strongly influenced by outside innovators.

Median Time Frame Round 2

3

Median Impact Round 2

4

Median Desirability Round 2

Median Time Frame Round 3

Minority Opinion(s)

4 - This is already occurring.

Median Impact Round 3

Median Desirability Round 3

3

\section{Question 45}

Project-based and work-based learning will become more common.

Median Time Frame Round 2

Median Impact Round 2

Median Desirability Round 2

Median Time Frame Round 3

Median Impact Round 3

Median Desirability Round 3
2

\section{4}

5

2

4 


\section{Question 46}

The use of technology to drive the teaching and learning process will become common place.

Median Time Frame Round 2

Median Impact Round 2

Median Desirability Round 2

Median Time Frame Round 3

Median Impact Round 3

Median Desirability Round 3
2

5

2

4

5

\section{Question 47}

Student flight from low performance public schools to other viable options will occur.

Median Time Frame Round 2

Median Impact Round 2

Median Desirability Round 2

Median Time Frame Round 3

Minority Opinion(s)

4 - Where are they going????

Median Impact Round 3

Minority Opinion(s)

1 - This is available now under NCLB and we don't really see a lot of movement.

Median Desirability Round 3 3

Minority Opinion(s)

1 - I think the goal is to improve teaching and learning not just move people around.

1 - Public school options ensure affordability and services for all options. Private options are not as likely to address this.
3

3

3 


\section{Question 48}

Current education hierarchies will be challenged, especially the school board authority, will be eliminated as an archaic way of running a school system.

Median Time Frame Round 2

Median Impact Round 2

Median Desirability Round 2

Median Time Frame Round 3

Minority Opinion(s)
3

$$
3
$$

3

3

I - I don't see any support for this at a local level.

5 - Although this may occur in some places, the school board structure has been around for a long time and it is unlikely that this structue will be replaced within 10 years.

4 - In my state I believe local control will be maintained for quite some time.

Median Impact Round 3

3

Minority Opinion(s)

5 - The current education system is of school district governance is archaic and is very political. Do the school board members really care about the students? If they do, why are we continuing to be mediocre at best?

Median Desirability Round 3

3

Minority Opinion(s)

5 - Rural WV won't change anytime soon.

5 - Sorry, my desire to change the system is much stronger than the score of 3 . Why do people not see the mediocrity in this position?

\section{Question 49}

There will be a concentrated evaluation of the qualifications for County (or Regional) Board of Education membership---there will be a requirement that individuals have some interest in or value for education and the public schools—and, perhaps, even some education themselves, which will take the credibility and influence of Board Members up several notches.

Median Time Frame Round 2

Median Impact Round 2

Median Desirability Round 2

Minority Opinion(s) 
1 - I don't see any movement for this at the local level. This is a local political issue. It would be very difficult for this to happen without a ground swell at the local level.

4 - I believe it will take longer.

Median Impact Round 3

4

Minority Opinion(s)

1 - Not going to happen.

Median Desirability Round 3

4

Question 50

Decision and policy makers will realize the gravity of allowing CTE to continue as the dumping ground for students who cannot succeed in the general education classroom.

Median Time Frame Round 2

2

Median Impact Round 2

5

Median Desirability Round $2 \quad 5$

Median Time Frame Round $3 \quad 2$

Minority Opinion(s)

1 - I have been in this field for forty years and have heard this as an issue with no movement. Not going to happen.

3 - While high on the radar now, I don't know that this will change that quickly.

Median Impact Round 3

5

Median Desirability Round 3

5

Question 51

Public education will remain but there will be expansion of private sector education and new hybrids of public-private sector partnerships.

Median Time Frame Round 2

3

Median Impact Round 2

4

Median Desirability Round 2

Median Time Frame Round $3 \quad 3$

Minority Opinion(s)

2 - Parents/guardians are looking for alternatives to the educational process--many are looking into virtual school programs.

Median Impact Round 3 
Median Desirability Round 3

Minority Opinion(s)

5 - My desire will not change. I accept and will advocate for any education alternatives that provide our students an excellent education even if it brings about the downfall of the current education system (which is a failure as it stands).

\section{Question 52}

High school dropout rates will continue to climb due to a disengaged student population from middle school upward.

Median Time Frame Round 2

2

Median Impact Round 2

Median Desirability Round 2

Median Time Frame Round 3

Median Impact Round 3

Median Desirability Round 3

2

Minority Opinion(s)

1 - The impact of droputs is to seriously undermine ROI.

\section{Question 53}

Career and technical education facilities and programs will have a strong, vocal and informed voice on Capitol Hill.

Median Time Frame Round 2

3

Median Impact Round 2

5

Median Desirability Round 2

5

Median Time Frame Round 3

3

Minority Opinion(s)

2 - I don't believe this will happen until more people get involved in the ACTE organization. Until CTE educators are willing to stand up and be counted, they will never have the ear of the folks on Capitol Hill. Too many teachers are waiting for "someone else" to take the lead. If we are to change the current thinking, we will have to have many more people willing to take a stand!

4 - I believe they already do.

Median Impact Round 3

5

Minority Opinion(s)

3 - Funding will have a high impact; or rather the lack of funding.

Median Desirability Round 3 


\section{Question 54 \\ Global, national, state, regional and local economic changes cause greater shifts in the wealth of populations.}

Median Time Frame Round 2

Median Impact Round 2

Median Desirability Round 2

Median Time Frame Round 3

Median Impact Round 3

Median Desirability Round 3

Minority Opinion(s)
3

\section{4}

3

3

4

2 - Cannot judge which side of middle because it is dependent upon in what direction the wealth shifts - greater poor or more equalized wealth.

\section{Question 55}

China and India will control the world economically pushing the United States to get very serious about creating, implementing and marketing innovation.

Median Time Frame Round 2

2

Median Impact Round 2

5

Median Desirability Round 2

Median Time Frame Round 3

Minority Opinion(s)

3 - From my reading of national press I think it will take longer than 1 to 3 years especially with the current economic situation.

Median Impact Round 3

5

Median Desirability Round 3

2

Minority Opinion(s)

5 - Needed.

4 - I don't think a lowering of our power in the world would be good for the United States.

4 - I can't see why global competition is bad. 


\section{Question 56 \\ Social systems move from the old manufacturing models of education, work and life to one where individuals decide what path they want to follow to fit in the global scheme.}

Median Time Frame Round 2

3

Median Impact Round 2

4

Median Desirability Round 2

Median Time Frame Round 3

Median Impact Round 3

4

Median Desirability Round 3

4

\section{Question 57}

Educators in career and technical education fields will be required to hold postsecondary degrees (associate, bachelor or master).

Median Time Frame Round 2

3

Median Impact Round 2

4

Median Desirability Round 2

Median Time Frame Round 3

Minority Opinion(s)

4 - It's a cost consideration.

1 - Advanced degrees are not necessary for many occupations that we train workers for.

Median Impact Round 3

4

Median Desirability Round 3

4

Minority Opinion(s)

1 - It is not necessary as I stated above and it would be very hard to find individuals in some fields that would have advanced degrees. 


\section{Question 58 \\ Career and technical education teachers will be required to hold industry certification.}

Median Time Frame Round 2

Median Impact Round 2

Median Desirability Round 2

Median Time Frame Round 3

Median Impact Round 3

Minority Opinion(s)

5 - If we (technology education teachers offer an industyr certification then we must lead by example and hold the industry certification first before working with the students).

Median Desirability Round 3

5

Minority Opinion(s)

4 - I believe programming at the high school level will need to be broader which may take a more braodly prepared teacher - not so occupationally specific in emphasis.

\section{Question 59}

The demand for CTE teachers will increase.

Median Time Frame Round 2

3

Median Impact Round 2

5

Median Desirability Round $2 \quad 5$

Median Time Frame Round 3

Minority Opinion(s)

2 - I am already seeing it. CTE teachers can make a lot more money doing their trade rather than teaching it. Median Impact Round 3 5

Median Desirability Round 3 


\section{Question 60}

Teacher education programs for CTE teachers will change significantly as a result of the blending of technical and academic delivery.

Median Time Frame Round 2

Median Impact Round 2

Median Desirability Round 2

Median Time Frame Round 3

Minority Opinion(s)
3

\section{5}

2 - CTE teachers will need assistance incorporating the academic component (especially if credit is awarded for academic subjects within the technical courses-techacademics) which means the teacher education programs will have to change.

Median Impact Round 3

5

Median Desirability Round 3

5

\section{Question 61}

There will be a teacher education tract in higher education for those wishing to pursue a career in industrial, technical or health occupations education much like regular education fields.

Median Time Frame Round 2

3

Median Impact Round 2

4

Median Desirability Round 2

4

Median Time Frame Round 3

3

Minority Opinion(s)

5 - My experience of discussing the possibilities for moving CTE Teacher Education from its present format into a more traditional teacher education track is a continuing reluctance on the part of the universities in our state because of the previous degree status of most industrial and technical teachers....the advancements in opportunities for degree seeking individuals have been significantly limited, although we have explored this at length with Extended Learning and the Education Department. Only a few university leaders are even willing to entertain such a bold concept as the feel it diminishes the validity of their teacher education programs with respect to NCATE.

Median Impact Round 3

4

Median Desirability Round 3

4

Minority Opinion(s)

1 - As general teacher education currently exists, it holds very little relevance to the needs and mission of CTE teacher preparation. There is a fundamental lack of interest in the application model which would be required for a more traditional teacher education model for CTE teachers, and the delivery through instructional technology must be moderated so that the in-service teachers do not lose the mentoring that occurs with the current CTE Teacher Education model. This points to another fundamental problem that 
exists in this state--that CTE Teachers do not receive adequate or appropriate mentoring as a general rule in the county in which they are employed.

\section{Question 62}

Many teachers will be part-time as opposed to full-time.

Median Time Frame Round 2

Median Impact Round 2

Median Desirability Round 2

Median Time Frame Round 3

Minority Opinion(s)

1 - Not sure I see this as a trend.

Median Impact Round 3

Median Desirability Round 3

Minority Opinion(s)

3

\section{4}

3

3

4

3

5 - This option would be desirable and could impact a new set of instructors considering the changes in teaching.

\section{Question 63}

CTE performance based educator pay will come to the forefront.

Median Time Frame Round 2

Median Impact Round 2

Median Desirability Round 2

Median Time Frame Round 3

Minority Opinion(s)

4 - WV is NOT going to fund this!!!

Median Impact Round 3

Median Desirability Round 3

Minority Opinion(s)
3

\section{4}

3

4

5 - As a technology education teacher we can perform and stand behind what we teach and the outcomes. If there is one group that should support performance it would be TE! 


\section{Question 64}

CTE instructors must understand and participate in professional development activities to prepare them for the subjects being taught and with a variety of strategies.

Median Time Frame Round 2

Median Impact Round 2

Median Desirability Round 2

Median Time Frame Round 3

Median Impact Round 3

Median Desirability Round 3
2

\section{4}

5

2

4

\section{Question 65}

CTE programs will have great teachers who foster passion and curiosity.

Median Time Frame Round 2

Median Impact Round 2

Median Desirability Round 2

Median Time Frame Round 3

Median Impact Round 3

Median Desirability Round 3
2

\section{5}

5

2

\section{5}

5

\section{Question 66}

Secondary school counselors will be informed and cognizant of the opportunities awaiting students in CTE programming.

Median Time Frame Round 2

3

Median Impact Round 2

5

Median Desirability Round 2

Median Time Frame Round 3

Minority Opinion(s)

1 - With all of the lip-service and "additions" at the state level which have been purportedly designed to increase the knowledge base, appreciation for and capacity to guide capable students to the appropriate CTE programming, the nature of guidance counselor undergraduate and graduate education is such that the effective counseling and guidance for high school students cannot and will not improve much if any in most schools and areas of the state. Even the individuals who are being charged with seeing this wish to fruition are largely uninformed and do not have the background necessary to see this monumental transition take place. 
Median Impact Round 3

Minority Opinion(s)

- It will not happen under the current model.

Median Desirability Round 3

5

Minority Opinion(s)

- The counseling and guidance issue cannot be resolved under the current system of graduation requirements and mind-set of the decision makers at the state and university levels.

Question 67

Stakeholders in various realms of education (CTE, secondary, post-secondary, general secondary, higher ed) will emerge steadily as important informants and collaborators in not only evaluating, but also planning and execution instructional programs.

Median Time Frame Round 2

3

Median Impact Round 2

4

Median Desirability Round $2 \quad 5$

Median Time Frame Round $3 \quad 3$

Median Impact Round 3

4

Median Desirability Round 3

5

Question 68

CTE Administrator preparation programs will be designed to better equip principals in the career and technical education realm.

Median Time Frame Round 2

3

Median Impact Round 2

4

Median Desirability Round $2 \quad 5$

Median Time Frame Round 3

Median Impact Round 3

4

Median Desirability Round 3

5

Minority Opinion(s)

3 - This must occur to give CTE equity. 


\section{Question 69}

There will be a shift in CTE governance resulting in an increase in contact between local educators and state/regional leaders.

Median Time Frame Round 2

3

Median Impact Round 2

4

Median Desirability Round $2 \quad 4$

Median Time Frame Round $3 \quad 3$

Median Impact Round 3

4

Median Desirability Round 3

4

\section{Question 70}

Faculty will become consultants to students, who will become clients, while the students will become innovators and entrepreneurs.

Median Time Frame Round 2

3

Median Impact Round 2

4

Median Desirability Round 2

Median Time Frame Round 3

Median Impact Round 3

4

Minority Opinion(s)

5 - This is already being done within the technology schools (Mircrosoft/Gates schools.)

Median Desirability Round 3

4

\section{Question 71}

The local industry advisory council will play a bigger role in ensuring that the lab tools and equipment are updated to meet and/or exceed the requirements of the workplace.

Median Time Frame Round 2

3

Median Impact Round 2

4

Median Desirability Round 2

Median Time Frame Round 3

Median Impact Round 3

4

Minority Opinion(s)

2 - In many cases CT Educators are the "experts." Schools cannot afford to engage tiem and money into programs that are in costant need of industry changes.

Median Desirability Round 3 
Minority Opinion(s)

5 - As we prepare workers for the $21^{\text {st }}$ century nothing could be more important.

Question 72

The demand for skilled workers will increase.

Median Time Frame Round 2

2

Median Impact Round 2

Median Desirability Round $2 \quad 5$

Median Time Frame Round $3 \quad 2$

Median Impact Round 3

5

Median Desirability Round 3

5

Question 73

Collaboration between stakeholders and CTE will increase.

Median Time Frame Round 2

Median Impact Round 2

Median Desirability Round 2

Median Time Frame Round 3

Median Impact Round 3

Median Desirability Round 3
2

4

5

2

4

Question 74

The demand for workers with postsecondary education will increase.

Median Time Frame Round 2

2

Median Impact Round 2

4

Median Desirability Round $2 \quad 5$

Median Time Frame Round $3 \quad 2$

Median Impact Round 3

4

Median Desirability Round 3 


\section{Question 75}

Career and technical education will be called upon to retrain America's workforce.

Median Time Frame Round 2

Median Impact Round 2

Median Desirability Round 2

Median Time Frame Round 3

Minority Opinion(s)

2 - This is happening now.

Median Impact Round 3

Median Desirability Round 3
3

\section{5}

5

3

Question 76

The focus of education will be on workforce development, which will mean the alignment of education and work and the use of data to develop what programs are offered.

Median Time Frame Round 2

3

Median Impact Round 2

4

Median Desirability Round 24

Median Time Frame Round 3

Median Impact Round 3

4

Median Desirability Round 3

4

Question 77

CTE is the link that connects business leaders with educators in a unified effort to help all students understand the relevance of their education to their future goals and prepare them with the knowledge, talent and skills valued and needed in today's workplace.

Median Time Frame Round 2

2

Median Impact Round 2

4

Median Desirability Round 2

4

Median Time Frame Round 3

2

Median Impact Round 3

4

Median Desirability Round 3

4 


\section{Question 78 \\ Jobs will constantly evolve to meet workforce demand forcing constant updating for career technical education in America formulating an Innovation Society driven by continuously enhanced human capital.}

Median Time Frame Round 2

Median Impact Round 2

Median Desirability Round 2

Median Time Frame Round 3

Median Impact Round 3

Median Desirability Round 3

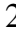

5

5

2

5

5

\section{Question 79}

All students will seek more specific technical skills training in order to be more competitive in the workplace.

Median Time Frame Round 2

3

Median Impact Round 2 5

Median Desirability Round $2 \quad 5$

Median Time Frame Round 3

Minority Opinion(s)

$I$ - I think it would be great if they did but I don't think people plan ahead like that all especially the people who need it the most.

2 - I think the timeframe on this is shorter.

Median Impact Round 3

5

Median Desirability Round 3

5

Question 80

CTE will serve as the change agent in building existing governance structures to bring state, regional and local leaders in education, workforce and economic development together to support and grow each state's economy.

Median Time Frame Round 2

3

Median Impact Round 2

5

Median Desirability Round 2

Median Time Frame Round 3

Median Impact Round 3

5

Median Desirability Round 3 


\section{Question 81}

Post secondary CTE programs will be absorbed in the community college system.

Median Time Frame Round 2

Median Impact Round 2

Median Desirability Round 2

Median Time Frame Round 3

Minority Opinion(s)

5 - Here in our state I do not see the community college system taking over all of the CTE programs. Sure they might like the Health Programs but would not want the other CTE programs.

1 - With the increase in for-profit options, I don't believe this will happen

Median Impact Round 3

5

Minority Opinion(s)

3 - While this would impact the programs and individuals deliverting the programs, I'm not sure the way the programs are delivered would be impacted.

3 - In many regards this currently exists and therefore if transitioned well would not have a huge impact.

Median Desirability Round 3

2

Minority Opinion(s)

5 - Where will postsecondary programs be absorbed if not in the community college system? If one takes a look around, the universities and four-year colleges are not rushing to the aid of CTE.

3 - There are both positive and negative implications that would occur as a result of changes.

3 - Both conditions in and out of the postsecondary system could work well depending on the attitudes and systems supporting the conditions.

\section{Question 82}

Career and Technical Education will be recognized as a credible choice for college-bound high school students, rather than as a last resort for marginalized students.

Median Time Frame Round 2

3

Median Impact Round 2

5

Median Desirability Round 2

5

Median Time Frame Round 3

3

Median Impact Round 3

Minority Opinion(s) 
3 - It is already seen as a credible choice in our region and therefore is not having a very high impact.

Median Desirability Round 3

Question 83

There will be better program alignment with community colleges enabling a much more seamless transition to post secondary education.

Median Time Frame Round $2 \quad 3$

Median Impact Round 2

4

Median Desirability Round 2

Median Time Frame Round $3 \quad 3$

Minority Opinion(s)

2 - This is already occuring in most areas and should only increase.

Median Impact Round 3

4

Median Desirability Round $3 \quad 4$

\section{Question 84}

Higher education will offer multiple tracks for advancement through the degree process for students entering from Career and Technical Education with certifications/completions in similar career fields.

Median Time Frame Round 2

3

Median Impact Round 2

4

Median Desirability Round $2 \quad 5$

Median Time Frame Round $3 \quad 3$

Minority Opinion(s)

1 - Higher education is the least likely to change about anything, this included.

Median Impact Round 3

4

Median Desirability Round 3

5

Question 85

Worldwide articulation agreements will be implemented to assure smooth transition of students from high school to college and from college to college.

Median Time Frame Round 2

3

Median Impact Round 2 
Median Desirability Round $2 \quad 5$

Median Time Frame Round $3 \quad 3$

Minority Opinion(s)

1 - This is a coordination issue second to none and is not going to happen.

1 - I don't really see the global angle that you are going for here.

Median Impact Round 3

Minority Opinion(s)

2 - Again, I don't see this happening so the impact will be low.

Median Desirability Round 3

Minority Opinion(s)

3 - Put my answer at 3 as I don't know how desirable this is if we don't have study abroad students.

\section{Question 86}

Learning centers will exist and traditional schools will be obsolete.

Median Time Frame Round 2

Median Impact Round 2

Median Desirability Round 2

Median Time Frame Round 3

Minority Opinion(s)

\section{4}

5

1 - This would require a political change and would have to be driven from the ground up. Most people are not interested.

Median Impact Round 3

5

Median Desirability Round 3

3 


\section{Question 87}

The chasm between secondary and postsecondary career and technical education will either get smaller or be eliminated with the implementation of programs of study.

Median Time Frame Round 2

Median Impact Round 2

Median Desirability Round 2

Median Time Frame Round 3

Median Impact Round 3

Median Desirability Round 3
3

4

4

3

\section{4}

\section{Question 88}

High school CTE will become more agile and focused on supporting transitions to higher education that support the local, regional, state, national and GLOBAL workforce and economic needs.

Median Time Frame Round 2

Median Impact Round 2

4

Median Desirability Round $2 \quad 4$

Median Time Frame Round 3

Median Impact Round 3

4

Median Desirability Round 3

4

\section{Question 89}

CTE will be a valuable part of all students' overall high school experience and is used to help them prepare for postsecondary education and/or training and career success.

Median Time Frame Round 2

3

Median Impact Round 2

5

Median Desirability Round 2

Median Time Frame Round 3

Minority Opinion(s)

2 - There is a division that exists between academic and vocational preparation I have not seen any sign that that is disappearing.

5 - In over 30 total years in CTE related work, I have not seen any indication that such a transition could or would occur so quickly in our current political and educational climate. I think that 15-20 years is being extremely optimistic. 
Median Impact Round 3

Minority Opinion(s)

3 - CTE is being integrated into all students training more regionally here than the median response indictates.

Median Desirability Round 3 5

Question 90

CTE drives innovation and creativity in the state's high schools by transforming the culture of education so every school produces lifelong learners that are both academically-skilled and career-ready.

Median Time Frame Round 2

3

Median Impact Round 2

5

Median Desirability Round 2

5

Median Time Frame Round 3

3

Median Impact Round 3

5

Median Desirability Round 3

5

Question 91

CTE funding will become more dependent on "competitive grants" which would require additional "proof" that programs are valid.

Median Time Frame Round 2

3

Median Impact Round 2

4

Median Desirability Round 2

Median Time Frame Round 3

Median Impact Round 3

4

Median Desirability Round 3

3

Minority Opinion(s)

4 - Programming supported by data will become more critical for CTE. 


\section{Question 92}

Federal funding will be the key to the survival or demise of career and technical education.

Median Time Frame Round 2

Median Impact Round 2

Median Desirability Round 2

Median Time Frame Round 3

Median Impact Round 3

Minority Opinion(s)

4 - CTE instructors/administrators will need to utilize Federal, State or local grants.

Median Desirability Round 3

3

\section{Question 93}

Career and technical education research database will grow significantly, providing a valid and substantial foundation for increasing and stabilizing funding for higher quality CTE teachers and higher quality CTE programming.

Median Time Frame Round 2

3

Median Impact Round 2

4

Median Desirability Round 2

Median Time Frame Round 3

Minority Opinion(s)

2 - I believe it is changing now and with the focus on data gathering and analysis, it will only get bigger.

Median Impact Round 3

4

Median Desirability Round 3 


\section{Question 94}

CTE programs will be certified or recognized by industry, professional, trade associations, or state licensing agencies and that will lead to Performance Based Program support dollars.

Median Time Frame Round 2

Median Impact Round 2

Median Desirability Round 2

Median Time Frame Round 3

Median Impact Round 3

Median Desirability Round 3
3

\section{4}

4

3$$
4
$$

4

\section{Question 95}

Perkins funding may be replaced or greatly modified as CTE merges with general education, higher education and community colleges.

Median Time Frame Round $2 \quad 3$

Median Impact Round 2

Median Desirability Round 2

Median Time Frame Round 3

Median Impact Round 3

4

Median Desirability Round 3

Minority Opinion(s)

5 - I predict Congress will not re-authorize Perkins because of the financial ineptitude of the local districts and community colleges (not drawing down funds on a regular basis).

\section{Question 96}

There will not be a re-authorization of the Carl D. Perkins Career and Technical Education Act of 2006 beyond 2018.

Median Time Frame Round 2

Median Impact Round 2

Median Desirability Round 2

3

Median Time Frame Round 3

Median Impact Round 3

Minority Opinion(s) 
3 - It all depends how the issue is addressed. For instance, what if new legislation required CTE as a part of Title I ESEA activities.

Median Desirability Round 3 3

Question 97

The focus on research-based and test driven education will increase.

Median Time Frame Round 2

Median Impact Round 2

4

Median Desirability Round 2

Median Time Frame Round $3 \quad 2$

Median Impact Round 3

4

Median Desirability Round 3

3

Minority Opinion(s)

5 - This is already being seen.

\section{Question 98}

Performance-based assessment will replace degrees and diplomas. Student competencies will be observable and documented on a Certificate of Achievement.

Median Time Frame Round 2

Median Impact Round 2

Median Desirability Round 2

Median Time Frame Round 3

Minority Opinion(s)
3

\section{4}

5

3

5 - It will take longer than 10 years for the industrial and business sectors, community and technical colleges and major institutions in our society to transition thinking and acceptance of the assessment result in lieu of a degree or diploma.

Median Impact Round 3

4

Median Desirability Round 3 


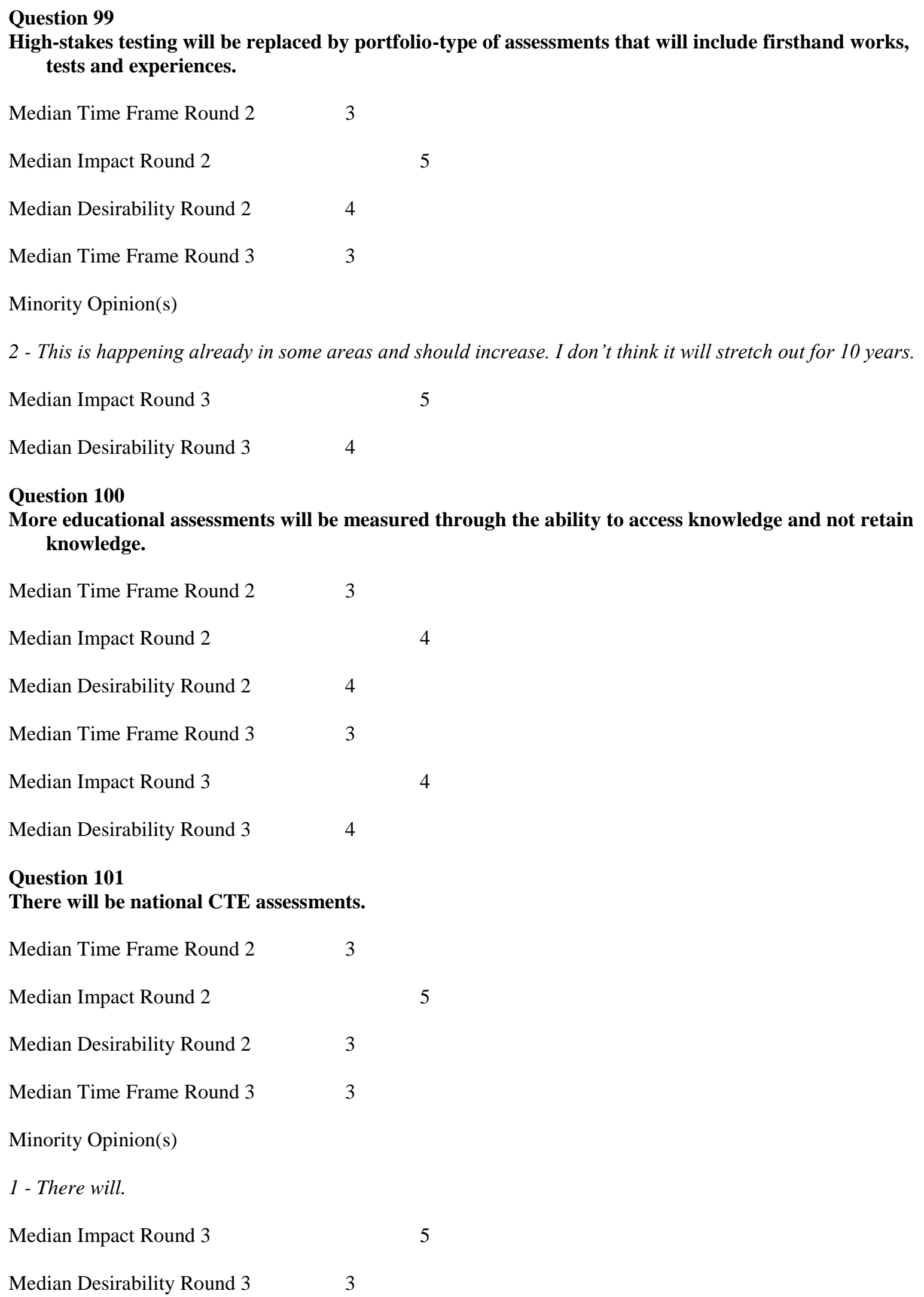


Minority Opinion(s)

4 - I believe this would provide more focus on CTE issues in schools.

\section{Question 102}

Enhanced accountability will include longitudinal data systems designed to improve collection and data integrity which will aid in data-driven decision making.

Median Time Frame Round 2

3

Median Impact Round 2

5

Median Desirability Round 2

Median Time Frame Round 3

Minority Opinion(s)

2 - I believe we are headed to increased accountability standards and I believe our collection methods will improve which will help guide our decision-making process.

Median Impact Round 3

5

Median Desirability Round 3

4

Question 103

Lifelong learning will become more important because people will live longer, work longer and need more frequent training.

Median Time Frame Round 2

3

Median Impact Round 2

4

Median Desirability Round $2 \quad 4$

Median Time Frame Round 3

Minority Opinion(s)

2 - I am already seeing many folks (of retirement age) returning to school and work in order to maintain a living. Many folks are realizing the importance of lifelong learning and with the onset of advanced technology, it will be necessary to upgrade skills. I do not believe we will be able to count on social security for years to come.

2 - I believe this is the case now.

Median Impact Round 3

4

Median Desirability Round 3 


\section{Question 104}

The emphasis on accountability in all secondary education programs will continue with career and technical education at great risk to prove that their contribution is worth the expense.

Median Time Frame Round 2

3

Median Impact Round 2

Median Desirability Round 2

3

Median Time Frame Round 3

3

Median Impact Round 3

5

Median Desirability Round 3

3

Question 105

The contribution to economic development must be recognized or career and technical education will continue to be marginalized.

Median Time Frame Round 2

2

Median Impact Round 2

5

Median Desirability Round $2 \quad 5$

Median Time Frame Round 3

Median Impact Round 3

5

Median Desirability Round 3

5

Question 106

The high school dropout rates will decrease as enrollment in CTE classes increase because students see relevancy in their learning environment.

Median Time Frame Round 2

3

Median Impact Round 2

Median Desirability Round 2

5

Median Time Frame Round 3

3

Median Impact Round 3

Median Desirability Round 3 


\section{Question 107 \\ Career and technical education will be expected to address the needs of the lowest quartile and the difficult-to-educate children.}

Median Time Frame Round 2

Median Impact Round 2

Median Desirability Round 2

Median Time Frame Round 3

Median Impact Round 3

Median Desirability Round 3
2

4

3

2

4

\section{Question 108}

The "trades" will once again be positions of respect and education will be tied to economic development.

Median Time Frame Round 2 3

Median Impact Round 2

5

Median Desirability Round $2 \quad 5$

Median Time Frame Round 3

Median Impact Round 3

5

Median Desirability Round 3

5

Question 109

CTE will move from the elective side of the high school graduation requirements to the required core side of high school graduation.

Median Time Frame Round 2

3

Median Impact Round 2

5

Median Desirability Round $2 \quad 5$

Median Time Frame Round 3

Minority Opinion(s)

1 - As long as professional educators are in control of education it will never happen.

5 - Based on historical timelines, and considering the substantial lack of understanding and need for education of the policy and decision makers, the years required for a possible transition of this magnitude will be much greater than 10 years.

Median Impact Round 3

Median Desirability Round 3

5 


\section{Question 110}

Students will need to apply to be accepted into CTE programs.

Median Time Frame Round 2

Median Impact Round 2

5

Median Desirability Round $2 \quad 4$

Median Time Frame Round 3

Minority Opinion(s)

2 - This is already happening for some programs in some areas so I think the timeline is shorter.

Median Impact Round 3

Minority Opinion(s)

2 - We have a state required application process now.

Median Desirability Round $3 \quad 4$

Minority Opinion(s)

5 - I honestly believe if students have to choose CTE, CTE will advance and become more desirable. Students who decide to take the CTE track will want to do it and I believe they will be more successful.

2 - While this is desirable for some reasons, many students need access to CTE and applying for the programming will prevent access to some.

3 - We have a state required admissions policy.

\section{Question 111}

Parents will recognize that CTE is paramount to achieving education and career goals.

Median Time Frame Round 2

Median Impact Round 2

Median Desirability Round 2

Median Time Frame Round 3

Minority Opinion(s)
3

5

1 - CTE has difficulty competing with the marketing strategies and communication of worth from general education and the fundamental lack of CTE friendly counseling and guidance will require a complete restructuring of the mind set of higher education and administrative preparation programming coordinators and developers. We will not see this accomplished in the next few years.

Median Impact Round 3

5

Median Desirability Round 3

5 


\section{Question 112}

The location of CTE will move from behind the scenes of the school to a front showcase and become the hub in which all high school knowledge revolves.

Median Time Frame Round 2

3

Median Impact Round 2

5

Median Desirability Round $2 \quad 5$

Median Time Frame Round $3 \quad 3$

Minority Opinion(s)

1 - Not going to happen due to what the population in general thinks about career and technical education (vocational education).

1 - This may be accomplished on a regional basis in the United States, but not in our local area due to the politics of education.

Median Impact Round 3

5

Minority Opinion(s)

- This is a desirable event; however, under the current direction of educational politics, it cannot occur.

Median Desirability Round 3

5

Minority Opinion(s)

- Because of current educational politics, this event will not occur in the foreseeable future.

\section{Question 113}

Students who complete a secondary program, go to work, and continue to learn either on the job and/or receive training provided by the employer will be valued as much as a person who has a degree.

Median Time Frame Round 2

3

Median Impact Round 2

5

Median Desirability Round $2 \quad 5$

Median Time Frame Round $3 \quad 3$

Minority Opinion(s)

4 - Not in our society unless there is some change that I am not aware of.

Median Impact Round 3

5

Median Desirability Round 3 


\section{Question 114}

Education funding will plateau in the states or decline due to a lack of understanding of the need to be educated and employed to compete in a world-wide economy.

Median Time Frame Round 2

2

Median Impact Round 2

5

Median Desirability Round 2

2

Median Time Frame Round 3

2

Median Impact Round 3

5

Median Desirability Round 3

2 
Appendix E

Summary of All Responses in Numerical Order 


\section{Appendix E}

Summary of All Results

\begin{tabular}{|c|c|c|c|c|c|c|c|c|c|c|c|c|c|c|}
\hline Event & M2 & $\begin{array}{c}\text { Con- } \\
\text { sensus }\end{array}$ & M3 & $\begin{array}{c}\text { Con- } \\
\text { sensus }\end{array}$ & Event & M2 & $\begin{array}{c}\text { Con- } \\
\text { sensus }\end{array}$ & M3 & $\begin{array}{c}\text { Con- } \\
\text { sensus }\end{array}$ & Event & M2 & $\begin{array}{c}\text { Con- } \\
\text { sensus }\end{array}$ & M3 & $\begin{array}{l}\text { Con- } \\
\text { sensus }\end{array}$ \\
\hline T1 & 2 & - & 2 & + & I1 & 3 & - & 3 & + & D1 & 4 & - & 4 & + \\
\hline $\mathrm{T} 2$ & 2 & - & 2 & + & I2 & 3 & - & 3 & + & D2 & 4 & - & 4 & + \\
\hline $\mathrm{T} 3$ & 2 & - & 2 & + & I3 & 4 & - & 4 & + & D3 & 4 & - & 4 & + \\
\hline T4 & 3 & - & 3 & + & I4 & 3 & - & 3 & + & D4 & 2 & - & 2 & + \\
\hline T5 & 2 & - & 2 & + & I5 & 5 & - & 5 & + & D5 & 4 & - & 4 & + \\
\hline T6 & 2 & + & 2 & + & I6 & 5 & - & 5 & + & D6 & 5 & - & 5 & + \\
\hline $\mathrm{T} 7$ & 3 & + & 3 & + & I7 & 4 & - & 4 & + & D7 & 4 & - & 4 & + \\
\hline T8 & 2 & - & 2 & + & I8 & 4 & - & 4 & + & D8 & 3 & - & 3 & + \\
\hline T9 & 3 & - & 3 & + & I9 & 4 & - & 4 & + & D9 & 4 & - & 4 & + \\
\hline T10 & 2 & - & 2 & + & I10 & 4 & - & 4 & + & D10 & 5 & - & 5 & + \\
\hline T11 & 3 & - & 3 & + & I11 & 4 & - & 4 & + & D11 & 3 & - & 3 & + \\
\hline T12 & 3 & - & 3 & + & $\mathrm{I} 12$ & 4 & - & 4 & + & D12 & 4 & - & 4 & + \\
\hline $\mathrm{T} 13$ & 2 & + & 2 & + & I13 & 4 & - & 4 & + & D13 & 5 & + & 5 & + \\
\hline T14 & 2 & + & 2 & + & I14 & 5 & + & 5 & + & D14 & 5 & + & 5 & + \\
\hline T15 & 2 & - & 2 & + & I15 & 4 & - & 4 & + & D15 & 3 & - & 3 & + \\
\hline T16 & 2 & + & 2 & + & I16 & 4 & - & 4 & + & D16 & 5 & - & 5 & - \\
\hline T17 & 3 & - & 3 & + & I17 & 5 & + & 5 & + & D17 & 5 & + & 5 & + \\
\hline T18 & 3 & - & 3 & + & I18 & 4 & - & 4 & + & D18 & 4 & - & 4 & + \\
\hline T19 & 3 & - & 3 & + & I19 & 3 & - & 3 & + & D19 & 4 & - & 4 & + \\
\hline T20 & 3 & - & 3 & + & I 20 & 4 & - & 4 & + & D20 & 4 & - & 4 & + \\
\hline T21 & 3 & - & 3 & + & I21 & 3 & - & 3 & + & D21 & 4 & - & 4 & + \\
\hline T22 & 3 & - & 3 & + & I 22 & 4 & - & 4 & + & D22 & 4 & - & 4 & + \\
\hline $\mathrm{T} 23$ & 3 & - & 3 & + & $\mathrm{I} 23$ & 4 & - & 4 & + & D23 & 2 & - & 2 & + \\
\hline $\mathrm{T} 24$ & 3 & - & 3 & + & I24 & 4 & - & 4 & + & D24 & 5 & - & 5 & + \\
\hline $\mathrm{T} 25$ & 3 & - & 3 & + & I 25 & 5 & + & 5 & + & D25 & 5 & - & 5 & + \\
\hline T26 & 3 & - & 3 & + & I26 & 4 & - & 4 & + & D26 & 3 & - & 3 & + \\
\hline $\mathrm{T} 27$ & 2 & - & 2 & + & I27 & 3 & - & 3 & + & D27 & 2 & - & 2 & + \\
\hline $\mathrm{T} 28$ & 3 & - & 3 & + & I 28 & 4 & - & 4 & + & D28 & 4 & - & 4 & + \\
\hline T29 & 3 & - & 3 & + & I 29 & 4 & - & 4 & + & D29 & 4 & - & 4 & + \\
\hline T30 & 2 & - & 2 & + & I30 & 4 & - & 4 & + & D30 & 4 & - & 4 & + \\
\hline T31 & 3 & - & 3 & + & I31 & 4 & - & 4 & + & D31 & 3 & - & 3 & + \\
\hline T32 & 4 & - & 4 & + & I32 & 4 & + & 4 & + & D32 & 4 & - & 4 & + \\
\hline T33 & 3 & - & 3 & + & I33 & 4 & - & 4 & + & D33 & 5 & - & 5 & + \\
\hline T34 & 3 & - & 3 & + & I34 & 3 & - & 3 & + & D34 & 5 & + & 5 & + \\
\hline T35 & 3 & - & 3 & + & I35 & 4 & - & 4 & + & D35 & 4 & - & 4 & + \\
\hline T36 & 2 & + & 2 & + & I36 & 4 & - & 4 & + & D36 & 5 & - & 5 & + \\
\hline T37 & 3 & - & 3 & + & I37 & 5 & + & 5 & + & D37 & 5 & + & 5 & + \\
\hline T38 & 2 & - & 2 & + & I38 & 5 & + & 5 & + & D38 & 5 & + & 5 & + \\
\hline T39 & 2 & - & 2 & + & I39 & 4 & - & 4 & + & D39 & 5 & - & 5 & + \\
\hline
\end{tabular}




\begin{tabular}{|c|c|c|c|c|c|c|c|c|c|c|c|c|c|c|}
\hline Event & M2 & $\begin{array}{c}\text { Con- } \\
\text { sensus }\end{array}$ & M3 & $\begin{array}{c}\text { Con- } \\
\text { sensus }\end{array}$ & Event & M2 & $\begin{array}{c}\text { Con- } \\
\text { sensus }\end{array}$ & M3 & $\begin{array}{c}\text { Con- } \\
\text { sensus }\end{array}$ & Event & M2 & $\begin{array}{c}\text { Con- } \\
\text { sensus }\end{array}$ & M3 & $\begin{array}{l}\text { Con- } \\
\text { sensus }\end{array}$ \\
\hline T40 & 3 & - & 3 & + & $\mathrm{I} 40$ & 4 & - & 4 & + & D40 & 4 & - & 4 & + \\
\hline $\mathrm{T} 41$ & 2 & - & 2 & + & I41 & 4 & - & 4 & + & D41 & 4 & - & 4 & + \\
\hline $\mathrm{T} 42$ & 2 & - & 2 & + & I42 & 4 & - & 4 & + & D42 & 4 & - & 4 & + \\
\hline $\mathrm{T} 43$ & 2 & + & 2 & + & I43 & 4 & - & 4 & + & D43 & 4 & - & 4 & + \\
\hline T44 & 3 & + & 3 & + & I44 & 4 & - & 4 & + & D44 & 3 & - & 3 & + \\
\hline T45 & 2 & - & 2 & + & I45 & 4 & - & 4 & + & D45 & 5 & + & 5 & + \\
\hline T46 & 2 & - & 2 & + & I46 & 4 & - & 4 & + & D46 & 5 & - & 5 & + \\
\hline T47 & 3 & - & 3 & + & I47 & 4 & - & 4 & + & D47 & 3 & - & 3 & + \\
\hline T48 & 3 & - & 3 & + & I48 & 3 & - & 3 & + & D48 & 3 & - & 3 & + \\
\hline T49 & 3 & - & 3 & + & I49 & 4 & - & 4 & + & D49 & 4 & - & 4 & + \\
\hline T50 & 2 & - & 2 & + & I50 & 5 & - & 5 & + & D50 & 5 & + & 5 & + \\
\hline T51 & 3 & - & 3 & + & I51 & 4 & - & 4 & + & D51 & 3 & - & 3 & + \\
\hline T52 & 2 & - & 2 & + & I52 & 4 & - & 4 & + & D52 & 2 & - & 2 & + \\
\hline T53 & 3 & - & 3 & + & I53 & 5 & + & 5 & + & D53 & 5 & + & 5 & + \\
\hline T54 & 3 & - & 3 & + & I54 & 4 & - & 4 & + & D54 & 3 & - & 3 & + \\
\hline T55 & 2 & - & 2 & + & I55 & 5 & - & 5 & + & D55 & 2 & - & 2 & + \\
\hline T56 & 3 & - & 3 & + & I56 & 4 & - & 4 & + & D56 & 4 & - & 4 & + \\
\hline T57 & 3 & - & 3 & + & I57 & 4 & - & 4 & + & D57 & 4 & - & 4 & + \\
\hline T58 & 3 & - & 3 & + & I58 & 4 & - & 4 & + & D58 & 5 & - & 5 & + \\
\hline T59 & 3 & - & 3 & + & I59 & 5 & - & 5 & + & D59 & 5 & - & 5 & + \\
\hline T60 & 3 & - & 3 & + & I60 & 5 & + & 5 & + & D60 & 5 & - & 5 & + \\
\hline T61 & 3 & - & 3 & + & I61 & 4 & - & 4 & + & D61 & 4 & - & 4 & + \\
\hline T62 & 3 & - & 3 & + & I62 & 4 & - & 4 & + & D62 & 3 & - & 3 & + \\
\hline T63 & 3 & - & 3 & + & I63 & 4 & - & 4 & + & D63 & 3 & - & 3 & + \\
\hline T64 & 2 & - & 2 & + & I64 & 4 & - & 4 & + & D64 & 5 & + & 5 & + \\
\hline T65 & 2 & - & 2 & + & I65 & 5 & + & 5 & + & D65 & 5 & + & 5 & + \\
\hline T66 & 3 & - & 3 & + & I66 & 5 & + & 5 & + & D66 & 5 & + & 5 & + \\
\hline T67 & 3 & - & 3 & + & I67 & 4 & - & 4 & + & D67 & 5 & + & 5 & + \\
\hline T68 & 3 & - & 3 & + & I68 & 4 & - & 4 & + & D68 & 5 & - & 5 & + \\
\hline T69 & 3 & - & 3 & + & I69 & 4 & - & 4 & + & D69 & 4 & - & 4 & + \\
\hline $\mathrm{T} 70$ & 3 & - & 3 & + & I70 & 4 & - & 4 & + & D70 & 4 & - & 4 & + \\
\hline T71 & 3 & - & 3 & + & I71 & 4 & - & 4 & + & D71 & 4 & - & 4 & + \\
\hline T72 & 2 & + & 2 & + & I72 & 5 & + & 5 & + & D72 & 5 & + & 5 & + \\
\hline T73 & 2 & - & 2 & + & I73 & 4 & - & 4 & + & D73 & 5 & - & 5 & + \\
\hline T74 & 2 & - & 2 & + & I74 & 4 & - & 4 & + & D74 & 5 & - & 5 & + \\
\hline T75 & 3 & - & 3 & + & I75 & 5 & - & 5 & + & D75 & 5 & - & 5 & + \\
\hline T76 & 3 & - & 3 & + & I76 & 4 & - & 4 & + & D76 & 4 & - & 4 & + \\
\hline T77 & 2 & - & 2 & + & I77 & 4 & - & 4 & + & D77 & 4 & - & 4 & + \\
\hline T78 & 2 & - & 2 & + & I78 & 5 & - & 5 & + & D78 & 5 & - & 5 & + \\
\hline T79 & 3 & - & 3 & + & I79 & 5 & - & 5 & + & D79 & 5 & - & 5 & + \\
\hline T80 & 3 & - & 3 & + & I80 & 5 & - & 5 & + & D80 & 5 & - & 5 & + \\
\hline T81 & 3 & - & 3 & + & I81 & 5 & - & 5 & + & D81 & 2 & - & 2 & + \\
\hline T82 & 3 & - & 3 & + & I82 & 5 & + & 5 & + & D82 & 5 & + & 5 & + \\
\hline T83 & 3 & - & 3 & + & I83 & 4 & - & 4 & + & D83 & 4 & - & 4 & + \\
\hline
\end{tabular}




\begin{tabular}{|c|c|c|c|c|c|c|c|c|c|c|c|c|c|c|}
\hline Event & M2 & $\begin{array}{c}\text { Con- } \\
\text { sensus }\end{array}$ & M3 & $\begin{array}{c}\text { Con- } \\
\text { sensus }\end{array}$ & Event & M2 & $\begin{array}{c}\text { Con- } \\
\text { sensus }\end{array}$ & M3 & $\begin{array}{c}\text { Con- } \\
\text { sensus }\end{array}$ & Event & M2 & $\begin{array}{c}\text { Con- } \\
\text { sensus }\end{array}$ & M3 & $\begin{array}{l}\text { Con- } \\
\text { sensus } \\
\end{array}$ \\
\hline T84 & 3 & - & 3 & + & I84 & 4 & - & 4 & + & D84 & 5 & - & 5 & + \\
\hline T85 & 3 & - & 3 & + & I85 & 5 & - & 5 & + & D85 & 5 & - & 5 & + \\
\hline T86 & 4 & - & 4 & + & I86 & 5 & - & 5 & + & D86 & 3 & - & 3 & + \\
\hline T87 & 3 & - & 3 & + & I87 & 4 & - & 4 & + & D87 & 4 & - & 4 & + \\
\hline T88 & 3 & - & 3 & + & I88 & 4 & - & 4 & + & D88 & 4 & - & 4 & + \\
\hline T89 & 3 & - & 3 & + & I89 & 5 & + & 5 & + & D89 & 5 & + & 5 & + \\
\hline T90 & 3 & - & 3 & + & I90 & 5 & - & 5 & + & D90 & 5 & + & 5 & + \\
\hline T91 & 3 & - & 3 & + & I91 & 4 & - & 4 & + & D91 & 3 & - & 3 & + \\
\hline T92 & 2 & - & 2 & + & I92 & 5 & - & 5 & + & D92 & 3 & - & 3 & + \\
\hline T93 & 3 & - & 3 & + & I93 & 4 & - & 4 & + & D93 & 5 & - & 5 & + \\
\hline T94 & 3 & - & 3 & + & I94 & 4 & - & 4 & + & D94 & 4 & - & 4 & + \\
\hline T95 & 3 & + & 3 & + & I95 & 4 & - & 4 & + & D95 & 3 & - & 3 & + \\
\hline T96 & 3 & - & 3 & + & I96 & 5 & - & 5 & + & D96 & 3 & - & 3 & + \\
\hline T97 & 2 & + & 2 & + & I97 & 4 & - & 4 & + & D97 & 3 & - & 3 & + \\
\hline T98 & 3 & - & 3 & + & I98 & 4 & - & 4 & + & D98 & 5 & - & 5 & + \\
\hline T99 & 3 & - & 3 & + & I99 & 5 & + & 5 & + & D99 & 4 & - & 4 & + \\
\hline T100 & 3 & - & 3 & + & I100 & 4 & - & 4 & + & D100 & 4 & - & 4 & + \\
\hline T101 & 3 & - & 3 & + & I101 & 5 & - & 5 & + & D101 & 3 & - & 3 & + \\
\hline T102 & 3 & - & 3 & + & I102 & 5 & - & 5 & + & D102 & 4 & - & 4 & + \\
\hline T103 & 3 & - & 3 & + & I103 & 4 & - & 4 & + & D103 & 4 & - & 4 & + \\
\hline T104 & 3 & - & 3 & + & I104 & 5 & - & 5 & + & D104 & 3 & - & 3 & + \\
\hline T105 & 2 & + & 2 & + & I105 & 5 & + & 5 & + & D105 & 5 & - & 5 & + \\
\hline T106 & 3 & - & 3 & + & I106 & 5 & + & 5 & + & D106 & 5 & + & 5 & + \\
\hline T107 & 2 & - & 2 & + & I107 & 4 & - & 4 & + & D107 & 3 & - & 3 & + \\
\hline T108 & 3 & - & 3 & + & I108 & 5 & - & 5 & + & D108 & 5 & + & 5 & + \\
\hline T109 & 3 & - & 3 & + & I109 & 5 & + & 5 & + & D109 & 5 & + & 5 & + \\
\hline $\mathrm{T} 110$ & 3 & - & 3 & + & I1 10 & 5 & - & 5 & + & D110 & 4 & - & 4 & + \\
\hline $\mathrm{T} 111$ & 3 & - & 3 & + & I111 & 5 & - & 5 & + & D111 & 5 & + & 5 & + \\
\hline T112 & 3 & - & 3 & + & I112 & 5 & - & 5 & + & D112 & 5 & + & 5 & + \\
\hline $\mathrm{T} 113$ & 3 & - & 3 & + & I113 & 5 & - & 5 & + & D113 & 5 & + & 5 & + \\
\hline T114 & 2 & - & 2 & + & I114 & 5 & - & 5 & + & D114 & 2 & - & 2 & + \\
\hline
\end{tabular}

T\# = Time Frame $\quad$ I\# = Impact $\quad$ D\# = Desirability

M2 = Round 2 Median $\quad$ M3 = Round 3 Median

Green $=$ Consensus Reached in Round 2, Continued in Round 3

Red $=$ No Consensus in Round 2, Consensus Reached in Round 3

Black $=$ Consensus Not Reached 


\section{Appendix F}

Response Frequency Distributions 


\section{Response Frequency Distribution Round 2}

Time Frame: 1-Never; 2-Immediate (1-3 years); 3-Mid-Range (4-10 years); 4-LongRange (11-20 years); and 5-beyond 20 years.

Impact: 1-Very Low Impact; 2- Low Impact; 3-Moderate Impact; 4-High Impact and 5Very High Impact.

Desirability: 1-Very Undesirable; 2-Undesirable; 3-Somewhat Desirable; 4-Desirable and 5-Very Desirable.

\begin{tabular}{|c|c|c|c|c|c|}
\hline Question 1 & 1 & 2 & 3 & 4 & 5 \\
\hline \multirow{2}{*}{ Time Frame } & 1 & 9 & 9 & 0 & 0 \\
\hline & $5 \%$ & $47 \%$ & $47 \%$ & $0 \%$ & $0 \%$ \\
\hline \multirow{2}{*}{$\begin{array}{c}\text { Impact on } \\
\text { CTE }\end{array}$} & 0 & 4 & 8 & 2 & 5 \\
\hline & $0 \%$ & $21 \%$ & $42 \%$ & $11 \%$ & $26 \%$ \\
\hline \multirow{2}{*}{ Desirability } & 0 & 3 & 5 & 6 & 5 \\
\hline & $0 \%$ & $16 \%$ & $26 \%$ & $32 \%$ & $26 \%$ \\
\hline Question 2 & 1 & 2 & 3 & 4 & 5 \\
\hline \multirow{2}{*}{ Time Frame } & 0 & 10 & 6 & 3 & 0 \\
\hline & $0 \%$ & $53 \%$ & $32 \%$ & $16 \%$ & $0 \%$ \\
\hline \multirow{2}{*}{$\begin{array}{c}\text { Impact on } \\
\text { CTE }\end{array}$} & 0 & 0 & 4 & 10 & 5 \\
\hline & $0 \%$ & $0 \%$ & $21 \%$ & $53 \%$ & $26 \%$ \\
\hline \multirow{2}{*}{ Desirability } & 0 & 2 & 2 & 8 & 7 \\
\hline & $0 \%$ & $11 \%$ & $11 \%$ & $42 \%$ & $37 \%$ \\
\hline Question 3 & 1 & 2 & 3 & 4 & 5 \\
\hline \multirow{2}{*}{ Time Frame } & 0 & 10 & 6 & 2 & 0 \\
\hline & $0 \%$ & $53 \%$ & $32 \%$ & $11 \%$ & $0 \%$ \\
\hline \multirow{2}{*}{$\begin{array}{c}\text { Impact on } \\
\text { CTE }\end{array}$} & 0 & 2 & 7 & 4 & 5 \\
\hline & $0 \%$ & $11 \%$ & $37 \%$ & $21 \%$ & $26 \%$ \\
\hline \multirow{2}{*}{ Desirability } & 0 & 1 & 5 & 5 & 6 \\
\hline & $0 \%$ & $5 \%$ & $26 \%$ & $26 \%$ & $32 \%$ \\
\hline Question 4 & 1 & 2 & 3 & 4 & 5 \\
\hline \multirow{2}{*}{ Time Frame } & 6 & 2 & 5 & 4 & 2 \\
\hline & $32 \%$ & $11 \%$ & $26 \%$ & $21 \%$ & $11 \%$ \\
\hline \multirow{2}{*}{$\begin{array}{l}\text { Impact on } \\
\text { CTE }\end{array}$} & 4 & 3 & 5 & 2 & 3 \\
\hline & $21 \%$ & $16 \%$ & $26 \%$ & $11 \%$ & $16 \%$ \\
\hline \multirow{2}{*}{ Desirability } & 4 & 6 & 3 & 2 & 3 \\
\hline & $21 \%$ & $32 \%$ & $16 \%$ & $11 \%$ & $16 \%$ \\
\hline
\end{tabular}




\begin{tabular}{|c|c|c|c|c|c|}
\hline Question 5 & 1 & 2 & 3 & 4 & 5 \\
\hline \multirow{2}{*}{ Time Frame } & 1 & 10 & 5 & 2 & 1 \\
\hline & $5 \%$ & $53 \%$ & $26 \%$ & $11 \%$ & $5 \%$ \\
\hline Impact on & 0 & 1 & 2 & 5 & 10 \\
\hline CTE & $0 \%$ & $5 \%$ & $11 \%$ & $26 \%$ & $53 \%$ \\
\hline \multirow{2}{*}{ Desirability } & 0 & 2 & 2 & 6 & 9 \\
\hline & $0 \%$ & $11 \%$ & $11 \%$ & $32 \%$ & $47 \%$ \\
\hline Question 6 & 1 & 2 & 3 & 4 & 5 \\
\hline \multirow{2}{*}{ Time Frame } & 0 & 12 & 6 & 1 & 0 \\
\hline & $0 \%$ & $63 \%$ & $32 \%$ & $5 \%$ & $0 \%$ \\
\hline Impact on & 0 & 1 & 0 & 7 & 11 \\
\hline CTE & $0 \%$ & $5 \%$ & $0 \%$ & $37 \%$ & $58 \%$ \\
\hline \multirow{2}{*}{ Desirability } & 0 & 2 & 0 & 7 & 10 \\
\hline & $0 \%$ & $11 \%$ & $0 \%$ & $37 \%$ & $53 \%$ \\
\hline Question 7 & 1 & 2 & 3 & 4 & 5 \\
\hline \multirow{2}{*}{ Time Frame } & 1 & 4 & 12 & 1 & 1 \\
\hline & $5 \%$ & $21 \%$ & $63 \%$ & $5 \%$ & $5 \%$ \\
\hline Impact on & 2 & 2 & 4 & 5 & 6 \\
\hline CTE & $11 \%$ & $11 \%$ & $21 \%$ & $26 \%$ & $32 \%$ \\
\hline \multirow{2}{*}{ Desirability } & 0 & 3 & 4 & 6 & 6 \\
\hline & $0 \%$ & $16 \%$ & $21 \%$ & $32 \%$ & $32 \%$ \\
\hline Question 8 & 1 & 2 & 3 & 4 & 5 \\
\hline \multirow{2}{*}{ Time Frame } & 3 & 11 & 1 & 2 & 1 \\
\hline & $16 \%$ & $58 \%$ & $5 \%$ & $11 \%$ & $5 \%$ \\
\hline Impact on & 2 & 3 & 3 & 7 & 2 \\
\hline CTE & $11 \%$ & $16 \%$ & $16 \%$ & $37 \%$ & $11 \%$ \\
\hline \multirow{2}{*}{ Desirability } & 1 & 6 & 3 & 5 & 3 \\
\hline & $5 \%$ & $32 \%$ & $16 \%$ & $26 \%$ & $16 \%$ \\
\hline Question 9 & 1 & 2 & 3 & 4 & 5 \\
\hline \multirow{2}{*}{ Time Frame } & 1 & 5 & 9 & 4 & 0 \\
\hline & $5 \%$ & $26 \%$ & $47 \%$ & $21 \%$ & $0 \%$ \\
\hline Impact on & 1 & 1 & 4 & 6 & 7 \\
\hline CTE & $5 \%$ & $5 \%$ & $21 \%$ & $32 \%$ & $37 \%$ \\
\hline \multirow{2}{*}{ Desirability } & 0 & 2 & 7 & 5 & 5 \\
\hline & $0 \%$ & $11 \%$ & $37 \%$ & $26 \%$ & $26 \%$ \\
\hline Question 10 & 1 & 2 & 3 & 4 & 5 \\
\hline \multirow{2}{*}{ Time Frame } & 0 & 10 & 3 & 6 & 0 \\
\hline & $0 \%$ & $53 \%$ & $16 \%$ & $32 \%$ & $0 \%$ \\
\hline Impact on & 0 & 2 & 3 & 7 & 7 \\
\hline CTE & $0 \%$ & $11 \%$ & $16 \%$ & $37 \%$ & $37 \%$ \\
\hline \multirow{2}{*}{ Desirability } & 0 & 2 & 1 & 6 & 10 \\
\hline & $0 \%$ & $11 \%$ & $5 \%$ & $32 \%$ & $53 \%$ \\
\hline
\end{tabular}




\begin{tabular}{|c|c|c|c|c|c|}
\hline Question 11 & 1 & 2 & 3 & 4 & 5 \\
\hline \multirow{2}{*}{ Time Frame } & 3 & 3 & 8 & 3 & 2 \\
\hline & $16 \%$ & $16 \%$ & $42 \%$ & $16 \%$ & $11 \%$ \\
\hline Impact on & 1 & 3 & 5 & 6 & 3 \\
\hline CTE & $5 \%$ & $16 \%$ & $26 \%$ & $32 \%$ & $16 \%$ \\
\hline \multirow{2}{*}{ Desirability } & 2 & 3 & 5 & 4 & 4 \\
\hline & $11 \%$ & $16 \%$ & $26 \%$ & $21 \%$ & $21 \%$ \\
\hline Question 12 & 1 & 2 & 3 & 4 & 5 \\
\hline \multirow{2}{*}{ Time Frame } & 1 & 2 & 10 & 3 & 3 \\
\hline & $5 \%$ & $11 \%$ & $53 \%$ & $16 \%$ & $16 \%$ \\
\hline Impact on & 0 & 1 & 4 & 7 & 6 \\
\hline CTE & $0 \%$ & $5 \%$ & $21 \%$ & $37 \%$ & $32 \%$ \\
\hline \multirow{2}{*}{ Desirability } & 0 & 1 & 3 & 5 & 10 \\
\hline & $0 \%$ & $5 \%$ & $16 \%$ & $26 \%$ & $53 \%$ \\
\hline Question 13 & 1 & 2 & 3 & 4 & 5 \\
\hline \multirow{2}{*}{ Time Frame } & 0 & 12 & 1 & 6 & 0 \\
\hline & $0 \%$ & $63 \%$ & $5 \%$ & $32 \%$ & $0 \%$ \\
\hline Impact on & 0 & 1 & 3 & 6 & 9 \\
\hline CTE & $0 \%$ & $5 \%$ & $16 \%$ & $32 \%$ & $47 \%$ \\
\hline \multirow{2}{*}{ Desirability } & 0 & 1 & 0 & 4 & 13 \\
\hline & $0 \%$ & $5 \%$ & $0 \%$ & $21 \%$ & $68 \%$ \\
\hline Question 14 & 1 & 2 & 3 & 4 & 5 \\
\hline \multirow{2}{*}{ Time Frame } & 0 & 13 & 2 & 3 & 1 \\
\hline & $0 \%$ & $68 \%$ & $11 \%$ & $16 \%$ & $5 \%$ \\
\hline Impact on & 0 & 1 & 2 & 3 & 13 \\
\hline CTE & $0 \%$ & $5 \%$ & $11 \%$ & $16 \%$ & $68 \%$ \\
\hline \multirow{2}{*}{ Desirability } & 0 & 1 & 0 & 2 & 16 \\
\hline & $0 \%$ & $5 \%$ & $0 \%$ & $11 \%$ & $84 \%$ \\
\hline Question 15 & 1 & 2 & 3 & 4 & 5 \\
\hline \multirow{2}{*}{ Time Frame } & 6 & 4 & 4 & 4 & 1 \\
\hline & $32 \%$ & $21 \%$ & $21 \%$ & $21 \%$ & $5 \%$ \\
\hline Impact on & 3 & 2 & 3 & 4 & 5 \\
\hline CTE & $16 \%$ & $11 \%$ & $16 \%$ & $21 \%$ & $26 \%$ \\
\hline \multirow{2}{*}{ Desirability } & 7 & 2 & 3 & 2 & 4 \\
\hline & $37 \%$ & $11 \%$ & $16 \%$ & $11 \%$ & $21 \%$ \\
\hline Question 16 & 1 & 2 & 3 & 4 & 5 \\
\hline \multirow{2}{*}{ Time Frame } & 0 & 13 & 4 & 2 & 0 \\
\hline & $0 \%$ & $68 \%$ & $21 \%$ & $11 \%$ & $0 \%$ \\
\hline Impact on & 0 & 1 & 3 & 6 & 9 \\
\hline CTE & $0 \%$ & $5 \%$ & $16 \%$ & $32 \%$ & $47 \%$ \\
\hline \multirow{2}{*}{ Desirability } & 0 & 1 & 1 & 5 & 11 \\
\hline & $0 \%$ & $5 \%$ & $5 \%$ & $26 \%$ & $58 \%$ \\
\hline
\end{tabular}




\begin{tabular}{|c|c|c|c|c|c|}
\hline Question 17 & 1 & 2 & 3 & 4 & 5 \\
\hline \multirow{2}{*}{ Time Frame } & 1 & 7 & 5 & 4 & 2 \\
\hline & $5 \%$ & $37 \%$ & $26 \%$ & $21 \%$ & $11 \%$ \\
\hline Impact on & 0 & 1 & 1 & 5 & 12 \\
\hline CTE & $0 \%$ & $5 \%$ & $5 \%$ & $26 \%$ & $63 \%$ \\
\hline \multirow{2}{*}{ Desirability } & 1 & 1 & 2 & 2 & 13 \\
\hline & $5 \%$ & $5 \%$ & $11 \%$ & $11 \%$ & $68 \%$ \\
\hline Question 18 & 1 & 2 & 3 & 4 & 5 \\
\hline \multirow{2}{*}{ Time Frame } & 3 & 3 & 5 & 3 & 5 \\
\hline & $16 \%$ & $16 \%$ & $26 \%$ & $16 \%$ & $26 \%$ \\
\hline Impact on & 1 & 2 & 5 & 4 & 6 \\
\hline CTE & $5 \%$ & $11 \%$ & $26 \%$ & $21 \%$ & $32 \%$ \\
\hline \multirow{2}{*}{ Desirability } & 2 & 1 & 6 & 5 & 5 \\
\hline & $11 \%$ & $5 \%$ & $32 \%$ & $26 \%$ & $26 \%$ \\
\hline Question 19 & 1 & 2 & 3 & 4 & 5 \\
\hline \multirow{2}{*}{ Time Frame } & 5 & 3 & 7 & 2 & 2 \\
\hline & $26 \%$ & $16 \%$ & $37 \%$ & $11 \%$ & $11 \%$ \\
\hline Impact on & 2 & 2 & 6 & 3 & 4 \\
\hline CTE & $11 \%$ & $11 \%$ & $32 \%$ & $16 \%$ & $21 \%$ \\
\hline \multirow{2}{*}{ Desirability } & 3 & 2 & 2 & 6 & 4 \\
\hline & $16 \%$ & $11 \%$ & $11 \%$ & $32 \%$ & $21 \%$ \\
\hline Question 20 & 1 & 2 & 3 & 4 & 5 \\
\hline \multirow{2}{*}{ Time Frame } & 3 & 2 & 9 & 3 & 2 \\
\hline & $16 \%$ & $11 \%$ & $47 \%$ & $16 \%$ & $11 \%$ \\
\hline Impact on & 1 & 2 & 2 & 6 & 8 \\
\hline CTE & $5 \%$ & $11 \%$ & $11 \%$ & $32 \%$ & $42 \%$ \\
\hline \multirow{2}{*}{ Desirability } & 1 & 2 & 3 & 5 & 8 \\
\hline & $5 \%$ & $11 \%$ & $16 \%$ & $26 \%$ & $42 \%$ \\
\hline Question 21 & 1 & 2 & 3 & 4 & 5 \\
\hline \multirow{2}{*}{ Time Frame } & 5 & 3 & 5 & 4 & 2 \\
\hline & $26 \%$ & $16 \%$ & $26 \%$ & $21 \%$ & $11 \%$ \\
\hline Impact on & 3 & 2 & 5 & 5 & 3 \\
\hline CTE & $16 \%$ & $11 \%$ & $26 \%$ & $26 \%$ & $16 \%$ \\
\hline \multirow{2}{*}{ Desirability } & 3 & 1 & 5 & 7 & 2 \\
\hline & $16 \%$ & $5 \%$ & $26 \%$ & $37 \%$ & $11 \%$ \\
\hline Question 22 & 1 & 2 & 3 & 4 & 5 \\
\hline \multirow{2}{*}{ Time Frame } & 5 & 3 & 7 & 3 & 1 \\
\hline & $26 \%$ & $16 \%$ & $37 \%$ & $16 \%$ & $5 \%$ \\
\hline Impact on & 1 & 1 & 6 & 3 & 6 \\
\hline CTE & $5 \%$ & $5 \%$ & $32 \%$ & $16 \%$ & $32 \%$ \\
\hline \multirow{2}{*}{ Desirability } & 1 & 1 & 5 & 3 & 8 \\
\hline & $5 \%$ & $5 \%$ & $26 \%$ & $16 \%$ & $42 \%$ \\
\hline
\end{tabular}




\begin{tabular}{|c|c|c|c|c|c|}
\hline Question 23 & 1 & 2 & 3 & 4 & 5 \\
\hline \multirow{2}{*}{ Time Frame } & 8 & 1 & 6 & 4 & 0 \\
\hline & $42 \%$ & $5 \%$ & $32 \%$ & $21 \%$ & $0 \%$ \\
\hline Impact on & 4 & 2 & 2 & 2 & 5 \\
\hline CTE & $21 \%$ & $11 \%$ & $11 \%$ & $11 \%$ & $26 \%$ \\
\hline \multirow{2}{*}{ Desirability } & 7 & 4 & 2 & 2 & 4 \\
\hline & $37 \%$ & $21 \%$ & $11 \%$ & $11 \%$ & $21 \%$ \\
\hline Question 24 & 1 & 2 & 3 & 4 & 5 \\
\hline \multirow{2}{*}{ Time Frame } & 2 & 3 & 6 & 7 & 1 \\
\hline & $11 \%$ & $16 \%$ & $32 \%$ & $37 \%$ & $5 \%$ \\
\hline Impact on & 1 & 3 & 1 & 8 & 4 \\
\hline CTE & $5 \%$ & $16 \%$ & $5 \%$ & $42 \%$ & $21 \%$ \\
\hline \multirow{2}{*}{ Desirability } & 1 & 1 & 5 & 2 & 9 \\
\hline & $5 \%$ & $5 \%$ & $26 \%$ & $11 \%$ & $47 \%$ \\
\hline Question 25 & 1 & 2 & 3 & 4 & 5 \\
\hline \multirow{2}{*}{ Time Frame } & 3 & 6 & 5 & 5 & 0 \\
\hline & $16 \%$ & $32 \%$ & $26 \%$ & $26 \%$ & $0 \%$ \\
\hline Impact on & 1 & 1 & 1 & 3 & 12 \\
\hline CTE & $5 \%$ & $5 \%$ & $5 \%$ & $16 \%$ & $63 \%$ \\
\hline \multirow{2}{*}{ Desirability } & 1 & 2 & 1 & 3 & 11 \\
\hline & $5 \%$ & $11 \%$ & $5 \%$ & $16 \%$ & $58 \%$ \\
\hline Question 26 & 1 & 2 & 3 & 4 & 5 \\
\hline \multirow{2}{*}{ Time Frame } & 4 & 2 & 6 & 3 & 4 \\
\hline & $21 \%$ & $11 \%$ & $32 \%$ & $16 \%$ & $21 \%$ \\
\hline Impact on & 2 & 3 & 3 & 5 & 4 \\
\hline CTE & $11 \%$ & $16 \%$ & $16 \%$ & $26 \%$ & $21 \%$ \\
\hline \multirow{2}{*}{ Desirability } & 2 & 3 & 5 & 2 & 5 \\
\hline & $11 \%$ & $16 \%$ & $26 \%$ & $11 \%$ & $26 \%$ \\
\hline Question 27 & 1 & 2 & 3 & 4 & 5 \\
\hline \multirow{2}{*}{ Time Frame } & 4 & 6 & 6 & 0 & 3 \\
\hline & $21 \%$ & $32 \%$ & $32 \%$ & $0 \%$ & $16 \%$ \\
\hline Impact on & 2 & 6 & 5 & 1 & 5 \\
\hline CTE & $11 \%$ & $32 \%$ & $26 \%$ & $5 \%$ & $26 \%$ \\
\hline \multirow{2}{*}{ Desirability } & 4 & 6 & 7 & 2 & 0 \\
\hline & $21 \%$ & $32 \%$ & $37 \%$ & $11 \%$ & $0 \%$ \\
\hline Question 28 & 1 & 2 & 3 & 4 & 5 \\
\hline \multirow{2}{*}{ Time Frame } & 4 & 1 & 5 & 7 & 2 \\
\hline & $21 \%$ & $5 \%$ & $26 \%$ & $37 \%$ & $11 \%$ \\
\hline Impact on & 1 & 1 & 5 & 7 & 4 \\
\hline CTE & $5 \%$ & $5 \%$ & $26 \%$ & $37 \%$ & $21 \%$ \\
\hline \multirow{2}{*}{ Desirability } & 4 & 0 & 4 & 7 & 4 \\
\hline & $21 \%$ & $0 \%$ & $21 \%$ & $37 \%$ & $21 \%$ \\
\hline
\end{tabular}




\begin{tabular}{|c|c|c|c|c|c|}
\hline Question 29 & 1 & 2 & 3 & 4 & 5 \\
\hline \multirow{2}{*}{ Time Frame } & 0 & 8 & 10 & 1 & 0 \\
\hline & $0 \%$ & $42 \%$ & $53 \%$ & $5 \%$ & $0 \%$ \\
\hline Impact on & 0 & 1 & 3 & 5 & 10 \\
\hline CTE & $0 \%$ & $5 \%$ & $16 \%$ & $26 \%$ & $53 \%$ \\
\hline \multirow{2}{*}{ Desirability } & 0 & 1 & 3 & 7 & 8 \\
\hline & $0 \%$ & $5 \%$ & $16 \%$ & $37 \%$ & $42 \%$ \\
\hline Question 30 & 1 & 2 & 3 & 4 & 5 \\
\hline \multirow{2}{*}{ Time Frame } & 0 & 11 & 4 & 4 & 0 \\
\hline & $0 \%$ & $58 \%$ & $21 \%$ & $21 \%$ & $0 \%$ \\
\hline Impact on & 0 & 2 & 6 & 6 & 5 \\
\hline CTE & $0 \%$ & $11 \%$ & $32 \%$ & $32 \%$ & $26 \%$ \\
\hline \multirow{2}{*}{ Desirability } & 0 & 3 & 3 & 7 & 6 \\
\hline & $0 \%$ & $16 \%$ & $16 \%$ & $37 \%$ & $32 \%$ \\
\hline Question 31 & 1 & 2 & 3 & 4 & 5 \\
\hline \multirow{2}{*}{ Time Frame } & 4 & 3 & 7 & 3 & 2 \\
\hline & $21 \%$ & $16 \%$ & $37 \%$ & $16 \%$ & $11 \%$ \\
\hline Impact on & 1 & 2 & 6 & 4 & 5 \\
\hline CTE & $5 \%$ & $11 \%$ & $32 \%$ & $21 \%$ & $26 \%$ \\
\hline \multirow{2}{*}{ Desirability } & 1 & 3 & 6 & 4 & 4 \\
\hline & $5 \%$ & $16 \%$ & $32 \%$ & $21 \%$ & $21 \%$ \\
\hline Question 32 & 1 & 2 & 3 & 4 & 5 \\
\hline \multirow{2}{*}{ Time Frame } & 0 & 3 & 4 & 7 & 5 \\
\hline & $0 \%$ & $16 \%$ & $21 \%$ & $37 \%$ & $26 \%$ \\
\hline Impact on & 0 & 1 & 1 & 12 & 5 \\
\hline CTE & $0 \%$ & $5 \%$ & $5 \%$ & $63 \%$ & $26 \%$ \\
\hline \multirow{2}{*}{ Desirability } & 0 & 1 & 2 & 8 & 8 \\
\hline & $0 \%$ & $5 \%$ & $11 \%$ & $42 \%$ & $42 \%$ \\
\hline Question 33 & 1 & 2 & 3 & 4 & 5 \\
\hline \multirow{2}{*}{ Time Frame } & 0 & 8 & 9 & 2 & 0 \\
\hline & $0 \%$ & $42 \%$ & $47 \%$ & $11 \%$ & $0 \%$ \\
\hline Impact on & 0 & 1 & 2 & 8 & 8 \\
\hline CTE & $0 \%$ & $5 \%$ & $11 \%$ & $42 \%$ & $42 \%$ \\
\hline \multirow{2}{*}{ Desirability } & 0 & 1 & 2 & 6 & 10 \\
\hline & $0 \%$ & $5 \%$ & $11 \%$ & $32 \%$ & $53 \%$ \\
\hline Question 34 & 1 & 2 & 3 & 4 & 5 \\
\hline \multirow{2}{*}{ Time Frame } & 0 & 3 & 11 & 3 & 2 \\
\hline & $0 \%$ & $16 \%$ & $58 \%$ & $16 \%$ & $11 \%$ \\
\hline Impact on & 0 & 2 & 4 & 5 & 8 \\
\hline CTE & $0 \%$ & $11 \%$ & $21 \%$ & $26 \%$ & $42 \%$ \\
\hline \multirow{2}{*}{ Desirability } & 0 & 1 & 2 & 2 & 14 \\
\hline & $0 \%$ & $5 \%$ & $11 \%$ & $11 \%$ & $74 \%$ \\
\hline
\end{tabular}




\begin{tabular}{|c|c|c|c|c|c|}
\hline Question 35 & 1 & 2 & 3 & 4 & 5 \\
\hline \multirow{2}{*}{ Time Frame } & 1 & 5 & 9 & 3 & 1 \\
\hline & $5 \%$ & $26 \%$ & $47 \%$ & $16 \%$ & $5 \%$ \\
\hline Impact on & 0 & 3 & 3 & 7 & 5 \\
\hline CTE & $0 \%$ & $16 \%$ & $16 \%$ & $37 \%$ & $26 \%$ \\
\hline \multirow{2}{*}{ Desirability } & 0 & 3 & 1 & 7 & 7 \\
\hline & $0 \%$ & $16 \%$ & $5 \%$ & $37 \%$ & $37 \%$ \\
\hline Question 36 & 1 & 2 & 3 & 4 & 5 \\
\hline \multirow{2}{*}{ Time Frame } & 0 & 12 & 5 & 1 & 1 \\
\hline & $0 \%$ & $63 \%$ & $26 \%$ & $5 \%$ & $5 \%$ \\
\hline Impact on & 0 & 2 & 3 & 6 & 8 \\
\hline CTE & $0 \%$ & $11 \%$ & $16 \%$ & $32 \%$ & $42 \%$ \\
\hline \multirow{2}{*}{ Desirability } & 0 & 1 & 1 & 6 & 11 \\
\hline & $0 \%$ & $5 \%$ & $5 \%$ & $32 \%$ & $58 \%$ \\
\hline Question 37 & 1 & 2 & 3 & 4 & 5 \\
\hline \multirow{2}{*}{ Time Frame } & 0 & 9 & 6 & 4 & 0 \\
\hline & $0 \%$ & $47 \%$ & $32 \%$ & $21 \%$ & $0 \%$ \\
\hline Impact on & 0 & 1 & 1 & 3 & 13 \\
\hline CTE & $0 \%$ & $5 \%$ & $5 \%$ & $16 \%$ & $68 \%$ \\
\hline \multirow{2}{*}{ Desirability } & 0 & 0 & 1 & 1 & 16 \\
\hline & $0 \%$ & $0 \%$ & $5 \%$ & $5 \%$ & $84 \%$ \\
\hline Question 38 & 1 & 2 & 3 & 4 & 5 \\
\hline \multirow{2}{*}{ Time Frame } & 0 & 11 & 7 & 1 & 0 \\
\hline & $0 \%$ & $58 \%$ & $37 \%$ & $5 \%$ & $0 \%$ \\
\hline Impact on & 0 & 1 & 3 & 3 & 12 \\
\hline CTE & $0 \%$ & $5 \%$ & $16 \%$ & $16 \%$ & $63 \%$ \\
\hline \multirow{2}{*}{ Desirability } & 0 & 1 & 1 & 2 & 15 \\
\hline & $0 \%$ & $5 \%$ & $5 \%$ & $11 \%$ & $79 \%$ \\
\hline Question 39 & 1 & 2 & 3 & 4 & 5 \\
\hline \multirow{2}{*}{ Time Frame } & 0 & 14 & 4 & 1 & 0 \\
\hline & $0 \%$ & $74 \%$ & $21 \%$ & $5 \%$ & $0 \%$ \\
\hline Impact on & 0 & 3 & 4 & 6 & 6 \\
\hline CTE & $0 \%$ & $16 \%$ & $21 \%$ & $32 \%$ & $32 \%$ \\
\hline \multirow{2}{*}{ Desirability } & 0 & 2 & 0 & 5 & 11 \\
\hline & $0 \%$ & $11 \%$ & $0 \%$ & $26 \%$ & $58 \%$ \\
\hline Question 40 & 1 & 2 & 3 & 4 & 5 \\
\hline \multirow{2}{*}{ Time Frame } & 0 & 9 & 6 & 4 & 0 \\
\hline & $0 \%$ & $47 \%$ & $32 \%$ & $21 \%$ & $0 \%$ \\
\hline Impact on & 0 & 1 & 6 & 8 & 4 \\
\hline CTE & $0 \%$ & $5 \%$ & $32 \%$ & $42 \%$ & $21 \%$ \\
\hline \multirow{2}{*}{ Desirability } & 0 & 1 & 4 & 8 & 6 \\
\hline & $0 \%$ & $5 \%$ & $21 \%$ & $42 \%$ & $32 \%$ \\
\hline
\end{tabular}




\begin{tabular}{|c|c|c|c|c|c|}
\hline Question 41 & 1 & 2 & 3 & 4 & 5 \\
\hline \multirow{2}{*}{ Time Frame } & 0 & 13 & 3 & 3 & 0 \\
\hline & $0 \%$ & $68 \%$ & $16 \%$ & $16 \%$ & $0 \%$ \\
\hline Impact on & 1 & 2 & 6 & 4 & 6 \\
\hline CTE & $5 \%$ & $11 \%$ & $32 \%$ & $21 \%$ & $32 \%$ \\
\hline \multirow{2}{*}{ Desirability } & 0 & 2 & 4 & 5 & 7 \\
\hline & $0 \%$ & $11 \%$ & $21 \%$ & $26 \%$ & $37 \%$ \\
\hline Question 42 & 1 & 2 & 3 & 4 & 5 \\
\hline \multirow{2}{*}{ Time Frame } & 0 & 11 & 5 & 2 & 1 \\
\hline & $0 \%$ & $58 \%$ & $26 \%$ & $11 \%$ & $5 \%$ \\
\hline Impact on & 0 & 1 & 2 & 8 & 8 \\
\hline CTE & $0 \%$ & $5 \%$ & $11 \%$ & $42 \%$ & $42 \%$ \\
\hline \multirow{2}{*}{ Desirability } & 0 & 1 & 3 & 9 & 6 \\
\hline & $0 \%$ & $5 \%$ & $16 \%$ & $47 \%$ & $32 \%$ \\
\hline Question 43 & 1 & 2 & 3 & 4 & 5 \\
\hline \multirow{2}{*}{ Time Frame } & 0 & 12 & 4 & 2 & 0 \\
\hline & $0 \%$ & $63 \%$ & $21 \%$ & $11 \%$ & $0 \%$ \\
\hline Impact on & 0 & 1 & 2 & 8 & 7 \\
\hline CTE & $0 \%$ & $5 \%$ & $11 \%$ & $42 \%$ & $37 \%$ \\
\hline \multirow{2}{*}{ Desirability } & 0 & 1 & 1 & 10 & 6 \\
\hline & $0 \%$ & $5 \%$ & $5 \%$ & $53 \%$ & $32 \%$ \\
\hline Question 44 & 1 & 2 & 3 & 4 & 5 \\
\hline \multirow{2}{*}{ Time Frame } & 0 & 5 & 12 & 2 & 0 \\
\hline & $0 \%$ & $26 \%$ & $63 \%$ & $11 \%$ & $0 \%$ \\
\hline Impact on & 0 & 2 & 5 & 7 & 5 \\
\hline CTE & $0 \%$ & $11 \%$ & $26 \%$ & $37 \%$ & $26 \%$ \\
\hline \multirow{2}{*}{ Desirability } & 0 & 2 & 8 & 5 & 4 \\
\hline & $0 \%$ & $11 \%$ & $42 \%$ & $26 \%$ & $21 \%$ \\
\hline Question 45 & 1 & 2 & 3 & 4 & 5 \\
\hline \multirow{2}{*}{ Time Frame } & 0 & 11 & 6 & 2 & 0 \\
\hline & $0 \%$ & $58 \%$ & $32 \%$ & $11 \%$ & $0 \%$ \\
\hline Impact on & 0 & 2 & 2 & 6 & 9 \\
\hline CTE & $0 \%$ & $11 \%$ & $11 \%$ & $32 \%$ & $47 \%$ \\
\hline \multirow{2}{*}{ Desirability } & 0 & 1 & 1 & 4 & 13 \\
\hline & $0 \%$ & $5 \%$ & $5 \%$ & $21 \%$ & $68 \%$ \\
\hline Question 46 & 1 & 2 & 3 & 4 & 5 \\
\hline \multirow{2}{*}{ Time Frame } & 0 & 11 & 6 & 2 & 0 \\
\hline & $0 \%$ & $58 \%$ & $32 \%$ & $11 \%$ & $0 \%$ \\
\hline Impact on & 0 & 1 & 4 & 7 & 7 \\
\hline CTE & $0 \%$ & $5 \%$ & $21 \%$ & $37 \%$ & $37 \%$ \\
\hline \multirow{2}{*}{ Desirability } & 0 & 1 & 3 & 5 & 10 \\
\hline & $0 \%$ & $5 \%$ & $16 \%$ & $26 \%$ & $53 \%$ \\
\hline
\end{tabular}




\begin{tabular}{|c|c|c|c|c|c|}
\hline Question 47 & 1 & 2 & 3 & 4 & 5 \\
\hline \multirow{2}{*}{ Time Frame } & 2 & 7 & 9 & 1 & 0 \\
\hline & $11 \%$ & $37 \%$ & $47 \%$ & $5 \%$ & $0 \%$ \\
\hline Impact on & 1 & 3 & 3 & 6 & 5 \\
\hline CTE & $5 \%$ & $16 \%$ & $16 \%$ & $32 \%$ & $26 \%$ \\
\hline \multirow{2}{*}{ Desirability } & 3 & 2 & 6 & 5 & 2 \\
\hline & $16 \%$ & $11 \%$ & $32 \%$ & $26 \%$ & $11 \%$ \\
\hline Question 48 & 1 & 2 & 3 & 4 & 5 \\
\hline \multirow{2}{*}{ Time Frame } & 4 & 0 & 8 & 3 & 4 \\
\hline & $21 \%$ & $0 \%$ & $42 \%$ & $16 \%$ & $21 \%$ \\
\hline Impact on & 1 & 2 & 8 & 3 & 3 \\
\hline CTE & $5 \%$ & $11 \%$ & $42 \%$ & $16 \%$ & $16 \%$ \\
\hline \multirow{2}{*}{ Desirability } & 3 & 2 & 8 & 2 & 3 \\
\hline & $16 \%$ & $11 \%$ & $42 \%$ & $11 \%$ & $16 \%$ \\
\hline Question 49 & 1 & 2 & 3 & 4 & 5 \\
\hline \multirow{2}{*}{ Time Frame } & 4 & 1 & 8 & 5 & 1 \\
\hline & $21 \%$ & $5 \%$ & $42 \%$ & $26 \%$ & $5 \%$ \\
\hline Impact on & 1 & 1 & 4 & 7 & 3 \\
\hline CTE & $5 \%$ & $5 \%$ & $21 \%$ & $37 \%$ & $16 \%$ \\
\hline \multirow{2}{*}{ Desirability } & 2 & 2 & 3 & 5 & 6 \\
\hline & $11 \%$ & $11 \%$ & $16 \%$ & $26 \%$ & $32 \%$ \\
\hline Question 50 & 1 & 2 & 3 & 4 & 5 \\
\hline \multirow{2}{*}{ Time Frame } & 3 & 10 & 5 & 1 & 0 \\
\hline & $16 \%$ & $53 \%$ & $26 \%$ & $5 \%$ & $0 \%$ \\
\hline Impact on & 0 & 1 & 2 & 5 & 9 \\
\hline CTE & $0 \%$ & $5 \%$ & $11 \%$ & $26 \%$ & $47 \%$ \\
\hline \multirow{2}{*}{ Desirability } & 1 & 2 & 1 & 2 & 12 \\
\hline & $5 \%$ & $11 \%$ & $5 \%$ & $11 \%$ & $63 \%$ \\
\hline Question 51 & 1 & 2 & 3 & 4 & 5 \\
\hline \multirow{2}{*}{ Time Frame } & 0 & 9 & 7 & 3 & 0 \\
\hline & $0 \%$ & $47 \%$ & $37 \%$ & $16 \%$ & $0 \%$ \\
\hline Impact on & 0 & 2 & 1 & 7 & 9 \\
\hline CTE & $0 \%$ & $11 \%$ & $5 \%$ & $37 \%$ & $47 \%$ \\
\hline \multirow{2}{*}{ Desirability } & 1 & 6 & 5 & 3 & 4 \\
\hline & $5 \%$ & $32 \%$ & $26 \%$ & $16 \%$ & $21 \%$ \\
\hline Question 52 & 1 & 2 & 3 & 4 & 5 \\
\hline \multirow{2}{*}{ Time Frame } & 1 & 13 & 5 & 0 & 0 \\
\hline & $5 \%$ & $68 \%$ & $26 \%$ & $0 \%$ & $0 \%$ \\
\hline Impact on & 0 & 2 & 3 & 9 & 4 \\
\hline CTE & $0 \%$ & $11 \%$ & $16 \%$ & $47 \%$ & $21 \%$ \\
\hline \multirow{2}{*}{ Desirability } & 4 & 8 & 2 & 3 & 1 \\
\hline & $21 \%$ & $42 \%$ & $11 \%$ & $16 \%$ & $5 \%$ \\
\hline
\end{tabular}




\begin{tabular}{|c|c|c|c|c|c|}
\hline Question 53 & 1 & 2 & 3 & 4 & 5 \\
\hline \multirow{2}{*}{ Time Frame } & 1 & 7 & 6 & 3 & 2 \\
\hline & $5 \%$ & $37 \%$ & $32 \%$ & $16 \%$ & $11 \%$ \\
\hline Impact on & 0 & 1 & 2 & 1 & 14 \\
\hline CTE & $0 \%$ & $5 \%$ & $11 \%$ & $5 \%$ & $74 \%$ \\
\hline \multirow{2}{*}{ Desirability } & 0 & 1 & 1 & 1 & 15 \\
\hline & $0 \%$ & $5 \%$ & $5 \%$ & $5 \%$ & $79 \%$ \\
\hline Question 54 & 1 & 2 & 3 & 4 & 5 \\
\hline \multirow{2}{*}{ Time Frame } & 0 & 8 & 5 & 5 & 1 \\
\hline & $0 \%$ & $42 \%$ & $26 \%$ & $26 \%$ & $5 \%$ \\
\hline Impact on & 1 & 3 & 3 & 6 & 6 \\
\hline CTE & $5 \%$ & $16 \%$ & $16 \%$ & $32 \%$ & $32 \%$ \\
\hline \multirow{2}{*}{ Desirability } & 1 & 6 & 5 & 3 & 4 \\
\hline & $5 \%$ & $32 \%$ & $26 \%$ & $16 \%$ & $21 \%$ \\
\hline Question 55 & 1 & 2 & 3 & 4 & 5 \\
\hline \multirow{2}{*}{ Time Frame } & 3 & 7 & 5 & 1 & 3 \\
\hline & $16 \%$ & $37 \%$ & $26 \%$ & $5 \%$ & $16 \%$ \\
\hline Impact on & 0 & 3 & 0 & 5 & 8 \\
\hline CTE & $0 \%$ & $16 \%$ & $0 \%$ & $26 \%$ & $42 \%$ \\
\hline \multirow{2}{*}{ Desirability } & 5 & 5 & 1 & 3 & 5 \\
\hline & $26 \%$ & $26 \%$ & $5 \%$ & $16 \%$ & $26 \%$ \\
\hline Question 56 & 1 & 2 & 3 & 4 & 5 \\
\hline \multirow{2}{*}{ Time Frame } & 1 & 6 & 3 & 6 & 3 \\
\hline & $5 \%$ & $32 \%$ & $16 \%$ & $32 \%$ & $16 \%$ \\
\hline Impact on & 0 & 1 & 3 & 6 & 8 \\
\hline CTE & $0 \%$ & $5 \%$ & $16 \%$ & $32 \%$ & $42 \%$ \\
\hline \multirow{2}{*}{ Desirability } & 0 & 1 & 6 & 6 & 5 \\
\hline & $0 \%$ & $5 \%$ & $32 \%$ & $32 \%$ & $26 \%$ \\
\hline Question 57 & 1 & 2 & 3 & 4 & 5 \\
\hline \multirow{2}{*}{ Time Frame } & 3 & 5 & 4 & 5 & 2 \\
\hline & $16 \%$ & $26 \%$ & $21 \%$ & $26 \%$ & $11 \%$ \\
\hline Impact on & 1 & 1 & 1 & 7 & 7 \\
\hline CTE & $5 \%$ & $5 \%$ & $5 \%$ & $37 \%$ & $37 \%$ \\
\hline \multirow{2}{*}{ Desirability } & 2 & 0 & 5 & 7 & 4 \\
\hline & $11 \%$ & $0 \%$ & $26 \%$ & $37 \%$ & $21 \%$ \\
\hline Question 58 & 1 & 2 & 3 & 4 & 5 \\
\hline \multirow{2}{*}{ Time Frame } & 1 & 7 & 5 & 6 & 0 \\
\hline & $5 \%$ & $37 \%$ & $26 \%$ & $32 \%$ & $0 \%$ \\
\hline \multirow{2}{*}{$\begin{array}{c}\text { Impact on } \\
\text { CTE }\end{array}$} & 0 & 1 & 3 & 6 & 9 \\
\hline & $0 \%$ & $5 \%$ & $16 \%$ & $32 \%$ & $47 \%$ \\
\hline \multirow{2}{*}{ Desirability } & 1 & 0 & 2 & 6 & 10 \\
\hline & $5 \%$ & $0 \%$ & $11 \%$ & $32 \%$ & $53 \%$ \\
\hline
\end{tabular}




\begin{tabular}{|c|c|c|c|c|c|}
\hline Question 59 & 1 & 2 & 3 & 4 & 5 \\
\hline \multirow{2}{*}{ Time Frame } & 0 & 6 & 11 & 1 & 1 \\
\hline & $0 \%$ & $32 \%$ & $58 \%$ & $5 \%$ & $5 \%$ \\
\hline Impact on & 0 & 1 & 1 & 7 & 10 \\
\hline CTE & $0 \%$ & $5 \%$ & $5 \%$ & $37 \%$ & $53 \%$ \\
\hline \multirow{2}{*}{ Desirability } & 0 & 1 & 2 & 5 & 11 \\
\hline & $0 \%$ & $5 \%$ & $11 \%$ & $26 \%$ & $58 \%$ \\
\hline Question 60 & 1 & 2 & 3 & 4 & 5 \\
\hline \multirow{2}{*}{ Time Frame } & 0 & 3 & 10 & 6 & 0 \\
\hline & $0 \%$ & $16 \%$ & $53 \%$ & $32 \%$ & $0 \%$ \\
\hline Impact on & 0 & 1 & 1 & 5 & 12 \\
\hline CTE & $0 \%$ & $5 \%$ & $5 \%$ & $26 \%$ & $63 \%$ \\
\hline \multirow{2}{*}{ Desirability } & 0 & 2 & 4 & 3 & 9 \\
\hline & $0 \%$ & $11 \%$ & $21 \%$ & $16 \%$ & $47 \%$ \\
\hline Question 61 & 1 & 2 & 3 & 4 & 5 \\
\hline \multirow{2}{*}{ Time Frame } & 1 & 2 & 11 & 3 & 2 \\
\hline & $5 \%$ & $11 \%$ & $58 \%$ & $16 \%$ & $11 \%$ \\
\hline Impact on & 0 & 1 & 1 & 11 & 6 \\
\hline CTE & $0 \%$ & $5 \%$ & $5 \%$ & $58 \%$ & $32 \%$ \\
\hline \multirow{2}{*}{ Desirability } & 2 & 0 & 3 & 7 & 7 \\
\hline & $11 \%$ & $0 \%$ & $16 \%$ & $37 \%$ & $37 \%$ \\
\hline Question 62 & 1 & 2 & 3 & 4 & 5 \\
\hline \multirow{2}{*}{ Time Frame } & 6 & 2 & 9 & 1 & 1 \\
\hline & $32 \%$ & $11 \%$ & $47 \%$ & $5 \%$ & $5 \%$ \\
\hline Impact on & 2 & 2 & 4 & 2 & 6 \\
\hline CTE & $11 \%$ & $11 \%$ & $21 \%$ & $11 \%$ & $32 \%$ \\
\hline \multirow{2}{*}{ Desirability } & 5 & 4 & 6 & 0 & 2 \\
\hline & $26 \%$ & $21 \%$ & $32 \%$ & $0 \%$ & $11 \%$ \\
\hline Question 63 & 1 & 2 & 3 & 4 & 5 \\
\hline \multirow{2}{*}{ Time Frame } & 5 & 1 & 9 & 3 & 1 \\
\hline & $26 \%$ & $5 \%$ & $47 \%$ & $16 \%$ & $5 \%$ \\
\hline Impact on & 2 & 2 & 1 & 5 & 7 \\
\hline CTE & $11 \%$ & $11 \%$ & $5 \%$ & $26 \%$ & $37 \%$ \\
\hline \multirow{2}{*}{ Desirability } & 5 & 3 & 3 & 2 & 5 \\
\hline & $26 \%$ & $16 \%$ & $16 \%$ & $11 \%$ & $26 \%$ \\
\hline Question 64 & 1 & 2 & 3 & 4 & 5 \\
\hline \multirow{2}{*}{ Time Frame } & 0 & 11 & 6 & 1 & 1 \\
\hline & $0 \%$ & $58 \%$ & $32 \%$ & $5 \%$ & $5 \%$ \\
\hline \multirow{2}{*}{$\begin{array}{c}\text { Impact on } \\
\text { CTE }\end{array}$} & 0 & 1 & 1 & 10 & 7 \\
\hline & $0 \%$ & $5 \%$ & $5 \%$ & $53 \%$ & $37 \%$ \\
\hline \multirow{2}{*}{ Desirability } & 0 & 1 & 0 & 5 & 13 \\
\hline & $0 \%$ & $5 \%$ & $0 \%$ & $26 \%$ & $68 \%$ \\
\hline
\end{tabular}




\begin{tabular}{|c|c|c|c|c|c|}
\hline Question 65 & 1 & 2 & 3 & 4 & 5 \\
\hline \multirow{2}{*}{ Time Frame } & 0 & 11 & 6 & 1 & 1 \\
\hline & $0 \%$ & $58 \%$ & $32 \%$ & $5 \%$ & $5 \%$ \\
\hline Impact on & 0 & 2 & 0 & 5 & 12 \\
\hline CTE & $0 \%$ & $11 \%$ & $0 \%$ & $26 \%$ & $63 \%$ \\
\hline \multirow{2}{*}{ Desirability } & 0 & 1 & 0 & 1 & 17 \\
\hline & $0 \%$ & $5 \%$ & $0 \%$ & $5 \%$ & $89 \%$ \\
\hline Question 66 & 1 & 2 & 3 & 4 & 5 \\
\hline \multirow{2}{*}{ Time Frame } & 1 & 7 & 7 & 3 & 1 \\
\hline & $5 \%$ & $37 \%$ & $37 \%$ & $16 \%$ & $5 \%$ \\
\hline Impact on & 0 & 1 & 0 & 4 & 13 \\
\hline CTE & $0 \%$ & $5 \%$ & $0 \%$ & $21 \%$ & $68 \%$ \\
\hline \multirow{2}{*}{ Desirability } & 0 & 1 & 0 & 2 & 15 \\
\hline & $0 \%$ & $5 \%$ & $0 \%$ & $11 \%$ & $79 \%$ \\
\hline Question 67 & 1 & 2 & 3 & 4 & 5 \\
\hline \multirow{2}{*}{ Time Frame } & 0 & 6 & 9 & 3 & 1 \\
\hline & $0 \%$ & $32 \%$ & $47 \%$ & $16 \%$ & $5 \%$ \\
\hline Impact on & 0 & 1 & 4 & 5 & 9 \\
\hline CTE & $0 \%$ & $5 \%$ & $21 \%$ & $26 \%$ & $47 \%$ \\
\hline \multirow{2}{*}{ Desirability } & 0 & 2 & 1 & 4 & 12 \\
\hline & $0 \%$ & $11 \%$ & $5 \%$ & $21 \%$ & $63 \%$ \\
\hline Question 68 & 1 & 2 & 3 & 4 & 5 \\
\hline \multirow{2}{*}{ Time Frame } & 0 & 2 & 10 & 7 & 0 \\
\hline & $0 \%$ & $11 \%$ & $53 \%$ & $37 \%$ & $0 \%$ \\
\hline Impact on & 0 & 1 & 3 & 7 & 8 \\
\hline CTE & $0 \%$ & $5 \%$ & $16 \%$ & $37 \%$ & $42 \%$ \\
\hline \multirow{2}{*}{ Desirability } & 0 & 1 & 2 & 5 & 11 \\
\hline & $0 \%$ & $5 \%$ & $11 \%$ & $26 \%$ & $58 \%$ \\
\hline Question 69 & 1 & 2 & 3 & 4 & 5 \\
\hline \multirow{2}{*}{ Time Frame } & 2 & 4 & 7 & 4 & 2 \\
\hline & $11 \%$ & $21 \%$ & $37 \%$ & $21 \%$ & $11 \%$ \\
\hline Impact on & 0 & 1 & 6 & 5 & 6 \\
\hline CTE & $0 \%$ & $5 \%$ & $32 \%$ & $26 \%$ & $32 \%$ \\
\hline \multirow{2}{*}{ Desirability } & 1 & 1 & 4 & 4 & 7 \\
\hline & $5 \%$ & $5 \%$ & $21 \%$ & $21 \%$ & $37 \%$ \\
\hline Question 70 & 1 & 2 & 3 & 4 & 5 \\
\hline \multirow{2}{*}{ Time Frame } & 2 & 3 & 8 & 3 & 3 \\
\hline & $11 \%$ & $16 \%$ & $42 \%$ & $16 \%$ & $16 \%$ \\
\hline Impact on & 0 & 1 & 2 & 7 & 7 \\
\hline CTE & $0 \%$ & $5 \%$ & $11 \%$ & $37 \%$ & $37 \%$ \\
\hline \multirow{2}{*}{ Desirability } & 0 & 2 & 4 & 5 & 7 \\
\hline & $0 \%$ & $11 \%$ & $21 \%$ & $26 \%$ & $37 \%$ \\
\hline
\end{tabular}




\begin{tabular}{|c|c|c|c|c|c|}
\hline Question 71 & 1 & 2 & 3 & 4 & 5 \\
\hline \multirow{2}{*}{ Time Frame } & 0 & 7 & 9 & 2 & 1 \\
\hline & $0 \%$ & $37 \%$ & $47 \%$ & $11 \%$ & $5 \%$ \\
\hline Impact on & 0 & 2 & 4 & 6 & 7 \\
\hline CTE & $0 \%$ & $11 \%$ & $21 \%$ & $32 \%$ & $37 \%$ \\
\hline \multirow{2}{*}{ Desirability } & 1 & 1 & 2 & 5 & 10 \\
\hline & $5 \%$ & $5 \%$ & $11 \%$ & $26 \%$ & $53 \%$ \\
\hline Question 72 & 1 & 2 & 3 & 4 & 5 \\
\hline \multirow{2}{*}{ Time Frame } & 0 & 13 & 3 & 3 & 0 \\
\hline & $0 \%$ & $68 \%$ & $16 \%$ & $16 \%$ & $0 \%$ \\
\hline Impact on & 0 & 1 & 1 & 4 & 13 \\
\hline CTE & $0 \%$ & $5 \%$ & $5 \%$ & $21 \%$ & $68 \%$ \\
\hline \multirow{2}{*}{ Desirability } & 0 & 1 & 0 & 4 & 13 \\
\hline & $0 \%$ & $5 \%$ & $0 \%$ & $21 \%$ & $68 \%$ \\
\hline Question 73 & 1 & 2 & 3 & 4 & 5 \\
\hline \multirow{2}{*}{ Time Frame } & 0 & 11 & 4 & 4 & 0 \\
\hline & $0 \%$ & $58 \%$ & $21 \%$ & $21 \%$ & $0 \%$ \\
\hline Impact on & 0 & 1 & 2 & 7 & 9 \\
\hline CTE & $0 \%$ & $5 \%$ & $11 \%$ & $37 \%$ & $47 \%$ \\
\hline \multirow{2}{*}{ Desirability } & 0 & 1 & 1 & 6 & 11 \\
\hline & $0 \%$ & $5 \%$ & $5 \%$ & $32 \%$ & $58 \%$ \\
\hline Question 74 & 1 & 2 & 3 & 4 & 5 \\
\hline \multirow{2}{*}{ Time Frame } & 0 & 11 & 5 & 2 & 1 \\
\hline & $0 \%$ & $58 \%$ & $26 \%$ & $11 \%$ & $5 \%$ \\
\hline Impact on & 0 & 1 & 3 & 6 & 9 \\
\hline CTE & $0 \%$ & $5 \%$ & $16 \%$ & $32 \%$ & $47 \%$ \\
\hline \multirow{2}{*}{ Desirability } & 0 & 1 & 1 & 7 & 10 \\
\hline & $0 \%$ & $5 \%$ & $5 \%$ & $37 \%$ & $53 \%$ \\
\hline Question 75 & 1 & 2 & 3 & 4 & 5 \\
\hline \multirow{2}{*}{ Time Frame } & 0 & 7 & 8 & 3 & 1 \\
\hline & $0 \%$ & $37 \%$ & $42 \%$ & $16 \%$ & $5 \%$ \\
\hline Impact on & 0 & 1 & 2 & 5 & 11 \\
\hline CTE & $0 \%$ & $5 \%$ & $11 \%$ & $26 \%$ & $58 \%$ \\
\hline \multirow{2}{*}{ Desirability } & 0 & 1 & 1 & 7 & 9 \\
\hline & $0 \%$ & $5 \%$ & $5 \%$ & $37 \%$ & $47 \%$ \\
\hline Question 76 & 1 & 2 & 3 & 4 & 5 \\
\hline \multirow{2}{*}{ Time Frame } & 0 & 7 & 8 & 2 & 2 \\
\hline & $0 \%$ & $37 \%$ & $42 \%$ & $11 \%$ & $11 \%$ \\
\hline Impact on & 0 & 1 & 1 & 9 & 8 \\
\hline CTE & $0 \%$ & $5 \%$ & $5 \%$ & $47 \%$ & $42 \%$ \\
\hline \multirow{2}{*}{ Desirability } & 0 & 1 & 3 & 6 & 9 \\
\hline & $0 \%$ & $5 \%$ & $16 \%$ & $32 \%$ & $47 \%$ \\
\hline
\end{tabular}




\begin{tabular}{|c|c|c|c|c|c|}
\hline Question 77 & 1 & 2 & 3 & 4 & 5 \\
\hline \multirow{2}{*}{ Time Frame } & 0 & 10 & 4 & 5 & 0 \\
\hline & $0 \%$ & $53 \%$ & $21 \%$ & $26 \%$ & $0 \%$ \\
\hline Impact on & 0 & 1 & 3 & 8 & 7 \\
\hline CTE & $0 \%$ & $5 \%$ & $16 \%$ & $42 \%$ & $37 \%$ \\
\hline \multirow{2}{*}{ Desirability } & 0 & 1 & 1 & 8 & 9 \\
\hline & $0 \%$ & $5 \%$ & $5 \%$ & $42 \%$ & $47 \%$ \\
\hline Question 78 & 1 & 2 & 3 & 4 & 5 \\
\hline \multirow{2}{*}{ Time Frame } & 0 & 10 & 5 & 3 & 1 \\
\hline & $0 \%$ & $53 \%$ & $26 \%$ & $16 \%$ & $5 \%$ \\
\hline Impact on & 0 & 1 & 0 & 8 & 10 \\
\hline CTE & $0 \%$ & $5 \%$ & $0 \%$ & $42 \%$ & $53 \%$ \\
\hline \multirow{2}{*}{ Desirability } & 0 & 1 & 1 & 7 & 10 \\
\hline & $0 \%$ & $5 \%$ & $5 \%$ & $37 \%$ & $53 \%$ \\
\hline Question 79 & 1 & 2 & 3 & 4 & 5 \\
\hline \multirow{2}{*}{ Time Frame } & 1 & 8 & 7 & 3 & 0 \\
\hline & $5 \%$ & $42 \%$ & $37 \%$ & $16 \%$ & $0 \%$ \\
\hline Impact on & 1 & 1 & 0 & 6 & 11 \\
\hline CTE & $5 \%$ & $5 \%$ & $0 \%$ & $32 \%$ & $58 \%$ \\
\hline \multirow{2}{*}{ Desirability } & 0 & 1 & 0 & 6 & 11 \\
\hline & $0 \%$ & $5 \%$ & $0 \%$ & $32 \%$ & $58 \%$ \\
\hline Question 80 & 1 & 2 & 3 & 4 & 5 \\
\hline \multirow{2}{*}{ Time Frame } & 0 & 7 & 5 & 6 & 1 \\
\hline & $0 \%$ & $37 \%$ & $26 \%$ & $32 \%$ & $5 \%$ \\
\hline Impact on & 0 & 1 & 1 & 7 & 10 \\
\hline CTE & $0 \%$ & $5 \%$ & $5 \%$ & $37 \%$ & $53 \%$ \\
\hline \multirow{2}{*}{ Desirability } & 0 & 1 & 1 & 7 & 10 \\
\hline & $0 \%$ & $5 \%$ & $5 \%$ & $37 \%$ & $53 \%$ \\
\hline Question 81 & 1 & 2 & 3 & 4 & 5 \\
\hline \multirow{2}{*}{ Time Frame } & 3 & 4 & 9 & 0 & 3 \\
\hline & $16 \%$ & $21 \%$ & $47 \%$ & $0 \%$ & $16 \%$ \\
\hline Impact on & 1 & 2 & 3 & 1 & 9 \\
\hline CTE & $5 \%$ & $11 \%$ & $16 \%$ & $5 \%$ & $47 \%$ \\
\hline \multirow{2}{*}{ Desirability } & 6 & 4 & 5 & 1 & 1 \\
\hline & $32 \%$ & $21 \%$ & $26 \%$ & $5 \%$ & $5 \%$ \\
\hline Question 82 & 1 & 2 & 3 & 4 & 5 \\
\hline \multirow{2}{*}{ Time Frame } & 0 & 6 & 9 & 3 & 1 \\
\hline & $0 \%$ & $32 \%$ & $47 \%$ & $16 \%$ & $5 \%$ \\
\hline Impact on & 0 & 1 & 1 & 5 & 12 \\
\hline CTE & $0 \%$ & $5 \%$ & $5 \%$ & $26 \%$ & $63 \%$ \\
\hline \multirow{2}{*}{ Desirability } & 0 & 1 & 0 & 4 & 14 \\
\hline & $0 \%$ & $5 \%$ & $0 \%$ & $21 \%$ & $74 \%$ \\
\hline
\end{tabular}




\begin{tabular}{|c|c|c|c|c|c|}
\hline Question 83 & 1 & 2 & 3 & 4 & 5 \\
\hline \multirow{2}{*}{ Time Frame } & 0 & 7 & 8 & 3 & 1 \\
\hline & $0 \%$ & $37 \%$ & $42 \%$ & $16 \%$ & $5 \%$ \\
\hline Impact on & 0 & 1 & 3 & 7 & 8 \\
\hline CTE & $0 \%$ & $5 \%$ & $16 \%$ & $37 \%$ & $42 \%$ \\
\hline \multirow{2}{*}{ Desirability } & 0 & 1 & 3 & 7 & 8 \\
\hline & $0 \%$ & $5 \%$ & $16 \%$ & $37 \%$ & $42 \%$ \\
\hline Question 84 & 1 & 2 & 3 & 4 & 5 \\
\hline \multirow{2}{*}{ Time Frame } & 1 & 3 & 11 & 1 & 3 \\
\hline & $5 \%$ & $16 \%$ & $58 \%$ & $5 \%$ & $16 \%$ \\
\hline Impact on & 0 & 1 & 3 & 8 & 6 \\
\hline CTE & $0 \%$ & $5 \%$ & $16 \%$ & $42 \%$ & $32 \%$ \\
\hline \multirow{2}{*}{ Desirability } & 0 & 1 & 4 & 4 & 9 \\
\hline & $0 \%$ & $5 \%$ & $21 \%$ & $21 \%$ & $47 \%$ \\
\hline Question 85 & 1 & 2 & 3 & 4 & 5 \\
\hline \multirow{2}{*}{ Time Frame } & 4 & 0 & 6 & 5 & 4 \\
\hline & $21 \%$ & $0 \%$ & $32 \%$ & $26 \%$ & $21 \%$ \\
\hline Impact on & 0 & 1 & 2 & 5 & 8 \\
\hline CTE & $0 \%$ & $5 \%$ & $11 \%$ & $26 \%$ & $42 \%$ \\
\hline \multirow{2}{*}{ Desirability } & 1 & 1 & 3 & 4 & 8 \\
\hline & $5 \%$ & $5 \%$ & $16 \%$ & $21 \%$ & $42 \%$ \\
\hline Question 86 & 1 & 2 & 3 & 4 & 5 \\
\hline \multirow{2}{*}{ Time Frame } & 6 & 0 & 2 & 7 & 4 \\
\hline & $32 \%$ & $0 \%$ & $11 \%$ & $37 \%$ & $21 \%$ \\
\hline Impact on & 0 & 1 & 3 & 4 & 7 \\
\hline CTE & $0 \%$ & $5 \%$ & $16 \%$ & $21 \%$ & $37 \%$ \\
\hline \multirow{2}{*}{ Desirability } & 2 & 2 & 7 & 4 & 2 \\
\hline & $11 \%$ & $11 \%$ & $37 \%$ & $21 \%$ & $11 \%$ \\
\hline Question 87 & 1 & 2 & 3 & 4 & 5 \\
\hline \multirow{2}{*}{ Time Frame } & 1 & 3 & 8 & 5 & 2 \\
\hline & $5 \%$ & $16 \%$ & $42 \%$ & $26 \%$ & $11 \%$ \\
\hline Impact on & 0 & 2 & 5 & 4 & 8 \\
\hline CTE & $0 \%$ & $11 \%$ & $26 \%$ & $21 \%$ & $42 \%$ \\
\hline \multirow{2}{*}{ Desirability } & 1 & 0 & 5 & 4 & 9 \\
\hline & $5 \%$ & $0 \%$ & $26 \%$ & $21 \%$ & $47 \%$ \\
\hline Question 88 & 1 & 2 & 3 & 4 & 5 \\
\hline \multirow{2}{*}{ Time Frame } & 0 & 5 & 9 & 4 & 1 \\
\hline & $0 \%$ & $26 \%$ & $47 \%$ & $21 \%$ & $5 \%$ \\
\hline Impact on & 0 & 1 & 4 & 6 & 8 \\
\hline CTE & $0 \%$ & $5 \%$ & $21 \%$ & $32 \%$ & $42 \%$ \\
\hline \multirow{2}{*}{ Desirability } & 0 & 3 & 2 & 6 & 8 \\
\hline & $0 \%$ & $16 \%$ & $11 \%$ & $32 \%$ & $42 \%$ \\
\hline
\end{tabular}




\begin{tabular}{|c|c|c|c|c|c|}
\hline Question 89 & 1 & 2 & 3 & 4 & 5 \\
\hline \multirow{2}{*}{ Time Frame } & 0 & 7 & 7 & 3 & 1 \\
\hline & $0 \%$ & $37 \%$ & $37 \%$ & $16 \%$ & $5 \%$ \\
\hline Impact on & 0 & 1 & 3 & 3 & 12 \\
\hline CTE & $0 \%$ & $5 \%$ & $16 \%$ & $16 \%$ & $63 \%$ \\
\hline \multirow{2}{*}{ Desirability } & 0 & 1 & 1 & 0 & 17 \\
\hline & $0 \%$ & $5 \%$ & $5 \%$ & $0 \%$ & $89 \%$ \\
\hline Question 90 & 1 & 2 & 3 & 4 & 5 \\
\hline \multirow{2}{*}{ Time Frame } & 1 & 4 & 9 & 4 & 1 \\
\hline & $5 \%$ & $21 \%$ & $47 \%$ & $21 \%$ & $5 \%$ \\
\hline Impact on & 0 & 1 & 0 & 6 & 11 \\
\hline CTE & $0 \%$ & $5 \%$ & $0 \%$ & $32 \%$ & $58 \%$ \\
\hline \multirow{2}{*}{ Desirability } & 0 & 1 & 1 & 4 & 12 \\
\hline & $0 \%$ & $5 \%$ & $5 \%$ & $21 \%$ & $63 \%$ \\
\hline Question 91 & 1 & 2 & 3 & 4 & 5 \\
\hline \multirow{2}{*}{ Time Frame } & 3 & 6 & 7 & 2 & 1 \\
\hline & $16 \%$ & $32 \%$ & $37 \%$ & $11 \%$ & $5 \%$ \\
\hline Impact on & 0 & 3 & 3 & 4 & 7 \\
\hline CTE & $0 \%$ & $16 \%$ & $16 \%$ & $21 \%$ & $37 \%$ \\
\hline \multirow{2}{*}{ Desirability } & 4 & 3 & 6 & 3 & 1 \\
\hline & $21 \%$ & $16 \%$ & $32 \%$ & $16 \%$ & $5 \%$ \\
\hline Question 92 & 1 & 2 & 3 & 4 & 5 \\
\hline \multirow{2}{*}{ Time Frame } & 4 & 8 & 4 & 1 & 2 \\
\hline & $21 \%$ & $42 \%$ & $21 \%$ & $5 \%$ & $11 \%$ \\
\hline Impact on & 0 & 1 & 2 & 3 & 10 \\
\hline CTE & $0 \%$ & $5 \%$ & $11 \%$ & $16 \%$ & $53 \%$ \\
\hline \multirow{2}{*}{ Desirability } & 5 & 3 & 5 & 3 & 1 \\
\hline & $26 \%$ & $16 \%$ & $26 \%$ & $16 \%$ & $5 \%$ \\
\hline Question 93 & 1 & 2 & 3 & 4 & 5 \\
\hline \multirow{2}{*}{ Time Frame } & 1 & 2 & 11 & 3 & 1 \\
\hline & $5 \%$ & $11 \%$ & $58 \%$ & $16 \%$ & $5 \%$ \\
\hline Impact on & 0 & 3 & 0 & 9 & 7 \\
\hline CTE & $0 \%$ & $16 \%$ & $0 \%$ & $47 \%$ & $37 \%$ \\
\hline \multirow{2}{*}{ Desirability } & 0 & 2 & 2 & 5 & 10 \\
\hline & $0 \%$ & $11 \%$ & $11 \%$ & $26 \%$ & $53 \%$ \\
\hline Question 94 & 1 & 2 & 3 & 4 & 5 \\
\hline \multirow{2}{*}{ Time Frame } & 0 & 6 & 8 & 5 & 0 \\
\hline & $0 \%$ & $32 \%$ & $42 \%$ & $26 \%$ & $0 \%$ \\
\hline Impact on & 0 & 2 & 1 & 7 & 9 \\
\hline CTE & $0 \%$ & $11 \%$ & $5 \%$ & $37 \%$ & $47 \%$ \\
\hline \multirow{2}{*}{ Desirability } & 0 & 2 & 3 & 6 & 8 \\
\hline & $0 \%$ & $11 \%$ & $16 \%$ & $32 \%$ & $42 \%$ \\
\hline
\end{tabular}




\begin{tabular}{|c|c|c|c|c|c|}
\hline Question 95 & 1 & 2 & 3 & 4 & 5 \\
\hline \multirow{2}{*}{ Time Frame } & 1 & 2 & 12 & 3 & 1 \\
\hline & $5 \%$ & $11 \%$ & $63 \%$ & $16 \%$ & $5 \%$ \\
\hline Impact on & 1 & 1 & 2 & 5 & 10 \\
\hline CTE & $5 \%$ & $5 \%$ & $11 \%$ & $26 \%$ & $53 \%$ \\
\hline \multirow{2}{*}{ Desirability } & 5 & 4 & 4 & 4 & 2 \\
\hline & $26 \%$ & $21 \%$ & $21 \%$ & $21 \%$ & $11 \%$ \\
\hline Question 96 & 1 & 2 & 3 & 4 & 5 \\
\hline \multirow{2}{*}{ Time Frame } & 6 & 1 & 8 & 4 & 0 \\
\hline & $32 \%$ & $5 \%$ & $42 \%$ & $21 \%$ & $0 \%$ \\
\hline Impact on & 2 & 1 & 1 & 2 & 10 \\
\hline CTE & $11 \%$ & $5 \%$ & $5 \%$ & $11 \%$ & $53 \%$ \\
\hline \multirow{2}{*}{ Desirability } & 7 & 2 & 2 & 0 & 4 \\
\hline & $37 \%$ & $11 \%$ & $11 \%$ & $0 \%$ & $21 \%$ \\
\hline Question 97 & 1 & 2 & 3 & 4 & 5 \\
\hline \multirow{2}{*}{ Time Frame } & 0 & 12 & 5 & 2 & 0 \\
\hline & $0 \%$ & $63 \%$ & $26 \%$ & $11 \%$ & $0 \%$ \\
\hline Impact on & 0 & 2 & 4 & 6 & 7 \\
\hline CTE & $0 \%$ & $11 \%$ & $21 \%$ & $32 \%$ & $37 \%$ \\
\hline \multirow{2}{*}{ Desirability } & 1 & 2 & 8 & 4 & 4 \\
\hline & $5 \%$ & $11 \%$ & $42 \%$ & $21 \%$ & $21 \%$ \\
\hline Question 98 & 1 & 2 & 3 & 4 & 5 \\
\hline \multirow{2}{*}{ Time Frame } & 1 & 3 & 6 & 6 & 2 \\
\hline & $5 \%$ & $16 \%$ & $32 \%$ & $32 \%$ & $11 \%$ \\
\hline Impact on & 0 & 0 & 3 & 7 & 7 \\
\hline CTE & $0 \%$ & $0 \%$ & $16 \%$ & $37 \%$ & $37 \%$ \\
\hline \multirow{2}{*}{ Desirability } & 0 & 1 & 1 & 7 & 9 \\
\hline & $0 \%$ & $5 \%$ & $5 \%$ & $37 \%$ & $47 \%$ \\
\hline Question 99 & 1 & 2 & 3 & 4 & 5 \\
\hline \multirow{2}{*}{ Time Frame } & 1 & 4 & 8 & 4 & 2 \\
\hline & $5 \%$ & $21 \%$ & $42 \%$ & $21 \%$ & $11 \%$ \\
\hline Impact on & 0 & 1 & 3 & 2 & 12 \\
\hline CTE & $0 \%$ & $5 \%$ & $16 \%$ & $11 \%$ & $63 \%$ \\
\hline \multirow{2}{*}{ Desirability } & 0 & 2 & 5 & 4 & 8 \\
\hline & $0 \%$ & $11 \%$ & $26 \%$ & $21 \%$ & $42 \%$ \\
\hline Question 100 & 1 & 2 & 3 & 4 & 5 \\
\hline \multirow{2}{*}{ Time Frame } & 0 & 6 & 8 & 4 & 1 \\
\hline & $0 \%$ & $32 \%$ & $42 \%$ & $21 \%$ & $5 \%$ \\
\hline Impact on & 0 & 2 & 6 & 5 & 6 \\
\hline CTE & $0 \%$ & $11 \%$ & $32 \%$ & $26 \%$ & $32 \%$ \\
\hline \multirow{2}{*}{ Desirability } & 1 & 3 & 3 & 8 & 4 \\
\hline & $5 \%$ & $16 \%$ & $16 \%$ & $42 \%$ & $21 \%$ \\
\hline
\end{tabular}




\begin{tabular}{|c|c|c|c|c|c|}
\hline Question 101 & 1 & 2 & 3 & 4 & 5 \\
\hline \multirow{2}{*}{ Time Frame } & 3 & 3 & 5 & 8 & 0 \\
\hline & $16 \%$ & $16 \%$ & $26 \%$ & $42 \%$ & $0 \%$ \\
\hline Impact on & 1 & 1 & 2 & 3 & 9 \\
\hline CTE & $5 \%$ & $5 \%$ & $11 \%$ & $16 \%$ & $47 \%$ \\
\hline \multirow{2}{*}{ Desirability } & 2 & 4 & 4 & 3 & 4 \\
\hline & $11 \%$ & $21 \%$ & $21 \%$ & $16 \%$ & $21 \%$ \\
\hline Question 102 & 1 & 2 & 3 & 4 & 5 \\
\hline \multirow{2}{*}{ Time Frame } & 0 & 5 & 9 & 5 & 0 \\
\hline & $0 \%$ & $26 \%$ & $47 \%$ & $26 \%$ & $0 \%$ \\
\hline Impact on & 0 & 1 & 4 & 4 & 10 \\
\hline CTE & $0 \%$ & $5 \%$ & $21 \%$ & $21 \%$ & $53 \%$ \\
\hline \multirow{2}{*}{ Desirability } & 0 & 1 & 6 & 4 & 8 \\
\hline & $0 \%$ & $5 \%$ & $32 \%$ & $21 \%$ & $42 \%$ \\
\hline Question 103 & 1 & 2 & 3 & 4 & 5 \\
\hline \multirow{2}{*}{ Time Frame } & 0 & 9 & 4 & 4 & 2 \\
\hline & $0 \%$ & $47 \%$ & $21 \%$ & $21 \%$ & $11 \%$ \\
\hline Impact on & 0 & 1 & 5 & 7 & 6 \\
\hline CTE & $0 \%$ & $5 \%$ & $26 \%$ & $37 \%$ & $32 \%$ \\
\hline \multirow{2}{*}{ Desirability } & 0 & 1 & 6 & 6 & 6 \\
\hline & $0 \%$ & $5 \%$ & $32 \%$ & $32 \%$ & $32 \%$ \\
\hline Question 104 & 1 & 2 & 3 & 4 & 5 \\
\hline \multirow{2}{*}{ Time Frame } & 0 & 8 & 6 & 5 & 0 \\
\hline & $0 \%$ & $42 \%$ & $32 \%$ & $26 \%$ & $0 \%$ \\
\hline Impact on & 0 & 1 & 3 & 4 & 11 \\
\hline CTE & $0 \%$ & $5 \%$ & $16 \%$ & $21 \%$ & $58 \%$ \\
\hline \multirow{2}{*}{ Desirability } & 2 & 1 & 7 & 7 & 1 \\
\hline & $11 \%$ & $5 \%$ & $37 \%$ & $37 \%$ & $5 \%$ \\
\hline Question 105 & 1 & 2 & 3 & 4 & 5 \\
\hline \multirow{2}{*}{ Time Frame } & 0 & 12 & 5 & 2 & 0 \\
\hline & $0 \%$ & $63 \%$ & $26 \%$ & $11 \%$ & $0 \%$ \\
\hline Impact on & 0 & 1 & 0 & 4 & 13 \\
\hline CTE & $0 \%$ & $5 \%$ & $0 \%$ & $21 \%$ & $68 \%$ \\
\hline \multirow{2}{*}{ Desirability } & 0 & 1 & 1 & 5 & 11 \\
\hline & $0 \%$ & $5 \%$ & $5 \%$ & $26 \%$ & $58 \%$ \\
\hline Question 106 & 1 & 2 & 3 & 4 & 5 \\
\hline \multirow{2}{*}{ Time Frame } & 0 & 6 & 10 & 2 & 1 \\
\hline & $0 \%$ & $32 \%$ & $53 \%$ & $11 \%$ & $5 \%$ \\
\hline Impact on & 0 & 1 & 1 & 3 & 14 \\
\hline CTE & $0 \%$ & $5 \%$ & $5 \%$ & $16 \%$ & $74 \%$ \\
\hline \multirow{2}{*}{ Desirability } & 0 & 1 & 0 & 2 & 15 \\
\hline & $0 \%$ & $5 \%$ & $0 \%$ & $11 \%$ & $79 \%$ \\
\hline
\end{tabular}




\begin{tabular}{|c|c|c|c|c|c|}
\hline Question 107 & 1 & 2 & 3 & 4 & 5 \\
\hline \multirow{2}{*}{ Time Frame } & 0 & 10 & 6 & 3 & 0 \\
\hline & $0 \%$ & $53 \%$ & $32 \%$ & $16 \%$ & $0 \%$ \\
\hline Impact on & 0 & 2 & 5 & 4 & 8 \\
\hline CTE & $0 \%$ & $11 \%$ & $26 \%$ & $21 \%$ & $42 \%$ \\
\hline \multirow{2}{*}{ Desirability } & 3 & 5 & 9 & 2 & 0 \\
\hline & $16 \%$ & $26 \%$ & $47 \%$ & $11 \%$ & $0 \%$ \\
\hline Question 108 & 1 & 2 & 3 & 4 & 5 \\
\hline \multirow{2}{*}{ Time Frame } & 1 & 6 & 7 & 4 & 1 \\
\hline & $5 \%$ & $32 \%$ & $37 \%$ & $21 \%$ & $5 \%$ \\
\hline Impact on & 0 & 2 & 2 & 4 & 10 \\
\hline CTE & $0 \%$ & $11 \%$ & $11 \%$ & $21 \%$ & $53 \%$ \\
\hline \multirow{2}{*}{ Desirability } & 0 & 1 & 3 & 1 & 12 \\
\hline & $0 \%$ & $5 \%$ & $16 \%$ & $5 \%$ & $63 \%$ \\
\hline Question 109 & 1 & 2 & 3 & 4 & 5 \\
\hline \multirow{2}{*}{ Time Frame } & 1 & 5 & 6 & 5 & 2 \\
\hline & $5 \%$ & $26 \%$ & $32 \%$ & $26 \%$ & $11 \%$ \\
\hline Impact on & 0 & 1 & 1 & 2 & 14 \\
\hline CTE & $0 \%$ & $5 \%$ & $5 \%$ & $11 \%$ & $74 \%$ \\
\hline \multirow{2}{*}{ Desirability } & 0 & 1 & 1 & 4 & 13 \\
\hline & $0 \%$ & $5 \%$ & $5 \%$ & $21 \%$ & $68 \%$ \\
\hline Question 110 & $\mathbf{1}$ & 2 & 3 & 4 & 5 \\
\hline \multirow{2}{*}{ Time Frame } & 5 & 3 & 7 & 3 & 1 \\
\hline & $26 \%$ & $16 \%$ & $37 \%$ & $16 \%$ & $5 \%$ \\
\hline Impact on & 0 & 2 & 3 & 2 & 9 \\
\hline CTE & $0 \%$ & $11 \%$ & $16 \%$ & $11 \%$ & $47 \%$ \\
\hline \multirow{2}{*}{ Desirability } & 4 & 1 & 4 & 3 & 6 \\
\hline & $21 \%$ & $5 \%$ & $21 \%$ & $16 \%$ & $32 \%$ \\
\hline Question 111 & $\mathbf{1}$ & 2 & 3 & 4 & 5 \\
\hline \multirow{2}{*}{ Time Frame } & 1 & 6 & 6 & 6 & 0 \\
\hline & $5 \%$ & $32 \%$ & $32 \%$ & $32 \%$ & $0 \%$ \\
\hline Impact on & 0 & 1 & 1 & 5 & 11 \\
\hline CTE & $0 \%$ & $5 \%$ & $5 \%$ & $26 \%$ & $58 \%$ \\
\hline \multirow{2}{*}{ Desirability } & 0 & 1 & 1 & 3 & 13 \\
\hline & $0 \%$ & $5 \%$ & $5 \%$ & $16 \%$ & $68 \%$ \\
\hline Question 112 & 1 & 2 & 3 & 4 & 5 \\
\hline \multirow{2}{*}{ Time Frame } & 4 & 4 & 7 & 4 & 0 \\
\hline & $21 \%$ & $21 \%$ & $37 \%$ & $21 \%$ & $0 \%$ \\
\hline Impact on & 0 & 1 & 0 & 3 & 11 \\
\hline CTE & $0 \%$ & $5 \%$ & $0 \%$ & $16 \%$ & $58 \%$ \\
\hline \multirow{2}{*}{ Desirability } & 0 & 1 & 1 & 2 & 13 \\
\hline & $0 \%$ & $5 \%$ & $5 \%$ & $11 \%$ & $68 \%$ \\
\hline
\end{tabular}




\begin{tabular}{lrrrrr}
\hline Question 113 & $\mathbf{1}$ & $\mathbf{2}$ & $\mathbf{3}$ & $\mathbf{4}$ & $\mathbf{5}$ \\
Time Frame & 2 & 3 & 8 & 4 & 2 \\
Impact on & $11 \%$ & $16 \%$ & $42 \%$ & $21 \%$ & $11 \%$ \\
CTE & 0 & 1 & 1 & 5 & 11 \\
Desirability & $0 \%$ & $5 \%$ & $5 \%$ & $26 \%$ & $58 \%$ \\
& 1 & 1 & 1 & 3 & 12 \\
Question 114 & $5 \%$ & $5 \%$ & $5 \%$ & $16 \%$ & $63 \%$ \\
Time Frame & & & & & \\
Impact on & $\mathbf{1}$ & $\mathbf{2}$ & $\mathbf{3}$ & $\mathbf{4}$ & $\mathbf{5}$ \\
CTE & 4 & 9 & 4 & 2 & 0 \\
Desirability & $21 \%$ & $47 \%$ & $21 \%$ & $11 \%$ & $0 \%$ \\
& 0 & 1 & 2 & 3 & 9 \\
& $0 \%$ & $5 \%$ & $11 \%$ & $16 \%$ & $47 \%$ \\
& $47 \%$ & 3 & 2 & 1 & 2 \\
& & $16 \%$ & $11 \%$ & $5 \%$ & $11 \%$ \\
\hline
\end{tabular}




\section{Response Frequency Distribution Round 3}

Time Frame: 1-Never; 2-Immediate (1-3 years); 3-Mid-Range (4-10 years); 4-LongRange (11-20 years); and 5-beyond 20 years.

Impact: 1-Very Low Impact; 2- Low Impact; 3-Moderate Impact; 4-High Impact and 5Very High Impact.

Desirability: 1-Very Undesirable; 2-Undesirable; 3-Somewhat Desirable; 4-Desirable and 5-Very Desirable.

Question 1

Time Frame

Impact on

CTE

Desirability

Question 2

Time Frame

Impact on

CTE

Desirability

Question 3

Time Frame

Impact on

CTE

Desirability

Question 4

Time Frame

Impact on

CTE

Desirability

$\begin{array}{rr}\mathbf{1} & \mathbf{2} \\ 1 & 14 \\ 5 \% & 74 \% \\ 0 & 1 \\ 0 \% & 5 \% \\ 0 & 0 \\ 0 \% & 0 \%\end{array}$

\section{3}

4

$21 \%$

16

$84 \%$

2

$11 \%$

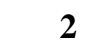

16

$84 \%$

0

$0 \%$

1

$5 \%$

$0 \%$

1

0

$0 \%$

0

$0 \%$

0

$0 \%$

2
17
$89 \%$
1
$5 \%$
1
$5 \%$

3

2

$11 \%$

0

$0 \%$

0

$0 \%$

3

14

$74 \%$

13

$68 \%$

2

$11 \%$

$74 \%$

$0 \%$

$\%$

$16 \%$

14

$\begin{array}{rr}\mathbf{4} & \mathbf{5} \\ 0 & 0 \\ 0 \% & 0 \% \\ 0 & 2 \\ 0 \% & 11 \% \\ 16 & 1 \\ 84 \% & 5 \%\end{array}$

5

0

2

$\%$

$5 \%$

$\begin{array}{rr}\mathbf{4} & \mathbf{5} \\ 1 & 0 \\ 5 \% & 0 \% \\ 3 & 1 \\ 16 \% & 5 \% \\ 18 & 0 \\ 95 \% & 0 \%\end{array}$

45

$0 \quad 0$

$0 \% \quad 0 \%$

$17 \quad 1$

$89 \% \quad 5 \%$

$18 \quad 0$

$95 \% \quad 0 \%$

$$
74 \%
$$

$11 \%$

$\begin{array}{rr}\mathbf{4} & \mathbf{5} \\ 2 & 1 \\ 11 \% & 5 \% \\ 0 & 2 \\ 0 \% & 11 \% \\ 0 & 3 \\ 0 \% & 16 \%\end{array}$




\begin{tabular}{|c|c|c|c|c|c|}
\hline Question 5 & 1 & 2 & 3 & 4 & 5 \\
\hline \multirow{2}{*}{ Time Frame } & 0 & 16 & 2 & 1 & 0 \\
\hline & $0 \%$ & $84 \%$ & $11 \%$ & $5 \%$ & $0 \%$ \\
\hline Impact on & 0 & 1 & 2 & 1 & 15 \\
\hline CTE & $0 \%$ & $5 \%$ & $11 \%$ & $5 \%$ & $79 \%$ \\
\hline \multirow{2}{*}{ Desirability } & 0 & 2 & 1 & 12 & 4 \\
\hline & $0 \%$ & $11 \%$ & $5 \%$ & $63 \%$ & $21 \%$ \\
\hline Question 6 & 1 & 2 & 3 & 4 & 5 \\
\hline \multirow{2}{*}{ Time Frame } & 0 & 18 & 1 & 0 & 0 \\
\hline & $0 \%$ & $95 \%$ & $5 \%$ & $0 \%$ & $0 \%$ \\
\hline Impact on & 0 & 1 & 0 & 1 & 17 \\
\hline CTE & $0 \%$ & $5 \%$ & $0 \%$ & $5 \%$ & $89 \%$ \\
\hline \multirow{2}{*}{ Desirability } & 0 & 2 & 0 & 2 & 15 \\
\hline & $0 \%$ & $11 \%$ & $0 \%$ & $11 \%$ & $79 \%$ \\
\hline Question 7 & 1 & 2 & 3 & 4 & 5 \\
\hline \multirow{2}{*}{ Time Frame } & 0 & 2 & 17 & 0 & 0 \\
\hline & $0 \%$ & $11 \%$ & $89 \%$ & $0 \%$ & $0 \%$ \\
\hline Impact on & 0 & 1 & 0 & 18 & 0 \\
\hline CTE & $0 \%$ & $5 \%$ & $0 \%$ & $95 \%$ & $0 \%$ \\
\hline \multirow{2}{*}{ Desirability } & 0 & 2 & 0 & 17 & 0 \\
\hline & $0 \%$ & $11 \%$ & $0 \%$ & $89 \%$ & $0 \%$ \\
\hline Question 8 & 1 & 2 & 3 & 4 & 5 \\
\hline \multirow{2}{*}{ Time Frame } & 1 & 16 & 0 & 2 & 0 \\
\hline & $5 \%$ & $84 \%$ & $0 \%$ & $11 \%$ & $0 \%$ \\
\hline Impact on & 1 & 3 & 1 & 14 & 0 \\
\hline CTE & $5 \%$ & $16 \%$ & $5 \%$ & $74 \%$ & $0 \%$ \\
\hline \multirow{2}{*}{ Desirability } & 0 & 2 & 14 & 1 & 2 \\
\hline & $0 \%$ & $11 \%$ & $74 \%$ & $5 \%$ & $11 \%$ \\
\hline Question 9 & 1 & 2 & 3 & 4 & 5 \\
\hline \multirow{2}{*}{ Time Frame } & 0 & 2 & 17 & 0 & 0 \\
\hline & $0 \%$ & $11 \%$ & $89 \%$ & $0 \%$ & $0 \%$ \\
\hline Impact on & 0 & 1 & 0 & 18 & 0 \\
\hline CTE & $0 \%$ & $5 \%$ & $0 \%$ & $95 \%$ & $0 \%$ \\
\hline \multirow{2}{*}{ Desirability } & 0 & 2 & 0 & 16 & 1 \\
\hline & $0 \%$ & $11 \%$ & $0 \%$ & $84 \%$ & $5 \%$ \\
\hline Question 10 & 1 & 2 & 3 & 4 & 5 \\
\hline \multirow{2}{*}{ Time Frame } & 0 & 17 & 0 & 2 & 0 \\
\hline & $0 \%$ & $89 \%$ & $0 \%$ & $11 \%$ & $0 \%$ \\
\hline Impact on & 0 & 1 & 0 & 17 & 2 \\
\hline CTE & $0 \%$ & $5 \%$ & $0 \%$ & $89 \%$ & $11 \%$ \\
\hline \multirow{2}{*}{ Desirability } & 0 & 1 & 0 & 1 & 17 \\
\hline & $0 \%$ & $5 \%$ & $0 \%$ & $5 \%$ & $89 \%$ \\
\hline
\end{tabular}




\begin{tabular}{|c|c|c|c|c|c|}
\hline Question 11 & 1 & 2 & 3 & 4 & 5 \\
\hline \multirow{2}{*}{ Time Frame } & 1 & 1 & 15 & 1 & 1 \\
\hline & $5 \%$ & $5 \%$ & $79 \%$ & $5 \%$ & $5 \%$ \\
\hline Impact on & 0 & 1 & 0 & 17 & 1 \\
\hline CTE & $0 \%$ & $5 \%$ & $0 \%$ & $89 \%$ & $5 \%$ \\
\hline \multirow{2}{*}{ Desirability } & 0 & 1 & 16 & 1 & 1 \\
\hline & $0 \%$ & $5 \%$ & $84 \%$ & $5 \%$ & $5 \%$ \\
\hline Question 12 & 1 & 2 & 3 & 4 & 5 \\
\hline \multirow{2}{*}{ Time Frame } & 0 & 1 & 15 & 1 & 2 \\
\hline & $0 \%$ & $5 \%$ & $79 \%$ & $5 \%$ & $11 \%$ \\
\hline Impact on & 0 & 1 & 2 & 16 & 0 \\
\hline CTE & $0 \%$ & $5 \%$ & $11 \%$ & $84 \%$ & $0 \%$ \\
\hline \multirow{2}{*}{ Desirability } & 0 & 1 & 2 & 15 & 1 \\
\hline & $0 \%$ & $5 \%$ & $11 \%$ & $79 \%$ & $5 \%$ \\
\hline Question 13 & 1 & 2 & 3 & 4 & 5 \\
\hline \multirow{2}{*}{ Time Frame } & 0 & 18 & 0 & 1 & 0 \\
\hline & $0 \%$ & $95 \%$ & $0 \%$ & $5 \%$ & $0 \%$ \\
\hline Impact on & 0 & 1 & 0 & 17 & 1 \\
\hline CTE & $0 \%$ & $5 \%$ & $0 \%$ & $89 \%$ & $5 \%$ \\
\hline \multirow{2}{*}{ Desirability } & 0 & 1 & 0 & 1 & 17 \\
\hline & $0 \%$ & $5 \%$ & $0 \%$ & $5 \%$ & $89 \%$ \\
\hline Question 14 & 1 & 2 & 3 & 4 & 5 \\
\hline \multirow{2}{*}{ Time Frame } & 0 & 18 & 0 & 1 & 0 \\
\hline & $0 \%$ & $95 \%$ & $0 \%$ & $5 \%$ & $0 \%$ \\
\hline Impact on & 0 & 1 & 0 & 0 & 18 \\
\hline CTE & $0 \%$ & $5 \%$ & $0 \%$ & $0 \%$ & $95 \%$ \\
\hline \multirow{2}{*}{ Desirability } & 0 & 1 & 0 & 0 & 18 \\
\hline & $0 \%$ & $5 \%$ & $0 \%$ & $0 \%$ & $95 \%$ \\
\hline Question 15 & 1 & 2 & 3 & 4 & 5 \\
\hline \multirow{2}{*}{ Time Frame } & 2 & 13 & 2 & 1 & 1 \\
\hline & $11 \%$ & $68 \%$ & $11 \%$ & $5 \%$ & $5 \%$ \\
\hline Impact on & 1 & 1 & 1 & 15 & 0 \\
\hline CTE & $6 \%$ & $6 \%$ & $6 \%$ & $83 \%$ & $0 \%$ \\
\hline \multirow{2}{*}{ Desirability } & 4 & 0 & 15 & 0 & 0 \\
\hline & $21 \%$ & $0 \%$ & $79 \%$ & $0 \%$ & $0 \%$ \\
\hline Question 16 & 1 & 2 & 3 & 4 & 5 \\
\hline \multirow{2}{*}{ Time Frame } & 0 & 17 & 1 & 1 & 0 \\
\hline & $0 \%$ & $89 \%$ & $5 \%$ & $5 \%$ & $0 \%$ \\
\hline Impact on & 0 & 1 & 0 & 16 & 2 \\
\hline CTE & $0 \%$ & $5 \%$ & $0 \%$ & $84 \%$ & $11 \%$ \\
\hline \multirow{2}{*}{ Desirability } & 0 & 11 & 1 & 2 & 5 \\
\hline & $0 \%$ & $58 \%$ & $5 \%$ & $11 \%$ & $26 \%$ \\
\hline
\end{tabular}




\begin{tabular}{|c|c|c|c|c|c|}
\hline Question 17 & 1 & 2 & 3 & 4 & 5 \\
\hline \multirow{2}{*}{ Time Frame } & 1 & 2 & 13 & 2 & 1 \\
\hline & $5 \%$ & $11 \%$ & $68 \%$ & $11 \%$ & $5 \%$ \\
\hline Impact on & 0 & 1 & 0 & 2 & 16 \\
\hline CTE & $0 \%$ & $5 \%$ & $0 \%$ & $11 \%$ & $84 \%$ \\
\hline \multirow{2}{*}{ Desirability } & 1 & 1 & 1 & 0 & 16 \\
\hline & $5 \%$ & $5 \%$ & $5 \%$ & $0 \%$ & $84 \%$ \\
\hline Question 18 & 1 & 2 & 3 & 4 & 5 \\
\hline \multirow{2}{*}{ Time Frame } & 1 & 1 & 17 & 0 & 0 \\
\hline & $5 \%$ & $5 \%$ & $89 \%$ & $0 \%$ & $0 \%$ \\
\hline Impact on & 0 & 1 & 1 & 17 & 0 \\
\hline CTE & $0 \%$ & $5 \%$ & $5 \%$ & $89 \%$ & $0 \%$ \\
\hline \multirow{2}{*}{ Desirability } & 2 & 0 & 2 & 15 & 0 \\
\hline & $11 \%$ & $0 \%$ & $11 \%$ & $79 \%$ & $0 \%$ \\
\hline Question 19 & 1 & 2 & 3 & 4 & 5 \\
\hline \multirow{2}{*}{ Time Frame } & 5 & 1 & 12 & 0 & 1 \\
\hline & $26 \%$ & $5 \%$ & $63 \%$ & $0 \%$ & $5 \%$ \\
\hline Impact on & 2 & 2 & 12 & 1 & 0 \\
\hline CTE & $11 \%$ & $11 \%$ & $63 \%$ & $5 \%$ & $0 \%$ \\
\hline \multirow{2}{*}{ Desirability } & 2 & 2 & 1 & 12 & 0 \\
\hline & $11 \%$ & $11 \%$ & $5 \%$ & $63 \%$ & $0 \%$ \\
\hline Question 20 & 1 & 2 & 3 & 4 & 5 \\
\hline \multirow{2}{*}{ Time Frame } & 2 & 0 & 17 & 0 & 0 \\
\hline & $11 \%$ & $0 \%$ & $89 \%$ & $0 \%$ & $0 \%$ \\
\hline Impact on & 0 & 1 & 0 & 17 & 1 \\
\hline CTE & $0 \%$ & $5 \%$ & $0 \%$ & $89 \%$ & $5 \%$ \\
\hline \multirow{2}{*}{ Desirability } & 0 & 1 & 0 & 17 & 1 \\
\hline & $0 \%$ & $5 \%$ & $0 \%$ & $89 \%$ & $5 \%$ \\
\hline Question 21 & 1 & 2 & 3 & 4 & 5 \\
\hline \multirow{2}{*}{ Time Frame } & 2 & 2 & 15 & 0 & 0 \\
\hline & $11 \%$ & $11 \%$ & $79 \%$ & $0 \%$ & $0 \%$ \\
\hline Impact on & 3 & 1 & 14 & 1 & 0 \\
\hline CTE & $16 \%$ & $5 \%$ & $74 \%$ & $5 \%$ & $0 \%$ \\
\hline \multirow{2}{*}{ Desirability } & 1 & 1 & 1 & 16 & 0 \\
\hline & $5 \%$ & $5 \%$ & $5 \%$ & $84 \%$ & $0 \%$ \\
\hline Question 22 & 1 & 2 & 3 & 4 & 5 \\
\hline \multirow{2}{*}{ Time Frame } & 2 & 0 & 16 & 1 & 0 \\
\hline & $11 \%$ & $0 \%$ & $84 \%$ & $5 \%$ & $0 \%$ \\
\hline Impact on & 1 & 1 & 0 & 15 & 2 \\
\hline CTE & $5 \%$ & $5 \%$ & $0 \%$ & $79 \%$ & $11 \%$ \\
\hline \multirow{2}{*}{ Desirability } & 1 & 1 & 0 & 15 & 2 \\
\hline & $5 \%$ & $5 \%$ & $0 \%$ & $79 \%$ & $11 \%$ \\
\hline
\end{tabular}




\begin{tabular}{|c|c|c|c|c|c|}
\hline Question 23 & 1 & 2 & 3 & 4 & 5 \\
\hline \multirow{2}{*}{ Time Frame } & 6 & 1 & 12 & 0 & 0 \\
\hline & $32 \%$ & $5 \%$ & $63 \%$ & $0 \%$ & $0 \%$ \\
\hline Impact on & 3 & 2 & 1 & 12 & 0 \\
\hline CTE & $17 \%$ & $11 \%$ & $6 \%$ & $67 \%$ & $0 \%$ \\
\hline \multirow{2}{*}{ Desirability } & 2 & 15 & 1 & 1 & 0 \\
\hline & $11 \%$ & $79 \%$ & $5 \%$ & $5 \%$ & $0 \%$ \\
\hline Question 24 & 1 & 2 & 3 & 4 & 5 \\
\hline \multirow{2}{*}{ Time Frame } & 0 & 0 & 18 & 1 & 0 \\
\hline & $0 \%$ & $0 \%$ & $95 \%$ & $5 \%$ & $0 \%$ \\
\hline Impact on & 0 & 1 & 0 & 17 & 1 \\
\hline CTE & $0 \%$ & $5 \%$ & $0 \%$ & $89 \%$ & $5 \%$ \\
\hline \multirow{2}{*}{ Desirability } & 0 & 0 & 2 & 0 & 17 \\
\hline & $0 \%$ & $0 \%$ & $11 \%$ & $0 \%$ & $89 \%$ \\
\hline Question 25 & 1 & 2 & 3 & 4 & 5 \\
\hline \multirow{2}{*}{ Time Frame } & 2 & 2 & 15 & 0 & 0 \\
\hline & $11 \%$ & $11 \%$ & $79 \%$ & $0 \%$ & $0 \%$ \\
\hline Impact on & 1 & 1 & 0 & 0 & 17 \\
\hline CTE & $5 \%$ & $5 \%$ & $0 \%$ & $0 \%$ & $89 \%$ \\
\hline \multirow{2}{*}{ Desirability } & 0 & 1 & 0 & 0 & 18 \\
\hline & $0 \%$ & $5 \%$ & $0 \%$ & $0 \%$ & $95 \%$ \\
\hline Question 26 & 1 & 2 & 3 & 4 & 5 \\
\hline \multirow{2}{*}{ Time Frame } & 1 & 2 & 15 & 0 & 1 \\
\hline & $5 \%$ & $11 \%$ & $79 \%$ & $0 \%$ & $5 \%$ \\
\hline Impact on & 1 & 2 & 0 & 16 & 0 \\
\hline CTE & $5 \%$ & $11 \%$ & $0 \%$ & $84 \%$ & $0 \%$ \\
\hline \multirow{2}{*}{ Desirability } & 0 & 2 & 15 & 0 & 2 \\
\hline & $0 \%$ & $11 \%$ & $79 \%$ & $0 \%$ & $11 \%$ \\
\hline Question 27 & 1 & 2 & 3 & 4 & 5 \\
\hline \multirow{2}{*}{ Time Frame } & 1 & 15 & 2 & 0 & 1 \\
\hline & $5 \%$ & $79 \%$ & $11 \%$ & $0 \%$ & $5 \%$ \\
\hline Impact on & 0 & 1 & 18 & 0 & 0 \\
\hline CTE & $0 \%$ & $5 \%$ & $95 \%$ & $0 \%$ & $0 \%$ \\
\hline \multirow{2}{*}{ Desirability } & 1 & 15 & 2 & 1 & 0 \\
\hline & $5 \%$ & $79 \%$ & $11 \%$ & $5 \%$ & $0 \%$ \\
\hline Question 28 & 1 & 2 & 3 & 4 & 5 \\
\hline \multirow{2}{*}{ Time Frame } & 2 & 0 & 16 & 0 & 1 \\
\hline & $11 \%$ & $0 \%$ & $84 \%$ & $0 \%$ & $5 \%$ \\
\hline Impact on & 1 & 1 & 0 & 17 & 0 \\
\hline CTE & $5 \%$ & $5 \%$ & $0 \%$ & $89 \%$ & $0 \%$ \\
\hline \multirow{2}{*}{ Desirability } & 2 & 0 & 0 & 17 & 0 \\
\hline & $11 \%$ & $0 \%$ & $0 \%$ & $89 \%$ & $0 \%$ \\
\hline
\end{tabular}




\begin{tabular}{|c|c|c|c|c|c|}
\hline Question 29 & 1 & 2 & 3 & 4 & 5 \\
\hline \multirow{2}{*}{ Time Frame } & 0 & 2 & 17 & 0 & 0 \\
\hline & $0 \%$ & $11 \%$ & $89 \%$ & $0 \%$ & $0 \%$ \\
\hline Impact on & 0 & 1 & 1 & 16 & 1 \\
\hline CTE & $0 \%$ & $5 \%$ & $5 \%$ & $84 \%$ & $5 \%$ \\
\hline \multirow{2}{*}{ Desirability } & 0 & 1 & 1 & 16 & 1 \\
\hline & $0 \%$ & $5 \%$ & $5 \%$ & $84 \%$ & $5 \%$ \\
\hline Question 30 & 1 & 2 & 3 & 4 & 5 \\
\hline \multirow{2}{*}{ Time Frame } & 0 & 17 & 2 & 0 & 0 \\
\hline & $0 \%$ & $89 \%$ & $11 \%$ & $0 \%$ & $0 \%$ \\
\hline Impact on & 0 & 1 & 0 & 18 & 0 \\
\hline CTE & $0 \%$ & $5 \%$ & $0 \%$ & $95 \%$ & $0 \%$ \\
\hline \multirow{2}{*}{ Desirability } & 0 & 1 & 0 & 17 & 1 \\
\hline & $0 \%$ & $5 \%$ & $0 \%$ & $89 \%$ & $5 \%$ \\
\hline Question 31 & 1 & 2 & 3 & 4 & 5 \\
\hline \multirow{2}{*}{ Time Frame } & 2 & 3 & 14 & 0 & 0 \\
\hline & $11 \%$ & $16 \%$ & $74 \%$ & $0 \%$ & $0 \%$ \\
\hline Impact on & 1 & 2 & 1 & 14 & 1 \\
\hline CTE & $5 \%$ & $11 \%$ & $5 \%$ & $74 \%$ & $5 \%$ \\
\hline \multirow{2}{*}{ Desirability } & 1 & 1 & 14 & 1 & 2 \\
\hline & $5 \%$ & $5 \%$ & $74 \%$ & $5 \%$ & $11 \%$ \\
\hline Question 32 & 1 & 2 & 3 & 4 & 5 \\
\hline \multirow{2}{*}{ Time Frame } & 0 & 2 & 1 & 16 & 0 \\
\hline & $0 \%$ & $11 \%$ & $5 \%$ & $84 \%$ & $0 \%$ \\
\hline Impact on & 0 & 1 & 0 & 18 & 0 \\
\hline CTE & $0 \%$ & $5 \%$ & $0 \%$ & $95 \%$ & $0 \%$ \\
\hline \multirow{2}{*}{ Desirability } & 0 & 1 & 0 & 18 & 0 \\
\hline & $0 \%$ & $5 \%$ & $0 \%$ & $95 \%$ & $0 \%$ \\
\hline Question 33 & 1 & 2 & 3 & 4 & 5 \\
\hline \multirow{2}{*}{ Time Frame } & 0 & 3 & 16 & 0 & 0 \\
\hline & $0 \%$ & $16 \%$ & $84 \%$ & $0 \%$ & $0 \%$ \\
\hline Impact on & 0 & 1 & 0 & 18 & 0 \\
\hline CTE & $0 \%$ & $5 \%$ & $0 \%$ & $95 \%$ & $0 \%$ \\
\hline \multirow{2}{*}{ Desirability } & 0 & 1 & 0 & 1 & 17 \\
\hline & $0 \%$ & $5 \%$ & $0 \%$ & $5 \%$ & $89 \%$ \\
\hline Question 34 & 1 & 2 & 3 & 4 & 5 \\
\hline \multirow{2}{*}{ Time Frame } & 0 & 1 & 18 & 0 & 0 \\
\hline & $0 \%$ & $5 \%$ & $95 \%$ & $0 \%$ & $0 \%$ \\
\hline \multirow{2}{*}{$\begin{array}{c}\text { Impact on } \\
\text { CTE }\end{array}$} & 0 & 1 & 14 & 1 & 3 \\
\hline & $0 \%$ & $5 \%$ & $74 \%$ & $5 \%$ & $16 \%$ \\
\hline \multirow{2}{*}{ Desirability } & 0 & 1 & 0 & 1 & 17 \\
\hline & $0 \%$ & $5 \%$ & $0 \%$ & $5 \%$ & $89 \%$ \\
\hline
\end{tabular}




\begin{tabular}{|c|c|c|c|c|c|}
\hline Question 35 & 1 & 2 & 3 & 4 & 5 \\
\hline \multirow{2}{*}{ Time Frame } & 0 & 2 & 17 & 0 & 0 \\
\hline & $0 \%$ & $11 \%$ & $89 \%$ & $0 \%$ & $0 \%$ \\
\hline Impact on & 0 & 1 & 0 & 17 & 1 \\
\hline CTE & $0 \%$ & $5 \%$ & $0 \%$ & $89 \%$ & $5 \%$ \\
\hline \multirow{2}{*}{ Desirability } & 0 & 1 & 0 & 17 & 1 \\
\hline & $0 \%$ & $5 \%$ & $0 \%$ & $89 \%$ & $5 \%$ \\
\hline Question 36 & 1 & 2 & 3 & 4 & 5 \\
\hline \multirow{2}{*}{ Time Frame } & 0 & 18 & 1 & 0 & 0 \\
\hline & $0 \%$ & $95 \%$ & $5 \%$ & $0 \%$ & $0 \%$ \\
\hline Impact on & 0 & 2 & 0 & 15 & 2 \\
\hline CTE & $0 \%$ & $11 \%$ & $0 \%$ & $79 \%$ & $11 \%$ \\
\hline \multirow{2}{*}{ Desirability } & 0 & 1 & 0 & 1 & 17 \\
\hline & $0 \%$ & $5 \%$ & $0 \%$ & $5 \%$ & $89 \%$ \\
\hline Question 37 & 1 & 2 & 3 & 4 & 5 \\
\hline \multirow{2}{*}{ Time Frame } & 0 & 2 & 17 & 0 & 0 \\
\hline & $0 \%$ & $11 \%$ & $89 \%$ & $0 \%$ & $0 \%$ \\
\hline Impact on & 0 & 1 & 1 & 0 & 17 \\
\hline CTE & $0 \%$ & $5 \%$ & $5 \%$ & $0 \%$ & $89 \%$ \\
\hline \multirow{2}{*}{ Desirability } & 0 & 0 & 1 & 1 & 16 \\
\hline & $0 \%$ & $0 \%$ & $6 \%$ & $6 \%$ & $89 \%$ \\
\hline Question 38 & 1 & 2 & 3 & 4 & 5 \\
\hline \multirow{2}{*}{ Time Frame } & 0 & 19 & 0 & 0 & 0 \\
\hline & $0 \%$ & $100 \%$ & $0 \%$ & $0 \%$ & $0 \%$ \\
\hline Impact on & 0 & 1 & 1 & 0 & 17 \\
\hline CTE & $0 \%$ & $5 \%$ & $5 \%$ & $0 \%$ & $89 \%$ \\
\hline \multirow{2}{*}{ Desirability } & 0 & 1 & 0 & 0 & 18 \\
\hline & $0 \%$ & $5 \%$ & $0 \%$ & $0 \%$ & $95 \%$ \\
\hline Question 39 & 1 & 2 & 3 & 4 & 5 \\
\hline \multirow{2}{*}{ Time Frame } & 0 & 18 & 1 & 0 & 0 \\
\hline & $0 \%$ & $95 \%$ & $5 \%$ & $0 \%$ & $0 \%$ \\
\hline Impact on & 0 & 1 & 1 & 17 & 0 \\
\hline CTE & $0 \%$ & $5 \%$ & $5 \%$ & $89 \%$ & $0 \%$ \\
\hline \multirow{2}{*}{ Desirability } & 0 & 1 & 0 & 0 & 18 \\
\hline & $0 \%$ & $5 \%$ & $0 \%$ & $0 \%$ & $95 \%$ \\
\hline Question 40 & 1 & 2 & 3 & 4 & 5 \\
\hline \multirow{2}{*}{ Time Frame } & 0 & 3 & 16 & 0 & 0 \\
\hline & $0 \%$ & $16 \%$ & $84 \%$ & $0 \%$ & $0 \%$ \\
\hline Impact on & 0 & 1 & 0 & 17 & 1 \\
\hline \multirow[t]{2}{*}{ CTE } & $0 \%$ & $5 \%$ & $0 \%$ & $89 \%$ & $5 \%$ \\
\hline & 0 & 1 & 0 & 17 & 1 \\
\hline Desirability & $0 \%$ & $5 \%$ & $0 \%$ & $89 \%$ & $5 \%$ \\
\hline
\end{tabular}




\begin{tabular}{|c|c|c|c|c|c|}
\hline Question 41 & 1 & 2 & 3 & 4 & 5 \\
\hline \multirow{2}{*}{ Time Frame } & 0 & 19 & 0 & 0 & 0 \\
\hline & $0 \%$ & $100 \%$ & $0 \%$ & $0 \%$ & $0 \%$ \\
\hline \multirow{2}{*}{$\begin{array}{c}\text { Impact on } \\
\text { CTE }\end{array}$} & 1 & 1 & 0 & 17 & 0 \\
\hline & $5 \%$ & $5 \%$ & $0 \%$ & $89 \%$ & $0 \%$ \\
\hline \multirow{2}{*}{ Desirability } & 0 & 1 & 0 & 18 & 0 \\
\hline & $0 \%$ & $5 \%$ & $0 \%$ & $95 \%$ & $0 \%$ \\
\hline Question 42 & 1 & 2 & 3 & 4 & 5 \\
\hline \multirow{2}{*}{ Time Frame } & 0 & 18 & 1 & 0 & 0 \\
\hline & $0 \%$ & $95 \%$ & $5 \%$ & $0 \%$ & $0 \%$ \\
\hline \multirow{2}{*}{$\begin{array}{c}\text { Impact on } \\
\text { CTE }\end{array}$} & 0 & 1 & 0 & 17 & 1 \\
\hline & $0 \%$ & $5 \%$ & $0 \%$ & $89 \%$ & $5 \%$ \\
\hline \multirow{2}{*}{ Desirability } & 0 & 1 & 0 & 17 & 1 \\
\hline & $0 \%$ & $5 \%$ & $0 \%$ & $89 \%$ & $5 \%$ \\
\hline Question 43 & 1 & 2 & 3 & 4 & 5 \\
\hline \multirow{2}{*}{ Time Frame } & 0 & 19 & 0 & 0 & 0 \\
\hline & $0 \%$ & $100 \%$ & $0 \%$ & $0 \%$ & $0 \%$ \\
\hline Impact on & 0 & 1 & 0 & 17 & 1 \\
\hline CTE & $0 \%$ & $5 \%$ & $0 \%$ & $89 \%$ & $5 \%$ \\
\hline \multirow{2}{*}{ Desirability } & 0 & 1 & 0 & 17 & 1 \\
\hline & $0 \%$ & $5 \%$ & $0 \%$ & $89 \%$ & $5 \%$ \\
\hline Question 44 & 1 & 2 & 3 & 4 & 5 \\
\hline \multirow{2}{*}{ Time Frame } & 0 & 3 & 15 & 1 & 0 \\
\hline & $0 \%$ & $16 \%$ & $79 \%$ & $5 \%$ & $0 \%$ \\
\hline Impact on & 0 & 1 & 1 & 17 & 0 \\
\hline CTE & $0 \%$ & $5 \%$ & $5 \%$ & $89 \%$ & $0 \%$ \\
\hline \multirow{2}{*}{ Desirability } & 0 & 1 & 17 & 1 & 0 \\
\hline & $0 \%$ & $5 \%$ & $89 \%$ & $5 \%$ & $0 \%$ \\
\hline Question 45 & 1 & 2 & 3 & 4 & 5 \\
\hline \multirow{2}{*}{ Time Frame } & 0 & 1 & 0 & 1 & 17 \\
\hline & $0 \%$ & $5 \%$ & $0 \%$ & $5 \%$ & $89 \%$ \\
\hline \multirow{2}{*}{$\begin{array}{c}\text { Impact on } \\
\text { CTE }\end{array}$} & 0 & 0 & 0 & 0 & 0 \\
\hline & $0 \%$ & $0 \%$ & $0 \%$ & $0 \%$ & $0 \%$ \\
\hline \multirow{2}{*}{ Desirability } & 0 & 0 & 0 & 0 & 0 \\
\hline & $0 \%$ & $0 \%$ & $0 \%$ & $0 \%$ & $0 \%$ \\
\hline Question 46 & 1 & 2 & 3 & 4 & 5 \\
\hline \multirow{2}{*}{ Time Frame } & 0 & 19 & 0 & 0 & 0 \\
\hline & $0 \%$ & $100 \%$ & $0 \%$ & $0 \%$ & $0 \%$ \\
\hline Impact on & 0 & 1 & 0 & 17 & 1 \\
\hline CTE & $0 \%$ & $5 \%$ & $0 \%$ & $89 \%$ & $5 \%$ \\
\hline \multirow{2}{*}{ Desirability } & 0 & 1 & 0 & 0 & 18 \\
\hline & $0 \%$ & $5 \%$ & $0 \%$ & $0 \%$ & $95 \%$ \\
\hline
\end{tabular}




\begin{tabular}{|c|c|c|c|c|c|}
\hline Question 47 & 1 & 2 & 3 & 4 & 5 \\
\hline \multirow{2}{*}{ Time Frame } & 0 & 2 & 16 & 1 & 0 \\
\hline & $0 \%$ & $11 \%$ & $84 \%$ & $5 \%$ & $0 \%$ \\
\hline Impact on & 1 & 2 & 1 & 15 & 0 \\
\hline CTE & $5 \%$ & $11 \%$ & $5 \%$ & $79 \%$ & $0 \%$ \\
\hline \multirow{2}{*}{ Desirability } & 2 & 1 & 15 & 1 & 0 \\
\hline & $11 \%$ & $5 \%$ & $79 \%$ & $5 \%$ & $0 \%$ \\
\hline Question 48 & 1 & 2 & 3 & 4 & 5 \\
\hline \multirow{2}{*}{ Time Frame } & 1 & 0 & 16 & 1 & 1 \\
\hline & $5 \%$ & $0 \%$ & $84 \%$ & $5 \%$ & $5 \%$ \\
\hline Impact on & 0 & 1 & 17 & 0 & 1 \\
\hline CTE & $0 \%$ & $5 \%$ & $89 \%$ & $0 \%$ & $5 \%$ \\
\hline \multirow{2}{*}{ Desirability } & 0 & 1 & 16 & 0 & 2 \\
\hline & $0 \%$ & $5 \%$ & $84 \%$ & $0 \%$ & $11 \%$ \\
\hline Question 49 & 1 & 2 & 3 & 4 & 5 \\
\hline \multirow{2}{*}{ Time Frame } & 1 & 1 & 16 & 1 & 0 \\
\hline & $5 \%$ & $5 \%$ & $84 \%$ & $5 \%$ & $0 \%$ \\
\hline Impact on & 1 & 1 & 2 & 15 & 0 \\
\hline CTE & $5 \%$ & $5 \%$ & $11 \%$ & $79 \%$ & $0 \%$ \\
\hline \multirow{2}{*}{ Desirability } & 0 & 2 & 2 & 15 & 0 \\
\hline & $0 \%$ & $11 \%$ & $11 \%$ & $79 \%$ & $0 \%$ \\
\hline Question 50 & 1 & 2 & 3 & 4 & 5 \\
\hline \multirow{2}{*}{ Time Frame } & 1 & 15 & 3 & 0 & 0 \\
\hline & $5 \%$ & $79 \%$ & $16 \%$ & $0 \%$ & $0 \%$ \\
\hline Impact on & 0 & 1 & 1 & 1 & 16 \\
\hline CTE & $0 \%$ & $5 \%$ & $5 \%$ & $5 \%$ & $84 \%$ \\
\hline \multirow{2}{*}{ Desirability } & 0 & 1 & 1 & 1 & 16 \\
\hline & $0 \%$ & $5 \%$ & $5 \%$ & $5 \%$ & $84 \%$ \\
\hline Question 51 & 1 & 2 & 3 & 4 & 5 \\
\hline \multirow{2}{*}{ Time Frame } & 0 & 3 & 16 & 0 & 0 \\
\hline & $0 \%$ & $16 \%$ & $84 \%$ & $0 \%$ & $0 \%$ \\
\hline Impact on & 0 & 2 & 0 & 16 & 1 \\
\hline CTE & $0 \%$ & $11 \%$ & $0 \%$ & $84 \%$ & $5 \%$ \\
\hline \multirow{2}{*}{ Desirability } & 0 & 3 & 15 & 0 & 1 \\
\hline & $0 \%$ & $16 \%$ & $79 \%$ & $0 \%$ & $5 \%$ \\
\hline Question 52 & 1 & 2 & 3 & 4 & 5 \\
\hline \multirow{2}{*}{ Time Frame } & 0 & 18 & 1 & 0 & 0 \\
\hline & $0 \%$ & $95 \%$ & $5 \%$ & $0 \%$ & $0 \%$ \\
\hline Impact on & 0 & 2 & 0 & 17 & 0 \\
\hline CTE & $0 \%$ & $11 \%$ & $0 \%$ & $89 \%$ & $0 \%$ \\
\hline \multirow{2}{*}{ Desirability } & 1 & 16 & 1 & 1 & 0 \\
\hline & $5 \%$ & $84 \%$ & $5 \%$ & $5 \%$ & $0 \%$ \\
\hline
\end{tabular}




\begin{tabular}{|c|c|c|c|c|c|}
\hline Question 53 & 1 & 2 & 3 & 4 & 5 \\
\hline \multirow{2}{*}{ Time Frame } & 0 & 1 & 17 & 1 & 0 \\
\hline & $0 \%$ & $5 \%$ & $89 \%$ & $5 \%$ & $0 \%$ \\
\hline Impact on & 0 & 1 & 2 & 0 & 16 \\
\hline CTE & $0 \%$ & $5 \%$ & $11 \%$ & $0 \%$ & $84 \%$ \\
\hline \multirow{2}{*}{ Desirability } & 0 & 1 & 1 & 0 & 17 \\
\hline & $0 \%$ & $5 \%$ & $5 \%$ & $0 \%$ & $89 \%$ \\
\hline Question 54 & 1 & 2 & 3 & 4 & 5 \\
\hline \multirow{2}{*}{ Time Frame } & 0 & 2 & 17 & 0 & 0 \\
\hline & $0 \%$ & $11 \%$ & $89 \%$ & $0 \%$ & $0 \%$ \\
\hline Impact on & 0 & 2 & 0 & 17 & 0 \\
\hline CTE & $0 \%$ & $11 \%$ & $0 \%$ & $89 \%$ & $0 \%$ \\
\hline \multirow{2}{*}{ Desirability } & 0 & 3 & 16 & 0 & 0 \\
\hline & $0 \%$ & $16 \%$ & $84 \%$ & $0 \%$ & $0 \%$ \\
\hline Question 55 & 1 & 2 & 3 & 4 & 5 \\
\hline \multirow{2}{*}{ Time Frame } & 0 & 18 & 1 & 0 & 0 \\
\hline & $0 \%$ & $95 \%$ & $5 \%$ & $0 \%$ & $0 \%$ \\
\hline Impact on & 0 & 2 & 0 & 0 & 17 \\
\hline CTE & $0 \%$ & $11 \%$ & $0 \%$ & $0 \%$ & $89 \%$ \\
\hline \multirow{2}{*}{ Desirability } & 1 & 14 & 0 & 2 & 2 \\
\hline & $5 \%$ & $74 \%$ & $0 \%$ & $11 \%$ & $11 \%$ \\
\hline Question 56 & 1 & 2 & 3 & 4 & 5 \\
\hline \multirow{2}{*}{ Time Frame } & 0 & 3 & 16 & 0 & 0 \\
\hline & $0 \%$ & $16 \%$ & $84 \%$ & $0 \%$ & $0 \%$ \\
\hline Impact on & 0 & 1 & 0 & 17 & 1 \\
\hline CTE & $0 \%$ & $5 \%$ & $0 \%$ & $89 \%$ & $5 \%$ \\
\hline \multirow{2}{*}{ Desirability } & 0 & 1 & 0 & 17 & 1 \\
\hline & $0 \%$ & $5 \%$ & $0 \%$ & $89 \%$ & $5 \%$ \\
\hline Question 57 & 1 & 2 & 3 & 4 & 5 \\
\hline \multirow{2}{*}{ Time Frame } & 1 & 1 & 15 & 1 & 1 \\
\hline & $5 \%$ & $5 \%$ & $79 \%$ & $5 \%$ & $5 \%$ \\
\hline Impact on & 0 & 1 & 0 & 18 & 0 \\
\hline CTE & $0 \%$ & $5 \%$ & $0 \%$ & $95 \%$ & $0 \%$ \\
\hline \multirow{2}{*}{ Desirability } & 1 & 0 & 1 & 17 & 0 \\
\hline & $5 \%$ & $0 \%$ & $5 \%$ & $89 \%$ & $0 \%$ \\
\hline Question 58 & 1 & 2 & 3 & 4 & 5 \\
\hline \multirow{2}{*}{ Time Frame } & 1 & 1 & 17 & 0 & 0 \\
\hline & $5 \%$ & $5 \%$ & $89 \%$ & $0 \%$ & $0 \%$ \\
\hline Impact on & 0 & 1 & 1 & 16 & 1 \\
\hline CTE & $0 \%$ & $5 \%$ & $5 \%$ & $84 \%$ & $5 \%$ \\
\hline \multirow{2}{*}{ Desirability } & 1 & 0 & 1 & 1 & 16 \\
\hline & $5 \%$ & $0 \%$ & $5 \%$ & $5 \%$ & $84 \%$ \\
\hline
\end{tabular}




\begin{tabular}{|c|c|c|c|c|c|}
\hline Question 59 & 1 & 2 & 3 & 4 & 5 \\
\hline \multirow{2}{*}{ Time Frame } & 0 & 3 & 16 & 0 & 0 \\
\hline & $0 \%$ & $16 \%$ & $84 \%$ & $0 \%$ & $0 \%$ \\
\hline Impact on & 0 & 1 & 1 & 0 & 17 \\
\hline CTE & $0 \%$ & $5 \%$ & $5 \%$ & $0 \%$ & $89 \%$ \\
\hline \multirow{2}{*}{ Desirability } & 0 & 1 & 1 & 0 & 17 \\
\hline & $0 \%$ & $5 \%$ & $5 \%$ & $0 \%$ & $89 \%$ \\
\hline Question 60 & 1 & 2 & 3 & 4 & 5 \\
\hline \multirow{2}{*}{ Time Frame } & 0 & 2 & 17 & 0 & 0 \\
\hline & $0 \%$ & $11 \%$ & $89 \%$ & $0 \%$ & $0 \%$ \\
\hline Impact on & 0 & 1 & 0 & 0 & 18 \\
\hline CTE & $0 \%$ & $5 \%$ & $0 \%$ & $0 \%$ & $95 \%$ \\
\hline \multirow{2}{*}{ Desirability } & 0 & 1 & 0 & 0 & 18 \\
\hline & $0 \%$ & $5 \%$ & $0 \%$ & $0 \%$ & $95 \%$ \\
\hline Question 61 & 1 & 2 & 3 & 4 & 5 \\
\hline \multirow{2}{*}{ Time Frame } & 1 & 0 & 17 & 0 & 1 \\
\hline & $5 \%$ & $0 \%$ & $89 \%$ & $0 \%$ & $5 \%$ \\
\hline Impact on & 0 & 1 & 0 & 18 & 0 \\
\hline CTE & $0 \%$ & $5 \%$ & $0 \%$ & $95 \%$ & $0 \%$ \\
\hline \multirow{2}{*}{ Desirability } & 2 & 0 & 0 & 17 & 0 \\
\hline & $11 \%$ & $0 \%$ & $0 \%$ & $89 \%$ & $0 \%$ \\
\hline Question 62 & 1 & 2 & 3 & 4 & 5 \\
\hline \multirow{2}{*}{ Time Frame } & 2 & 1 & 16 & 0 & 0 \\
\hline & $11 \%$ & $5 \%$ & $84 \%$ & $0 \%$ & $0 \%$ \\
\hline Impact on & 1 & 1 & 0 & 16 & 0 \\
\hline CTE & $6 \%$ & $6 \%$ & $0 \%$ & $89 \%$ & $0 \%$ \\
\hline \multirow{2}{*}{ Desirability } & 2 & 0 & 16 & 0 & 1 \\
\hline & $11 \%$ & $0 \%$ & $84 \%$ & $0 \%$ & $5 \%$ \\
\hline Question 63 & 1 & 2 & 3 & 4 & 5 \\
\hline \multirow{2}{*}{ Time Frame } & 2 & 0 & 16 & 1 & 0 \\
\hline & $11 \%$ & $0 \%$ & $84 \%$ & $5 \%$ & $0 \%$ \\
\hline Impact on & 1 & 1 & 0 & 17 & 0 \\
\hline CTE & $5 \%$ & $5 \%$ & $0 \%$ & $89 \%$ & $0 \%$ \\
\hline \multirow{2}{*}{ Desirability } & 2 & 0 & 15 & 1 & 1 \\
\hline & $11 \%$ & $0 \%$ & $79 \%$ & $5 \%$ & $5 \%$ \\
\hline Question 64 & 1 & 2 & 3 & 4 & 5 \\
\hline \multirow{2}{*}{ Time Frame } & 0 & 19 & 0 & 0 & 0 \\
\hline & $0 \%$ & $100 \%$ & $0 \%$ & $0 \%$ & $0 \%$ \\
\hline Impact on & 0 & 1 & 0 & 18 & 0 \\
\hline CTE & $0 \%$ & $5 \%$ & $0 \%$ & $95 \%$ & $0 \%$ \\
\hline \multirow{2}{*}{ Desirability } & 0 & 1 & 0 & 1 & 17 \\
\hline & $0 \%$ & $5 \%$ & $0 \%$ & $5 \%$ & $89 \%$ \\
\hline
\end{tabular}




\begin{tabular}{|c|c|c|c|c|c|}
\hline Question 65 & 1 & 2 & 3 & 4 & 5 \\
\hline \multirow{2}{*}{ Time Frame } & 0 & 18 & 1 & 0 & 0 \\
\hline & $0 \%$ & $95 \%$ & $5 \%$ & $0 \%$ & $0 \%$ \\
\hline Impact on & 0 & 1 & 0 & 0 & 18 \\
\hline CTE & $0 \%$ & $5 \%$ & $0 \%$ & $0 \%$ & $95 \%$ \\
\hline \multirow{2}{*}{ Desirability } & 0 & 1 & 0 & 0 & 18 \\
\hline & $0 \%$ & $5 \%$ & $0 \%$ & $0 \%$ & $95 \%$ \\
\hline Question 66 & 1 & 2 & 3 & 4 & 5 \\
\hline \multirow{2}{*}{ Time Frame } & 1 & 1 & 17 & 0 & 0 \\
\hline & $5 \%$ & $5 \%$ & $89 \%$ & $0 \%$ & $0 \%$ \\
\hline Impact on & 0 & 1 & 0 & 1 & 16 \\
\hline CTE & $0 \%$ & $6 \%$ & $0 \%$ & $6 \%$ & $89 \%$ \\
\hline \multirow{2}{*}{ Desirability } & 0 & 1 & 0 & 1 & 16 \\
\hline & $0 \%$ & $6 \%$ & $0 \%$ & $6 \%$ & $89 \%$ \\
\hline Question 67 & 1 & 2 & 3 & 4 & 5 \\
\hline \multirow{2}{*}{ Time Frame } & 0 & 1 & 18 & 0 & 0 \\
\hline & $0 \%$ & $5 \%$ & $95 \%$ & $0 \%$ & $0 \%$ \\
\hline Impact on & 0 & 1 & 1 & 17 & 0 \\
\hline CTE & $0 \%$ & $5 \%$ & $5 \%$ & $89 \%$ & $0 \%$ \\
\hline \multirow{2}{*}{ Desirability } & 0 & 1 & 1 & 0 & 17 \\
\hline & $0 \%$ & $5 \%$ & $5 \%$ & $0 \%$ & $89 \%$ \\
\hline Question 68 & 1 & 2 & 3 & 4 & 5 \\
\hline \multirow{2}{*}{ Time Frame } & 0 & 1 & 18 & 0 & 0 \\
\hline & $0 \%$ & $5 \%$ & $95 \%$ & $0 \%$ & $0 \%$ \\
\hline Impact on & 0 & 1 & 1 & 17 & 0 \\
\hline CTE & $0 \%$ & $5 \%$ & $5 \%$ & $89 \%$ & $0 \%$ \\
\hline \multirow{2}{*}{ Desirability } & 0 & 1 & 1 & 0 & 17 \\
\hline & $0 \%$ & $5 \%$ & $5 \%$ & $0 \%$ & $89 \%$ \\
\hline Question 69 & 1 & 2 & 3 & 4 & 5 \\
\hline \multirow{2}{*}{ Time Frame } & 0 & 1 & 18 & 0 & 0 \\
\hline & $0 \%$ & $5 \%$ & $95 \%$ & $0 \%$ & $0 \%$ \\
\hline Impact on & 0 & 1 & 1 & 17 & 0 \\
\hline CTE & $0 \%$ & $5 \%$ & $5 \%$ & $89 \%$ & $0 \%$ \\
\hline \multirow{2}{*}{ Desirability } & 0 & 1 & 1 & 17 & 0 \\
\hline & $0 \%$ & $5 \%$ & $5 \%$ & $89 \%$ & $0 \%$ \\
\hline Question 70 & 1 & 2 & 3 & 4 & 5 \\
\hline \multirow{2}{*}{ Time Frame } & 0 & 1 & 18 & 0 & 0 \\
\hline & $0 \%$ & $5 \%$ & $95 \%$ & $0 \%$ & $0 \%$ \\
\hline Impact on & 0 & 1 & 1 & 16 & 1 \\
\hline \multirow[t]{2}{*}{ CTE } & $0 \%$ & $5 \%$ & $5 \%$ & $84 \%$ & $5 \%$ \\
\hline & 0 & 1 & 1 & 16 & 1 \\
\hline Desirability & $0 \%$ & $5 \%$ & $5 \%$ & $84 \%$ & $5 \%$ \\
\hline
\end{tabular}




\begin{tabular}{|c|c|c|c|c|c|}
\hline Question 71 & 1 & 2 & 3 & 4 & 5 \\
\hline \multirow{2}{*}{ Time Frame } & 0 & 1 & 18 & 0 & 0 \\
\hline & $0 \%$ & $5 \%$ & $95 \%$ & $0 \%$ & $0 \%$ \\
\hline Impact on & 0 & 2 & 1 & 16 & 0 \\
\hline CTE & $0 \%$ & $11 \%$ & $5 \%$ & $84 \%$ & $0 \%$ \\
\hline \multirow{2}{*}{ Desirability } & 0 & 1 & 1 & 16 & 1 \\
\hline & $0 \%$ & $5 \%$ & $5 \%$ & $84 \%$ & $5 \%$ \\
\hline Question 72 & 1 & 2 & 3 & 4 & 5 \\
\hline \multirow{2}{*}{ Time Frame } & 0 & 18 & 1 & 0 & 0 \\
\hline & $0 \%$ & $95 \%$ & $5 \%$ & $0 \%$ & $0 \%$ \\
\hline Impact on & 0 & 1 & 0 & 1 & 17 \\
\hline CTE & $0 \%$ & $5 \%$ & $0 \%$ & $5 \%$ & $89 \%$ \\
\hline \multirow{2}{*}{ Desirability } & 0 & 1 & 0 & 1 & 17 \\
\hline & $0 \%$ & $5 \%$ & $0 \%$ & $5 \%$ & $89 \%$ \\
\hline Question 73 & $\mathbf{1}$ & 2 & 3 & 4 & 5 \\
\hline \multirow{2}{*}{ Time Frame } & 0 & 19 & 0 & 0 & 0 \\
\hline & $0 \%$ & $100 \%$ & $0 \%$ & $0 \%$ & $0 \%$ \\
\hline Impact on & 0 & 1 & 0 & 18 & 0 \\
\hline CTE & $0 \%$ & $5 \%$ & $0 \%$ & $95 \%$ & $0 \%$ \\
\hline \multirow{2}{*}{ Desirability } & 0 & 1 & 0 & 1 & 17 \\
\hline & $0 \%$ & $5 \%$ & $0 \%$ & $5 \%$ & $89 \%$ \\
\hline Question 74 & 1 & 2 & 3 & 4 & 5 \\
\hline \multirow{2}{*}{ Time Frame } & 0 & 19 & 0 & 0 & 0 \\
\hline & $0 \%$ & $100 \%$ & $0 \%$ & $0 \%$ & $0 \%$ \\
\hline Impact on & 0 & 1 & 0 & 17 & 1 \\
\hline CTE & $0 \%$ & $5 \%$ & $0 \%$ & $89 \%$ & $5 \%$ \\
\hline \multirow{2}{*}{ Desirability } & 0 & 1 & 0 & 1 & 17 \\
\hline & $0 \%$ & $5 \%$ & $0 \%$ & $5 \%$ & $89 \%$ \\
\hline Question 75 & 1 & 2 & 3 & 4 & 5 \\
\hline \multirow{2}{*}{ Time Frame } & 0 & 3 & 16 & 0 & 0 \\
\hline & $0 \%$ & $16 \%$ & $84 \%$ & $0 \%$ & $0 \%$ \\
\hline Impact on & 0 & 1 & 0 & 2 & 16 \\
\hline CTE & $0 \%$ & $5 \%$ & $0 \%$ & $11 \%$ & $84 \%$ \\
\hline \multirow{2}{*}{ Desirability } & 0 & 1 & 0 & 2 & 16 \\
\hline & $0 \%$ & $5 \%$ & $0 \%$ & $11 \%$ & $84 \%$ \\
\hline Question 76 & 1 & 2 & 3 & 4 & 5 \\
\hline \multirow{2}{*}{ Time Frame } & 0 & 2 & 17 & 0 & 0 \\
\hline & $0 \%$ & $11 \%$ & $89 \%$ & $0 \%$ & $0 \%$ \\
\hline \multirow{3}{*}{$\begin{array}{c}\text { Impact on } \\
\text { CTE }\end{array}$} & 0 & 1 & 0 & 18 & 0 \\
\hline & $0 \%$ & $5 \%$ & $0 \%$ & $95 \%$ & $0 \%$ \\
\hline & 0 & 1 & 0 & 18 & 0 \\
\hline Desirability & $0 \%$ & $5 \%$ & $0 \%$ & $95 \%$ & $0 \%$ \\
\hline
\end{tabular}




\begin{tabular}{|c|c|c|c|c|c|}
\hline Question 77 & 1 & 2 & 3 & 4 & 5 \\
\hline \multirow{2}{*}{ Time Frame } & 0 & 19 & 0 & 0 & 0 \\
\hline & $0 \%$ & $100 \%$ & $0 \%$ & $0 \%$ & $0 \%$ \\
\hline Impact on & 0 & 1 & 0 & 18 & 0 \\
\hline CTE & $0 \%$ & $5 \%$ & $0 \%$ & $95 \%$ & $0 \%$ \\
\hline \multirow{2}{*}{ Desirability } & 0 & 1 & 0 & 18 & 0 \\
\hline & $0 \%$ & $5 \%$ & $0 \%$ & $95 \%$ & $0 \%$ \\
\hline Question 78 & 1 & 2 & 3 & 4 & 5 \\
\hline \multirow{2}{*}{ Time Frame } & 0 & 19 & 0 & 0 & 0 \\
\hline & $0 \%$ & $100 \%$ & $0 \%$ & $0 \%$ & $0 \%$ \\
\hline Impact on & 0 & 1 & 0 & 1 & 17 \\
\hline CTE & $0 \%$ & $5 \%$ & $0 \%$ & $5 \%$ & $89 \%$ \\
\hline \multirow{2}{*}{ Desirability } & 0 & 1 & 0 & 1 & 17 \\
\hline & $0 \%$ & $5 \%$ & $0 \%$ & $5 \%$ & $89 \%$ \\
\hline Question 79 & 1 & 2 & 3 & 4 & 5 \\
\hline \multirow{2}{*}{ Time Frame } & 1 & 3 & 15 & 0 & 0 \\
\hline & $5 \%$ & $16 \%$ & $79 \%$ & $0 \%$ & $0 \%$ \\
\hline Impact on & 0 & 1 & 0 & 1 & 17 \\
\hline CTE & $0 \%$ & $5 \%$ & $0 \%$ & $5 \%$ & $89 \%$ \\
\hline \multirow{2}{*}{ Desirability } & 0 & 1 & 0 & 1 & 17 \\
\hline & $0 \%$ & $5 \%$ & $0 \%$ & $5 \%$ & $89 \%$ \\
\hline Question 80 & 1 & 2 & 3 & 4 & 5 \\
\hline \multirow{2}{*}{ Time Frame } & 0 & 2 & 17 & 0 & 0 \\
\hline & $0 \%$ & $11 \%$ & $89 \%$ & $0 \%$ & $0 \%$ \\
\hline Impact on & 0 & 1 & 0 & 1 & 17 \\
\hline CTE & $0 \%$ & $5 \%$ & $0 \%$ & $5 \%$ & $89 \%$ \\
\hline \multirow{2}{*}{ Desirability } & 0 & 1 & 0 & 1 & 17 \\
\hline & $0 \%$ & $5 \%$ & $0 \%$ & $5 \%$ & $89 \%$ \\
\hline Question 81 & 1 & 2 & 3 & 4 & 5 \\
\hline \multirow{2}{*}{ Time Frame } & 1 & 1 & 16 & 0 & 1 \\
\hline & $5 \%$ & $5 \%$ & $84 \%$ & $0 \%$ & $5 \%$ \\
\hline Impact on & 1 & 1 & 2 & 1 & 13 \\
\hline CTE & $6 \%$ & $6 \%$ & $11 \%$ & $6 \%$ & $72 \%$ \\
\hline \multirow{2}{*}{ Desirability } & 1 & 13 & 4 & 0 & 1 \\
\hline & $5 \%$ & $68 \%$ & $21 \%$ & $0 \%$ & $5 \%$ \\
\hline Question 82 & 1 & 2 & 3 & 4 & 5 \\
\hline \multirow{2}{*}{ Time Frame } & 0 & 1 & 18 & 0 & 0 \\
\hline & $0 \%$ & $5 \%$ & $95 \%$ & $0 \%$ & $0 \%$ \\
\hline Impact on & 0 & 1 & 1 & 1 & 16 \\
\hline CTE & $0 \%$ & $5 \%$ & $5 \%$ & $5 \%$ & $84 \%$ \\
\hline \multirow{2}{*}{ Desirability } & 0 & 1 & 0 & 1 & 17 \\
\hline & $0 \%$ & $5 \%$ & $0 \%$ & $5 \%$ & $89 \%$ \\
\hline
\end{tabular}




\begin{tabular}{|c|c|c|c|c|c|}
\hline Question 83 & 1 & 2 & 3 & 4 & 5 \\
\hline \multirow{2}{*}{ Time Frame } & 0 & 3 & 16 & 0 & 0 \\
\hline & $0 \%$ & $16 \%$ & $84 \%$ & $0 \%$ & $0 \%$ \\
\hline Impact on & 0 & 1 & 0 & 18 & 0 \\
\hline CTE & $0 \%$ & $5 \%$ & $0 \%$ & $95 \%$ & $0 \%$ \\
\hline \multirow{2}{*}{ Desirability } & 0 & 1 & 0 & 18 & 0 \\
\hline & $0 \%$ & $5 \%$ & $0 \%$ & $95 \%$ & $0 \%$ \\
\hline Question 84 & 1 & 2 & 3 & 4 & 5 \\
\hline \multirow{2}{*}{ Time Frame } & 1 & 2 & 16 & 0 & 0 \\
\hline & $5 \%$ & $11 \%$ & $84 \%$ & $0 \%$ & $0 \%$ \\
\hline Impact on & 0 & 1 & 0 & 18 & 0 \\
\hline CTE & $0 \%$ & $5 \%$ & $0 \%$ & $95 \%$ & $0 \%$ \\
\hline \multirow{2}{*}{ Desirability } & 0 & 1 & 0 & 1 & 17 \\
\hline & $0 \%$ & $5 \%$ & $0 \%$ & $5 \%$ & $89 \%$ \\
\hline Question 85 & 1 & 2 & 3 & 4 & 5 \\
\hline \multirow{2}{*}{ Time Frame } & 2 & 0 & 16 & 0 & 1 \\
\hline & $11 \%$ & $0 \%$ & $84 \%$ & $0 \%$ & $5 \%$ \\
\hline Impact on & 0 & 1 & 1 & 1 & 14 \\
\hline CTE & $0 \%$ & $6 \%$ & $6 \%$ & $6 \%$ & $82 \%$ \\
\hline \multirow{2}{*}{ Desirability } & 0 & 1 & 1 & 1 & 14 \\
\hline & $0 \%$ & $6 \%$ & $6 \%$ & $6 \%$ & $82 \%$ \\
\hline Question 86 & 1 & 2 & 3 & 4 & 5 \\
\hline \multirow{2}{*}{ Time Frame } & 1 & 0 & 1 & 16 & 1 \\
\hline & $5 \%$ & $0 \%$ & $5 \%$ & $84 \%$ & $5 \%$ \\
\hline Impact on & 0 & 1 & 1 & 0 & 16 \\
\hline CTE & $0 \%$ & $6 \%$ & $6 \%$ & $0 \%$ & $89 \%$ \\
\hline \multirow{2}{*}{ Desirability } & 0 & 0 & 18 & 0 & 0 \\
\hline & $0 \%$ & $0 \%$ & $100 \%$ & $0 \%$ & $0 \%$ \\
\hline Question 87 & 1 & 2 & 3 & 4 & 5 \\
\hline \multirow{2}{*}{ Time Frame } & 0 & 0 & 18 & 0 & 1 \\
\hline & $0 \%$ & $0 \%$ & $95 \%$ & $0 \%$ & $5 \%$ \\
\hline Impact on & 0 & 1 & 0 & 18 & 0 \\
\hline CTE & $0 \%$ & $5 \%$ & $0 \%$ & $95 \%$ & $0 \%$ \\
\hline \multirow{2}{*}{ Desirability } & 0 & 0 & 1 & 18 & 0 \\
\hline & $0 \%$ & $0 \%$ & $5 \%$ & $95 \%$ & $0 \%$ \\
\hline Question 88 & 1 & 2 & 3 & 4 & 5 \\
\hline \multirow{2}{*}{ Time Frame } & 0 & 2 & 17 & 0 & 0 \\
\hline & $0 \%$ & $11 \%$ & $89 \%$ & $0 \%$ & $0 \%$ \\
\hline Impact on & 0 & 1 & 0 & 18 & 0 \\
\hline CTE & $0 \%$ & $5 \%$ & $0 \%$ & $95 \%$ & $0 \%$ \\
\hline \multirow{2}{*}{ Desirability } & 0 & 1 & 0 & 18 & 0 \\
\hline & $0 \%$ & $5 \%$ & $0 \%$ & $95 \%$ & $0 \%$ \\
\hline
\end{tabular}




\begin{tabular}{|c|c|c|c|c|c|}
\hline Question 89 & 1 & 2 & 3 & 4 & 5 \\
\hline \multirow{2}{*}{ Time Frame } & 0 & 3 & 15 & 0 & 1 \\
\hline & $0 \%$ & $16 \%$ & $79 \%$ & $0 \%$ & $5 \%$ \\
\hline Impact on & 0 & 1 & 1 & 0 & 17 \\
\hline CTE & $0 \%$ & $5 \%$ & $5 \%$ & $0 \%$ & $89 \%$ \\
\hline \multirow{2}{*}{ Desirability } & 0 & 1 & 0 & 0 & 18 \\
\hline & $0 \%$ & $5 \%$ & $0 \%$ & $0 \%$ & $95 \%$ \\
\hline Question 90 & 1 & 2 & 3 & 4 & 5 \\
\hline \multirow{2}{*}{ Time Frame } & 0 & 1 & 18 & 0 & 0 \\
\hline & $0 \%$ & $5 \%$ & $95 \%$ & $0 \%$ & $0 \%$ \\
\hline Impact on & 0 & 1 & 0 & 0 & 18 \\
\hline CTE & $0 \%$ & $5 \%$ & $0 \%$ & $0 \%$ & $95 \%$ \\
\hline \multirow{2}{*}{ Desirability } & 0 & 1 & 0 & 0 & 18 \\
\hline & $0 \%$ & $5 \%$ & $0 \%$ & $0 \%$ & $95 \%$ \\
\hline Question 91 & 1 & 2 & 3 & 4 & 5 \\
\hline \multirow{2}{*}{ Time Frame } & 1 & 1 & 17 & 0 & 0 \\
\hline & $5 \%$ & $5 \%$ & $89 \%$ & $0 \%$ & $0 \%$ \\
\hline Impact on & 0 & 2 & 0 & 17 & 0 \\
\hline CTE & $0 \%$ & $11 \%$ & $0 \%$ & $89 \%$ & $0 \%$ \\
\hline \multirow{2}{*}{ Desirability } & 1 & 1 & 16 & 1 & 0 \\
\hline & $5 \%$ & $5 \%$ & $84 \%$ & $5 \%$ & $0 \%$ \\
\hline Question 92 & 1 & 2 & 3 & 4 & 5 \\
\hline \multirow{2}{*}{ Time Frame } & 0 & 19 & 0 & 0 & 0 \\
\hline & $0 \%$ & $100 \%$ & $0 \%$ & $0 \%$ & $0 \%$ \\
\hline Impact on & 0 & 1 & 0 & 2 & 16 \\
\hline CTE & $0 \%$ & $5 \%$ & $0 \%$ & $11 \%$ & $84 \%$ \\
\hline \multirow{2}{*}{ Desirability } & 0 & 1 & 17 & 1 & 0 \\
\hline & $0 \%$ & $5 \%$ & $89 \%$ & $5 \%$ & $0 \%$ \\
\hline Question 93 & 1 & 2 & 3 & 4 & 5 \\
\hline \multirow{2}{*}{ Time Frame } & 1 & 2 & 16 & 0 & 0 \\
\hline & $5 \%$ & $11 \%$ & $84 \%$ & $0 \%$ & $0 \%$ \\
\hline Impact on & 0 & 2 & 0 & 17 & 0 \\
\hline CTE & $0 \%$ & $11 \%$ & $0 \%$ & $89 \%$ & $0 \%$ \\
\hline \multirow{2}{*}{ Desirability } & 0 & 2 & 0 & 0 & 17 \\
\hline & $0 \%$ & $11 \%$ & $0 \%$ & $0 \%$ & $89 \%$ \\
\hline Question 94 & 1 & 2 & 3 & 4 & 5 \\
\hline \multirow{2}{*}{ Time Frame } & 0 & 2 & 17 & 0 & 0 \\
\hline & $0 \%$ & $11 \%$ & $89 \%$ & $0 \%$ & $0 \%$ \\
\hline Impact on & 0 & 2 & 0 & 16 & 1 \\
\hline CTE & $0 \%$ & $11 \%$ & $0 \%$ & $84 \%$ & $5 \%$ \\
\hline \multirow{2}{*}{ Desirability } & 0 & 2 & 0 & 17 & 0 \\
\hline & $0 \%$ & $11 \%$ & $0 \%$ & $89 \%$ & $0 \%$ \\
\hline
\end{tabular}




\begin{tabular}{|c|c|c|c|c|c|}
\hline Question 95 & 1 & 2 & 3 & 4 & 5 \\
\hline \multirow{2}{*}{ Time Frame } & 1 & 0 & 18 & 0 & 0 \\
\hline & $5 \%$ & $0 \%$ & $95 \%$ & $0 \%$ & $0 \%$ \\
\hline Impact on & 1 & 1 & 0 & 17 & 0 \\
\hline CTE & $5 \%$ & $5 \%$ & $0 \%$ & $89 \%$ & $0 \%$ \\
\hline \multirow{2}{*}{ Desirability } & 1 & 0 & 17 & 0 & 1 \\
\hline & $5 \%$ & $0 \%$ & $89 \%$ & $0 \%$ & $5 \%$ \\
\hline Question 96 & 1 & 2 & 3 & 4 & 5 \\
\hline \multirow{2}{*}{ Time Frame } & 2 & 0 & 17 & 0 & 0 \\
\hline & $11 \%$ & $0 \%$ & $89 \%$ & $0 \%$ & $0 \%$ \\
\hline Impact on & 1 & 1 & 1 & 0 & 16 \\
\hline CTE & $5 \%$ & $5 \%$ & $5 \%$ & $0 \%$ & $84 \%$ \\
\hline \multirow{2}{*}{ Desirability } & 2 & 0 & 15 & 0 & 2 \\
\hline & $11 \%$ & $0 \%$ & $79 \%$ & $0 \%$ & $11 \%$ \\
\hline Question 97 & 1 & 2 & 3 & 4 & 5 \\
\hline \multirow{2}{*}{ Time Frame } & 0 & 19 & 0 & 0 & 0 \\
\hline & $0 \%$ & $100 \%$ & $0 \%$ & $0 \%$ & $0 \%$ \\
\hline Impact on & 0 & 1 & 1 & 17 & 0 \\
\hline CTE & $0 \%$ & $5 \%$ & $5 \%$ & $89 \%$ & $0 \%$ \\
\hline \multirow{2}{*}{ Desirability } & 0 & 1 & 17 & 0 & 1 \\
\hline & $0 \%$ & $5 \%$ & $89 \%$ & $0 \%$ & $5 \%$ \\
\hline Question 98 & 1 & 2 & 3 & 4 & 5 \\
\hline \multirow{2}{*}{ Time Frame } & 0 & 1 & 16 & 0 & 1 \\
\hline & $0 \%$ & $6 \%$ & $89 \%$ & $0 \%$ & $6 \%$ \\
\hline Impact on & 0 & 0 & 1 & 16 & 1 \\
\hline CTE & $0 \%$ & $0 \%$ & $6 \%$ & $89 \%$ & $6 \%$ \\
\hline \multirow{2}{*}{ Desirability } & 0 & 0 & 1 & 0 & 17 \\
\hline & $0 \%$ & $0 \%$ & $6 \%$ & $0 \%$ & $94 \%$ \\
\hline Question 99 & 1 & 2 & 3 & 4 & 5 \\
\hline \multirow{2}{*}{ Time Frame } & 0 & 2 & 17 & 0 & 0 \\
\hline & $0 \%$ & $11 \%$ & $89 \%$ & $0 \%$ & $0 \%$ \\
\hline Impact on & 0 & 1 & 1 & 0 & 17 \\
\hline CTE & $0 \%$ & $5 \%$ & $5 \%$ & $0 \%$ & $89 \%$ \\
\hline \multirow{2}{*}{ Desirability } & 0 & 0 & 2 & 17 & 0 \\
\hline & $0 \%$ & $0 \%$ & $11 \%$ & $89 \%$ & $0 \%$ \\
\hline Question 100 & 1 & 2 & 3 & 4 & 5 \\
\hline \multirow{2}{*}{ Time Frame } & 0 & 2 & 17 & 0 & 0 \\
\hline & $0 \%$ & $11 \%$ & $89 \%$ & $0 \%$ & $0 \%$ \\
\hline Impact on & 0 & 1 & 1 & 17 & 0 \\
\hline CTE & $0 \%$ & $5 \%$ & $5 \%$ & $89 \%$ & $0 \%$ \\
\hline \multirow{2}{*}{ Desirability } & 0 & 1 & 0 & 18 & 0 \\
\hline & $0 \%$ & $5 \%$ & $0 \%$ & $95 \%$ & $0 \%$ \\
\hline
\end{tabular}




\begin{tabular}{|c|c|c|c|c|c|}
\hline Question 101 & 1 & 2 & 3 & 4 & 5 \\
\hline \multirow{2}{*}{ Time Frame } & 0 & 1 & 18 & 0 & 0 \\
\hline & $0 \%$ & $5 \%$ & $95 \%$ & $0 \%$ & $0 \%$ \\
\hline Impact on & 0 & 1 & 2 & 0 & 16 \\
\hline CTE & $0 \%$ & $5 \%$ & $11 \%$ & $0 \%$ & $84 \%$ \\
\hline \multirow{2}{*}{ Desirability } & 0 & 1 & 16 & 1 & 1 \\
\hline & $0 \%$ & $5 \%$ & $84 \%$ & $5 \%$ & $5 \%$ \\
\hline Question 102 & 1 & 2 & 3 & 4 & 5 \\
\hline \multirow{2}{*}{ Time Frame } & 0 & 2 & 17 & 0 & 0 \\
\hline & $0 \%$ & $11 \%$ & $89 \%$ & $0 \%$ & $0 \%$ \\
\hline Impact on & 0 & 1 & 1 & 0 & 17 \\
\hline CTE & $0 \%$ & $5 \%$ & $5 \%$ & $0 \%$ & $89 \%$ \\
\hline \multirow{2}{*}{ Desirability } & 0 & 1 & 1 & 17 & 0 \\
\hline & $0 \%$ & $5 \%$ & $5 \%$ & $89 \%$ & $0 \%$ \\
\hline Question 103 & 1 & 2 & 3 & 4 & 5 \\
\hline \multirow{2}{*}{ Time Frame } & 0 & 3 & 16 & 0 & 0 \\
\hline & $0 \%$ & $16 \%$ & $84 \%$ & $0 \%$ & $0 \%$ \\
\hline Impact on & 0 & 1 & 1 & 17 & 0 \\
\hline CTE & $0 \%$ & $5 \%$ & $5 \%$ & $89 \%$ & $0 \%$ \\
\hline \multirow{2}{*}{ Desirability } & 0 & 1 & 1 & 17 & 0 \\
\hline & $0 \%$ & $5 \%$ & $5 \%$ & $89 \%$ & $0 \%$ \\
\hline Question 104 & 1 & 2 & 3 & 4 & 5 \\
\hline \multirow{2}{*}{ Time Frame } & 0 & 1 & 18 & 0 & 0 \\
\hline & $0 \%$ & $5 \%$ & $95 \%$ & $0 \%$ & $0 \%$ \\
\hline Impact on & 0 & 1 & 1 & 0 & 17 \\
\hline CTE & $0 \%$ & $5 \%$ & $5 \%$ & $0 \%$ & $89 \%$ \\
\hline \multirow{2}{*}{ Desirability } & 0 & 1 & 17 & 0 & 1 \\
\hline & $0 \%$ & $5 \%$ & $89 \%$ & $0 \%$ & $5 \%$ \\
\hline Question 105 & 1 & 2 & 3 & 4 & 5 \\
\hline \multirow{2}{*}{ Time Frame } & 0 & 19 & 0 & 0 & 0 \\
\hline & $0 \%$ & $100 \%$ & $0 \%$ & $0 \%$ & $0 \%$ \\
\hline Impact on & 0 & 1 & 0 & 1 & 17 \\
\hline CTE & $0 \%$ & $5 \%$ & $0 \%$ & $5 \%$ & $89 \%$ \\
\hline \multirow{2}{*}{ Desirability } & 0 & 1 & 0 & 1 & 17 \\
\hline & $0 \%$ & $5 \%$ & $0 \%$ & $5 \%$ & $89 \%$ \\
\hline Question 106 & 1 & 2 & 3 & 4 & 5 \\
\hline \multirow{2}{*}{ Time Frame } & 0 & 2 & 17 & 0 & 0 \\
\hline & $0 \%$ & $11 \%$ & $89 \%$ & $0 \%$ & $0 \%$ \\
\hline Impact on & 0 & 1 & 0 & 1 & 17 \\
\hline CTE & $0 \%$ & $5 \%$ & $0 \%$ & $5 \%$ & $89 \%$ \\
\hline \multirow{2}{*}{ Desirability } & 0 & 1 & 0 & 1 & 17 \\
\hline & $0 \%$ & $5 \%$ & $0 \%$ & $5 \%$ & $89 \%$ \\
\hline
\end{tabular}




\begin{tabular}{|c|c|c|c|c|c|}
\hline Question 107 & 1 & 2 & 3 & 4 & 5 \\
\hline \multirow{2}{*}{ Time Frame } & 0 & 17 & 2 & 0 & 0 \\
\hline & $0 \%$ & $89 \%$ & $11 \%$ & $0 \%$ & $0 \%$ \\
\hline Impact on & 0 & 1 & 1 & 17 & 0 \\
\hline CTE & $0 \%$ & $5 \%$ & $5 \%$ & $89 \%$ & $0 \%$ \\
\hline \multirow{2}{*}{ Desirability } & 0 & 1 & 17 & 1 & 0 \\
\hline & $0 \%$ & $5 \%$ & $89 \%$ & $5 \%$ & $0 \%$ \\
\hline Question 108 & 1 & 2 & 3 & 4 & 5 \\
\hline \multirow{2}{*}{ Time Frame } & 0 & 2 & 17 & 0 & 0 \\
\hline & $0 \%$ & $11 \%$ & $89 \%$ & $0 \%$ & $0 \%$ \\
\hline Impact on & 0 & 1 & 1 & 0 & 17 \\
\hline CTE & $0 \%$ & $5 \%$ & $5 \%$ & $0 \%$ & $89 \%$ \\
\hline \multirow{2}{*}{ Desirability } & 0 & 1 & 1 & 0 & 17 \\
\hline & $0 \%$ & $5 \%$ & $5 \%$ & $0 \%$ & $89 \%$ \\
\hline Question 109 & 1 & 2 & 3 & 4 & 5 \\
\hline \multirow{2}{*}{ Time Frame } & 1 & 2 & 15 & 0 & 1 \\
\hline & $5 \%$ & $11 \%$ & $79 \%$ & $0 \%$ & $5 \%$ \\
\hline Impact on & 0 & 1 & 1 & 0 & 16 \\
\hline CTE & $0 \%$ & $6 \%$ & $6 \%$ & $0 \%$ & $89 \%$ \\
\hline \multirow{2}{*}{ Desirability } & 0 & 1 & 1 & 0 & 16 \\
\hline & $0 \%$ & $6 \%$ & $6 \%$ & $0 \%$ & $89 \%$ \\
\hline Question 110 & $\mathbf{1}$ & 2 & 3 & 4 & 5 \\
\hline \multirow{2}{*}{ Time Frame } & 1 & 1 & 17 & 0 & 0 \\
\hline & $5 \%$ & $5 \%$ & $89 \%$ & $0 \%$ & $0 \%$ \\
\hline Impact on & 0 & 2 & 0 & 0 & 16 \\
\hline CTE & $0 \%$ & $11 \%$ & $0 \%$ & $0 \%$ & $89 \%$ \\
\hline \multirow{2}{*}{ Desirability } & 0 & 1 & 2 & 14 & 1 \\
\hline & $0 \%$ & $6 \%$ & $11 \%$ & $78 \%$ & $6 \%$ \\
\hline Question 111 & $\mathbf{1}$ & 2 & 3 & 4 & 5 \\
\hline \multirow{2}{*}{ Time Frame } & 1 & 2 & 16 & 0 & 0 \\
\hline & $5 \%$ & $11 \%$ & $84 \%$ & $0 \%$ & $0 \%$ \\
\hline Impact on & 0 & 1 & 0 & 1 & 16 \\
\hline CTE & $0 \%$ & $6 \%$ & $0 \%$ & $6 \%$ & $89 \%$ \\
\hline \multirow{2}{*}{ Desirability } & 0 & 1 & 0 & 1 & 16 \\
\hline & $0 \%$ & $6 \%$ & $0 \%$ & $6 \%$ & $89 \%$ \\
\hline Question 112 & 1 & 2 & 3 & 4 & 5 \\
\hline \multirow{2}{*}{ Time Frame } & 2 & 1 & 16 & 0 & 0 \\
\hline & $11 \%$ & $5 \%$ & $84 \%$ & $0 \%$ & $0 \%$ \\
\hline Impact on & 0 & 1 & 0 & 0 & 16 \\
\hline CTE & $0 \%$ & $6 \%$ & $0 \%$ & $0 \%$ & $94 \%$ \\
\hline \multirow{2}{*}{ Desirability } & 0 & 1 & 0 & 0 & 17 \\
\hline & $0 \%$ & $6 \%$ & $0 \%$ & $0 \%$ & $94 \%$ \\
\hline
\end{tabular}




\begin{tabular}{lrrrrr}
\hline Question 113 & $\mathbf{1}$ & $\mathbf{2}$ & $\mathbf{3}$ & $\mathbf{4}$ & $\mathbf{5}$ \\
Time Frame & 0 & 2 & 16 & 1 & 0 \\
Impact on & $0 \%$ & $11 \%$ & $84 \%$ & $5 \%$ & $0 \%$ \\
CTE & 0 & 1 & 0 & 0 & 18 \\
Desirability & $0 \%$ & $5 \%$ & $0 \%$ & $0 \%$ & $95 \%$ \\
& 0 & 1 & 0 & 0 & 18 \\
Question 114 & $0 \%$ & $5 \%$ & $0 \%$ & $0 \%$ & $95 \%$ \\
Time Frame & & & & & \\
Impact on & $\mathbf{1}$ & $\mathbf{2}$ & $\mathbf{3}$ & $\mathbf{4}$ & $\mathbf{5}$ \\
CTE & $0 \%$ & 18 & 1 & 0 & 0 \\
Desirability & 0 & $95 \%$ & $5 \%$ & $0 \%$ & $0 \%$ \\
& $0 \%$ & $5 \%$ & $5 \%$ & $0 \%$ & $89 \%$ \\
& 0 & 17 & 1 & 0 & 1 \\
& $0 \%$ & $89 \%$ & $5 \%$ & $0 \%$ & $5 \%$ \\
\hline
\end{tabular}
John H. 